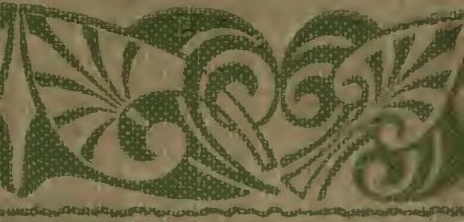

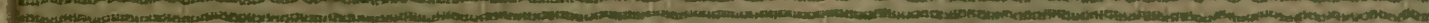

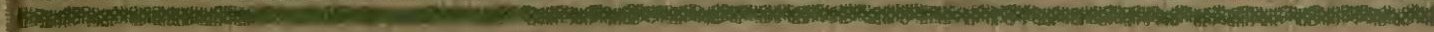
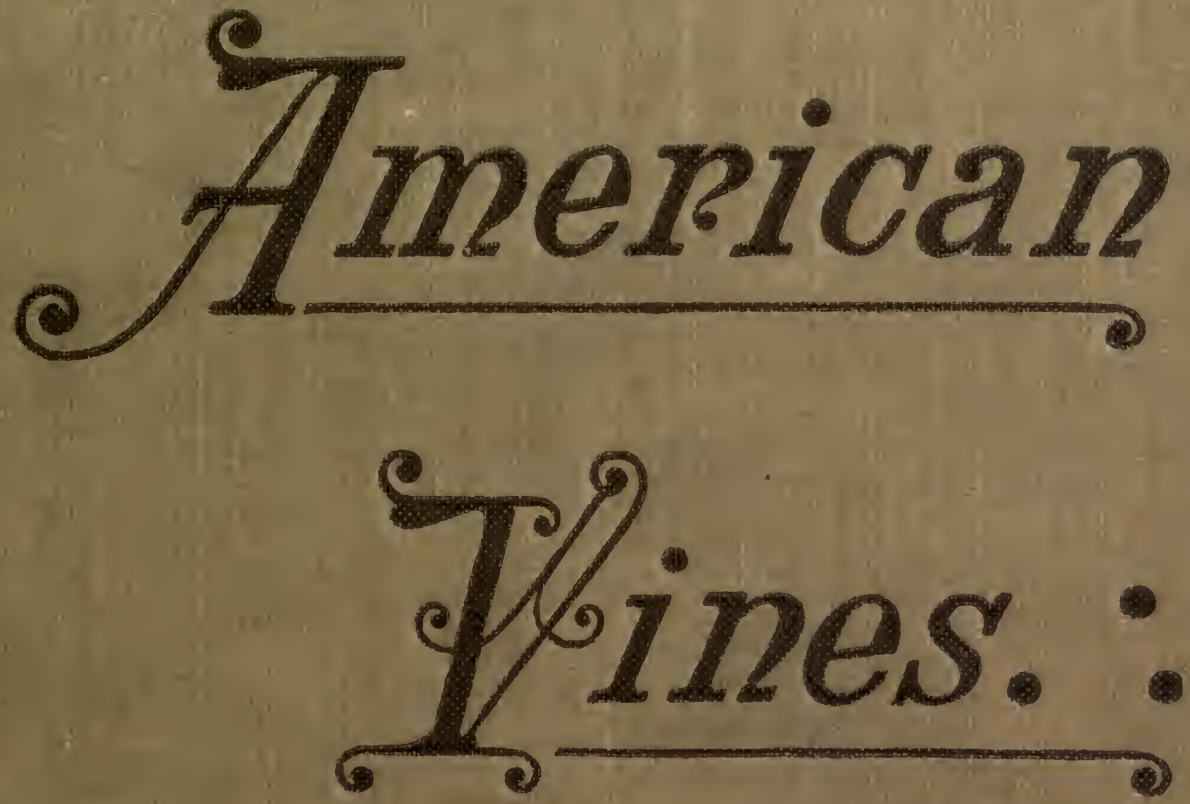

W

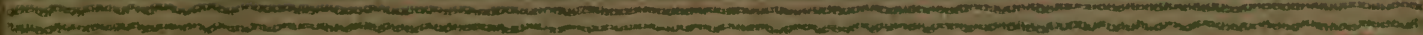

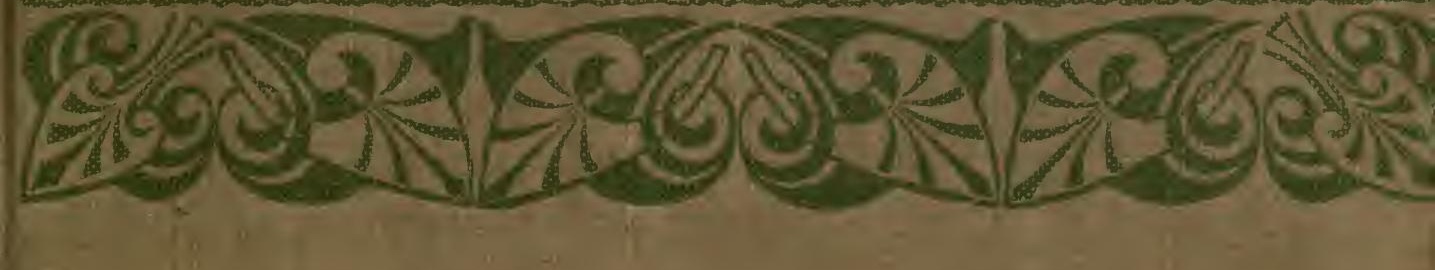










\title{
AMERICAN VINES
}

(RESISTANT STOCK)

\section{THEIR ADAPTATION, CULTURE, GRAFTING AND PROPAGATION}

\author{
BY \\ P. VIALA \\ Inspector-General of Viticulture, Professor of Viticulture (National Agronomic \\ Institute, Paris) \\ AND \\ L. RAVAZ
}

Professor of Viticulture, National School of Agriculture (Montpellier)

\section{COMPLETE TRANSLATION OF THE SECOND EDITION}

RAYMOND DUBOIS, B. Sc., F.R.C.S.

Ingenieur Agricole, Viticulturist to the Government of Cape Colony

AND

EDMUND H. TWIGHT B. Sc.

Ingenieur Agricole, Assistant Professor of Viticulture and Enology, College of Agriculture, University of California, Berkeley, Cal., U.S. A.

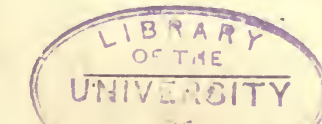

SAN FRANGISEO, CAL.

1903. 


$$
\begin{aligned}
& 58393 \\
& V 4 \\
& 1903
\end{aligned}
$$

$$
\operatorname{lig} g^{2}
$$

Press of Freygang-Leary Co., 113-119 Davis St., San Francisco. 


\title{
PREFACE TO CALIFORNIA EDITION.
}

\author{
(TRANSLATION.)
}

The translation of the book which Messrs. Raymond Dubois and Edmund $\mathrm{H}$. Twight are now presenting to California viticulturists is a summary of the efforts accomplished by the viticulturists of France in the struggle against phylloxera, and of the new knowledge they have definitely gained for the reconstitution of vineyards. This knowledge has been revised to date for the present translation, and all new facts which actually permit to direct the reconstitution of vineyards are brought together in this California translation.

The viticulturists of California are practically working under the same conditions as the viticulturists of the South of France, therefore the facts acquired in that region should be applied in their vineyards. These facts are simple, and consist, above all, in having recourse to the American vines most resistant to phylloxera, that is to say, in using pure species (V. Riparia, V. Rupestris, V. Berlandieri), or hybrids of these species (V. Riparia $X \cdot V$. Rupestris, V. Rupestris $\times \mathrm{V}$. Berlandieri, and V. Riparia $\times \mathrm{V}$. Berlandieri). The essential condition is to select different graft-bearers, according to the diverse classes of soils, and we trust that this book will assist California viticulturists in that direction.

The course to be followed in the struggle against phylloxera is nowadays definitely established. The immense efforts accomplished by our French viticulturists have vanquished an unprecedented crisis; their work, crowned with success, should benefit the viticulturists of the whole world. The most definite and general conclusion derived from this struggle is the superiority of reconstitution with American vines resisting the attacks of the insects. France possessed, before 
the phylloxera invasion, over 5,000,000 acres of vines; more than three-fourths of that area have been destroyed by phylloxera. By I899, 2,500,000 acres were reconstituted with American vines. The production of wine, which had fallen to $638,000,000$ gallons, exceeded, in $1900,1,430,000,000$ gallons; further, the average production was $\mathrm{I}, \mathrm{r}, 0,0,0,000$ gallons before the appearance of phylloxera. The Department of the Herault, in which 450,000 acres were formerly under vines, had, by I900, reconstituted 445,435 acres with American vines.

All other processes or methods of combating phylloxera can only be of transitory value, and only prepare, more or less progressively, the way for eventual reconstitution with American vines. The following comparative figures establish this beyond a doubt:-

Bisulphide of carbon was applied in France in 1890 to 155,595 acres; in I900, it was only applied to 90,500 acres. American vines, on the contrary, show the following progressive increase:-

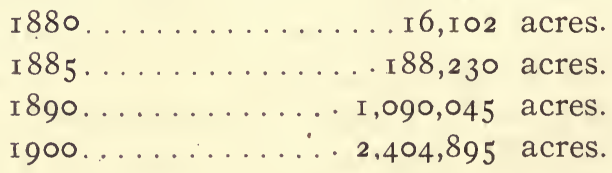

The use of American vines necessitates, however, greater supplementary care in culture; but these difficulties (selection of graft-bearers for different classes of soils and grafting) are insignificant for those who possess a sound knowledge of adaptation. The main object of this translation is to impart that knowledge, and we trust that the viticulturists of California will profit by the work which the translators have so willingly performed.

P. VIALA, Inspector-General of Viticulture.

PARIS, December, I902. 


\section{TRANSLATOR'S INTRODUCTION.}

As the area of phylloxera-attacked vineyards in California increases rapidly every year, and the insect has now obtained a firm footing in our most important viticultural centers, we may safely assume, in the light of the history of the rapid spread of phylloxera in European vine-growing countries, that at no distant date every vineyard in California will be devastated by this terrible insect.

Already we have seen the destruction it caused in the Napa, Sonoma, Sacramento and San Joaquin Valleys, reaching thousands of acres in extent, and it will spread slowly but surely to Southern California. The signal and worldwide failure of the extinction method to check the progress of the phylloxera should be clearly recognized by all Californian vine growers.

In looking over many serial writings published some twenty years ago, during the early period of phylloxera history in France, and bearing in mind that at present almost the whole of the French vineyards are phylloxerated and reconstituted, nothing now appears more ludicrous than the constantly reiterated advice tendered by authorities in vine districts free from the insect to unfortunate growers in attacked districts to persevere in their attempts at "total extinction" and not to plant American vines "because the phylloxera and other diseases lived on them." Authorities in European States free from phylloxera were especially loud in their praises of the extinction method, but undoubtedly their motives in recommending total extinction were not purely disinterested. Millardet one of the early advocates of reconstitution, quaintly remarked that the opponents of the American grafting stock 
had really adduced the strongest argument in their favor, namely, the fact that the phylloxera lived on them without causing injury.

The indisputable fact should be clearly grasped that phylloxera comes to stay, that the extinction method has proved an utter failure in Europe, no matter how thoroughly and expensively carried out, as in France, Switzerland, Germany, Austro-Hungary, Roumania, Italy, Spain, Bulgaria, Portugal, Russia, Servia.

In all of these countries without exception, phylloxera has spread and viticulturists have been finally compelled to reconstitute their vineyards with phylloxera-resistant American vines.

The vine growers of California have taken hold of that question for a good many years, and helped by the Agricultural Experiment Station of the University of California and also by the Viticultural Commission have been able to reestablish a great many of their vineyards. There seems nevertheless to be a need for more knowledge on the subject, a thorough understanding of these resistant vines. Their properties, grafting affinity with European stock, degree of resistance, adaptation to soils, becomes a matter of primary necessity as the first step towards permanent reconstitution on a phylloxera-resistant basis.

The difficult problems which were necessarily connected with the early culture of American resistant stock have been solved in the most practical manner in Europe; the culture of resistant stock no longer presents any trouble to the intelligent grower, and as a result, during the last twenty years the areas successfully reconstituted total some millions of acres, bearing heavier and finer crops than before the advent of the phylloxera.

All the best knowledge and information on the culture of American vines has been systematically gathered by Professors Viala and_Ravaz in their world-renowned work, "Les 
Vignes Americaines: Adaptation, Culture, Greffage, Pepinieres." We therefore deemed it advisable to translate the second edition of their book, which appeared in 1896 .

Professor Viala authorized the translation, and with great kindness undertook the laborious revision of the whole of the proof sheets, thus bringing the work to date I 902 .

We trust Californian Viticulturists will thoroughly appreciate Professor Viala's liberal-minded labours on their behalf, and benefit by the work he so willingly undertook for their guidance during the transition period-through which all vine-growing countries seem compelled to pass-of re-establishing on a phylloxera-resistant basis.

Edmund H. Twight, Berkeley, Jan., I903. U. S. A.
Raymond Dubois, Cape Town, Jan., I903. 



\title{
AMERICAN VINES
}

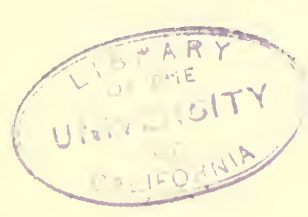

\author{
PART I. \\ ADAPTATION. \\ I.-INTRODUCTION.
}

When the American vines were first cultivated in France on a large scale, it was soon apparent that they were not thriving equally well in all soils. Such varieties as were thriving well in one soil grew indifferently in another; and, in the same soil, they were not all growing in the same manner.

Evidently, it would have been easy to foresee that this would be the case if beforehand, care had been taken to study the nature of the soils in which they were living in America. But, in the haste in which new vineyards were started. the mistake was made of thinking that American vines would grow in all kinds of soils just as the European (Vitis Vinifera) did.

All the European vines belong to one 'species-the $V$. Vinifera. Their pecularities and properties extend, with only slight differences, to all the varieties cultivated.

With the American vines we have to deal with species not only differing from the $V$. Vinifera, but also very different from one another. Consequently, their numerous varieties, which had adapted themselves to special conditons, gave very different results when planted in similar conditions.

But this was not taken into account. Hence, widelyspread failures were recorded; and extensive vineyards had to be uprooted after a few years growth. It was only then seen that it was necessary to study beforehand each American variety to discover its qualities and deficiencies, and especially its power of adaptation to different soils. 
Many of these failures were attributed to the action of the phylloxera. No doubt many of the American varieties cultivated had only a slight degree of resistance; but, with the greater number, the failures (and this has since been proved) were due only to their poor adaptation to the soil. Without doubt, the first quality required for a grafting stock. or even direct producer, is a high degree of resistance to phylloxera; this is a guarantee to its long duration in suitable soils. To make use of varities of small or even medium resistance is to court certain failure. However, it is none the less true that in some cases the phylloxera resistance is helped by growth in a thoroughly suitable soil.

It would be easy to cite numerous examples to prove this assertion. One of the clearest cases is offered by the old collections at the School of Agriculture, Montpellier. In a bad place, closely planted side by side, with interlacing roots, are Rupestris, Solonis, Cornucopia, and a number of other varieties. The Rupestris has only a few small nodosities at the extremity of the rootlets and no tuberosities, or very few, and its resistance may be expressed as I 8 - the maximum, or absolute indemnity, being 20. The Solonis, besides a great number of nodosities, bears, on the roots or secondary structures of the year or older, a few small hardly prominent tuberosities, the alteration of which rarely reaches the main roots; its resistance is expressed fairly accurately as I5. The roots of the Cornucopia are, on the contrary, covered with very large nodosities and very prominent tuberosities; and its resistance may be given as 4 .

These three varieties have been planted for twenty-one years. If the phylloxera had been the only factor concerned in the development of their exterior vegetation, it would be in the proportion of I8, I5, 4. The results are just the contrary. The Rupestris, on which the phylloxera has hardly any effect, is stunted, nearly dying, and its exterior vegetation is equal to 2 , the maximum being taken as 20 . The Solonis, although but slightly affected by the phylloxera, is also stunted, though not so badly as the preceding; its development may be expressed as 4 . The Cornucopia, on the contrary, although much attacked by phylloxera, has a great vigour and vegetation, that may be exactly expressed as I6. Thus the phylloxera had, after all, but little effect. 
The same anomalous facts apply to a large number of varieties, such as the Othello, Autuchon, and Canada, which, in spite of the phylloxera, often grow better in a very calcareous soil than the Riparia, Rupestris, etc.

This example shows how great is the influence of the soil on the vegetation of American vines. Any one may easily observe the same facts.

The attention of viticulturists was first called to the variation of the growth of American vines by Louis Vialla, in I 878 , and a little later by M. Despetis.

The subject was re-studied by B. Chauzit in 1880 ; by Foëx, Millardet, Desjardins, Audoynaud. in I88I; A. Verneuil. in I 882 ; and by E. Petit and a number of other viticulturists. They arrived at the conclusion that all American phylloxeraresistant vines grew well in clay-siliceous or siliceous-clay soils, and especially in siliceous soils, as also in pebbly red and fertile, but decayed in certain white soils. These observed facts have been explained in many different ways. We will speak of them later on.

Nowadays we have accurate ideas as to the value of the American varieties (now very numerous) introduced into France. Most of them have been relegated to collections or discarded. Quite a small number have been adopted in practice.

These have been cultivated for over 25 years, and in France now occupy an area of over 2,500,000 acres $(2,430,000$ acres in 1899$)$, distributed over more than 60 départements, in the most diverse soils and climates, and the total area under American vines in France yielded in 1899 and 1900 a quantity of wine equal to that obtained before the appearance of phylloxera. We now possess all the information needed to definitely solve the question of the adaptation of American vines to the soil.

This question has pre-occupied many viticulturists: Being given a soil, which American variety is to be cultivated in order to obtain the best results? The present work has for its object the determination of the elements affording a solution to that problem, to state exactly the rôle of each on the growth of each American variety, whether acting separately or combined, and through it to give viticulturists the means to choose precisely the most suitable variety.

In clay-siliceous or siliceous-clay soils, or those only containing a small quantity of limestone. all American vines 
resistant to phylloxera can be successfully cultivated. However, they show in their growth, fructification, etc., certain differences which must be taken into account. Not that in soils of this nature they would be a complete failure, but, as the creation of a vineyard actually necessitates a large expenditure, it is important to know the character and aptitude of each, so as to cultivate only those giving the best results.

In soils where the proportion of limestone is very high it is different. There most of the American vines, as also the varieties of $V$. Vinifera, do not grow so well. They grow badly, turn yellow, become stunted, and sometimes die. Others accommodate themselves better to this class of soil. From these facts, proved by observation, it must be admitted that for each class of soil there is an American vine superior to others. It must not be thought that the most vigorous and resistant vines should also be the best for all soils. The $V$. Berlandieri, for example, is the best grafting stock for soils rich in limestone. In soils where there is not much limestone it grows even better, but there it is inferior to the $V$. Rupestris and a few other varieties, which do not grow at all in calcareous soils.

It is undoubtedly the soil which acts on each American vine, and either retards or favours its development. Hence, we will need to examine:-

Ist. The influence of the soil on the growth of American vines in general. And as several elements (climate, humidity, dryness, grafting, phylloxera, general cultural operations, etc.) can modify, increase, or diminish its effect, we will search which way the modifications will be produced according to the case.

2nd. The aptitudes, properties, or exigencies of each species or variety of Ameircan vine, its resistance to phylloxera, the manner in which it behaves in various soils, its fertility and forwardness in ripening its fruit, whether it should be grafted or not, its affinity with the French vines, and those it can bear as grafts, the means of multiplying it, etc. And from this double examination we will then deduce results, which will probably have some importance in practical work. 


\section{II.-INFLUENCE OF THE SOIL.}

\section{A.-Soils Slightly or Non-Calcareous.}

(a) Role of sand and clay.-In the case of claysiliceous or siliceous-clay ground, we have only to take into account its compactness, degree of humidity, and fertility. Besides that, what rôle should be attributed to the sand and clay? Other things being equal, is it better for the sand to be in greater proportion than the clay, or vice versa? We do not know. But it does not appear that this point is of much importance. Chemically, these two elements have not much difference in their action on the growth of the vine. Their rôle is rather physical. They modify the nature of the soil, and, according as one or the other predominates. the ground is more or less humid, or more or less compact.

Siliceous sands formed of fine particles, mixed with a smaller quantity than 2 per cent. of cement, constitute light soils. European vines grow well in them, and, without attaining great dimensions, have a normal development. It is not so with American vines. Some of them, such as Lenoir, Herbemont, Vialla, Rupestris du Lot, etc., have a satisfactory growth. The Riparia and a few others do not suit these soils, and are anything but vigorous when planted in them.

(b) Compactness (Stiffness).-The compactness of the soil is due to an excess of clay, or an excess of very fine siliceous sand. In the latter case, when the amount of clay is less than 5 or 6 per cent., the soils are excessively hard and compact after a drought, the roots penetrate them with difficulty, and the vines do not grow well. An excess of clay seems to be less objectionable.

The compactness of the soil has a manifest influence. It is an obstacle to a good growth of the vine, which, like all plants, requires a friable, light, and warm soil. The more these conditions are satisfied the more vigorous its growth. It grows, however, in compact soils, but its vigour is less, and likely its life also. American vines are affected in a similar manner to European varieties, but some of them are not suited by soils of this nature. These ar Riparia, most 
of the Rupestris, etc, while Lenoir, Herbemont, Vialla, etc., accommodate themselves much better. We will examine later on all these varieties from this point of view, but will now give the reason for those differences. As it is not sufficient to only observe these facts, we must search for the causes and conditions producing them. This permits us to generalize, and also, frequently, to deduct results of the greatest importance.

Cazeaux-Cazalt, who made a complete study of the question of adaptation to soil, attributes the differences of vegetation shown by American vines in compact soils to their root structure.

The Riparia, most of the Rupestris, etc., have a poor root system. The roots are thin and very hard, much ramified. and ending in abundant very fine rootlets. The Lenoir, Vialla, Herbemont, Cunningham, Cinerea, York-Madeira, etc., have on the contrary, much stronger roots and less slender rootlets. The European vine, which grows well everywhere, has also very strong roots.

Why is it that vines with large roots adapt themselves to compact soils better than others? It is difficult to give a satisfactory explanation. Perhaps it is merely because strong roots have a penetrating force that is deficient in slender roots.

Whatever the reason is, the fact is constant, and must be taken into account. It demonstrates that American vines, either pure or crossed, having a powerful root system, also Franco-American hybrids, which have, like their French stock, strong roots, ought to develop vigorously in compact soils. Experiments which have continued for several years prove this very clearly.

(c) Humidity (Moisture).-Humidity has equally an influence on the growth of the vine, although it is not quite so important as was formerly thought. An exaggerated humidity of the soil favours the development of cryptogamic diseases, non-setting, etc., and, besides that action, considerably checks the spreading of the root system.

Vines growing in very damp soil often have very large exterior growth, but the roots, in proportion to the aerial parts, are always weak. This does not apply only to the vine, but is true in the case of nearly all plants. Up to a certain point, the drier the soil the larger the root system, because in those soils it is very likely necessary for them to 
develop powerful roots in order to search for the water they require. In damp soils, where moisture is plentiful, a small number of weak roots suffice to furnish the water necessary for the life of the plant.

Excess of water is undoubtedly an obstacle to the success of vineyards. In damp soils vines do not develop their roots, although the branches grow well, and when a sudden intense drought occurs they are not in a position to absorb the necessary water. They wither and die.

The humidity of the soil may, in some cases, indirectly favour the development of American or European vines. We know for a fact that it is a serious obstacle to the multiplication of phylloxera, as proved by the efficacy of artificial submersions. The humidity of the soil, when in excess, does not act in any other manner. It is a natural submersion It follows, under these conditions, that the resistance of American vines subject to phylloxera is increased. Certain direct producers, such as Othello, Canada, Brandt, Autuchon, etc., little resistant, have a longer life in damp soils. It is also the prolonged humidity during the last few years that has allowed the dying French vines to slightly regain their vigour in the compact clay soils which retained the water, and also in sandy soils. It is this also which has retarded the progress of the phylloxera, and rendered in many cases the insecticide treatments more efficacious, so that a part of their action, perhaps the largest, was derived from it. It is to this finally that must be attributed the revival of old vines badly affected by the phylloxera, and not to a particular system of pruning.

Humidity often acts in concert with compactness. It is the same with regard to the coldness of the soil, which is mostly the consequence of compactness and excessive humidity. In spring it delays the development of the roots and also checks the nutrition of the plants. All vines are not equally affected. Early kinds accommodate themselves better than late sorts.

(d) Fertility. - The fertility of the soil is a very powerful adjunct to the growth of the vine. The more fertile the soil, the larger its development. However, great fertility is not equally necessary to all vines. They have not from this point of view the same exigencies. The $V$. Rupestris is, perhaps best adapted to poor soils. It attains considerable dimensions, and carries very fine grafts, when other varieties 
do not grow under the same conditions. In America it grows in the beds of dry ravines, in the midst of stones mixed with very little organic soil. The Riparia is more particular. The Vialla, Lenoir, Herbemont, and especially $V$. Monticola, grow fairly well in poor soil.

Such are the principal conditions which influence the growth of the vine in slightly or non-calcareous soils. These conditions may be easily modified. Lightness, and consequently permeability of the soil, are necessary to a good growth of the vine; deep trenching, green manure, long manure (stable refuse with much straw), attentuate considerably the compactness of soil. Drainage and transference also diminish the excess of water and coldness in damp soils. On the contrary, in too dry soils irrigation when possible, with frequent ploughing, will maintain sufficient moisture. Finally, strong manuring will supply any deficiency in the fertility of the soil.

A good growth of all American vines can be assured after this in all classes of soils, but it is none the less necessary to take their preferences into account.

\section{B.-Calcareous Soils.}

\section{Chlorosis}

In calcareous soils, as already shown, both American and European vines, but the latter to a less extent, often become yellow. Sometimes the yellow colour is only slightly marked and transitory; again, on the contrary, it is more accentuated and causes the death of the vine. In most cases it is a characteristic symptom of the non-adaptation of the vine to such soils.

(a) Characteristic Symptoms of Chlorosis.-The intensity of the colour of leaves on vines attacked by chlorosis at first diminishes over the whole parenchyma, or on portions of it only. They then turn yellowish-green, and finally yellow. The leaf loses almost all colour, and from bright yellow turns to whitish. The tissue becomes brownish on the margin of the $\operatorname{limb}$, and this modification gradually invades the whole parenchyma, following the ribs. Finally the whole leaf dries up. The young shoots become yellow in the same 
way, and often when the chlorosis is very intense the extremities also dry and fall off.

Although being very yellow, the shoots continue to increase, but more slowly, and produce new leaves, but, as the green surfaces which alone elaborate the matters necessary to the nutrition of the various organs of the plant are altered, the new leaves always remain small and yellow. Numerous small shoots, always very short and slender, with rudimentary leaves, spring from the axillary buds, and the vine then presents a bushy and stunted growth. This form of chlorosis is c lled cottis.*

If the disease takes place before the vine blossoms (and it is almost always the case), it brings about non-setting of the flowers, and retards the maturation of the berry, which remains small, millerandé, yellowish with a few brown spots, and later on dries off.

The roots have a normal or weak development; they do not show any outside alteration; nothing indicates that they belong to a diseased vine, and a section does not show any internal lesion of the tissue. However, they are softer and more flexible than the roots of healthy vines, bending like india rubber, and are less lignified. They contain little or no reserve matters, except perhaps the larger ones, no reserve of starch in the cells after the wood has become lignified. The contents of the regions in a state of active life (generative layer, etc.) are very deficient in portoplasm. The fibrovascular bundles and cells of the liber are almost emptyin a word, there is a lack of nitrogenous matters and carbohydrates. In the branches there is an absence of the same matters as well as in the leaves and all the herbaceous organs.

In the leaves, not only has the chlorophyll disappeared, but also its sub-stratum, the chlorophyll corpuscles. However, in the chlorotic branches the chlorophyll does not disappear as early as in the case of the leaves; there is still some

* The disease which Dr. J. Guyot described in the Charentes under the name of cottis, is totally unknown there. The word cotti is an adjective, not a noun. One says a cotti fruit, a cotti branch, to designate a fruit or branch altered by any cause (insect larva, bruise, etc.), or bearing lesions similar to those resulting from a blow. A branch attacked by anthracnosis is cotti at the point where the canker shows, and by extension a plant is cotti when it presents any deformation. The actual cottis has been characterized in the South of France; it is known in the Charentes since the American vines have been cultivated there. The name is an adjective changed into a noun by Dr. Guyot and the vine-growers of the South. 
existing, although in very small quantity, even when the vine is diseased, and this explains, no doubt, why secondary branches can develop on primary branches even when all the leaves are chlorotic.

By way of compensation, in all the tissues there is an abundance of crystals of salts of lime, oxalates, and tartrates; the raphides are very abundant, so are the macles (caltrop or chiastolite), etc., and often small prismatic crystals are so abundant that they darken the microscope field.

In short, chlorosis impoverishes the tissues of the vine in all matters necessary for its existence, hence the active cells so impoverished are badly constituted, suffer, and work indifferently. The death of the vine may result, if the vine is very sensitive to this affection (most of the Riparias, the Vialla, and Cordifolia $\times$ Rupestris).

A given variety of vine is not equally subject to chlorosis at all periods of its existence. In soils where soil and subsoil are both very calcareous (chalky soils of Champagne and Charentes, and white Miocene marls of the south of France, etc.), a vine begins to turn yellow the first year of planting out, in August, September, or October, while up till that it had remained green.

The next spring the first shoots soon turn yellow, and the yellowing is somehow the continuation of the intensity of that of the previous year, and increases more and more till June or July. From that time forward the leaves often become green again till at the end of autumn they have completely turned to green. Then, the third year, chlorosis appears later on, the first shoots being green. It is only in May or June that they get chlorotic again, but to a smaller degree than in the second year. They also become green sooner, and it is not uncommon to see them completely green in August, or at the latest in September. The following years chlorosis only shows itself during a short period, almost always at the end of May or June, and during very rainy years, and does not involve grave consequences in the vegetation of the vine.

This order of things always takes place in the same way with European vines, and even, but with slighter differences, with the less sensitive to chlorosis of the American vines such as Berlandieri and "Franco-American hybrids of Berlandieri, Riparia, Rupestris, etc.

The second year chlorosis may be so intense on certain 
varieties (those which turned yellow the first year of planting out) that they only become green with difficulty, or not at all. These die the third year, and sometimes even in the second (Vialla, Noah, Rupestris $\times$ Cordifolia, Rupestris $\times$ Cinerea, etc.).

Finally, certain varieties do not become yellow the first year, but only the second; and in this case not at the start of the vegetation, but later on at the end of May or June.

They also become greener much earlier and much more completely (the best forms of $V$. Berlandieri and its hybrids with $V$. Vinifera).

In cases where the soil is slightly calcareous while the sub-soil is strongly so, the same phenomena sometimes occur, but they become retarded, especially in warm and dry localities. During the first, and even the second year, chlorosis may not be apparent as long as the roots are in the slightly calcareous surface soil, but directly they permeate to the sub-soil chlorosis starts, and the vine goes through the same phenomena.

Such are the variations of intensity which chlorosis may present with the age of plantation and the nature of the soil. We shall hereafter give the explanation of this phenomenon.

These characteristics are proper to this disease; and if they are found on vines dying from phylloxera, pourridié, etc., it is always in calcareous soils. Whether healthy or unhealthy, they never become yellow in clay or siliceous soil. This is a very definite fact which will enable us to indicate the exact cause of chlorosis in vines.

Sometimes, however, we observe in siliceous-clay soils, especially when the spring is cold and rainy, vines with part of their foliage yellow, leaves normally developed, showing yellow patches in places, or sometimes completely decolourized, and presenting a great analogy with those of variegated plants. Leaves variegated in this way seem to develop normally, and do not dry; the tissues, even the most yellow, remain alive, and often become completely green again. This phenomena is after all only a variegation, the cause of which is not yet known.

In, short, withering vines in any soil often have, when the spring is very rainy, a pale-green colour, which manuring and the return of fine weather dissipate. 
(b) Cause of Chlorosis.-The opinions advanced to explain the yellowing of the vine, and the distortment often resulting from it, are numerous.

Chlorosis has been attributed to humidity, to drought, or to alternatives of drought and humidity, to the climate, to lack of iron in the soil, to deficient coloration, and, therefore, heating power of the soil, to grafting, to " special properties, ', to carbonate of lime, etc.

Chlorosis and Humidity.-We have previously shown that excessive humidity of the soil has a certain influence on the growth of the vine. Can it bring about chlorosis? It suffices to examine vines planted in very damp soils, but non-calcareous, to satisfy oneself that it is not due to humidity. In the Charentes, in Cognac, in Holland, where vineyards are under water during the winter and part of the spring, so much so that culture is impossible up to the month of June, vines never become yellow, and if sometimes patches of chlorosis become manifest, it is always on the top of small calcareous rises, which, however, are drained well, although without being excessively dry. It is the same in the Saumurois, where the vines planted on the cretaceous banks of the Loire, which are aways dry, are frequently yellow, while those planted on the plain, which is very damp, never become yellow. In Bourgogne the vines on the hills become yellow in certain places every year; the vineyards on the plain established in siliceous clay soil, compact, and retaining water, are always completely green. In the Gironde and in Languedoc such examples are common.

Vines planted on the banks of rivers, in old swamp badly drained (such as certain vineyards established on the Marine Sands in the Charente-Inférieure (Arvert, etc.), in the Bouches-du-Rhône, the Loire-Inférieure, where the water is often I 2 to 16 inches over the surface, never show signs of chlorosis.

One of us, during a whole year, cultivated Riparias in ordinary water; they bore branches 24 inches long, and a small number of short roots, without developing the slightest patch of yellow on the leaves. An excess of humidity alone has, therefore, no action on the yellowing of the vines. As, however, in certain soils (calcareous), it is in spring, and after very frequent rains, that vines become most yellow, no doubt water has a certain action. We will study this case later on. 
Drought does not cause the vine to become more yellow. The experiments we made on this are absolutely decisive. Vines cultivated in pots were deprived during many weeks of water; their leaves dried and fell off, but were not attacked by chlorosis. Everybody has certainly had an opportunity of seeing, at a certain time of the year, vines dry off after a long drought. In $1890, \mathrm{r} 89 \mathrm{r}$, and $\mathrm{r} 893$ notably, vines in many regions in France of the Charente, Bourgogne, and of the shores of the Mediterranean and Rhône, etc., suffered from drought so severely as to lose all their leaves, but chlorosis was never noticed. Sometimes a very dry climate may occasion chlorosis, which does not become manifest in a cooler climate in soils of the same nature, as is, perhaps, the case in the south of France (Hérault, etc.). This is due to the drought forcing the roots to live deeper in a layer of calcareous sub-soil, but drought alone is not a cause of chlorosis. It can only increase the evil, as in the case above mentioned; more often it diminishes it. We will see later on in what way.

Drought and humidity acting alternately cannot be seriously invoked, for quite frequently many plantations are submitted to alternatives of drought and humidity, without, however, suffering from chlorosis.

According to this hypothesis, rains in certain soil would drown the roots, which later on would become completely dry. We have made researches to try and ascertain if this hypothesis is correct.

Vines cultivated for a long time in swamp land, saturated with water, and suddenly exposed to an intense drought never became yellow. In soils of Champagne, Charentes, and Bourgogne, in patches of land where the vines wither, in the Hérault, Saint-Emillionnais, Blayais, etc., it does not happen in those which become saturated with water and subsequently become dry. Even after heavy rains those soils may be worked, and in many of them vines have never suffered from drought, and yet chlorosis obtains an intense development.

What is above described shows also that neither the defective porosity of the soil nor excessive humidity can cause the vine to turn yellow.

Chlorosis and Iron.-As previously stated, chlorosis is characterized by the disappearance of chlorophyll from the leaves and all herbaceous organs. Sachs has shown that 
iron plays a useful part in the formation of chlorophyll. It was easy to conclude from this that its disappearance from the tissues of the plant was due to a deficiency of iron. The first studies of Chauzit and Foëx show, however, that in soils where this affection takes place there is the same amount of iron, and often more than in those where the vines remain green. The following figures prove this:-

1. Soil of the School of Agriculture, Montpellier, where

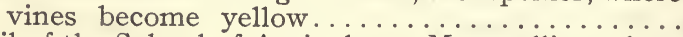

2. Soil of the School of Agriculture, Montpellier, where vines do not become yellow................

3. Soil of the School of Agriculture, Montpellier, where vines do not become yellow...............

And, again, the chalky soils of the environs of Cognac, which are the most refractory to the culture of American vines, often contain a large amount of iron, while in the same locality soils in which chlorosis does not occur contain less iron.

It is true that in many of these soils iron does not exist in the same state of oxidation, and therefore of assimilability. But it has often been obs rved that in the groies soils of the Charentes, the grèves soils of Bourgogne, and in many localities of the south where vines beome yellow, that such soils are strongly red-coloured by sesquioxide of iron, which is easily assimilable in this form. And, again, very siliceous soils, almost entirely white and poor in assimilable iron, never bear yellow vines (sandy soils of the Bartonian and Eocene of the south, and the upper Eocene of the Charentes-Inférieure).

On the other hand, Gautier's studies have shown that iron does not enter into the composition of chlorophyll. Should we conclude from this that iron, whatever be the form in which it exists in the soil, cannot prevent chlorosis, and that its absence is in no way an obstacle to the well-being of the American vines?

Chlorois and Iron Salts.-However, there is an undeniable fact; this is, the positive efficacy of salts of iron on vines and other plants in bringing about the return of the green colour.

If iron salts do not enter into the composition of chlorophyll they certainly induce its formation. Many experiments prove this. Eusèbe Gris ( 1840 ) and, later on, his son, Arthur 
Gris ( $185^{\circ}$ ), showed positively the action of sulphate of iron placed around the stump or on the leaves of chlorotic vines in causing the return of the green colour.

These facts, often contradicted, have been proved indisputably in recent years.

Max. Tord, for instance, experimented in a groie soil near Saint-Jean-d'Angely, on ten contiguous plots of identical composition, with many substances; sulphate of iron crystals placed near the stump of the vine, or between the vines, or distributed broadcast at the rate of 4 ounces per square yard; superphosphate and sulphate of potassium; sulphate of iron dissolved in water, at the rate of 4 to $4 \frac{1}{2}$ ounces per 2 or $2 \frac{1}{2}$ gallons of water per vine. The applications were made during March. Sulphate of iron in solution in water alone gave positive results. The plot treated in this way showed no chlorosis; the canes attained a normal development, while all the other plots, without exception, were of a bright orange colour the same as the whole vineyard. Tord draws the following conclusion:-

"Sulphate of iron used to check chlorosis is efficacious if applied early (at the end of February or beginning of March) at the rate of 4 to $4 \frac{1}{2}$ ounces per vine dissolved in 2 or $2 \frac{1}{2}$ gallons of water.

"Crushed crystals of stilphate of iron, alone, or united with potassic or phosphate compounds, does not produce any appreciable effect, at least during the first year of application.

"Sulphate of potassium and superphosphate used in the natural state do not give any apparent result.'

Cazeaux-Cazalet, and many other viticulturists, arrived at the same conclusions. Finally, we have also made experiments, the results of which are similar to the above. A Noah vine (a cépage very sensitive to chlorosis) planted in chalky soil was submitted to the following treatment:One row was treated with a solution of $10 \mathrm{I} / 2$ ounces of sulphate of iron in $2 \mathrm{r} / 2$ gallons of water placed at the foot of each vine; one row with a solution of $5 \frac{1}{4}$ ounces of sulphate of iron in $2 \mathrm{r} / 2$. gallons of water placed at the foot of each vine; one row with a solution of $101 / 2$ ounces of crystallized sulphate of iron per vine; one row not treated.

The application was made in May. After a few days the plants which had been treated with ro $1 / 2$ ounces of sulphate of iron in solution assumed a very marked green tint, which 
later on appeared, but in lesser intensity, in the row treated with $5 \frac{1}{4}$ ounces. The row treated with the crystals of sulphate of iron did not appear to be affected in any way. As for the non-treated row, it became yellower.

All these experiments prove that sulphate of iron has a marked action on the reappearance of the green colour, which is so much the more marked as the quantity applied is greater.

In crystals, its efficacy is much less. However, in the south of France, good results were obtained, especially after a few years use of sulphate of iron in that form in great quantities. Two and a quarter lbs. per vine, at least, should be applied, and even with that large amount good results do not always follow.

Sprayed on the leaves in the proportion of $\mathrm{r}$ per cent. dissolved in water, sulphate of iron brings about the disappearance of chlorosis. Eusèbe and Arthur Gris were the first to establish this definitely. Narbonne was able to diminish by this means the intensity of chlorosis in a large vineyard near Bize (Aude). We arrived at the same results also.

Gouirand recently experimented with numerous salts of iron in chalky soils of the Charentes, where chlorosis attains a very serious form. These salts were sulphate, tartrate, malate, acetate, tannate, sucrate, and carbonate of iron, applied by spraying on the leaves. The four first salts gave positive results, the three last had little or no action. The sulphate seemed to be the most active.

Many horticulturists and botanists attribute the reappearance of the green colour to the fact that the leaf contains tannin, which combining with the iron forms tannate of iron of blackish-green colour.

This explanation is not plausible; it suffices to examine a treated leaf under the microscope to ascertain that it does not take place, and that the reappearance of the green colour is due only to the reappearance of chlorophyll. Arthur Gris showed this long since (Ann. Scienc. nat. 1857. 4th series. Vol. VII., p. I79) by attentively following the developments and multiplications of the chlorophyll corpuscles and their colourations ( $p l$. V. to X.). What is then the action of the salts of iron on chlorophyll?

Eusèbe and Arthur Gris ascertained in etiolated plants the phenomena of the developing and colouring of chlorophyll corpuscles under the direct and intimate action 
of sulphate of iron but without giving any explanation. Sachs attributes the formation of the new chlorophyll corpuscles to the iron itself.

According to Max Tord, sulphate of iron placed in solution at the foot of the vine transforms the carbonate of lime dissolved in the water of the soil charged with carbonic acid into sulphate of lime. This explanation is no doubt partly correct, for by spraying chlorotic vines with sulphuric acid one seems to succeed in causing the reappearance of the green colour, but it is also very probable that the sulphate of iron has a direct action on the vine after being absorbed by the roots. This is proved by its action and that of other salts of iron soluble in the sappy liquids of the vine. In this case, it is true their efficacy may be attributed to their acidity. Chlorotic leaves are less acid than green leaves, as shown by Gouirand in the following table:-

Chlorotic leaves in calcareous soil.
Green

Acidity per 1,000 .

non-calcareous soil

2.63

4.65

5.73

Fremy noticed that the reappearance of the green colour in etiolated plants could be brought about by surrounding them with acid vapours. But Gouirand, by spraying the leaves with the diluted acids of the salts of iron above mentioned, did not obtain any appreciable results.

Whatever may be the cause, the beneficial effects of many iron compounds are certain. If it is not yet possible to give a satisfactory explanation of these phenomena, one can, however, in practice, derive advantage from them. Of all the iron salts above-studied the sulphate is, with slight difference, the most efficacious; it must, therefore, be utilized in prefer$\epsilon$ nce to any other.

It may be used in different ways. In fine pulverized crystals, spread on the soil round the stump, it does not give very good results. Is this because it is decomposed there and then by the undissolved carbonate of lime before it has penetrated to the roots? Whatever the cause may be, under this shape it only gives satisfactory results when used in large quantites $\left(2 \frac{1}{4}\right.$ or $41 / 2 \mathrm{lbs}$. per vine) and before the winter rains are over; later on its action is nil, except in cases where the application is followed by heavy irrigation.

It is more effective in solution The quantity used should 
be at least I $1 \mathrm{~b}$ dissolved in 2 gallons of water or liquid manure.

Poured about the foot of the vine in April, this solution has a very durable action, and in the majority of cases assures healthy vegetation during the whole summer.

Sprayed on the leaves the effect is more immediate; eight or ten days after being treated the leaves become green again. But the action is purely local, and does not extend to the tissues, which have not been placed in direct contact with the liquid. The new shoots gain very little by it. The spraying, therefore, must be repeated very frequently when the chlorosis is in an advanced form. The solution should be weak, even at I per cent. strength it sometimes burns the tissues; I I-3 ounces of sulphate of iron per gallon of water is the best strength to use.

Dr. Rassiguier proposed painting the trunk, before pruning, with a solution of sulphate of iron containing 30 to 45 per cent. The results are very satisfactory, and this method has been applied on a large scale in French vineyards. It is when the vine is in a state of active life that the effects of the painting are best: in autumn, before the leaves fall; the results are almost nil in spring, when the too abundant bleeding prevents the absorption of the ferrous solution, or rejects it outside. One proceeds with the pruning, and directly after, all the cuts, the spurs, the long rods and the trunk are painted in the same manner as is done in the treatment for anthracnosis. The Rassiguier method assures a good growth of the American vines in the majority of calcareous soils.

All these treatments may be applied simultaneously, their effects are added, and we may doubtless in this way attenuate chlorosis; but these operations become relatively expensive, and it is only in special cases that they may be applied, notably for vines which only become chlorotic at intervals; or, again, in order to assure the normal development of young vines which became yellow at the second or third year after planting.

Chlorosis, Light, and Heat.-Absence, as well as excess, of light may cause a disappearance of chlorophyll. Boussingault and Gris were the first to point out this phenomena. It suffices to recall the light colour of plants grown in a dark place, or of organs exposed to too much light, but in vines nothing of the sort takes place. 
Chlorosis manifests itself with as much intensity in the south, where light is never defective, as in the south-west or centre, where the sky is often cloudy, and vice versâ. Again, anybody may notice chlorotic vines side by side with green vines, that is to say vines receiving the same quantity of light.

The reflexion of the rays of the sun by soils of light colour (chalky soils of Dordogne, Blayais, etc.) cannot be invoked here, as vines become yellow in the darkest scils, such as the calcarous soil of the Charentes, Saumurois, Poitou, etc.

$G$ Foëx, in his remarkable study. "The Causes of Chlorosis in the Herbemont,' ' showed that the cépage became yellow, especially in cold (or sour) soils, in spring. The experiments made by him, which we witnessed ourselves, and the results obtained, show that a smaller or greater facility of heating of the soil may increase or attenuate chlorosis. Millardet and others arrived at almost the same conclusion.

We must draw attention to the fact that the chalky soils above-mentioned, as well as the red and chreous soils of the Charentes and the grèves soils of Bourgogne, are all coloured brown, or even dark red, and they are mellow, light, and permeable, and absorb heat easily. The first of these, notably during the summer, after a few sunny days, are burning; and it is in these soils that vines become most yellow. On the other hand. white, compact, and sour soils never bear yellow vines.

Finally, in measuring the temperature of different soils, some in which vines become yellow, others in which they remain constantly green, we have never been able to find any difference. We must, therefore, conclude that the coldness of soil has nothing to do with chlorosis. Yet the probatory experiments of Foëx and Millardet tend to prove the contrary. We will show later on how a soil remaining cold during a long period may, in certain cases, aggravate this affection, and also that the deficiency of light, which always accompanies an intensity of heat, acts in the same way.

Chlorosis and Climate.-The non-success of American vines in many soils has been attributed to the climate. The American vines, it is said, are not yet acclimatized. Has this assertion any value? Firstly, it seems strange that such opinion may have been expressed when yellow and 
green vines have been seen side by side in the same plot. And is the climate of America so different from ours? The same plants, the same cultures, succeed in both countries, and if there is a difference it is in favour of ours. In America the temperature often goes to very great extremes (from- $30^{\circ}$ to $+43^{\circ} \mathrm{C}$ ); rain falls in periods alternating with long and intense droughts to such an extent that many plants cannot reach complete development,-all conditions that are less favorable to the vegetation of the vines or other plants than our temperate climate, where rain does not alternate with long periods of drought, and where extremes of temperature are not so great.

American vines are less sensitive to cold than European; in the Rhône Valley, north of Lyons, the temperature went down to $-30^{\circ} \mathrm{C}$ in $\mathrm{r} 890$, the indigenous vines of all ages were entirely frozen and had to be cut down close to the ground. The American vines, on the contrary, resisted well and did not suffer from the cold; the Jacquez alone had a few buds frozen.

Therefore, without being taxed with exaggeration, we may say that the climate of France is more favorable to the American vines than the climate of America.

It suffices to examine what takes place in France to be convinced that the milder, more temperate, and less liable to drought a climate is, the more favorable it is to the growth of the American vines. Thus, in the south of France, Riparia and Rupestris are the only stocks commonly used. All the others do not grow well there. Vialla, Herbemont, and York-Madeira have been totally discarded. In less warm regions, such as the south-east, centre, and east of France, the Vialla, Herbemont, and York-Madeira have been for a long time cultivated with success, either as graftingstock or direct producers. The Vialla is almost the standard grafting-stock of the Beaujolais, as well as in certain soils of Bourgogne, Charentes and Gironde The Herbemont. which does not grow in the south, has a splendid vegetation in similar soils in Gironde or Charentes, etc. The same thing applies to York-Madeira and Oporto, etc. It is that in these warm regions these cépages can live in the upper layers of the soil, which is better, or, to be more correct, les; noxious; it is also that the phylloxera, which must be taken into account in the adaptation of a vine to the soil, does less harm in cold than in warm regions. If, therefore 
the reconstitution of vineyards has been made a success in the Mediterranean region, it must $d$ fortiori prove a much greater success in the other regions of France, and that is in effect what really occurs.

What other causes have not been invoked to $f$ xplain chlorosis? We will not examine them all. We must only remember this - that humidity, drought, or alternatives of humidity and drought, deficiency of iron, deficiency of light, coldness of soil, absence of colour on the surface of the soil, compactness, aridity, deficiency of fertilizing principles climates too cold or too dry are not, separately or combined, the cause of chlorosis.

Chlorosis and Carbonate of Lime.-Chlorosis has also been attributed to the influence of the carbonate of lime contained in the soil. What is certain and absolutely constant is that this disease only manifests itself in calcareous soils, and the greater the proportion of this substance present, the more intense the chlorosis will be. We have never seen vines become yellow except in calcareous soils, and this observation may be extended to the apricot, quince, pear, etc. A vine may be in a bad state, stunted, or attacked by disease, but if in non-calcareous soil it will never become yellow. No doubt it will not have the deep-green colour of vigorous vines, but its leaves will never show the characteristic appearance of chlorosis. This is a point upon which we wish to insist, and which limits the conditions under which this affection will always take place.

Some figures, due to Chauzit, will show the narrow relation (from cause to effect) existing between carbonate of lime and chlorosis.

I.-Soils in which American Vines grow well, and never turn yellow.

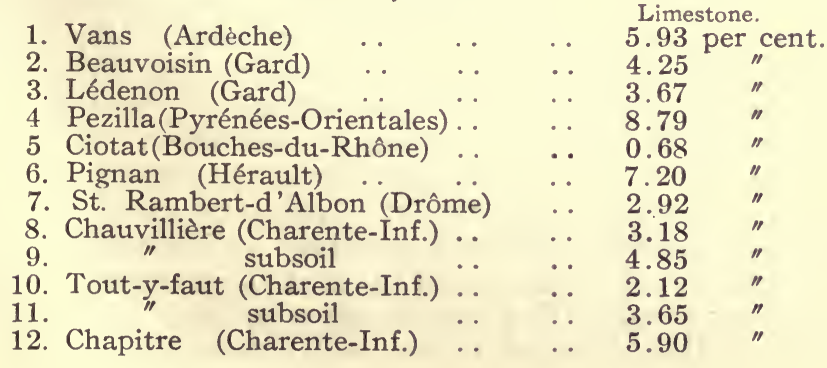


II.-Soils in, which American Vines become chlorosed:-

1. Quissac (Gard)
2. Pujaut (Gard) $\quad \ldots$

\begin{tabular}{|c|c|}
\hline \multicolumn{2}{|c|}{$\begin{array}{l}\text { Limestone. } \\
59.72 \text { per cent. }\end{array}$} \\
\hline 72.67 & \\
\hline 4.65 & \\
\hline 35.25 & $" \prime$ \\
\hline 58.86 & \\
\hline $\begin{array}{l}49.00 \\
52.00\end{array}$ & $"$ \\
\hline 56.46 & " \\
\hline 44.67 & " \\
\hline 52.75 & " \\
\hline 59.55 & " \\
\hline 67.80 & " \\
\hline 43.60 & 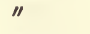 \\
\hline 68.55 & " \\
\hline 56.37 & " \\
\hline 48.53 & $"$ \\
\hline 75.76 & " \\
\hline
\end{tabular}

It is easy to prove that it is the carbonate of lime which makes the vine turn yellow. It suffices to convince oneself, to place at the foot of vines sensitive to this affection chalk or any pieces of calcareous material, débris from buildings, mortar, etc., and one will be able to obtain any degree of chlorosis.

How does the carbonate of lime act? Chauzit, who published a very remarkable work on this subject, advanced the idea that it acted in modifying the physical structure, or better, in communicating to the soil special properties.

It is more probable that carbonate of lime has a direct action on the vine, and that it is so much the more injurious as it is absorbed in greater quantity; or, what comes to the same thing, that it presents, itself in a more assimilable form. Fragments of hard limestone placed at the foot of the vine do not cause it to turn yellow, while similar fragments, if friable, and therefore easily attackable by rainwater and frost, generally produce chlorosis. By causing vines to grow in lime-water, the leaves rapidly turn yellow, while remaining green if in ordinary water.

The intimate action of carbonate of lime in the cells of the plant has not yet been sufficiently studied to enable us to give a precise explanation. Does it precipitate the organic acids while they are forming? The diminution of the acidity in yellow leaves, or even of those remaining green in calcareous soil, allow us to suppose so. It results in restraining the functions of the cells, which become poorer 
in nitrogenous matters and carbo-hydrates. The chlorophyll disappears first, and new chlorophyll corpuscles are not formed; consequently, the matters absorbed by the roots are not elaborated any longer by the green matter which has disappeared; or they are imperfectly elaborated by an insufficient quantity of badly-developed green matter.

Whatever the case may be, although the question has not been sufficiently elucidated, carbonate of lime is the true cause of chlorosis.*

Can the other salts of lime cause chlorosis? They have not all been studied from this point of view; however, in practice, we need not be pre-occupied by most of them. Sulphate of lime (gypsum) alone is found to a certain extent in some vineyards. It does not seem that it has the power of rendering the vine yellow. The study made by Chauzit of certain vineyards planted in gypseous land shows that chlorosis is only found when the gypsum exists side by side with carbonate of lime. One of us has cultivated American grafted vines in artificial soils containing 55 per cent. of sulphate of lime. The vegetation is stunted under these conditions; the vine after developing normally at the start, stops and remains weak. and although this circumstance is favorable to the appearance of chlorosis they have always remained green.

But from what has been said, one must not conclude that analysis will always give the measure of the effect of carbonate of lime on the vine. Its action may be modified by different circumstances, and increased or diminished very sensibly. It is, firstly, dependent not only on the quantity of carbonate of lime in the soil. but also on the distribution of this substance amongst others: sand, clay, etc.; and two soils equally calcareous may present from this point of view marked differences. If, in a given soil, the carbonate of lime is disposed around grains of siliceous matter (calcareous sandstone, tertiary sands surrounding Montpellier, etc.), the vines will become much more yellow than in the case of another soil where the

* Amongst white soils the exterior aspect of which is identical with that of chalky soils, and which might, perhaps, have an action as a cause of chlorosis, are the dolomitic soils (carbonate of magnesia) and the gypseous soils (sulphate of lime).

American vines have been cultivated with success in the dolomitic soils of the Gard (Bajocien, Bathonien and Infralias). It has been noticed that in soils containing up to 42 per cent. of carbonate of magnesium (Chauzit JeanJean, Desjardins) the American vines, even the Riparias, throve. 
carbonate of lime exists finely' pulverized, mixed with siliceous grains and coated with clay. In the former, notwithstanding the high percentage of silica. the roots are in immediate contact with carbonate of lime; in the second, on the contrary, the contact only exists at a few points, and the clay in some cases coating the small grains of limestone isolates them from the roots and renders them less attackable by water charged with carbonic acid, and so diminished its detrimental effect. The ameliorating effect of clay was pointed out by several observers, notably Cazeaux-Cazalet and Chauzit. We must also take into account the state of division of the carbonate of lime in the soil; in very small grains it offers a greater surface than when in large grains. In porous and soft grains (chalk) it is more noxious than when the grains are compact or crystallized.

It results from this, that the different states under which carbonate of lime is found in soils have different properties. Certain limestones are very easily attacked by dilute acids, while others are less so. This is shown in the following table, taken from Houdaille and Semichon:-

Rate of Specific Attack of Limestones

Description of Calcareous Rocks.

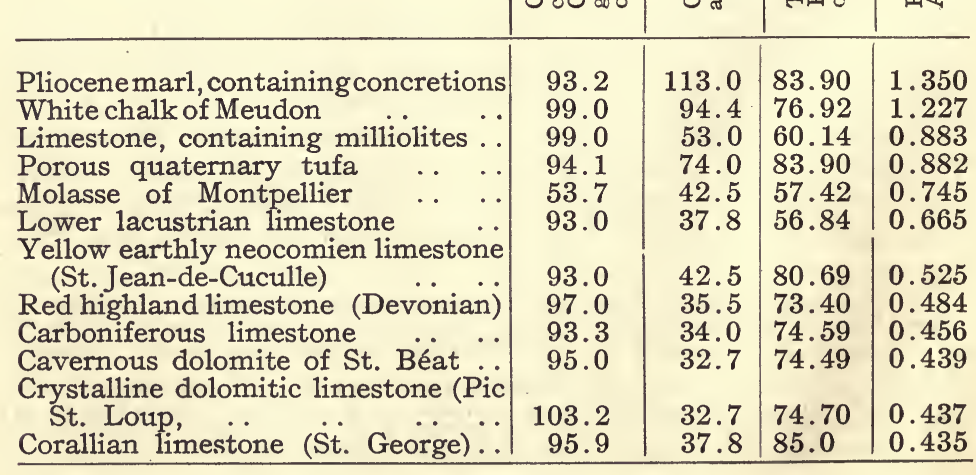


Rate of Specific Attack of Limestones-continued.

Description of Calcareous Rock.

Cipolin limestone

Shelly limestone (triturated ternary shells)

Jurassic limestone containing ammonite polyplocus

Upper lacustrian limestone

Neocomien limestone containing serpules

(i avalette)

Pink corallian limestone (Lavalette)

Devonian limestone of Caunes

Black limestone of Ariège (Primary strata)

Devonian black limestone of Marignac

Spar (limestone crystallized in rhombic system)

.. 100

Oxfordian limestone (St. George) ...

Bajocien limestone, containing encrines (starfish)

Bajocien limestone, containing chailles

Neocomian limestone (Lavalette) ..

Porous dolomite (Cargneule)
Aragonite (prismatic carbonate of lime

Bajocien limestone, containing cancelloficus

Pyrénéean disintegrated marble (primary strata)

Bajocien, dolomitic limestone

Black dolomitic limestone (Pic St. Loup)

Ferruginous dolomite of Ariège

Bituminous bajocien limestone

.. 35.5

$93.3 \quad 31.0$

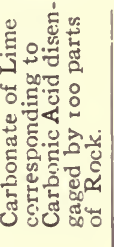

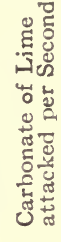

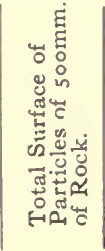

范

$\begin{array}{lll}76.0 & 0.407\end{array}$

97.5

42.5

$103.0 \quad 0.407$

97.0

31.0

83.160 .373

$98.0 \quad 48.5$

91.0

32.0

$\begin{array}{ll}95.9 & 28.3\end{array}$

$\begin{array}{ll}95.0 & 24.2\end{array}$

92.5

21.3

92.0

21.3

100.0

17.0

24.2

82.6

17.9

81.8

92.5

18.9

102.050 .370

$89.0 \quad 0.360$

$\begin{array}{ll}82.5 & 0.342\end{array}$

74.700 .325

74.830 .285

76.870 .277

$65.0 \quad 0.262$

$96.5 \quad 0.250$
90

$\begin{array}{ll}75.5 & 0.237\end{array}$

20.0

$91.0 \quad 0 \quad 200$

$69.5 \quad 16.5$

97.0

12.1

$102.0 \quad 0.198$

Devonian limestone (Lodeve)

.. 101.8

.. 80.0

.. 94.0

.. 77.0

98.050 .168

$\begin{array}{lll}75.0 & 0.160\end{array}$

7.95

$\begin{array}{lll}76.0 & 0.104\end{array}$

1.91

57.060 .035

\begin{tabular}{l|ll}
2.24 & 86.0 & 0.026
\end{tabular}

0.37373 .570 .00508

0.15476 .080 .00202

$\begin{array}{llll}0.100 & 78.0 & 0.00128\end{array}$

\begin{tabular}{l|l|l}
0.060 & 65.0 & 0.00093
\end{tabular}

Again, other causes modify the action of carbonate of lime on vines. All vinegrowers in the south of France, Saumurois, Bourgogne, Champagne, etc., have remarked that vines become yellow in the spring during very damp years, and that they remain yellow until the return of the heat of summer. 
Since we started studying chlorosis in French regions, we have always seen the same phenomena take place-intense yellowing during wet springs, slight on the contrary during dry springs, and in both cases disappearance in July or August. The same thing happens with American vines; but as chlorosis is generally more intense, the recovery of the green colour is not so complete; sometimes, even with certain varieties, it does not reappear at all. In this case, therefore, chlorosis seems to be in intimate relation with humidity, and yet we have seen that humidity alone had no such action.

How can we conciliate these apparently contradictory facts? As previously said, carbonate of lime seems to have a more noxious action on the vine when dissolved in large quantities of water. The rain water, which is always charged with carbonic acid, is its most active agent of dissolution, by infiltration in the soil, and the more abundant it is, the more carbonate of lime-in solution as bi-carbonatewill there be at the disposal of the plant, and consequently the more intense the chlorosis will be. In June or July, with the return of heat, the quantity of water contained in the soil diminishes; a great quantity of bi-carbonate of lime becomes insoluble again, and the chlorosis disappears.*

However, chlorosis does not seem to be manifested in direct relation with the percentage of water in the soil estimated by weight, as is usually determined in physical and mechanical analysis of soils. This is at least the result of Houdaille and Mazade's studies. It is the ratio between the quantity of water contained in the soil and the volume of the empty spaces existing between the particles of the soil which it is important to consider, for it expresses more accurately the state of saturation of the soil by rain water.

One can then easily account for the differences shown in the green parts of vines planted in soils containing the same percentage of lime and in the same state. It is evidently in places where water lies that vines will be the most yellow. This is why the bottom of the valleys of calcareous regions (Bourgogne, Charentes: Aude, Hérault,) and places where water springs naturally (surroundings of Vichy), which seem at first appearance very favorable to American

* It is easy to follow the progress of the dissolution and precipitation of the carbonate of lime in the chalky soils of the Charentes. These soils, grey or black, present during the drought, and, to a certain depth, numerous sinisous white lines entangled like a network, which are deposits of pure carbonate of lime in the drives formed by the roots of the vines. After heavy rains all these lines disappear to reappear again with the drought. 
vines, are in reality the most unfavorable, while the sides of the hills, which drain well and seem poorer and more calcareous, bear less chlorotic vines.

This explains also the beneficial effect of drainage, of deep trenching, and of all operations tending to diminish the amount of water in calcareous soils.*

This enables us, to interpret the results obtained by Foëx and Millardet, already mentioned above. It is that independently of the excellent conditions given to the root growth by warm soils, soils which easily become hot are generally also the driest.

Finally, the variation in intensity of chlorosis with the age of the vine and the season are not due to any other causes than those above studied. But can one explain the way in which they are produced? How is it that the influence of lime on the young plant does not manifest itself in the spring of the first year after planting out? It is that at the start the vine cutting or rootling mainly lives upon reserve matters accumulated in its tissues and the living cells, still almost normally constituted, resist longer the persistent action of carbonate of lime. But the latter supervenes eventually, and in September the leaves become yellow, and, working under difficulties, do not accumulate in the tissues of the trunk and root a sufficient quantity of reserve matters. The following spring, the first development takes place with the aid of this small quantity of reserve matters: hence, a more intense yellowing, which is, so to speak, the evolution of that of the previous year. The lime having at this moment, for reasons we have already made clear, a very great action. the yellow colour becomes more accentuated. Then with the fine weather, during June and July, a disappearance of the humidity of the soil places the vine in better condition for vegetation; the green colour returns, the leaves regain their normal condition. and assimilate and elaborate the reserve matters. In the spring of the following year, the active cells, well con stituted owing to the reserve matters which are in greater proportion than in the previous year, resist longer the effect of the carbonate of lime. That is why chlorosis is less

* If chlorosis has been attributed to humidity and compactness of soil, it is because one had not been able to distinguish between clay and clay-calcareous, or marly soils. In the first, chlorosis never occurs: in the two second, chlorosis is due to lime, the effect of which is increased by the water contained in such soils 
intense, or at least of shorter duration, the third year tian it was in the second

Maturation therefore takes place under better conditions and during a longer time; also, at the fourth year, and for the same reasons as previously given, the yellow colour is less marked, if it has not totally disappeared.

Chlorosis and Mildew.-All causes placing an obstacle in the normal functions of the cells of the vine hinder the formation and accumulation of reserve matters, and therefore the subsequent development of the vine. An increase of chlorosis results. Mildew, by prematurely causing the leaves to fall, acts in this manner, as was apparent enough in the years 1883,1885 , and 1886 , when the chlorosis was very intense, and the mildew, not yet combated with cupric salts, had exceptional gravity.

Chlorosis and Phylloxera.-Phylloxera acts in the same way, hindering the growth of the vine by the lesions it determines on the roots. A marked weakness soon becomes apparent, and, under the circumstances, it is less resistant to the carbonate of lime. Everybody has seen phylloxerated vines becoming intensely yellow in calcareous soils (never in any other soils) before succumbing. The phylloxera, by weakening the vine, renders it more sensitive to the action of carbonate of lime; their effects however accumulate, and this is why vines resist the phylloxera less in calcareous soils than in clay-siliceous soil.

The same phenomena take place with the American vines not absolutely resistant, but to a lesser extent. The nonsuccess of many plantations made with American vines must be attributed to the simultaneous action of phylloxera and soil; in a word, phylloxera diminishes the facility of adaptation to soil of American vines which are not very resistant. Consequently, the less resistant American vines should always be planted in soils which are the least noxious to them.

The lesions due to the white grub or any other parasite attacking the roots is attended with the same consequences.

Chlorosis and Grafting.-Grafting results in a relative diminution of the vigour of the vine (we will later on explain the reasons why), as well as its resistance to phylloxera, and also induces it to become yellow. Every one has noticed this. But this weakening effect is only produced when the species or varieties grafted differ from each other. In very calcareous soils, the Folle-Blanche grafted on its own roots 
does not become more yellow than when growing ungrafted on its own roots, but when grafted on Riparia, Solonis Rupestris, etc., it becomes withered, distorted, and dies. In the same way different stocks such as Riparia, Rupestris, Solonis, Lenoir, etc., may remain almost green and develop normally as long as they are growing on their own roots, but when grafted they very quickly succumb.

The weakening following grafting is not therefore the result of the operation of grafting itself; it results only from internal and external differences, or to be more exact from vital differences existing between stock and scion, or as it is called from the want of affinity between the varieties or species grafted. The swelling often existing at the knitting point has nothing to do with the weakening of grafted vines, neither has the knitting itself. No doubt a plant badly knitted, when placed in unsuitable conditions for growth, will become yellow quicker than a well-knitted plant (the chlorotic plants existing sometimes disseminated here and there in very green vineyards, are almost always grafts badly knitted); but the perfection of the knitting has not the importance attributed to it, from the point of view of its action on the change of colour of the leaves.

An imperfect knitting may be compared to a wound on the trunk of a vine; it has equal, but not greater importance.

We have shown that it is at the second year after planting that vines are most chlorotic. It is just at that time that grafting on the growing plant is performed. The weak state resulting from the want of adaptation to the soil, which is at its maximum then, is still increased by the weakening effect of the grafting. Grafting on the growing plant takes place therefore under more unsuitable conditions from this point of view; that is to say when the stock seems to suffer most from the presence of limestone. It is not a very serious trouble in siliceous-clay soils, but in soils rich in lime it is certainly so. We should therefore graft on the growing stock when it suffers least from the operation, that is to say, at the third or fourth year, when the plant has regained its normal green colour. This method has been followed in many vineyards of the south of France and the Charentes, and everywhere the results have been most satisfactory.

We may obtain the same result by grafting the cutting before planting out. A well-knitted plant, well rooted previously in the nursery, may become yellow when planted out 
in a calcareous soil, and perhaps a little more so than the same stock on its own roots, but certainly less than the stock grafted when growing on its own roots, for the disturbance which occurs directly after grafting does not exist in this case, as it took place when the plant was in the nursery, and for this reason under conditions which attenuated its effect on account of the perfect suitability of the nursery soil to the young plants. This has been noticed by many vinegrowers of the Charentes, Gironde, Bourgogne, etc., who observed that vineyards planted out with previously knitted and rooted cuttings never become as yellow as those of the same age grafted when growing.

Chlorosis and Ploughing.-Every one has noticed that in certain soils vines become yellow, especially in spring after deep ploughing. It has also been noticed that in the same vineyard a ploughed pàrt becomes more yellow than another part not ploughed. This fact is very frequently noticed in the Charentes, Corbières, and Auvergne. What is the reason for this? It is that deep ploughing, when the vine has already commenced to grow, suppresses the roots growing in the surface soil, that is to say, in the least calcareous portions. In addition to the ill effects produced by the suppression of a part of the absorbing organs of the plant, it forces it to live for a certain time-and that during the period when chlorosis has the greatest effect-with its deep roots penetrating the calcareous layers of soil. Superficial ploughing is, therefore, indicated for soils of this nature.

We have shown that humidity, compactness, and sourness of soil, if alone or combined do not constitute excellent conditions for the development of the vine, but are not a great obstacle to its culture, and that they are not the cause of chlorosis; that drought, lack of light, heat, defective coloration of the surface of the soil, aeration, grafting, phylloxera, etc., are not the cause of it either. Carbonate of lime, alone, causes the vine, whether American or European, to turn yellow, and its action is always more pronounced as it is present in a greater quantity or in a more assimilable form, and may be increased by water, which dissolves it and renders it available to the plant, and by grafting, phylloxera, and deep ploughing. We have shown on the contrary, that it is diminished by artificial drainage, salts of iron, etc. We will indicate, when speaking of culture, the important consequences resulting from the above considerations. 


\section{PART II.}

\section{CEPAGES.*}

It is not our intention to give here a complete monograph of all the cépages; we will only further develop for each what has been already stated in the first part of this work, and study from various points of view their cultural properties, insisting more particularly on their qualities of adaptation, resistance to phylloxera, and respective value for the reconstitution of vineyards according to circumstances.

All the cépages are derived from one or several species. Some have primordial characters which are transmissible in a greater or lesser degree to their descendants. We will examine in detail the properties of the diverse species of vines, so as to deduct the cultural value of their varieties or hybrids.

With this object we will study:-Ist, the species of Amercan vines; 2nd, the species of Asiatic vines; $3 \mathrm{rd}, \mathrm{V}$. Vinifera, from which all the European varieties are derived; 4th, the hybrids between American vines (AmericoAmericans); and 5th, the hybrids between American vines and V. Vinifera (Franco-Americans).**

We will only succinctly indicate the ampelographic characters of the species or hybrids, in order to be enabled to classify and distinguish the forms of superior cultural value. The question of selection of forms in each species or hybrids is of great practical value. Their distinction is difficult, as it only rests on slightly decided characters, but which must be defined. We know, for example, how varied the forms of Rupestris, Riparia, and Berlandieri are. Among them many are without value. Hence it is useful to be able to recognize those which should be selected for reconstitution of vineyards.

* This word is used as it has no true equivalent in the English language. It is usually translated by variety; this, however, dnes not convey the real meaning, as it may be applied to a species, variety, variation, hybrid, or metis.-(Trans.)

** Or Vinifera-Americans-(Trans.) 


\section{I.-SPECIES OF AMERICAN VINES.}

America is the part of the world which possesses the greatest number of species of vines; the numerous types derived from them are disseminated in all situations and conditions. Eighteen species of American vines, at least, are known, while only one exists in Europe, and eleven in Asia. The species from America alone resist more or. less the attacks of phylloxera, and this resistance is probably the result of natural selection determined by the action of the parasite itself. This natural selection is, therefore, a guarantee of the permanence of the resistance acquired by each of them.

Amongst the eighteen species of American vines, a few only are of cultural value for our vineyards. It is not useless, however, to know them all, for certain species of no intrinsic value have given, by direct or indirect hybridization, cépages which have or have had a certain reputation. We will study the species of American vines in the following order, in which they are grouped according to their botanical characters :-

Section I. Muscadinia Planchon

V. Rotundifolia, Michaux.

V. Munsoniana, Simpson.

Section II. Euvitis Planchon.

Series 1. LABRUSC瓜.

V. Labrusca, Linne.

Series 2. LABRUSCOIDEA.

V. Californica, Bentham.

V. Caribæa, de Candolle.

V. Coriacæ, Schuttleworth.

V. Candicans, Engelmann.

Series 3. ASTIVALES.

V. Lincecumii, Buckley.

V. Bicolor, Leconte.

V. Astivalis, Michaux.

Series 4. CINERASCENTES.

$\checkmark$ Berlandieri Planchon.

V Cordifolia, Michaux

V. Cinerea. Engelmann.

Series 5. RUPESTRES.

V. Rupestris, Scheele.

V. Monticola, Buckley.

V. Arizonica, Engelmann

Series 6. RIPARI $\mathrm{E}$.

V. Riparia, Michaux.

V. Rubra, Michaux. 


\section{ROTUNDIFOLIA.}

(a) Description.-Stump very vigorous, spreading habit, trunk very strong, branches (Fig. I) bark with disseminated lenticels, without diaphragms, of a deep shiny grey, tendrils simple, discontinuous. Leaves (Fig. 3) small, pentagonal, entire, thick, parchmentlike, apron nil; teeth in two series, wide, obliquely directed; green, shiny and glabrous on both faces, under-face lighter in colour. Bunch composed of a few berries maturing successively; large, spherical, colour yellowishbrown, with thick skin and fleshy pulp. Seeds (Fig. 2) large, elongated, flattened; chalaze and raphe nil; chalazic depression surrounded by radiating striations and two longitudinal depressions. Roots slender.

(b) Varieties.-The variations of $\mathrm{V}$. Rotundifolia in its wild state are not numerous; they exist mainly in the colours of the fruit, which are black, pink, or white, and in the intensity of the tint of the foliage. The varieties obtained from seedlings in America, such as Scuppernong, Thomas, Tender Pulp, Mish, Flowers, have the same properties of adaptation and the same cultural value as the pure species.

Hybrids between V. Rotundifolia and $V$. Vinifera have been tried, and notwithstanding the strongly accentuated botanical differences existing between these two species, some curious forms have been obtained.

(c) Adaptation and Culture.-The $\mathrm{V}$. Rotundifolia is limited, in America, to the southern states bordering the Atlantic, from Florida to Virginia, and in the centre of Texas. It lives in deep, siliceous, very rich moist soils. Great heat as well as moisture both in

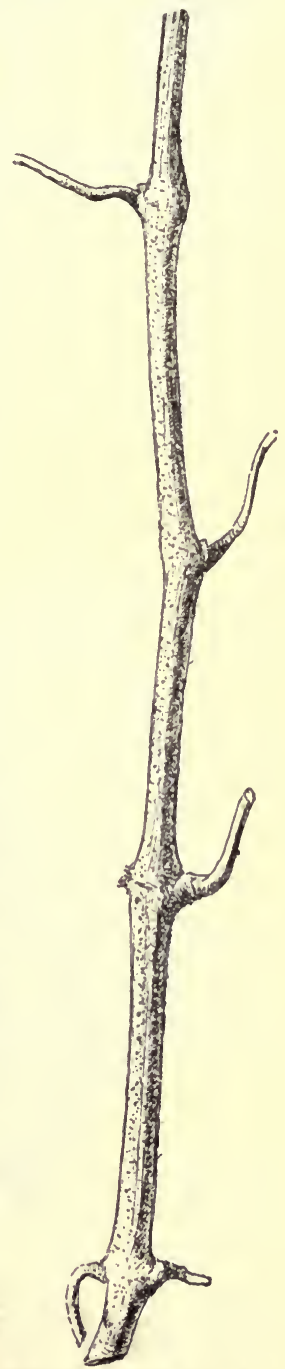

Fig. I. - Y oung shoot of 
soil and atmosphere are necessary to its development; it is only found in the rich sandy alluviums on the banks of rivers, where it acquires a remarkable growth. Trunks measuring from 3 to $4 \mathrm{I}-2$ feet in circumference are not rare in its wild state

V. Rotundifolia grows very badly in France, except in the mellow, fresh, deep, and fertile

Fig. 2.-Seed of soils of the south, and even in such soils its V. Rotundifolia. development is relatively poor, and it bears little fruit. In arid and in calcareous soils it dies very quickly. However, the phylloxera has no action on it;

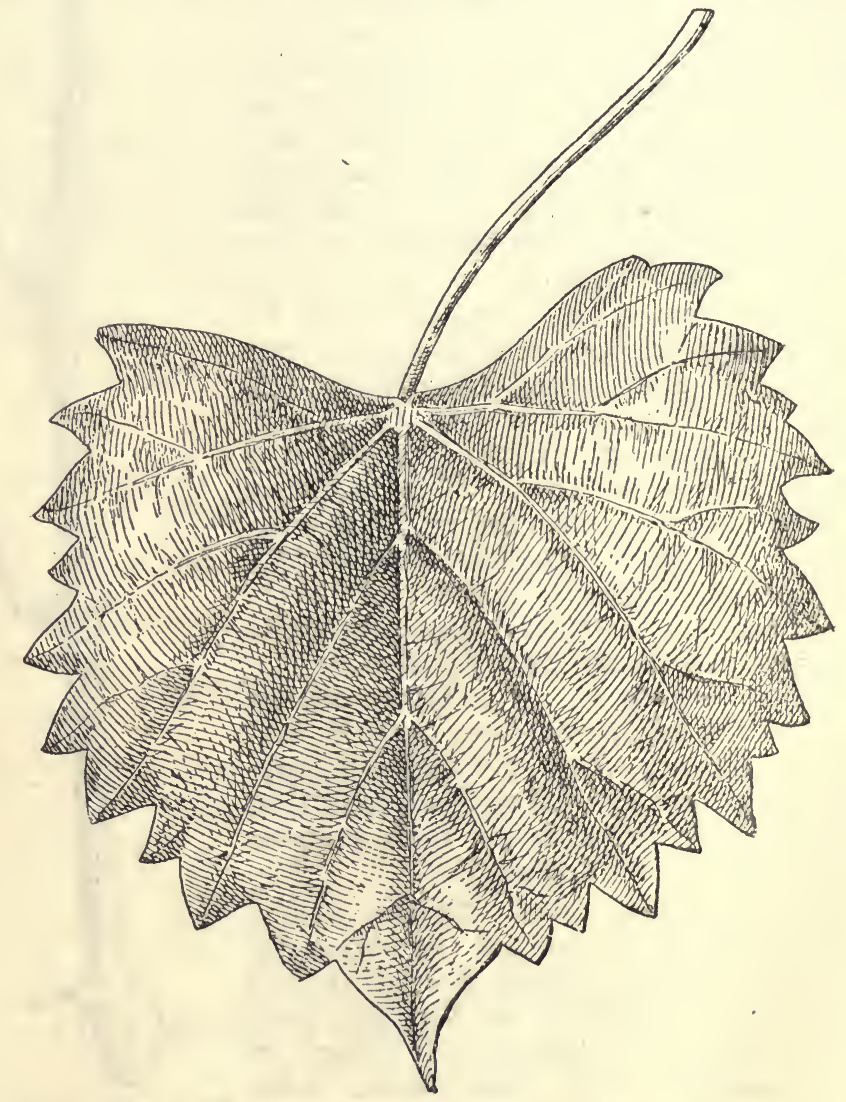

Fig. 3.-Leaf of V. Rotundifolia. 
the insect has never been observed on its roots, either in France or America; its resistance may therefore be expressed by I9.5. Cryptogamic diseases (Oidium, Mildew, Black Rot) are rare and without action on its leaves or fruit; its roots are not affected by stagnant or brackish water, nor by pourridié.*

This species is very difficult to grow from cuttings. The success of a few grafts of $\mathrm{V}$. Vinifera on it are mentioned as exceptions, which may be explained by the morphological and physiological similarities existing between the V. Rotundifolia and the Ampelopsis.

On account of its adaptation to deep, rich, fresh siliceous soil, to warm moist climates, and its difficulty of striking from cuttings, of its slight affinity to grafting with European vines, and its poor productivity, the $\mathrm{V}$. Rotundifolia is a valueless species for the reconstitution of vineyards; the same applies to the forms derived from it.

\section{MUNSONIANA.}

The V. Munsoniana is a new species, which was only introduced in France in 1887 , where it succeeds even less than V. Rotundifolia. It originates from the swampy districts, the tropical climate, and the very fertile siliceous soils of Florida.

The few vines which were planted in I 888 at the School of Agriculture, Montpellier, died two years after. This species belongs to the same botanical group as the $V$. Rotundifolia, from which it is distinguished by its vegetation being generally more slender, by its bunches composed of a great number of berries, which are small Fig. 4.-Seed of instead of large, by its very small seeds V. Munsoniana. (Fig. 4); the teeth of its leaves are straight instead of being convex on the sides, and are normal to the limb, instead of being disposed obliquely.

\section{LABRUSCA.}

(a) Description.-Stump, vigorous; habit, spreading; trunk, strong; canes rugose, with numerous thick hairs; tendrils continuous and opposite each leaf (Fig. 5), contrary

* A cryptogamic disease, attacking both European and American vines and caused by the develnpment of different fungi [Demntophora necatrix (R. Hartig), Agaricus II elleus (L.), Raxteria hypogaea (Thum. and Pass.)] often taken for ordinary root rot.-(Trans.) 
to all other species which have discontinuous or intermittent tendrils (Fig. 6). Leaves (Fig. 7), large, orbicular, entire,

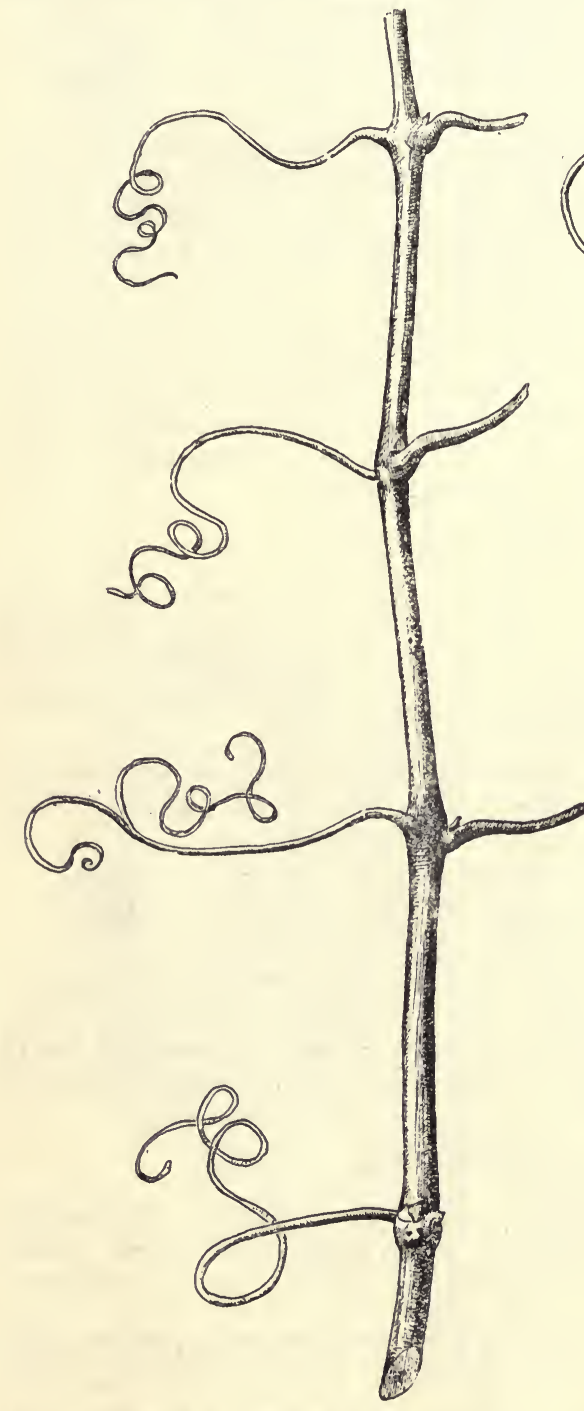

Fig. 5.-Shoot of V. Labrusca, with continuous tendrils.
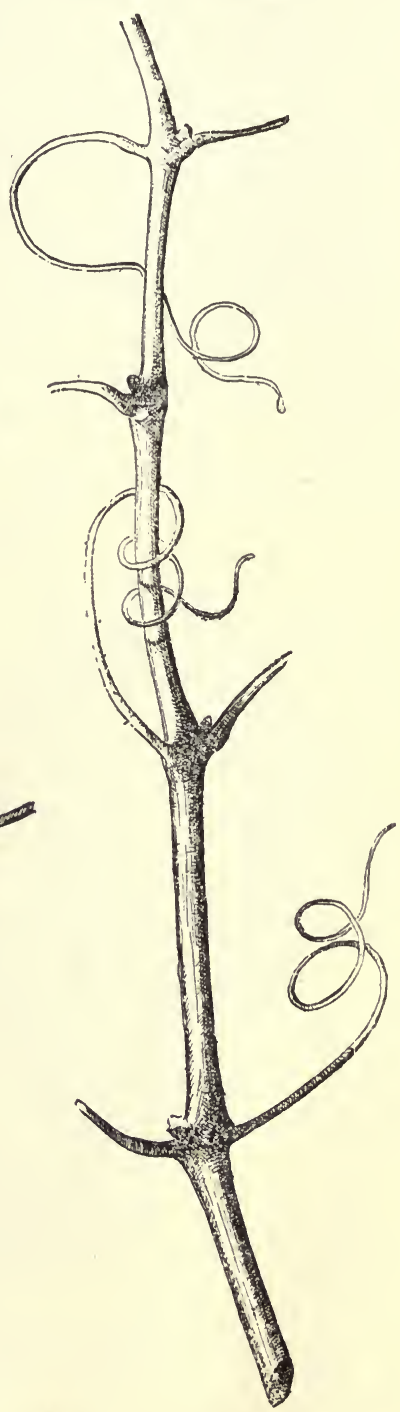

Fig. 6.-Shoot with discontinuous tendrils. 
bubbly; petiolar sinus, deep; upper-face bright green, slightly shiny; under-face covered with a whitish or golden

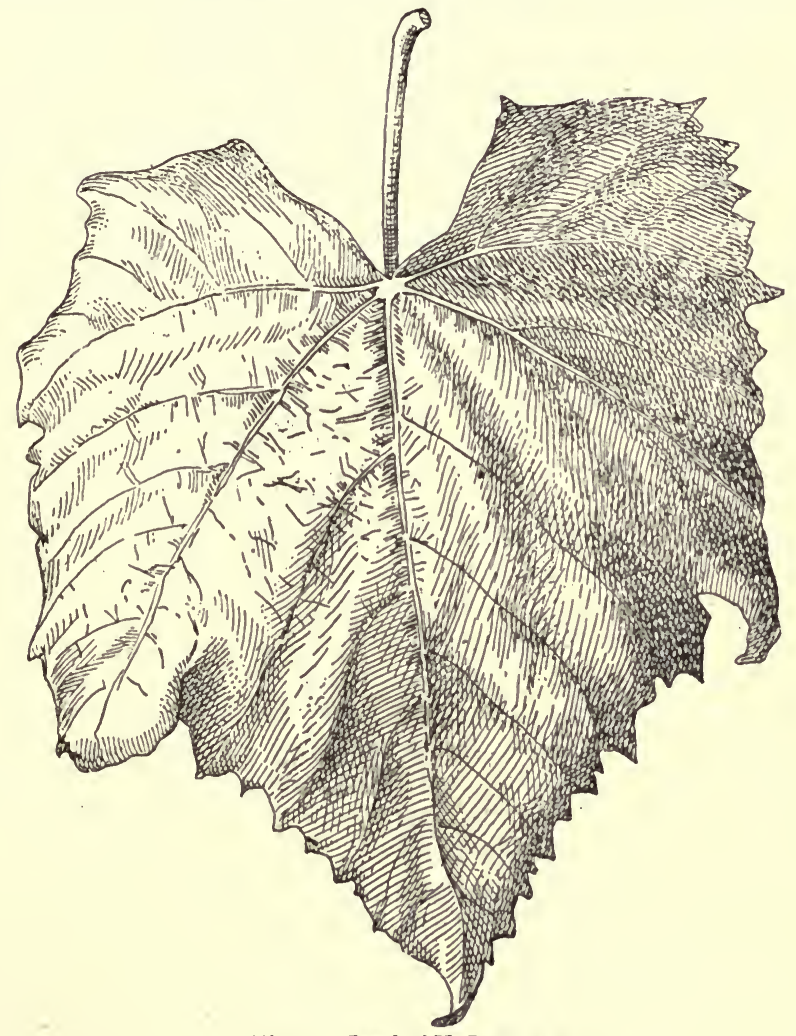

Fig. 7.-Leaf of V. Labrusca.

yellow felty tomentum. Bunch medium, with berries above the average size; colour, violet black; pulp, fleshy; strong foxy taste. Seeds (Fig. 8) large, thick set, short beak; chalaze and raphe nil; replaced by a very marked circular depression. Roots, thick and fleshy.

(b) Varieties.-The wild forms of V. Labrusca are very varied, but on account of their small cultural interest we will not study them at Fig. 8.- Seed -of length; but will note, however, that some of v. Labrusca. them have a close botanical analogy with the Asiatic species of vines. 
The cultivated forms, derived from the wild types of $\mathrm{V}$. Labrusca, are numerous; we will mention amongst them the Concord and seedlings resulting from it: Early Victor, Martha, Moore's Early, Niagara, Pocklington, Black Hawk, Cottage, Lady, Mason Seedling, and the Isabella, the American vine first introduced into France and its seedlings: Prentiss, Israella, Eureka, Union Village, and again Hartford Prolific, and Ives Seedling, which is a seedling of the latter, Belvidere, Alexander, Arrot, Maxatawney, North Carolina, Northern Muscadine, Perkins, Rebecca, Rentz, Telegraph, Venango, Vergeness, etc.

The botanical and cultural characters of the V. Labrusca are generally transmitted, in a very accentuated form, to the cépages derived from it. They all have very large fruit, with fleshy pulp, strong foxy taste; their resistance to phylloxera is very inferior, similar to that of the wild types of this species. We shall study their power of adaptation, but on account of the few essential defects above mentioned the numerous cépages derived from seeds of V. Labrusca and those which could be derived later on are of no value whatever for European vineyards.

(c) Adaptation and Culture.-The V. Labrusca, and its diverse varieties are the most sensitive to phylloxera of all the species of American vines; its resistance may be expressed by 5 , the maximum resistance or absolute immunity being 20 . However, when the soils are not too calcareous and the conditions very favorable to the development of this species, its resistance is sufficient to allow it to retain its vigour, especially in cold regions where the insect has less action. The hotter and drier a climate is, and the stronger the development of the phylloxera, the more difficult adaptation becomes. These facts are corroborated by what takes place in America as well as France, and are another proof of what we stated in the first part of this work.

The V. Labrusca grows more particularly in the cold regions of North America. It is rare in the south-east of Canada, and only begins to grow freely in the forests of New England, but it is more abundant, both in its wild and cultivated state, in the eastern states bordering the Atlantic.

The V. Labrusca not only requires a very special soil to be vigorous, but even requires it to live at all, and more so when cultivated in warm regions such as Virginia, Missouri, 
and Texas. The soils where this species grows naturally and those where its varieties are cultivated are sandy, or red, and siliceous, often resulting from the disintegration of granitic rocks. Further, the soils of New Jersey and those of the Islands in the neighborhood of New York are constituted of fine, very deep, fresh, and fertile sands; those of Maryland are red, fine, and very moist sands. In Virginia and Pennsylvania, etc., this species is limited to very rich granitic soils, and grows only in places where they are fresh and moist. In all these soils the V. Labrusca is very vigorous, although phylloxera produces nodosities and tuberosities on its roots.

The same facts have been noticed in Europe. It is exclusively in sandy fertile, deep, and fresh alluvial sands that the Concord and Isabella have proved vigorous and resistant; it is mostly in a few red and rich siliceous soils of the alpine diluvium that the Concord has maintained its vigour, as well as in the partly submerged and non-calcareous soils of the northern regions, that is to say, in surroundings where phylloxera has less effect.

When the V. Labrusca and its varieties are cultivated in other than sandy, granitic, clay-siliceous, or alluvial soils, they die under the action of phylloxera, in America as well as France; on account of its large roots this species thrives in compact but very fertile and rich soils. Further, in calcareous soils the different forms of $\mathrm{V}$. Labrusca rapidly become chlorotic and disappear even quicker than the European vines on account of the combined action of both soil and phylloxera.

These facts have been noticed since the beginning of reconstitution with American vines in the south of France (limestone and yellow marls of the Molasse) and in the Charentes (limestones of the Cretaceous period). It is the same in America. In the yellow, marly soils surrounding the great lakes (Sandusky) the V. Labrusca becomes chlorotic and dies quickly. In the south, in Texas for example, where the phylloxera has a still greater power on chlorotic plants in calcareous soils, the culture of the V. Labrusca is impossible in the black, often very rich, deep and compact, but calcareous soils surmounting the chalky subsoil. We are obliged, in order to maintain varieties of V. Labrusca in the more fertile soils, to layer each year (as is done in the Champagne) the canes of the preceding year. The maintenance of the 
varieties of $V$. Labrusca may be due, in this case, to the superficial layer of soil being only slightly calcareous and to the layering developing surface roots, which, for a certain time at least, live in that superficial layer, and also to the young roots replacing those destroyed by the phylloxera. In slightly calcareous, compact and rich soils, these varieties are grafted on Taylor. We shall see that its properties of adaptation and resistance are transmitted to its hybrids which are, therefore, very sensitive to chlorosis and phylloxera.

The V. Labrusca is, therefore, of no value for reconstitution of European vineyards. It roots freely from cuttings. as applies to all the species from the north of America, and the graft knits well with European vines; it resists attacks of oidium and mildew well, but its fruit is very sensitive to black rot, and its roots to pourridié.

\section{CALIFORNICA.}

(a) Description.-Stump very vigorous, trunk very strong; habit, creeping; wood of the year deep greyish-brown, tendrils discontinuous. Leaves (Fig. 9) large, entire, obicular, as wide as long; petiolar sinus widely open; limb, thin, bright green on the upper-face, whitish-green tomentose on under-face; teeth acute, in two series. Bunch long, small; berries small. spherical, of a deep violet black colour, clean taste. Seeds (Fig. ro) small, distended; beak blunt; chalaze oval, terminating level with the position of the raphe (which is absent). Roots rather large.

(b) Varieties. -The variations in form of V. Californica are excessively numerous; certain varieties have very marked characters, such as those growing in the dry sands of the south of California, which T. V. Munson regarded as a species and named $V$. Girdiana. These forms often have lobed leaves, without teeth, and thick, short, stiff hair on the under-face. We also meet with variations differing from the main type in other ways, such are the forms with very large, thin, entire leaves, with acute teeth, very slightly tomentose; these are the most vigorous forms. These morphological variations are almost always dependent on the fertility of the soil, but as they do not present any interest for the reconstitution of our vineyards it is of no advantage to discuss them. 
(c) Adaptation and Culture.-The V. Californica is limited to California and the south of Oregon; it is one of the most magnificent vines of the United States as far as vigour and vegetation are concerned. But it only attains remarkable

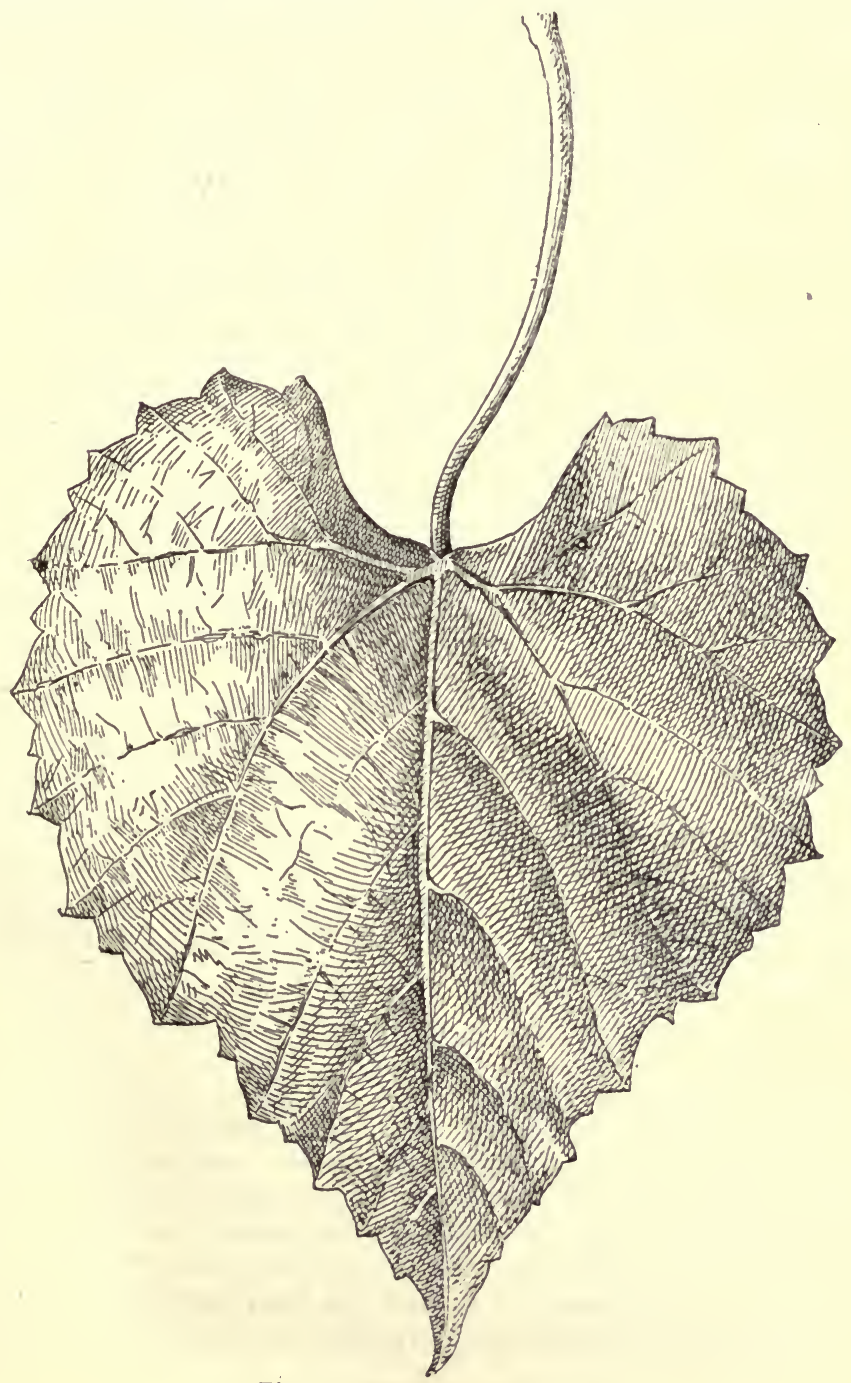

Fig. 9-Leaf of V. Californica. 
proportions and development on the banks of rivers, in brown alluvial, loose, very deep and fresh soils, or in pebbly soils containing only felspar, granitic, or siliceous pebbles. The forms with thick leaves, indented and tomentose (Girdiana group), live in siliceous soils, often in pure dry unfertile sands.

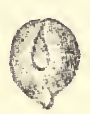

In the north of California (especially the counties of Napa and Sonoma) the V. Californica is found growing in calcareous soils, and in reddish or blackish rather Fig. ro-seed of calcareous marl. In these soils the wild v. Californica. forms of the species become rapidly chloratic. The Californians who tried to propagate it as grafting stock have been compelled to limit it to sandy, rich and fresh alluvials. This species is almost as sensitive to chlorosis as the V. Labrusca In chalky soils of the Charentes, it rapidly becomes yellow, and, what is more, its resistance to phylloxera is not even equal to that of the $\mathrm{V}$. Labrusca, and may be expressed by the number 4 .

It is on account of this feeble resistance that it has never been cultivated in Europe, where it only exists in collections. It roots freely from cuttings, and knits well with V. Vinifera; but its leaves are very liable to cryptogamic diseases

\section{CARIBÆA.}

This species is of no practical interest; it lives in tropical America, in the West Indies, the warm regions of Mexico, etc. It has frequently been imported into France and cultivated in collections, but has never thrived, and soon disappeared, owing to the unsuitable climate. Its value as far as adaptation and resistance to phylloxera are concerned has never been studied.

\section{CORIACEA.}

The V. Coriacea is like the V. Caribæa, of no practical cultural value; it is limited to Florida, where it grows in the same soils as the V. Munsoniana, in the very rich, generally swamp soils, of the Eocene and Quaternary period. It was introduced into France in 1887 , but grows badly in rather calcareous soils, without, however, becoming yellow. Its resistance to phylloxera has not yet been ascertained, but it does not seem to be superior to that of the Mustang, which 
the V. Coriacea resembles botanically, and in having large and fleshy roots. It differs from it in its small berries, its leaves (Fig. II) small and always plane, and the

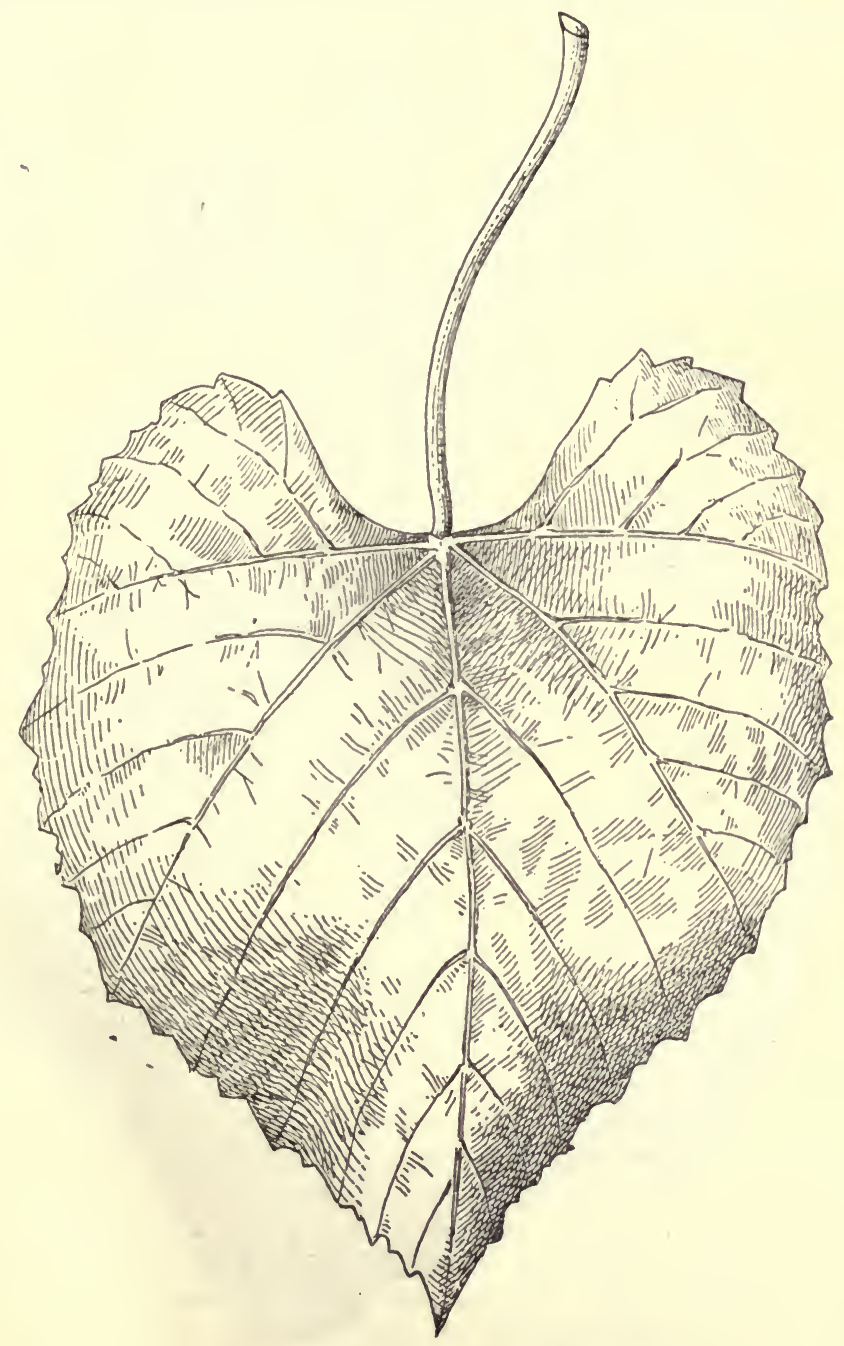

Fig. 11.-Leat of V. Coriacea. 
white-yellowish golden colour of its tomentum, which is less woolly and less fluffy than that of the Mustang, the seeds (Fig. I 2) are small, with both chalaze and raphe

Fig. 1 2.-Seed of

\section{CANDICANS.}

(a) Description.-Stump very vigorous habit creeping, trunk very strong; wood of the year deep brown, with numerous patches of long white hair; tendrils discontinuous. Leaves medium, rather large (Fig. I3), as wide as long, entire, cordiform, rounded, sometimes indented and lancinate

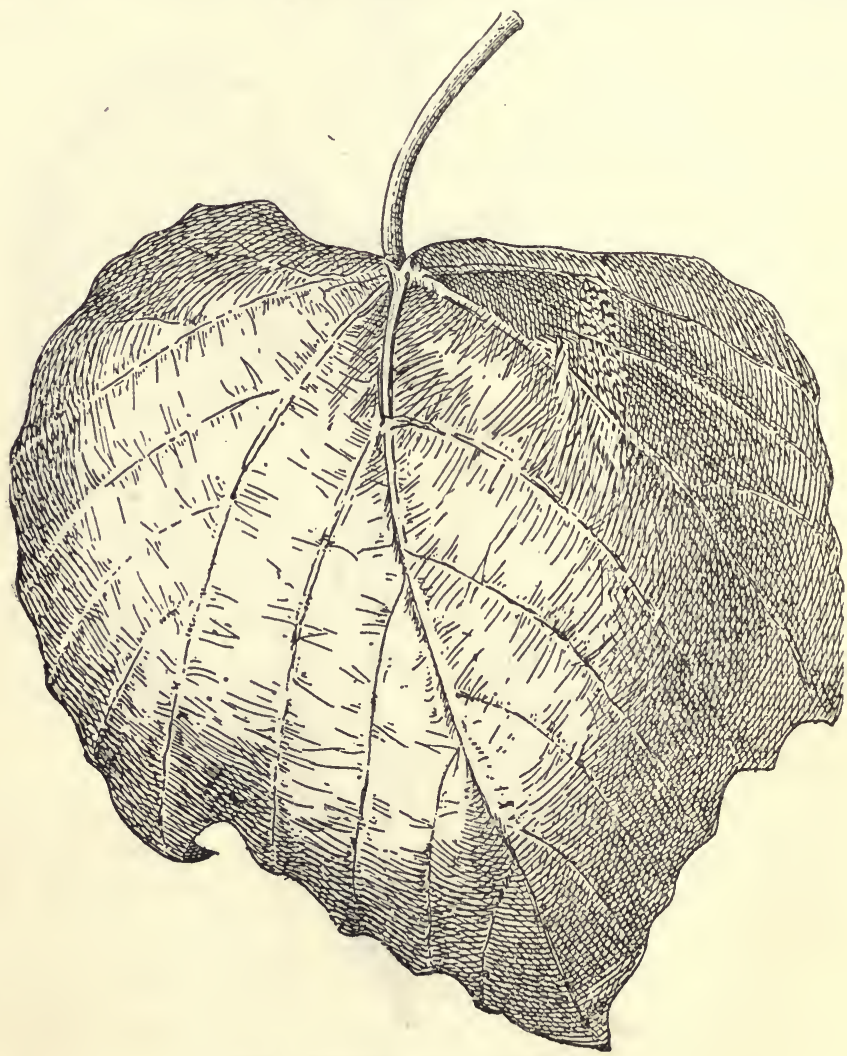

Fig. 13.-Leaf of V. Candicans. 
(Fig. I4); petiolar sinus shallow; limb thick, umbrella shaped; upper-face deep green; under-face with white, thick, felty tomentum. Bunch small, irregular; berries large, deep.

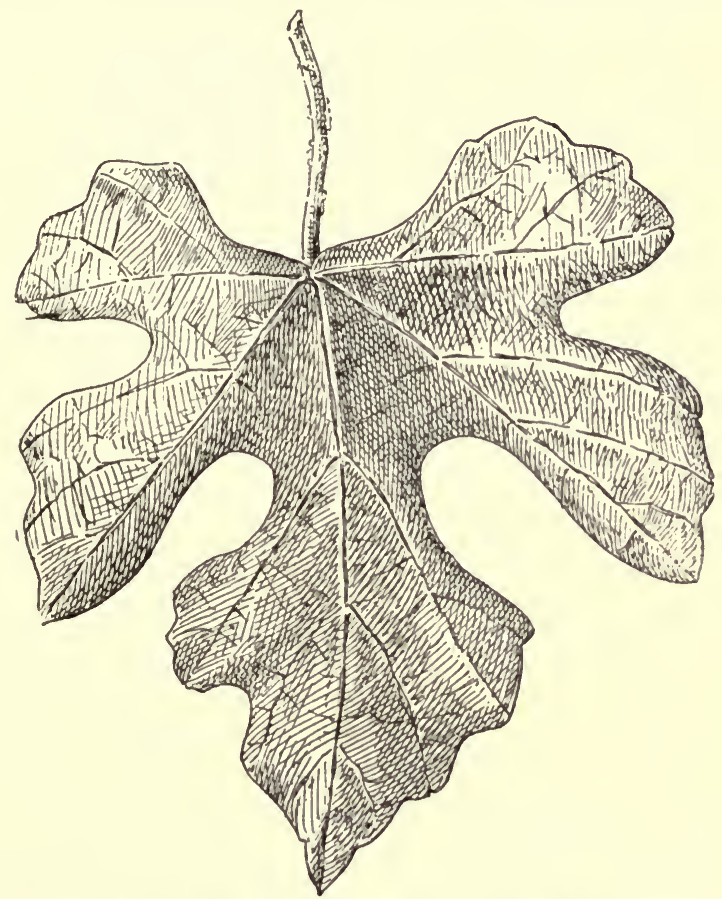

Fig. 14.-Lancinate Leaf of V. Candicans.

black colour, globular, discoid, pulpy, very harsh taste. Seeds (Fig. I5) very large, beak short; chalaze and raphe rudimentary, grooved round the chalazic depression. Roots large and fleshy.

(b) Varieties.-The variations of the V. Candicans or Mustang are not numerous; it is one of the species which has, in

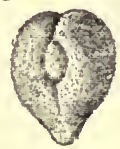
the wild state, the most fixed and defined characters. A few differences of secondary importance sometimes occur, but it is: only in dimensions of the leaves, which vary according to the richness of the soil. Fig. 15.- Seed of In the rich soils on the banks of rivers:
V. Candicans. 
the Mustang acquires its greatest development. On the other hand, the hybrids of this species are very numerous and varied, on account of its great geographical extension and its long period of florescence.

(c) Adaptation and Culture.-The Mustang is the most common vine in the south of the United States; it extends from the Arkansas River to the centre of Mexico; it traverses Arkansas, the Indian territory, a part of Louisiana, and Texas. It grows in the same regions as the V. Berlandieri, but over a more extended area; the variations of $\mathrm{V}$. Candicans are more numerous than those of the latter species. They are found, like the V. Cinerea and V. Cordifolia, vigorous and in great number in the "bottom lands" and on the banks of rivers; under these conditions the trunk attains a circumference of 35 inches.

The V. Candicans, however, resists drought well; it sometimes grows on the sides or tops of hills amongst plants living without much moisture, but then it is not vigorous. although green, and the types met with under these circumstances may be considered exceptions as compared with those living on the banks of rivers. The V. Candicans is a species belonging to hot countries. We will refer to the climate and regions it lives in, when studying the V. Berlandieri.

The alluvial river banks where the Mustang is generally found are soils of the greatest fertility. But it also exists in special soils, sometimes very unfertile and often very compact; the constitution of its large roots is in correlation with this fact. In France, for instance, the few types existing in collections grow vigorously in blue marl, or very compact red clay, less vigorously, however, than in fresh, fertile soil In the United States, near Dallas, it has an immense power of vegetation in the soils called by the Americans "black waxy lands" on account of their plasticity and inkyblack colour; these soils are very clayey, sour, little fertile, and rest on a compact bank of cretaceous limestone.

The Mustang, however, is not a vine peculiar to chalky soils. It rapidly becomes yellow in the friable chalks surrounding Cognac (France). It is true that in America some types only slightly vigorous are found growing on cretaceous formations, but only in cases where the black clay soil. rich in humus which covers the chalky rock, is rather abundant, particularly on hill-sides. An American soil where the 
Mustang had a fine development had the following percentage composition (analysis due to Chauzit):-

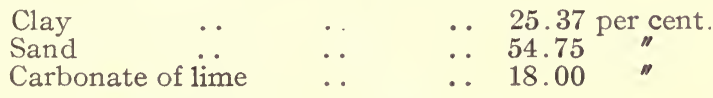

This species, therefore, is not peculiar to calcareous soils, and its hybrids, when they possess its characters in a high degree-which is often the case-become easily yellow in chalky soils.

Further, the Mustang is the most difficult species to root from cuttings more difficult even than the species originating from the warm regions of the United States. Its resistance to phylloxera, which may be represented by the number I 5, is not of the highest degree. Should varieties of this species be found to root freely from cuttings they would require to be tried with care in compact soils, for which they seem indicated; other American grafting-stocks are actually, at least, superior, and better known from the point of view of their adaptation. Let us note that the harsh taste of the Mustang is constantly transmitted to the American or Franco-American hybrids derived from it. The Mustang resists cryptogamic diseases well on both leaves and fruit. but is very liable to pourridié.

\section{LINCECUMII.}

(a) Description.-Stump very vigorous, creeping habit, trunk strong; wood of year hazelnut colour; tendrils discontinous. Leaves (Fig. I6) very large, almost as wide as long, orbicular, entire or lobed with deep sinuses; petiolar sinus very deep, with tangent lips; limb thick and rugose: upper-face deep green: under-face glaucous. Bunch medium, berries medium, discoid, skin covered with bloom, deep red; disagreeable taste. Seeds (Fig. I 7) large, pear-shaped, beak detached; chalaze wide, orbicular; raphe filiform. Roots of medium strength, hard and long.

(b) Varieties.-The $V$. Lincecumii or $V$. Linsecomii, Estivalis with large berries, Post Oak, is represented by a great number of types in its wild state. As it is fructiferous and resistant to cryptogamic diseases, the Americans tried to select it and create new varieties from seeds. H. Jæger has isolated over Ioo pure forms of this species, and obtained many hybrids between it and Rupestris. The Neosho 
(Racine, Far West) is the oldest form we possess in France. The Pulliat, obtained by G. Foëx from seeds of

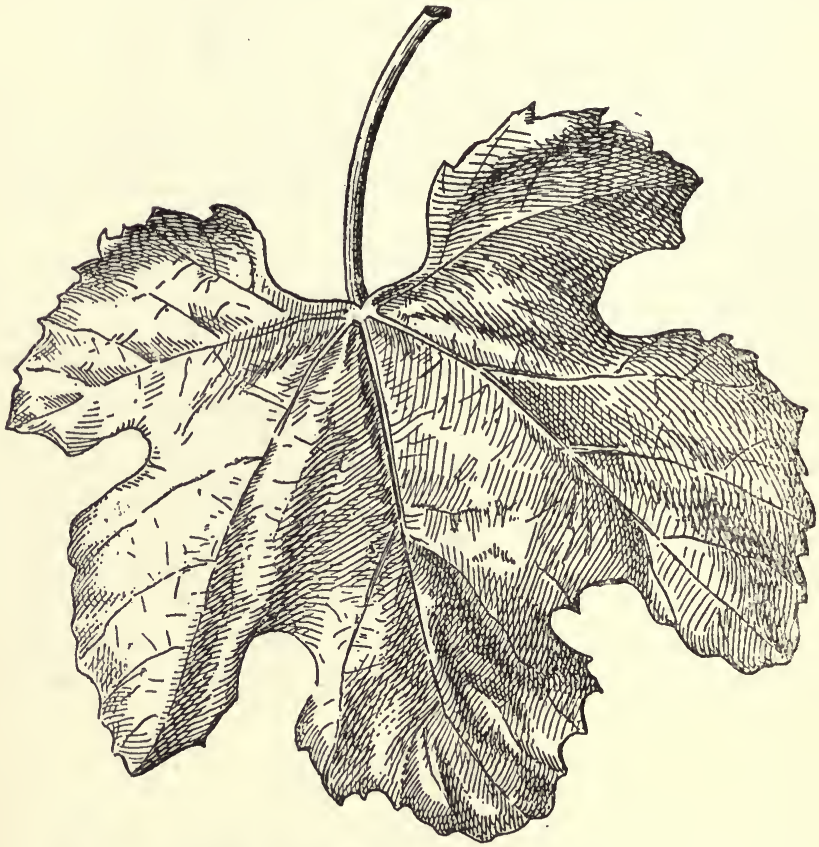

Fig. x6.-Leaf of V. Lincecumii.

Neosho, is again a pure form of the species; more fructiferous and of a cleaner taste than the Neosho.

But the ripening of all these forms is very late; their pro-

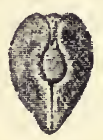
ductivity may be compared to that of the Gamay, and they ripen even later than the Carignane. The most fructiferous forms obtained by $H$. Jæger are No. I3 and Fig. 17.-Seed of No 43, but all retain a certain harsh taste V. Lincecumii. in the fruit, persisting even in the resulting wine; they are of no value as direct producers. Their resistance does not reach that of Solonis, and may be designated by the number I4; the cuttings root badly, although better than those of V. Candicans.

$1^{-}$(c) Adaptation and Culture.-The V. Lincecumii is limited in its geographical distribution; it grows in countries where 
a high temperature is reached in summer, especially in the extreme south-west of Missouri, in Arkansas, Indian Territory, north-west of Louisiana, and north-east of Texas. We will note that it is mostly found in the Rupestris region.

The V. Lincecumii generally grows in the red siliceous, very deep and rich soils of river banks; on the hills, it only lives in soils composed of siliceous or granitic pebbles, mixed with reddish clay, constituting a dry medium, but always. fairly fertile and compact. As a graft-bearer it is not superior to the Rupestris for the above-mentioned soils, and not superior to the Riparia for the rich deep soils, and, as we have said, its resistance to phylloxera is inferior to that of these two species. It is a species which succeeds even less in calcareous soils than the Rupestris; it has never been found growing in such soils, even accidently, in America. In France it only grows well in soils containing a small amount of limestone, slightly compact and rich; in white limestone soils it rapidly turns yellow.

\section{BICOLOR.}

$\mathrm{V}$. Bicolor is a species intermediate in its character, between V. Lincecumii and V. Estivalis; it only differs from the latter in the smaller indentations of its leaves, which are glaucous green and glabrous on the under-face, by its bunch small and close set, and above all by its small seeds (Fig. I 8). It is peculiar to the north-east of the United States, especially in Michigan, Indiana, and New York state. It only grows in soils derived from old formations, red siliceous and fertile (Carboniferous, Silurian, Devonian, etc.). The pure forms of this species, only recently imported into France, have, even in good soils, a comparatively small development. Its resistance to phylloxera has not yet been ascerta ned, but seems equal to that of the best Estivalis forms. This species does

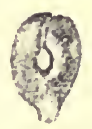
not succeed in chalky soils and marl, as applies also to the latter. In a word, the V. Bicolor is of no practical interest for reconstitution.

\section{ASTIVALIS.}

(a) Description.-Stump vigorous, creeping habit, trunk strong; wood of the year deep wine colour, with bloom at. 
the nodes; tendrils discontinuous; leaves carmine when young, medium, sub-orbicular, entire or lobed; petiolar sinus deep; upper-face dull deep green, under-face with patches of cobwebby rust-coloured hair. Bunch medium; berry sub-medium, spherical, vinous black; skin covered with bloom; coloured juice; taste clean. Seeds (Fig. I9) sub-medium; beak short; chalaze circular, prominent; raphe limited by a well-defined rib passing round the base of the seed. Roots hard, rather large.

(b) Varieties. - It has been considered for a long time, and many authors still consider, that certain cultivated vines of the United States, such as Cynthiana, Norton's Virginia, Baxter, Herbemont, Hermann, Cunningham, etc., are pure forms of the V. Astivalis, which they resemble more or less in their characters of adaptation. The

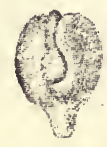

Fig. r. - Seed of V. Astivalis. researches of Millardet seem to have proved that these cépages, which have the characteristics of almost pure Estivalis, are, however, partially hybridized with others. We will study them later on. This also applies to other cépages, which $\mathrm{T}$. V. Munson included, with some of those above-mentioned, in a specific section under the name of $V$. Bourquina, Jacquez* for instance.

As for the variations of the wild forms of the species, they are of no interest. Let us recognize, however, that in a general way the thickening of the leaves increases from the north to the south, and, inversely to what often takes place, the abundance and the length of the hair diminishes when one passes from moist rich soils to poor dry soils, where the tomentum becomes at the same time stiffer.

The pure forms of V. Astivalis are difficult to root from cuttings, and sensitive to mildew and black-rot.

(c) Adaptation and Culture.-The V. Astivalis predominates in the centre and east-centre of the United States, from New England to Texas, especially in Pennsylvania, Virginia, and Carolina; it is also found represented by a small number of types in Florida, Louisiana, and even Mexico. Consequently the V. Estivalis is a variety for medium climates. The temperature in the regions where the species is most widely spread drops below $-25^{\circ} \mathrm{C}$.; the derived forms connected with this species can therefore be expected to resist cold (Herbemont, Jacquez). 
Wild forms rarely grow in very dry soils, they have never been observed in swampy low lands. They predominate in soils of old formation (granitic, Silurian, Devonian, Cambrian, carboniferous). They are generally pebbly soils, strongly red-coloured siliceous; sometimes very red siliceous sands, and very moist This species is very much affected by limestone; it is one of the most sensitive species to chalky limestone and white marl.

V. Aistivalis in its pure form is of no value for reconstitution; the types multiplied in France have grown (not vigorously) in red siliceous Alpine diluvium. Its pure forms have a fairly great resistance to phylloxera, which may be designated by the number 16 .

\section{BERLANDIERI.}

(a) Description (General Characters).-Stump vigorous, of creeping habit, trunk medium; wood of the year dull, with a few patches of woolly hair on the summits of the young shoots, of a cinnamon-brown grey colour, with seven very distinct ribs; tendrils discontinuous. Leaves, young; shining brownish green; adult; medium, rounded pentagonal shape, nearly entire; petiolar sinus deep, with convergent lobes; scarcely indented; limb thick, wide honeycomb structure, folded along the mid-rib inwards, margins sometimes curved inwards; upper-face dark-green and shining; under-face lighter green, often shining, with prominent veins covered with short hair. Bunch medium, compact; berries small, very firm, spherical; skin black, covered with bloom. Seeds (Fig. 20) medium, squat; beak short and strong; chalaze rounded, slightly prominent, tapering to a scarcely protuberant raphe. Roots running, rather Fig. 20.-Seed of strong, thick and fleshy.

(b) Varieties.-The variations of forms of V. Berlandieri are very numerous, even more numerous than in the cases of V. Rupestris and V. Riparia. Between them there exists considerable differences, especially from the point of view of their vigour and adaptation, and, consequently their cultural value, the only consideration which must be taken into account. These variations are the result of diverse natural phenomena, especially of their dissemination in very varied surroundings, and the natural selection which fixed their characters under these conditions. There are other variations 
which may be considered as individual or intrinsic, and these are shown in the various groups of the species by very marked differences of vigour in the same groups. Some have a feeble development which is a fixed individual character, and consequently transmissible by cuttings; these must be excluded from culture; only the vigorous forms in the various groups should be propagated. Finally, in a natural state, other individual variations (rather than varieties, for they are not always reproduced as such by seed) besides vigour, facility of rooting from cuttings, fertility, are seen, which are possessed in a greater or less degree by certain Berlandieri types, variations which may be maintained by propagating from cuttings.

Selection is necessary and indispensable amongst the various forms of Berlandieri which have been introduced into France since 1887 , and also those formerly obtained from seedlings. Perhaps it is premature, but in any case not useless, to attempt to define the forms that have been introduced and which appear to possess the greatest value. As a general fact, the most vigorous, without distinction of name. with very thick leaves, shining on both faces, with the extremities of the branches slightly tomentose, with goldenbrown young leaves, are the most perfect; these are the characters of forms which, in the wild state, grow in the most calcareous soils.

The thickness of the tomentum divides the Berlandieri into two large but still connected groups, for the hairs are never entirely absent, even in the most glabrous forms. The tomentose Berlandieri have cobwebby hairs, especially on the young branches, on the principal ribs, and numerous stiff hairs on the sub-ribs. The leaves are large, Io to I $2 \mathrm{~cm}$. (4 to 5 inches), dull under-face, goffered structure, sometimes thin. These varieties have occasionally cordiform leaves recalling $\mathrm{V}$. Cinerea, of which they are without doubt hybrids, especially when the upper-face is finely goffered and dull, as also on the under face. All these tomentose forms are peculiar to the rich and often siliceous soils, little calcareous and fresh, on the banks of rivers. Consequently they have no value for chalky soils. We will not attempt to characterize the forms of this group.

The less tomentose forms, which we will call, for distinction, glabrous Berlandieri, have smaller leaves, thicker, harder, and more or less folded inwards along the mid-rib, 
canes dark-tinted, with darker flutings: sometimes the fluffy hairs are only found on the summits of young branches; the short bushy hairs on the ribs and occasionally on the subribs on the under-face of the leaf are often rather scarce.

In the second group of glabrous Berlandieri, two subdivisions may again be established: Ist, those with leaves of a dull yellowish-grey on the under-face, comprising the least vigorous and least recommendable forms of Berlandieri; and, those with very thick leaves, dark-green and very shining on the upper-face, and shining yellowish green on the under-face, with short supple hairs on the ribs and sub-ribs. The varieties of this last group are the best and most vigorous for chalky soils.

Amongst these latter we will only indicate a certain number of forms; other better forms may, perhaps, be isolated by further selection. These forms, or rather groups of forms, have recently been studied and characterized in an important memoir published by Marcel Mazade in the Revue de Viticulture (vol. V., I896). They are mostly of very great vigour and a real value for reconstitution; their development equals that of the best varieties of Riparia. Mazade has isolated and selected most of these from forms introduced and cultivated in various French vineyards. Those which appear to us to have the greatest value in regard to their resistance to chlorosis are the forms belonging to group No. 2 ; the forms in groups Nos. I and 3 are very vigorous and of very great value, but they are, perhaps, a little inferior to the types of No. 2 (especially the Berlandieri Millardet).

It is certain that an elimination will be carried out among the diverse forms which we cite, and we may already safely consider the Berlandieri Millardet, Berlandieri Vialla, and Berlandieri Ecole as inferior to the others and consequently not worth cultivation. We will only mention the Berlandieri Planchon, Berlandieri de Grasset, Berlandieri Bouisset,forms named by T. V. Munson, which are hybrids and not pure Berlandieris, and are without value for resistance to chlorosis, although very vigorous.

Herewith the way in which Mazade subdivides and fixes. the distinctive character of the forms of Berlandieri actually known, taking into account the general characters which we have given for the species and which are common to all the forms, and also the general particularly distinctive characters for the whole of the most meritorious Berlandieris. 
GROUP No. I. - General colour, uniform light-green; wood light (clear rather brilliant hazel); leaves large. elongated, lateral sides often parallel, often rather regularly folded inwards along the mid-rib, sometimes flat,

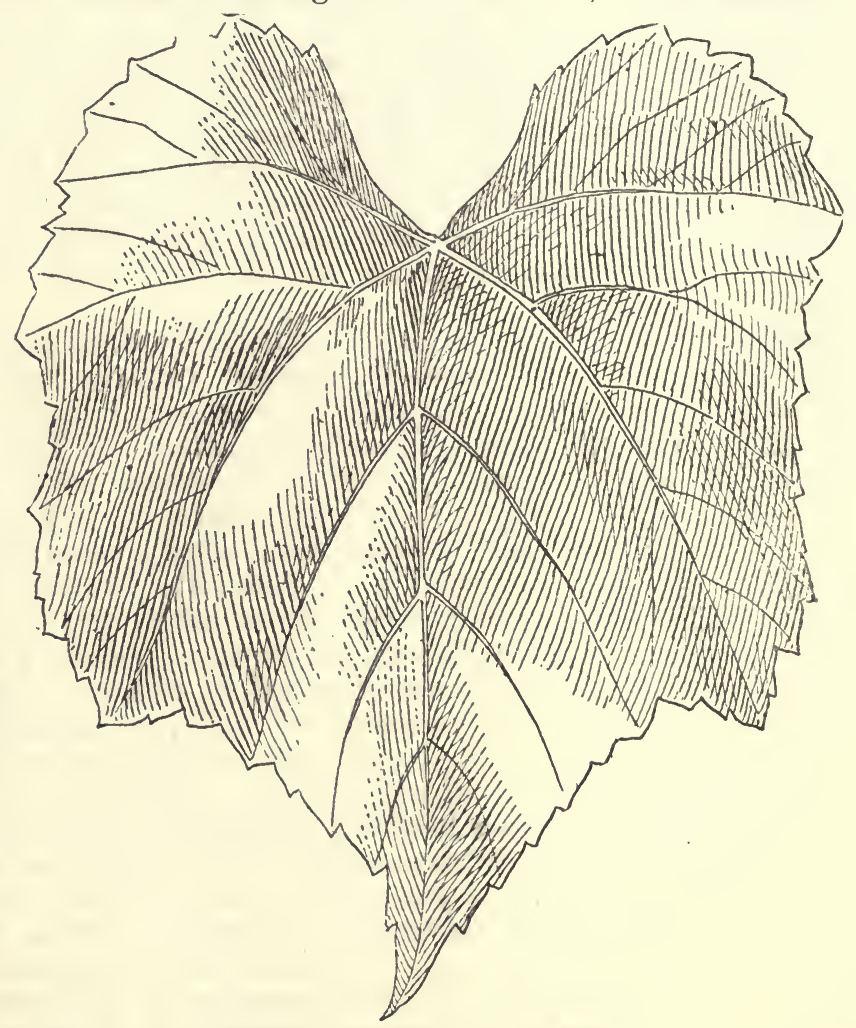

Fig. 21.-Leaf of Berlandieri Rességuier No. r.

relatively thin, supple, and smooth; extremities of the shoots ashy and light carmine; young leaves golden-yellow, passing gradually to the definitive tint; petiolar sinus straight, V shape; group very slightly tomentose.

In this group we will mention:-

Berlandieri Mazade.-Very vigorous form, named and multiplied by Malègue; leaves very large, young leaves very slight carmine tint, the shoots and young leaves the least tomentose of the group. 


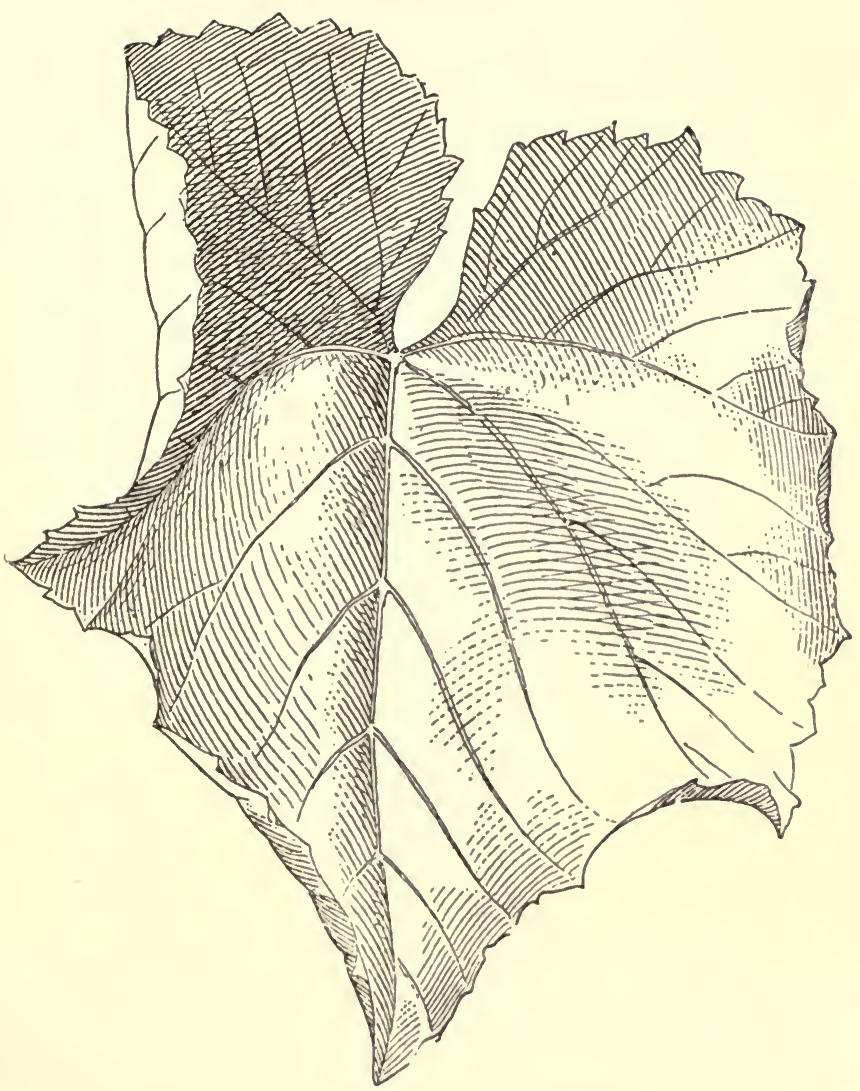

Fig. 22.-Leaf of Berlandieri Daignere.

Berlandieri Rességuier No. I.-(Fig. 21.) Having characters corresponding to those already given for the group; very vigorous form, with thick and long canes.

Berlandieri Daignere.-(Fig. 22.) This very vigorous form, like the preceding, is little different from No. I, unless it is by its leaves, which are slightly revolute on the edges or inside.

Berlandieri Millardet.-Form isolated and named by T. V. Munson. This group of Berlandieri has the smallest leaves and most carmine budding; the leaves are rather dull, the petiolar sinus very open, and the wood absolute ashy-grey. 


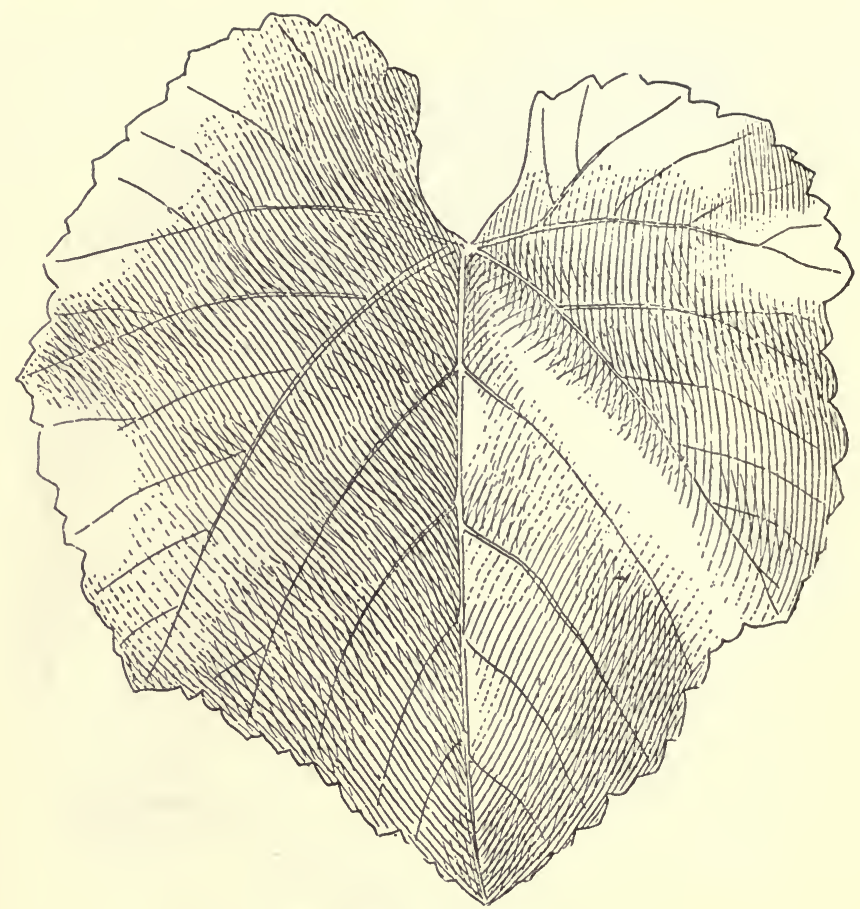

Fig. 23.-Leaf of Berlandieri Rességuier No. 2.

GROUP No. 2.-General colour very dark-green and very brilliant (varnished) appearance; wood hazel-grey reddish, strongly striated and excoriated; leaves dark-green, brilliant, appearing varnished on the upper face, rounded, thick, margin largely undulating; often folded conically; teeth very blunt; petiolar sinus lyre or $U$ shaped, but variable; apex of the shoots whitish, slightly carmine; young leaves bronze violet-ashy colour, turning to a real bronze and passing suddenly to the definitive colour. Forms of this group rather tomentose. We will only mention amongst them the Berlandieri Rességuier No. 2 (Fig. 23), which is one of the best for resisting chlorosis, and the Berlandieri Cristal, which is a form of great value.

GROUP No. 3.-Leaves very large, more or less honeycombed in structure along the principal ribs, brilliant on both faces; ribs always reddish at the point of insertion on the upperface; this colouration is prolonged half-way up the leaf; teeth 


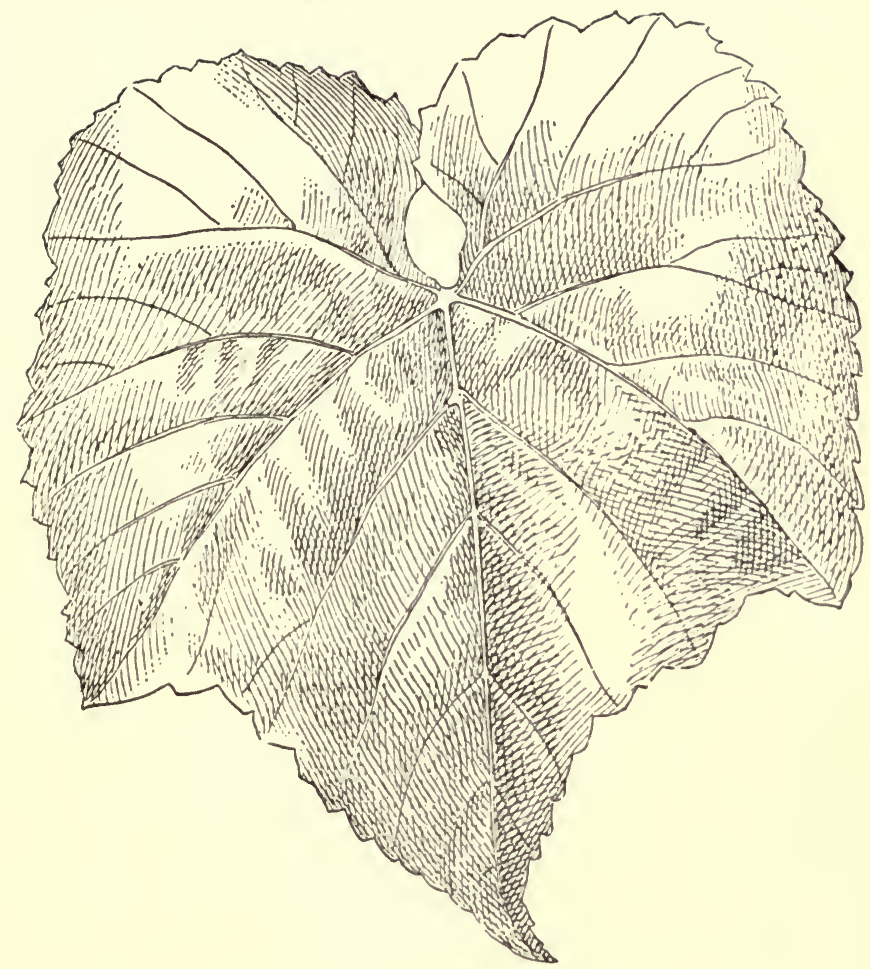

Fig. 24.-Leaf of Berlandieri Viala.

very blunt; petiolar sinus nearly closed. Amongst them we will mention as one of the most vigorous, selected on the property of Madame Jules Robin, at Saint-Même, near Cognac, the Berlandieri de Lafont No. 9. This variety is of considerable vigour, and in resistance to chlorosis is second to no other variety.

GROUP No. 4.-Leaves relatively dull, ribs pale green and distinct on the limb; indentations rather marked; fluffy hairs rather numerous on the ribs of the upper face; budding yellowish white with carmine margin rather marked on the young leaves; wood rather red for a Berlandieri; this last item may lead to a belief of hybridization, although the leaves have the general characters of the species. The Berlandieri d'Angeac belongs to this group; it has withstood, in the Charentes, relatively strong calcareous soils. It is a very vigorous vine, with stout wood, and is a good grafting stock in soils very liable to cause chlorosis. 


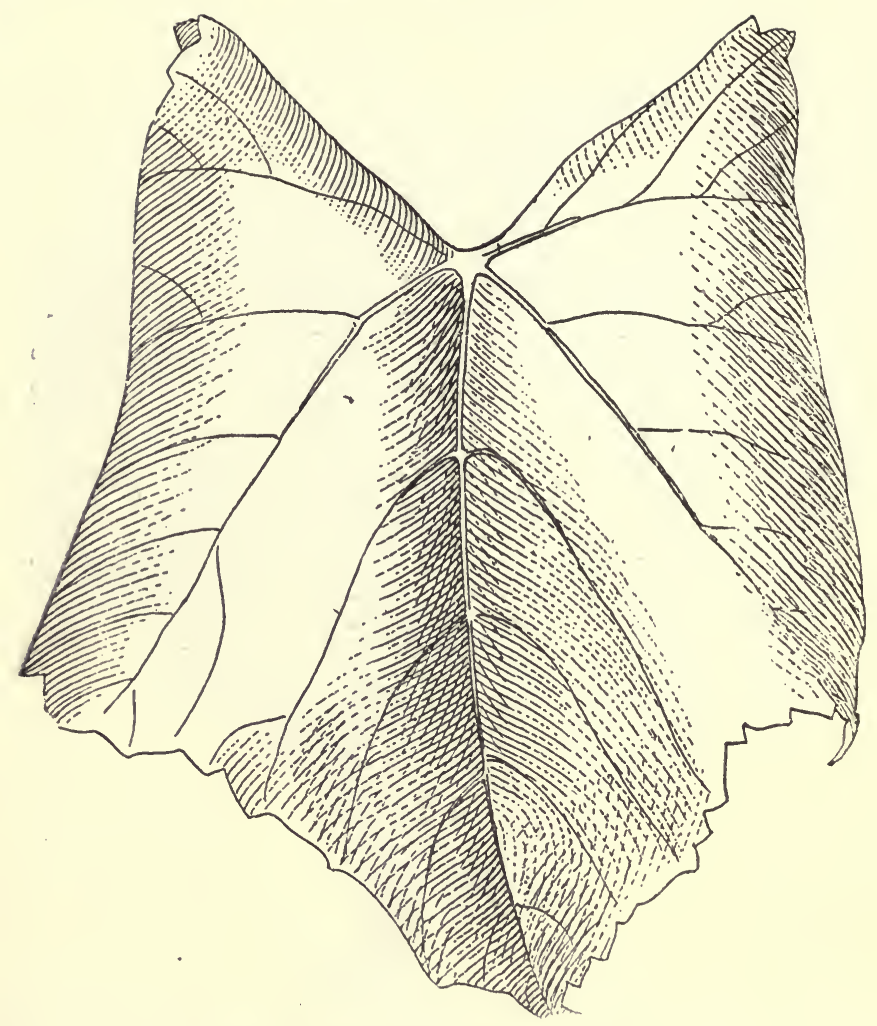

Fig. 25.-Leaf of Berlandieri Ecole.

GROUP No. 5.-Adult leaves very large, rounded, uneven, thick, sinus nearly closed, young leaves extremely bronzed and brilliant. These forms are well characterized. Amongst them we mention the Berlandieri Viala (Fig. 24), a form named and selected by $T$. V. Munson amongst the Berlandieris of the most chalky soils of Texas; it is less vigorous than those of Groups Nos. I 2, and 3. Certain forms of this group actually being studied in the Charentes seem to have a greater vigour than the above and will perhaps become of real value.

GROUP No. 6.-Adult leaves very characteristic; gondola shaped at the centre, strongly revolute inside on the margins. The Berlandieri of this group are mostly very inferior; amongst them we will mention Berlandieri Ecole (Fig. 25). 
(c) Adaptation and Culture.-The V. Berlandieri is a species belonging exclusively to the south of the United States. It grows south of the Brazos River, throughout the centre and south of Texas in the south of New Mexico, and in the north of Mexico.

The forms of Tomentose Berlandieri are most frequent on the river banks. The forms of glabrous Berlandieri inhabit the hilly or mountainous regions of medium elevation belonging to the various strata of the lower Cretacean; the individuals of these forms are distributed in very great numbers on the sides and tops of hills, where they resist extreme droughts, such as do not occur in the warm regions of the south of France. The temperature in Texas reaches $40^{\circ}$ to $42^{\circ} \mathrm{C}$. $\left(104^{\circ}\right.$ to $108^{\circ} \mathrm{F}$.) in summer. In Missouri and Texas the Berlandieri has resisted cold of $-23^{\circ}$ and $-28^{\circ} \mathrm{C}$. $\left(9.4^{\circ}\right.$ to $\mathrm{r} 8.4^{\circ} \mathrm{F}$.), without being damaged by the fall of temperature; by this it can support the temperature of our French regions and succeeds in both the north and south of France, if only the influence of the climate is taken into account. It has not suffered from the cold in the Charentes, Rhône, and Maine-et-Loire.

Of all species of American vines, the Berlandieri is the most resistant to chlorosis, and succeeds best in the chalky limestones and white marls. It grows luxuriantly in Texas, in soils belonging to the lower Cretaceous, which are rich in limestone, easily soluble in rain water. The soils there vary in fertility, but are always rather poor, they have a blackish colour similar to those of the Charentes, the calcareous fragments, mixed with the soil, which are produced by the displaced and decomposed rocks of the subsoil, are white and very soft. The subsoil is usually constituted of large fissured rocks, white and soft, with relatively scarce patches of siliceous nodules of various sizes; occasionally it is formed of laminated strata of very calcareous marl, bluish white, rather yellow. In these surroundings, the Berlandieri remains green and vigorous in very dry years, and also in very rainy springs.

In France, it had been noticed that the V. Berlandieri grew well in strongly calcareous soils; at Dr. Davin's, for example, and in very chalky soil; at J. E. Planchon's, in very calcareous quaternary tufa; in the Charente-Inférieure, and in the Groies soils. Examples of the resistance of Berlandieri to chlorosis are actually numerous and conclusive. In the experimental fields of the chalky Champagne (Champagne crayeuse), near Cognac, it has maintained a fairly constant green appearance. 
The soils of the Charentes have the following composition:-

Groie soils.-Soil light; colour, ochreous or red, more or less dark, formed of 50 to 70 parts fine sand and of 30 to 50 parts small angular calcareous fragments, having dimensions varying from $x$ to $3 \mathrm{~cm}$. ( $1 / 2$ to $x / / 4$ inch), and from 0.5 to $\mathrm{I} \mathrm{cm}$. ( $1 / 4$ to $1 / 2$ inch) in thickness. The depth of this bed is from I 5 to $25 \mathrm{~cm}$. ( 6 to ro inches). The subsoil is formed of calcareous fragments, larger, flattened, or of even dimensions on all sides ( 5 to $10 \mathrm{~cm}$.). A little under the soil they are not numerous, nor mixed with organic matter; they are decomposed outside, forming a yellowish marl, which covers them, and fills the interstices. Occasionally their decomposition is more complete. These soils are frequently met on the Jurassic and Cretaceous formations, and are found all over the Bourgogne.

The strong groies are more clayey. Under the soil, at a depth of 20 to $35 \mathrm{~cm}$. (8 to I4 inches) they become marly. Champagne Soils.-Dark grey or black vegetable soil, mixed with a small quantity of little fragments of limestone rock, soft, and easily broken by the hand; soil light and very friable, depth $x_{5}$ to $35 \mathrm{~cm}$. (6 to $\mathrm{I}_{4}$ inches). The subsoil is a chalky rock, friable or easily opening under the action of frosts. It is sometimes formed of irregular fragments, the interstices of which are filled, near the surface, with a vegetable soil; sometimes with layers I to $3 \mathrm{~cm}$. ( $\mathrm{I} / 2$ to $\mathrm{I} / 4 \mathrm{inch}$ ) thick, horizontally disposed; in the latter case the roots never penetrate to the subsoil.

The several analyses following, due to B. Chauzit, will show the amount of carbonate of lime in the chalky soils of Texas where the V. Berlandieri grows naturally, and also those where it has remained green in the Charentes:-

Belton soil, Texas

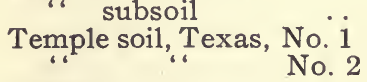

Austin

Champagne soil. Julliac-le-Coq, Charente . subsoil

، soil d'Angeac, Charente

Cognac soil subsoil

Genté soil$$
\text { subsoil.. }
$$

" subsoil..

$\ldots$
$\ldots$
$\ldots$
$\ldots$
Charente
".

.

.

$\therefore$

.
$96.42 \%$

94.90

76.10

51.51

79.48

90.65

43.60

68.65

56.37

75.35

48.55

75.76

32.37

56.48 
On comparing these analyses, in reference to the carbonate of lime, with those of the chalky or marly regions of France where no American vine has prospered, it will be seen that those soils contain an amount of carbonate of lime which is not higher than in the soils we have mentioned and where the V. Berlandieri has remained green.

Herewith several analyses of soils from highly calcareous regions, according to Chauzit and Margottet, expressing their percentage of carbonate of lime:-

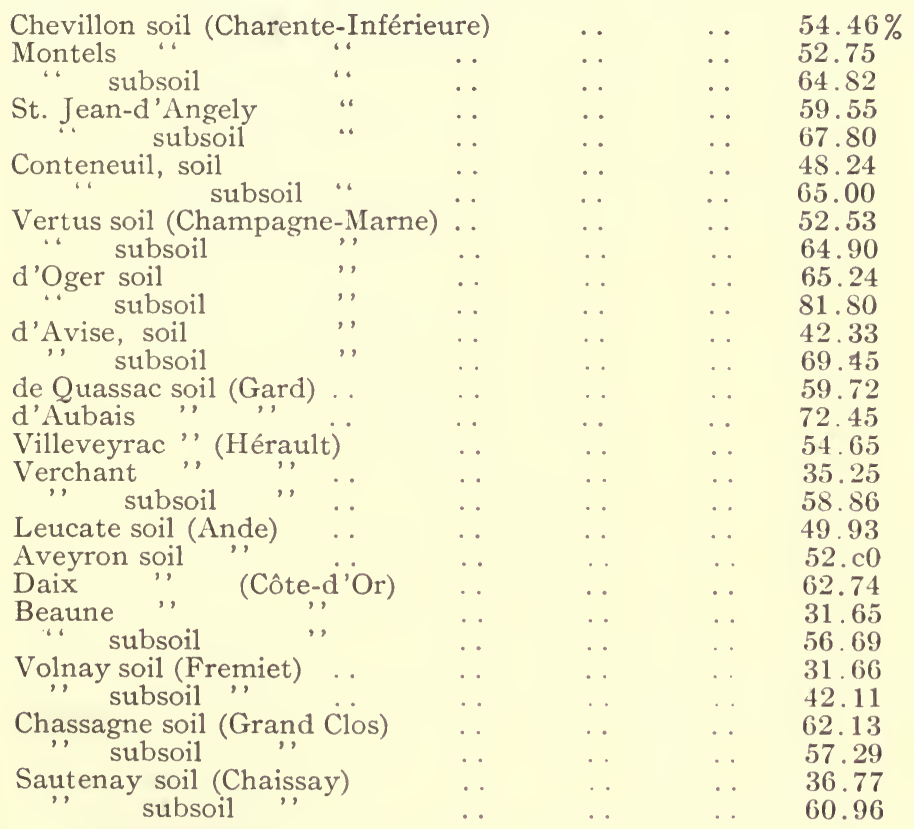

The other species of vines which have been experimented with in the Cognac district, in the chalky soils of which we have given the analysis, became completely stunted. Contrary to the V. Berlandieri, the Folle-Blanche, growing on its own roots, when planted in the $s$ me conditions as the $\mathrm{V}$. Berlandieri, was not always exempt from chlorosis.

We have pointed out, in the first part, the fact that a number of American vines sometimes remained green in chalky soils, , but rapidly turned yellow and died as soon as grafted. It was important that the question of the grafted 
Berlandieri in chalky soils should be resolved. Now it is done for most of the calcareous soils. Only one example had been observed in Texas, at Belton, where, in the very white, chalky, limestone soil. good varieties of Berlandieri had been planted in $\mathrm{r} 884$, out of which a few vines were grafted in $\mathrm{r} 886$; at the second leaf after the grafting, in I 887 , the grafts remanied very green and very vigorous, the canes were from 3 to 5 metres (ro to r 6 feet) long.

At J. E. Planchon's, Berlandieri were planted in 1880 , in soils partly formed by the decomposition of the Quaternary tufa, rich in carbonate of lime, and were grafted in r882. They were planted amongst many other American grafting stocks, such as Riparia, Taylor, Solonis, Jacquez.* Out of 30 grafted plants 25 have knitted, and the grafts are much more vigorous than those on the other grafting stocks. Besides, the trunk of the stock is more developed than that of the scion. At Bethmont's in a bad groie soil, where over 600 varieties have been experimented upon. the Berlandieri alone has resisted. The grafts, which are ten years old become more and more vigorous, although they are grafted with Mataro, which is known to do very badly on American vines. $\dagger$ In the experimental fields of the Viticultural Station of Cognac, in very chalky soils, the grafts on good varieties of the Berlandieri have remained green and vigorous.

Important reconstitutions with grafted Berlandieri have been made in the Charentes; these grafts, which are actually eleven and twelve years old, have always remained green and vigorous in a calcareous soil where the Solonis, Jacquez,* etc., grafted with the same varieties, turned yellow and died. At the School of Agriculture, Montpellier, the Berlandieri Nos. I and 2, grafted with Carignane since four years, are of an excessive vigour and very great fertility in a soil particularly liable to cause chlorosis, and where no other grafting stock has lived, not even the Franco-American hybrids At the same time a fact of the greatest interest has been remarked. The grafted Berlandieri have never shown a trace of chlorosis, while the Berlandieri No. I, on its own roots, of the same age, planted next to the grafted vines, turned yellow. These neat and conclusive facts, confirmed by other results of the same nature, prove that the grafts, contrary to what has happened to most of the other grafting stocks, do not diminish to a notable degree the power of resistance of the Berlandieri to chlorosis. 
And it forces us to the conclusion that, in soils conducive to chlorosis, the reconstitution should be made with rooted grafts. As the grafted cuttings of Berlandieri succeed as well as the freely-rooting grafting stocks (as we shall see later on), the reconstitution by this species in most of the chalky and marly soils seems actually certain.

The Berlandieri therefore resists chlorosis after grafting and if, exceptionally, chlorosis appears at the first or second year in the most calcareous soils, it is only transient and of no importance, and, as we have already pointed out in the first part, it does not become manifest after the fourth year, But it is absolutely necessary, and we insist on this point, that Berlandieri stocks be selected of the greatest vigour. The failures resulting in certain districts from slender, slightly vigorous Berlandieris were foreseen; this, however, does not minimize the value of the vigorous forms of this species for chalky soils.

The V. Berlandieri is a remarkable species for its grafting facility, and for the productivity of the grafts which it carries. Several European vines have been tried on it-Carignane, Aramon, Aspiran, Folle-Blanche, Cabernets, Merlot, Cinsaut, Pinot, etc.-and have all done well. No difference in size between the stock and the scion has been produced. Thus, at J. E. Planchon's, the Berlandieri planted on soils of the Quaternary tufa in 1880 , grafted in 1882 with various varieties, had, in 1895 , a very great vigour, and the stock had a larger diameter than the scion. It is the same at Mas de las Sorres, where the oldest grafted Berlandieris exist in rich slightly calcareous soils (grafted for nineteen years on two year old stocks), and which are of all the grafted American vines giving the greatest yield for the same scion. The same again is observed at Macquin's, Saint-Emilion, in the environs of Cognac, at the School of Agriculture, Montpellier; at Verneuil's in the Grande Champagne of Cognac, Frappin's of Segonzac, etc. From the points of view of perfection of knitting, affinity, and fine growth and fructification of the grafts, the Berlandieri is a remarkable grafting stock. The earliness of the maturity of the grafts on Berlandieri is comparable at Las Sorres and at the School of Agriculture, Montpellier, to those of Riparia grafts.*

* See in the chapter on Grafting the figures for comparative yields of Berlandieri and several other grafting stocks obtained at Las Sorres. 
Most of the varieties of V. Berlandieri have the drawback of not growing from cuttings. And it is to be noted that the most vigorous forms with types of character adapted to the calcareous soils, are those most difficult to grow from cuttings.

The resistance to phylloxera and superiority of resistance to chlorosis of the Berlandieri are actually without doubt, but the difficulty of multiplying the grafting stock would seem to render it of no use for reconstitution in chalky soils. This difficulty of multiplication is fortunately actually resolved beyond all doubt, the selection and isolation of the vigorous forms are definitely completed, and the utilization of the Berlandieri is now as common a practice as of the Rupestris and Riparia. Without actually entering into details, which will be explained later on, we will state that grafted cuttings of Berlandieri do, under the ordinary conditions, in well-conducted nurseries, root as freely as the grafted cuttings of Rupestris and Riparia. For several successive years the average strike of grafts (first choice) has been 50 per cent. at the School of Agriculture, Montpellier, and in various nurseries. When in possession of Berlandieri wood it is easy to obtain rooted-grafts; and this is possible in the most northerly as well as the meridional regions of France, for, at Thomery (near Paris), Salomon has obtained 40 per cent. of good grafts with grafted cuttings of Berlandieri, - as much as with the Riparia, and more than with the Franco-American hybrids of Rupestris. Besides, the grafted cuttings of Berlandieri are quite as well knitted as those obtained on most other grafting stocks. As it is not advantageous to reconstitute in calcareous soils with any but rooted grafts, and as these are easily obtained from Berlandieri wood, the utilization of this variety does not offer any considerable difficulty.

The only difficulty consists in having the Berlandieri wood to make the grafted cuttings. This difficulty is easily resolved by several very practical processes. The best, in our opinion, consists in grafting at a couple of inches under the soil on Riparia, Rupestris, or even European vines, the cuttings of selected Berlandieri (No. 2, No. I, Anjeac, Daignère, etc.). Berlandieris knit very freely. Englishcleft, whip-tongue, and side-cleft grafts are made according to the size of the stock. Generally, under these conditions, roots grow at the joint, but they give rapidly, in 
the first year after the grafting, good wood, and quantities of cuttings, which are annually utilized for grafting stocks.

To obtain mother stocks, the summer and autumn layerings may be had recourse to, or the bourturage en pousse,* but the process of grafting the Berlandieri on already grown vines (Rupestris, Riparia, and V. Vinifera) seems to us the most economical and practical, in order to procure, in quantity, the wood necessary to prepare grafted cuttings.

Its special and unique properties of adaptation to very bad chalky soils make the V. Berlandieri (or its AmericoAmerican hybrids) the only species permitting the reconstitution of the soft, white, calcareous, chalky soils, where all other American vines have succumbed. And when the supply of Berlandieri cuttings becomes plentiful, it will permit the reconstitution of all the doubtful soils, where many grafting stocks have not given satisfaction, and where reconstitution has been considered impossible, such as the Quaternary calcareous tufa of the south of France, the yellow and white marls, the lacustrine calcareous soils of the Eocene and Miocene, the chalky soils of the Cretaceous, the groies soils of the Jurassic of the Charentes, of Vendée, Dordogne, Saumurois; the Cretaceous chalks of Champagne (Marne), Yonne, Aube, etc.: the white marls of the Oolithic, Bathonian and Jurassic of the Côte-d'Or; of various chalky formations proceeding often from calcareous sources, and appertaining to the diverse geological formations of different regions.

But it must not be thought that the V. Berlandieri, on account of its resistance to chlorosis, and on account of its thick roots, should be preferred to other well-known meritorious grafting stocks, for clay-siliceous, siliceous, or clayey soils.

* Investigations made during the last five years, on the propagation of Berlandieri by ordinary cuttings, have resulted in definite success, and the use of Berlandieri has been rendered quite as easy as that of Riparia or Rupestris, specially in hot countries like Australia. Millions of cuttings have been planted in the Pyrénées Orientales during the last five years, and the percentage of strike was always as high as with Riparia (from 60 to 80 per cent).

To obtain these results, it suffices in practice to gather the cuttings from at least four or five years old stocks, and to take only those well lignified. Further, and this is essential, they nust be planted in a nursery, directly after the fali of the leaves, that is to say, in autumn, and not in spring, as is usually done. In a word, very early plantation must be performed; the nurseries must be watered and well attended to, and if these precautions are observed Berlandieris may be easily and practically propagated from cuttings. In $1900,1,800,000$ cuttings were planted, the average strike varying between 60 and 85 per cent. (P. V. r 900.$)$ 


\section{CORDIFOLIA.}

(a) Description.-Stump very vigorous, creeping habit, trunk very strong; wood of the year shining cinnamon-like colour, with the bases of hair persistent; tendrils discontinuous nodes flat. Leaves, young: unfolding early, varnished appearance, fawn colour; adult (Fig. 26): medium,

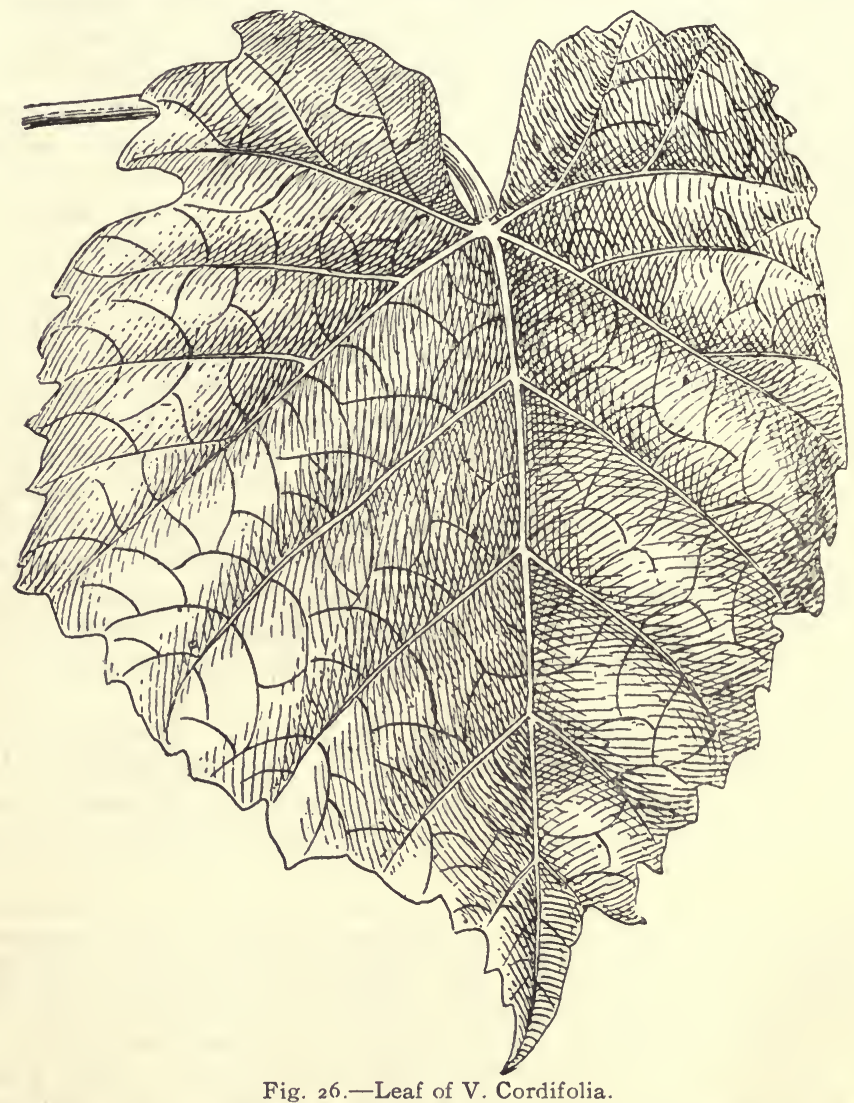

rounded cordiform, entire, thick; petiolar sinus deep and narrow; teeth regular, obtuse, normal to the limb; upper-face deep-green, shining; under-face lighter green, more shining, with ribs covered with short supple hair; petiole grooved. Bunch long, berries loose, spherical, black and shining, harsh 
taste. Seeds (Fig. 27) medium, stout; beak stout and short; chalaze round; raphe forming a small belt ending abruptly. Roots fairly strong and hard.

(b) Varieties.-The varieties of V. Cordifolia are not very numerous, and, although the species does not offer very great interest from a cultural point of view, it is well to indicate them. V. Cordifolia lives specially in rich, loose, fresh, deep soils on river banks, where it is mixed with Riparias; a few types are found exceptionally in calcareous soils; this is opposite to what takes place with V. Berlandieri, the types of which are more numerous in calcareous soils than on river

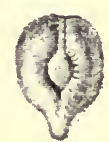
banks. It seems natural, therefore, for the Berlandieri imported into France to succeed in chalky soils. for the forms of this species are found widely distributed in such soil, and that the success of $\mathrm{V}$. Cordifolia in such soil is an accident, as its forms are more generally found in siliceous soils. This is in effect what occurs. However, the question is only of secondary interest, for the geographical area of dissemination of $\mathrm{V}$. Cordifolia in the American cretaceous soils is an exception, and its forms, even if they succeeded in - France, would not be superior to those of Berlandieri, for which resistance to chlorosis is the general case.

This applies also to V. Cinerea; we, therefore, will not mention it again when studying that species.

The varieties of $V$. Cordifolia may be divided into several groups. The varicties of Florida, very rare, have thin leaves of strong varnished appearance, glabrous on both faces, except on the under-face at the junction of the ribs. They have not been imported into France, and are of no interest for purposes of reconstitution.

The most numerous varieties, the only kind introduced in Europe, are those of rich soils; they have, in their wild state, a remarkable development, superior to that of Riparia especially in the size of trunk. It differs from the above group by the leaf having two series of alternating teeth, upper-face dull-green, under-face varnished like. Millardet has distinguished two forms in this group-bronze form, upper-face of leaf deep-green, the shoots, petiole and ribs bronze violet; and a yellow form with generally lighter appearance, under-face greenish-yellowish varnished like, with wood and ribs light in colour. 


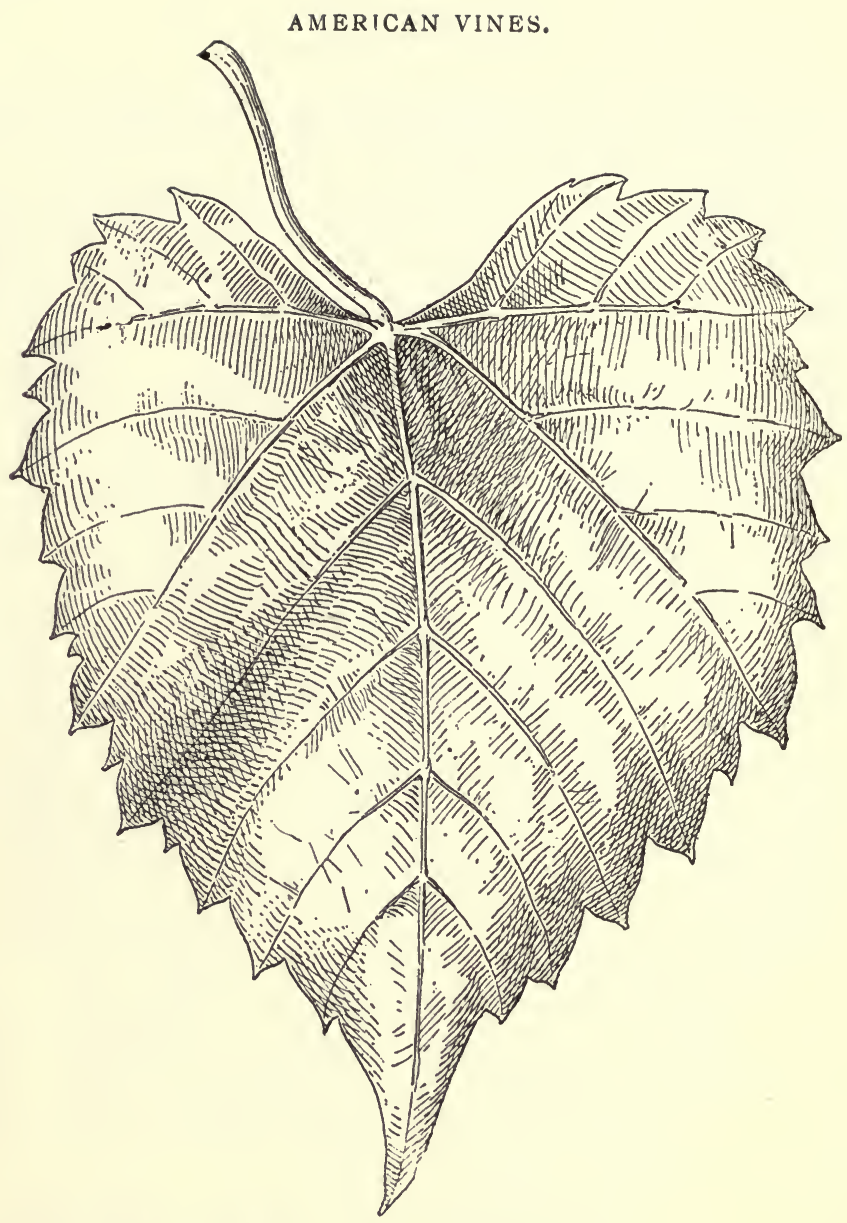

Fig. 28.-Leaf of V. Cordifolia Sempervirens.

Side by side with the latter, may be placed the $V$. Cordifolia Sempervirens (Fig. 28) of T. V. Munson, which was introduced into France in $\mathrm{I} 89 \mathrm{I}$, and which, according to him, would be a form belonging to calcareous soils. The leaves of this variety are very characteristic; they are triangular in shape, very long, lanceolate; the two ends of the petiolar sinus in a straight line, narrow at the base, completely glabrous and very varnished-like on both faces, slightly deeper colour on upper-face, thick, cartilaginous. The mid-rib is 
very prominent; the other ribs less marked. Petiole short and slender, has a deep groove bordered by numerous stiff hairs. Young shoots greenish, wine colour near the nodes; this is a very curious form from a botanical point of view.

The varieties which are represented by very few individuals in clay soils have shorter leaves than those growing in rich soils, almost orbicular, with rudimentary teeth, thick cartilaginous, golden-yellow shining colour on under-face, and incurved margins. Certain types are almost entirely glabrous, others have stiff fairly-abundant fawn-coloured hair on the ribs of the under-face.

(c) Adaptation and Culture.-The V. Cordifolia is one of the most widely-spread species in the United States. It exists from the Great Lakes to Florida, and is especially abundant in the Central States of the United States (Illinois, Tennessee, Missouri, Arkansas, North Texas) in regions, therefore, where the extremes of temperature are very great.

We have said that the greater number of individuals of V. Cordifolia are found in the centre and east-centre, on river banks, where they grow with V. Riparia in the greyish, black, fertile, deep, fresh, but not damp alluvials; on the Mississippi banks, for instance, where they attain the greatest development. They are also often found in rich pebbly soils, generally red, or in siliceous soils with fine, fertile sand (Silurian, Granitic, Devonian).

The forms belonging to calcareous soils exist (north of Texas) in white chalky soils, more siliceous and more clayey than those in which V. Berlandieri grows, or sometimes in almost pure white clay, in Tennessee for instance. Their vigour is always inferior to that of the forms growing in rich soils; their leaves, however, remain green in the driest soils; for instance, in the white clay siliceous soils of Missouri containing up to 83 per cent. of clay.

The Cordifolias grown in France have always had a remarkable vigour in slightly or non-calcareous soils, and especially in clay-calcareous, clay, and clay-siliceous soils. The grafting succeeds well with this species, which bears vigorous fructiferous scions, with strong trunks. In white chalky soils, the forms tried up to the present rapidly became yellow, and often died after the first year of planting out. 
$V$. Cordifolia does not root freely from cuttings, although it is better in this respect than V. Berlandieri; it has given up to 60 per cent. strikes with ordinary cuttings. For soils where the most vigorous forms might thrive, other species are quite as vigorous, and strike better from cuttings, and therefore are more practical.

The resistance to phylloxera of the V. Cordifolia is very high, and may be designated by i 9 . We shall see later on the interest its hybrids have on account of the remarkable transmitted resistance to phylloxera which they owe to it.

\section{CINEREA.}

(a) Description.-Stump very vigorous, trunk strong; wood of the year with prominent ribs, of an ashy-grey colour, with numerous short and stiff hairs; tendrils discontinuous. Leaves (Fig. 29) cordiform, elongated, entire; petiolar sinus very deep, slightly open; teeth wide and obtuse; limb with ribs regularly sunk on the upper-face of a dull greyish colour; under-face ashy-green, dull, with numerous short hairs on the principal and secondary ribs. Bunch large, with small berries, close spherical, deep shiny black colour; taste acid. Seeds (Fig. 30) medium. rather elongated; beak narrow and short; chalaze small, round; raphe in a thread-like cord surrounding the seed. Roots large and fleshy.

(b) Varieties.-The varieties of $\mathrm{V}$. Cinerea are not very numerous. Some of them, which we will call glabrous Cinereas, have, contrary to the most common forms, only a few fluffy hairs on the principal and secondary nerves of the under-face in the case of old and middle-aged leaves; they live in dry soils. The more numerous tomentose forms have the general characteristics of the species. and live, like the V. Cordifolia, in rich and fresh soils on the banks of rivers and water-courses. A third group of very rare forms, to which $\mathrm{T}$. V. Munson gave the name of Wichita, are represented by a few individuals in calcareous, but rather rich and siliceous soils, on the banks of the Red River, in the extreme north of Texas. The leaves of these forms, not yet introduced into France, are orbicular, sub-medium, thick, with rudimentary teeth, and short stiff numerous hairs on the principal ribs of the under-face. 


\section{CÉPAGES}

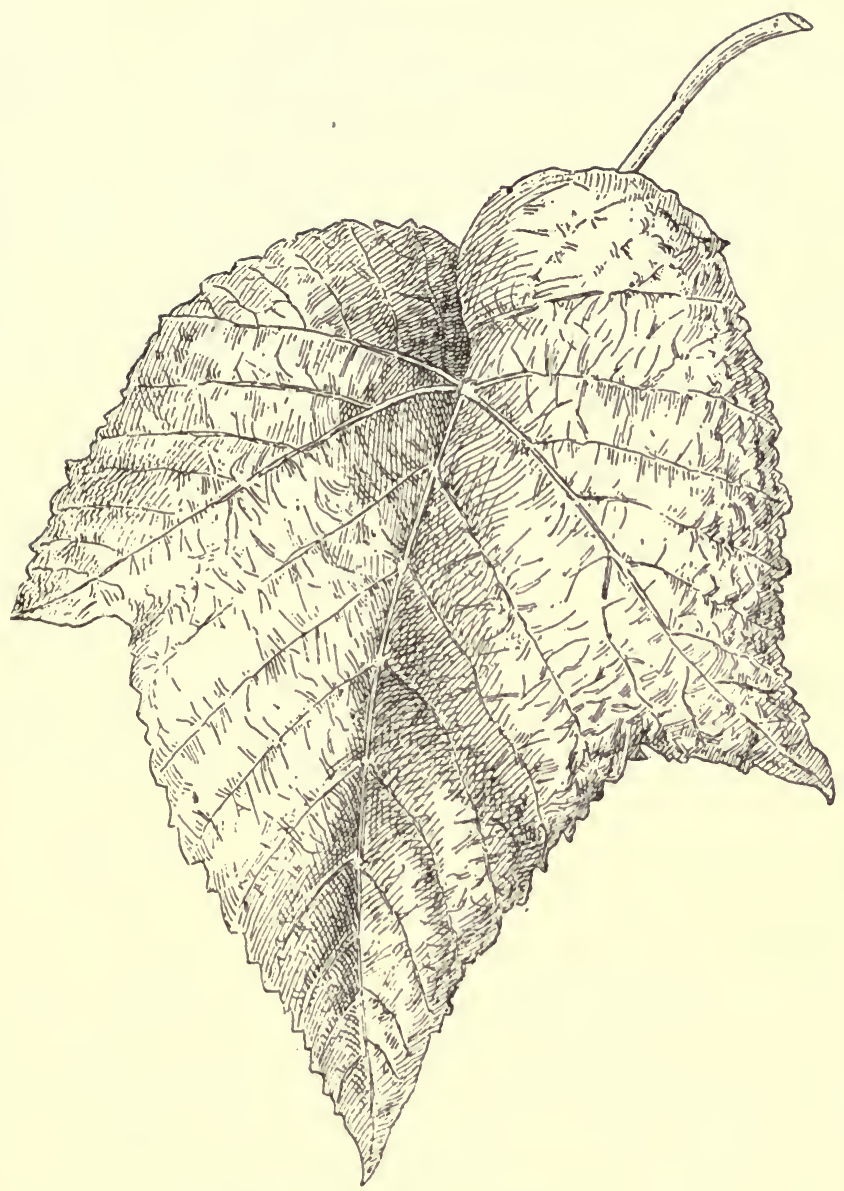

Fig. 29.-Leaf of V. Cinerea.

(c) Adaptation and Culture.-The geographical area of distribution of $\mathrm{V}$. Cinerea in America is about the same as that of $\mathrm{V}$. Cordifolia, but rather less: it extends from Illinois to the Brazos River in Texas, and there is sometimes associated, on the banks of rivers, with. the forms of Berlandieri belonging to rich soils, a fact worth noting, and which

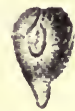

Fig. 30.-Seed of V. Cinerea. 
explains the numerous hybrids Berlandieri $\times$ Cinerea, recently introduced into France as pure forms of V. Berlandieri.

The soils where V. Cinerea grows are the same as in the case of V. Cordifolia. However, the Cinerea often grows alone quite abundantly in low swampy and clay lands in the states bordering the Gulf of Mexico. It is in soils of this nature-clay. clay-siliceous, or clay-calcareous-that this species thrives best in France, a fact which is in direct relation to the size of its roots. It is never found in the sandy siliceous soils of America, and it thrives very badly in France in very loose dry soils.

We will not repeat for the $\mathrm{V}$. Cinerea what has been already said as to the relative value of the various forms of V. Cordifoli $\iota$ in differ $n$ t soils. The forms of V. Cinerea peculiar to rich soils, tried in France in chalky soils, have rapidly become yellow and withered.

This species is difficult to propagate by cuttings; its resistance to phylloxera for the forms already studied may be represented as I5. As a species, the Cinerea is without value for reconstitution, excepting perhaps in the case of swampy clay soils, but it has yielded a great number of hybrids, which may be of some value.

\section{RUPESTRIS.}

(a) Description (General Characters).-Stump vigorous; bushy habit; trunk short and thick; wood of the year dull brown-red; sometimes shining chestnut-brown; tendrils discontinuous; leaves, young: transparent and bright, russetbrown; adult: small, wider than long, entire, folded inwards along the mid-rib, the sides turned up, glabrous, thick; petiolar sinus open and diminutive, indentations well-formed,

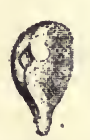

Fig. 31.-Seed of
V. Rupestris. wide and obtuse; upper-face dark-green and lustrous, under-face pale green and glossy; bunch small; berries small, subspherical, black-violet; pulp strongly red coloured, taste clean. Seeds (Fig. 3I) small, globular; beak thick and short; chalaze long and slightly prominent; raphe rudimentary; merging into the chalaze; roots long, slender, very hard, or strong and fleshy (Rupestris du Lot). 
(b) Varieties.-The varieties of the V. Rupestris are very numerous. H. Jæger, who was the first to study the variations presented by this vine in the wild state, isolated more than roo types. The great interest that this species offered as a grafting-stock for the reconstitution of vineyards, Millardet having drawn the attention of viticulturists to its value in 1882 , has been the origin of an important selection. Besides, the Rupestris were being discovered and imported at the time when great care was being exercised in the selection of Riparias; and it may be stated that the selection of forms of this species has been carried further than for any other. From this has resulted that most of the bad varieties have been rapidly eliminated, and that in culture now there are only very vigorous and meritorious forms of Rupestris. It is necessary in the case of Rupestris, as well as for Riparia and Berlandieri, to use, for reconstitution, only forms of the greatest vigour.

In a general way, great vigour, strong trunk and canes, thick and shining leaves, are the best characteristics of the superior varieties of Rupestris. All the varieties that are not vigorous (those with thin, dull, and light-green leaves), should be rejected from culture. If such varieties are used, failure is certain. The selection of vigorous forms is, perhaps, as important for Rupestris and Riparia as in the case of Berlandieri.

The Rupestris is divided into two principal groups, subdivisible according to the character of the leaves. The first group comprises the Rupestris, with comparatively small leaves; their habit is generally. very bushy. The subdivisions may be established in this group.

Ist. The Rupestris of very bushy habit, secondary and tertiary ramifications very numerous and erect, greenish and without lustre during the herbaceous state, the principal branches relatively short: leaves well folded along the midrib; margins parallel, almost touching each other, and plane, appearing as if imbricated on the branches; they are often thin, dull on the upper-face, and of a yellowish-green, slightly shining, underneath. These forms are the least vigorous; they easily lose their leaves, which are often spotted with small and numerous quadrangular black dots. In a general way they must be rejected.

2nd. A group of Rupestris comprising the most vigorous forms, with very large trunk, the principal canes strong and more or less trailing, the secondary ramifications very 
numerous and upright on the principal canes; leaves of medium dimensions in soils of ordinary fertility, lustrous on both faces, the shoots rather reddish in the herbaceous state. Amongst these Rupestris, we mention among the most vigorous forms, Rupestris Mission, Rupestris du Lot; then a second group: Rupestris Ganzin, Rupestris Martin, etc., all very vigorous and meritorious.

The second principal group is formed of all the Rupestris with large leaves, much larger than those of the preceding forms when grown in similar soil, of bushy habit, with numerous ramifications; leaves folded along the mid-rib, a little more open and less imbricated on the branches. Most of these Rupestris are very vigorous, and have large canes. We subdivide this group into:-

Ist. Rupestris with large thick leaves, very dark-green on the upper-face, slightly honeycomb structure, open. Ex.: Rupestris à feuilles métalliques or R. Metallica, Rupestris à pousses viollacées, etc.

2nd. Rupestris with large leaves, fleshy and very shining, open and sometimes thrown back at the edge, often very goffered in structure between the principal and secondary ribs. Ex.: Rupestris Ecole, Rupestris de Fortworth, etc.

3rd. Rupestris with very large leaves, plain, nearly as wide as long, non-bushy habit. These Rupestris have certainly been subject to hybridization with other species, although we mention them as pure Rupestris. Ex.: Rupestris Kansas, Rupestris No. 62 of Foger, etc.

Mazade has published a monograph of great value in the Revue de Viticulture, dealing only with meritorious forms of Rupestris, from this monograph most of the following information is taken, the forms being classed in three groups:-

Ist. Rupestris of bushy habit, leaves with slightly undulating margins, regularly folded along the mid-rib; usually small. General appearance yellowish. Ex.: Rupestris Ganzin.

2nd. Rupestris of erect habit, principal ramifications only trailing on the ground; leaves slightly folded along the mid-rib; petiolar sinus bracket shape. Ex.: Rupestris du Lot.

3rd. Rupestris of trailing habit, leaves with dark metallic sheen. Ex.. Rupestris Mission, Rupestris Martin, Rupestris Metallica, Rupesris de Fortworth. 
The following table shows the value of the phylloxera resistance, in the same slightly fertile clay limestone soil, of diverse forms of Rupestris studied at the same age:-

Rupestris Mission

Resistance.

Rupestris du Lot

18

Rupestris Ganzin

16

Rupestris Martin

18

Rupestris à pousse

Rupestris Metallica violacées

18

Rupestris Metallica

Rupestris Ecole

Rupestris de Fortworth (form described)

Rupestris de Kansas

Rupestris No. 62 of Jæger

Rupestris Y (Couderc)

Rupestris $x$ (Couderc)

Rupestris Arkansas (Jæger)

Rupestris of Cleburne (Jæger)

Rupestris No. 66 (Jæger)

Rupestris du Texas (Jæger)

Rupestris No. 64 (Jæger) . .

Rupestris No. 65 (Jæger) . .

\begin{tabular}{|c|}
\hline \multirow{2}{*}{$\cdots$} \\
\hline \\
\hline$\ldots$ \\
\hline$\ldots$ \\
\hline . \\
\hline . \\
\hline . \\
\hline . \\
\hline$\ldots$ \\
\hline . \\
\hline$\cdots$ \\
\hline$\cdots$ \\
\hline$\cdots$ \\
\hline$\cdots$ \\
\hline$\cdots$ \\
\hline$\cdots$ \\
\hline \\
\hline \\
\hline
\end{tabular}

Rupestris Mission.-This form of Rupestris grows at the School of Agriculture, Montpellier, where it was imported in $\mathrm{I} 887$, and which alone has persisted with vigour and remarkably large trunk, and always green leaves, in a plot of Rupestris and Riparia $\times$ Rupestris, planted in a very dry, slightly fertile, clay-limestone soil. Its habit is well spread, the canes strong and long, internodes of medium length, secondary ramifications relatively few. short and slender, young shoots smooth, shining and vinous-yellow. The lignified canes clear hazel colour, pinkish near the nodes, which are straight, cylindrical, and only slightly prominent. Leaves (Fig. 32) rather small, wider than long, symmetrical; they are, and this is characteristic, deeply folded along the mid-rib, with the two margins of the limb folded a little inwards

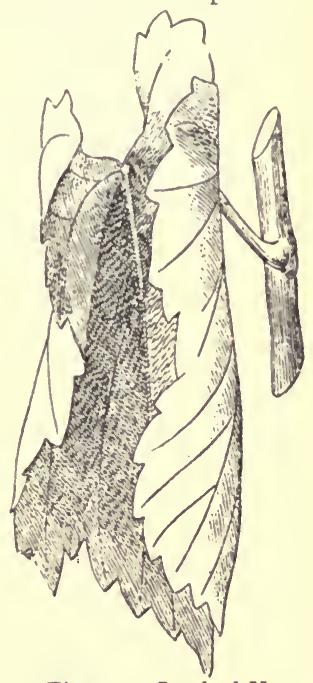

Fig. 32.-Leaf of V. Rupestris Mission. above the plane of the leaf, the under side of the leaf turned, and showing in front; completely glabrous; upper-face 
glaucous green, rather light; under-face, yellow-green; two series of indentations, wide and short; petiolar sinus

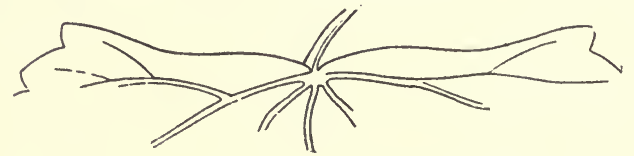

Fig. 33.-Petiolar Sinus of Rupestris Mission.

bracket-shape (Fig. 33). Petiole yellowish-pink, rather long and slender.

Rupestris $d u$ Lot.-This grafting stock is one of the most meritorious, and the most employed actually in reconstitution

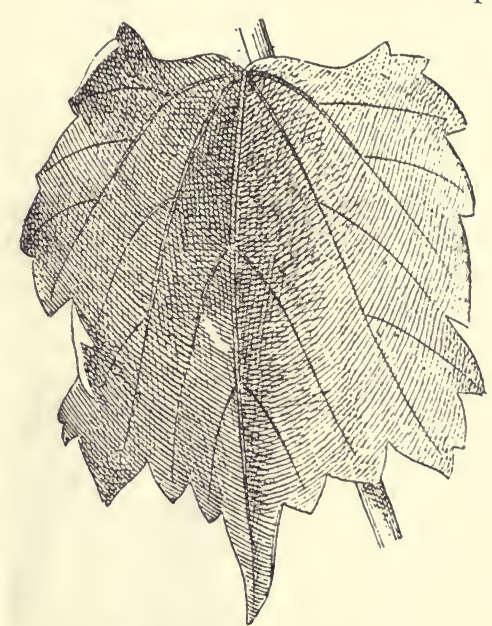

Fig. 34.-Leaf of V. Rupestris du Lot. on account of its adaptation to certain calcareous soils; it has numerous synonyms, but we will retain that of Rupestris $d u$ Lot on the ground of priority. It was first described by Millardet and de Grasset. It is also called Rupestris Phénomène or Phénomène $d u$ Lot, Rupestris Sijas, Rupestris Monticola, Rupestris SaintGeorges érigè. Rupestris Lacastelle, Rupestris Colineau, Rupestris Reich, but all these names, which are only synonyms, were given or at least printed, after that of Rupestris du Lot. We must not omit to state that Sijas was one of the first, if not the first, to isolate, in 1879 , this Rupestris in his vineyard

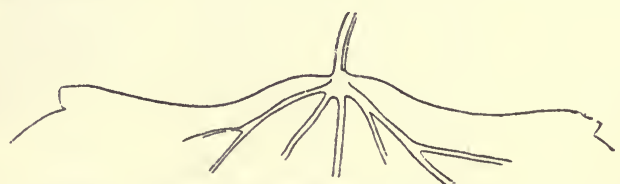

Fig. 35.-Petiolar Sinus of Rupestris du Lot.

at Montferrier (Hérault). The name Rupestris Monticola is entirely erroneous, as it has never been demonstrated 
that the $\mathrm{V}$. Rupestris has had any relations with the V. Monticola and this name can only lead to regrettable confusion. The distinctive characters of Rupestris $d u$ Lot, according to Mazade, are as follows:- "Stem very strong, of forcible vigour; habit erect (the principal ramifications only trailing on the ground); canes knotty, much ramified; inter-nodes short; leaves (Fig. 34) very slightly folded along the mid-rib, undulating margins, brilliant, with metallic sheen, relatively thin; petiolar sinus bracket-shaped (Fig.35); indentation irregular, well defined, relatively acute, that forming the terminal lobe long and pointed. Leaves of terminal ramifications occasionally extremely small; apex of the shoots bronzed. Under the influence of excessive drought the leaves become folded along the mid-rib and the metallic sheen disappears; roots a little less slender than those of most other Rupestris."

The resistance to phylloxera of the Rupestris $d u$ Lot has sometimes been doubted; its roots show, in certain circumstances, numerous nodosities, and occasionally tuberosities, but these lesions are excoriated at a favorable time, and never penetrate to the heart of the root; they have no, or only comparatively insignificant action on the really remarkable vigour of this grafting-stock when in suitable soil. Phylloxera galls have never been found on the leaves of the Rupestris du Lot; when perforated by the phylloxera the wound is shown by a deviation of the ribs, but the perforated tissues do not become galls.

The extraordinary vigour of the Rupestris $d u$ Lot in the generality of soils, its positive resistance to chlorosis in calcareous soils, its good growth in poor soils, and even in compact, siliceous, or clay soils, where it grows powerfully by reason of its strong roots, have caused it to be acknowledged a grafting-stock of the first order. It communicates to the grafts which it carries a powerful growth, increasing with the fertility of the soil. In extremely rich soils, if its excess of vigour is not checked by appropriate pruning, non-setting of the berries may result, but this inconvenience is of little importance, as it may be easily remedied This relative fault does not occur in poor soils, which are also those for which the Rupestris du Lot should be preferred.

The ungrafted Rupestris $d u$ Lot is always unfertile. A form very similar to the Rupestris du Lot in its exterior characters, which has been called Rupestris $d u$ Lot femelle 
or Rupestris monticola femelle, is fructiferous; but differs essentially in its less perfect qualities of vigour and resistance in calcareous soils.

Rupestris Ganzin.-This form, according to Millardet, who studied and named it, had its origin in Texas, from whence it was imported about $\mathrm{I} 874$ by Charles Martin. Dr. Davin and G. Couderc first noticed, multiplied, and then distributed it In I880, we had an opportunity of

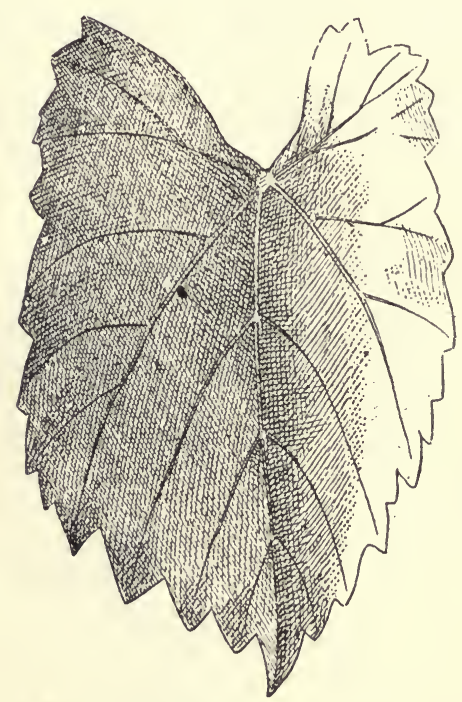

Fig. 36.-Leaf of Rupestris Ganzin. studying it at Ganzin's It is one of the Rupestris which had been extensively propagated in suitable soils; but is now actually discarded on account of its inferiority to Rupestris Martin, which is superior to it in similar soil.

Its characters are-stump vigorous, trunk rather large; young shoots of a dark reddish violet and shining; secondary ramfications rather numerous, giving to the stump a somewhat. bushy appearance. Canes fairly large, sinuous, internodes rather long, lively chestnut colour at maturity. Leaves (Fig. 36) of medium dimensions, a little wider than long, sub-trilobed, slightly folded along the mid-rib, symmetrical; upper-face rather light glaucous green and slightly shining; underface pale green and dull; two series of well-defined teeth; petiolar sinus (Fig 37) deep open V shape; ribs strong, prominent, dull rose colour for the

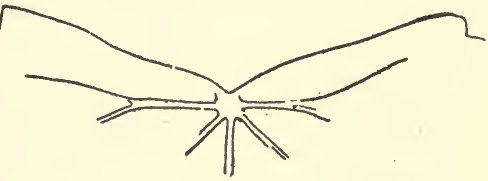

Fig. 37--Petiolar Sinus of Rupestris Ganzin. greater part of their length on the upper-face. Petiole red, rather strong, with a well-marked groove bordered with short stiff hair. 
Rupestris Martin.-Form named by Couderc. The best of all Rupestris, in our opinion, for dry, pebbly, non-calcareous and clay-siliceous soils, and also one of the graftingstocks having the highest resistance to phylloxera.

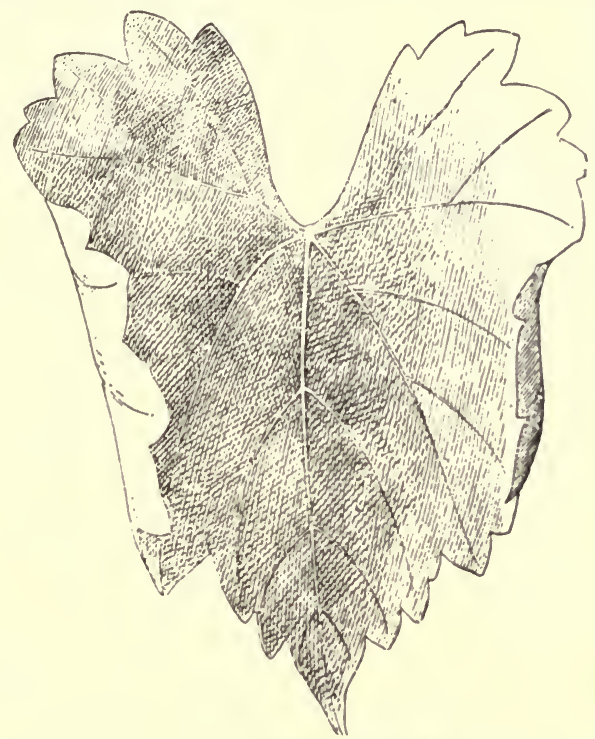

Fig. 38.-Leaf of Rupestris Martin.

Stump vigorous, trunk large; young shoots vinous red, and shining; secondary ramifications fairly numerous; canes large. sinuous, of a dark chestnut, dull; internodes rather short. Leaves (Fig. 38) medium, as wide as long, folded along the mid-rib, goffered. structure at the centre, the margins undulating, dull glaucous green on the upperface, lighter green a little shining under-face; petiolar sinus (Fig. 39) wide V shape; Fig. 39.-Petiolar Sinus of Rupestris two series of large teeth; ribs

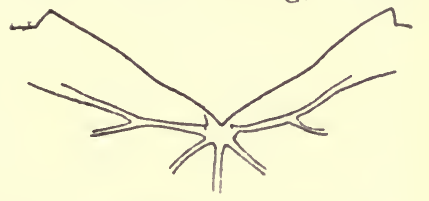
Martin. vinous red at their insertion at the upper-face, with rather long hairs at the angles formed by their insertion. Petiole short and slender, of a dirty vinous red near the cane, groove wide. 
Rupestris Metallica.-This assemblage of forms is also called Rupestris à fenilles métalliques, Rupestris métallique, Rupestris à feuilles plombées, Rupestris Saubens, Rupes-

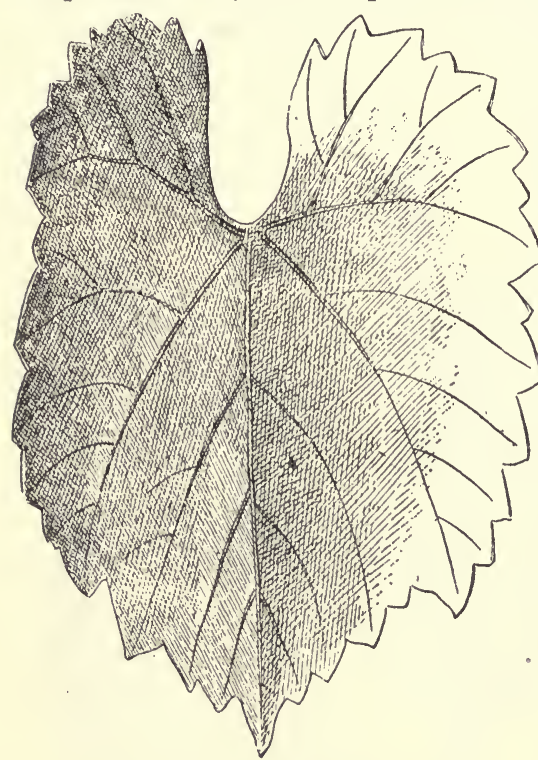

Fig. 40.-Leaf of Rupestris Metallica. tris Girand, and is not without merit. If the Rupestris du Lot did not exist, it would certainly be the Rupestris Metallica which would have been most propagated in clay calcareous soils, where the Rupestris du Lot actually occupies, and will occupy, a more and more predominant place. The vigour of the Rupestris Metallica is a little inferior to that of the Rupestris du Lot; their resistance to the phylloxera, which they owe to their positive relation to the Mustang, and on which depends slightly their relative inferiority of resistance to drought, will make one always prefer the Rupestris du Lot.

Here is the description given by Mazade of one of the best forms of Rupestris Metallica:- "Stump vigorous. Leaves (Fig. 40) orbicular, brilliant, parchment-like, very thick, hard; metallic sheen; slightly folded along the mid-rib, margins completely plane; very small difference in dimensions between the leaves on the principal as compared with the secondary ramifications. Indentations regular, saw

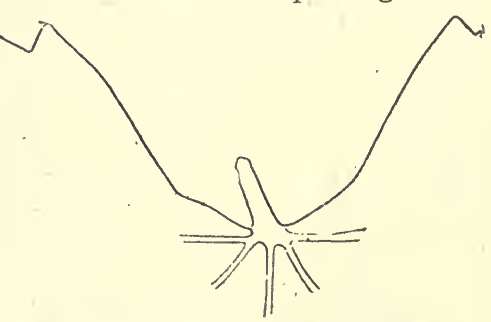

Fig. 41.-Petiolar Sinus of Rupestris Metallica. shape; petiole forming an acute angle with the limb, which gives to the vertical branches a special appearance of 
stiffness; petiolar sinus (Fig. 4I) deep open V shape. Tufts of down disseminated on the canes and petioles; whitish buds. Young roots red. This Rupestris is probably a hybrid of Rupestris and Mustang. The tomentum which covers the buds, the numerous tufts of down disseminated on the canes, the colour and texture of the leaves, gives a resemblance to certain forms of Champin. The Rupestris Metallica is very vigorous, and grows well on the dry hills of the environs of Montpellier.'

Rupestris with riolet shoots. - Stump of less vigour than those of the preceding forms and less meritorious, defoliation precocious, habit bushy. Canes large, hazel colour, with darker lines at their point of insertion; young shoots violet. Leaves large, a little longer than wide, slightly thin; petiolar sinus open, with straight sides; indentations rather long and acute, in two series; rather dark green on upper-face. Petiole, with very pronounced groove, violet-coloured.

Rupestris Ecole.-This very vigorous form, with large trunk, has existed in the collections of the School of Agriculture, Montpellier, since 1879 ; but it is very inferior to Rupestris Martin, and like it, very easily affected by calcareous soils. Stump and trunk very large, canes trailing, slightly bushy; canes vinous rose, slight bloom, bent at the nodes, internodes short. Leaves glabrous, sub-rectangular, thick, folded along the mid-rib, widely open, margin a little folded inwards, crepe-like structure between the ribs, glaucous green, slightly shining on the upper-face, lighter green and shining under-face: ribs strong, green, thickened at the level of the petiole; petiolar sinus very open $U$ shape; one series of large teeth, little marked. Petiole long and strong, with large flat groove, colour dull vinous-red, similar at the origin of the ribs on the upper-face.

Rupestris of Fortworth. - This form, according to Millardet, was sent, in 1882 , by Hermann Jæger of Neosho, to de Grasset. It comes from Fortworth, in Texas. The Rupestris de Fortworth, as it exists in commerce, represents a group in forms, rather than a typical form; they are inferior to the Rupestris $d u$ Lot, but are not without value on account of their great vigour. Herewith are the characters of one of the most vigorous forms:-

Stump very vigorous, trunk strong; young shoots rosy; canes rather large, bluish, clear hazel colour, slight bloom. Leaves (Fig. 42) very large thick, light glaucous green, 


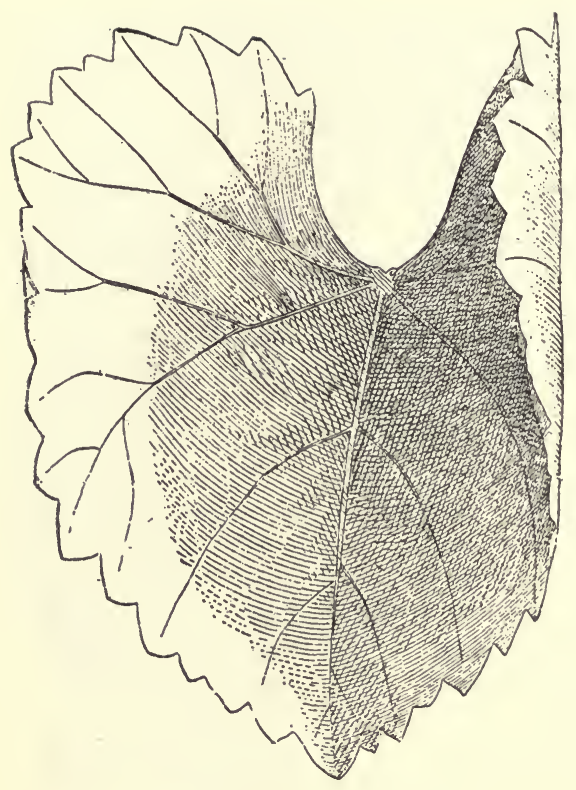

Fig. 42.-Leaf of Rupestris of Fortworth.

shining, crepe-like structure between the ribs, well folded along the mid-rib, but with margins slightly turning inwards; light-green yellow and shining underface; ribs transparent and yellow; teeth in two series, large and acute; petiolar sinus (Fig. 43) deep large $\mathrm{V}$ shape rounded at the base. Petiole light rose colour.

We will mention amongst other Rupestris, as being fairly vigorous, Rupestris No. 50, Rupestris No. 66, Rupestris No. 62, Rupestris de Cleburne, selected and named by Herman Jæger ; Rupestris Arkansas, Rupestris du Territoire Indien, Rupestris Nos. 64, 65, and 75, died of chlorosis at the School of Agriculture, Montpellier, when three years old in the same spot where the Rupestris Mission is always very vigorous. The $\mathrm{Ru}-$ pestris Jæger, Nos. $62,64,65,66,68$, are the most fertile, but they do not present, from this point of view, much interest for the vineyard.

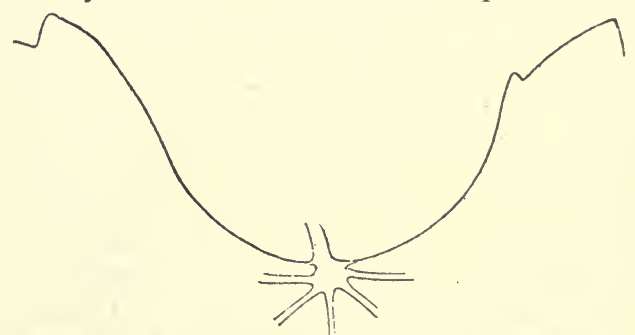

Fig. 43.-Petiolar Sinus of Rupestris of Fortworth.

(c) Adaptation and Culture.-The V. Rupestris occupy, in the United States, a wide area in the south, from the point of junction of the Missouri and Mississippi Rivers up to the south of Texas, in a series of soils which principally belong 
to the Carboniferous and Silurian, and partly to the Cambrian, Cretaceous, and Eocene. Instead of growing in the shade of virgin forests like most of the other species, the Rupestris always grows in very open places, free from timber, mostly in the beds of ravines exposed to the direct rays of a scorching sun. The grounds where Rupestris grows are very much drier and more burnt by the sun than the most arid of the French meridional regions; but in the United States it resists a temperature of $-28^{\circ} \mathrm{C}$. without being affected by the cold. In France, the Rupestris is the species which grows best in the dry and least fertile soils; in the Valley of the Rhône, north of Lyons, in the winter, I890-9I, it withstood cold as low as $-3 \mathrm{I}^{\circ} \mathrm{C}$. Its resistance to cold, drought, and heat is well proved by the numerous plantations of Rupestris which have been made in France.

The Rupestris grows, in the United States, in slightly fertile soil; it is, with V. Berlandieri and V. Monticola, the species which grows most vigorously in the least fertile soils. Most of the forms of V. Rupestris, and the most numerous vines (States of Missouri, Indian territory, Arkansas,) are found in the beds of dry ravines where the soil is formed of rounded siliceous pebbles, more or less large, mixed with a very plastic red clay; the number of pebbles is sometimes so considerable on the surface of the ravines that they appear to completely constitute the soil and through them the large trunk of this rustic stumpy species emerges. In other regions, the pebbles are formed of siliceous tufa, more or less decomposed, constituting a still drier and more unfertile soil. In the south-west of Missouri, the soils have the same constitution, but fragments of Devonian limestone, hard, compact, and crystalline, replace the siliceous pebbles; finally, in the Rupestris regions of the north of Texas (Fortworth, Cleburne), the limestone pebbles have been formed from cretaceous rocks mixed with a blackish clay soil, but the fragments of rock are always hard, never soft or chalky. It was from these regions that the Rupestris Mission and Rupestris Metallica came; it is also, probably, in those places that the Rupestris $d u$ Lot was found amongst the Rupestris Fortworth. When in the United States, a few wild vines have been found by chance in the soils formed by the decomposition of chalks, or in yellow soft marls, they have a feeble vigour, and often chlorosis. 
Herewith the composition of two American soils (analyzed by $B$. Chauzit), representing the type where the Rupestris grows most vigorously, and in the greatest profusion; these analysis were made on the fine soil, after mechanical separation of the rounded siliceous pebbles, which formed 70 to 80 per cent. of the total mass.

$\begin{array}{lcccrrrr} & & & & & \text { No. 1 } & & \text { No. } 2 \\ \text { Clay } & . & \ldots & \ldots & & 81.72 & \ldots & 64.60 \\ \text { Sand } & \ldots & \text {. } & \ldots & & 16.32 & \ldots & 32.85 \\ \text { Carbonate } & \text { of Lime } & \ldots & & \ldots & 4.71 & \ldots & 2.27\end{array}$

These properties of adaptation become practically identical in France, as proved by numerous examples of reconstitution which have been done with Rupestris, and the value of this species from that aspect is nowadays admitted. The Rupestris are not grafting-stock for chalky soils, in the soft and friable white Cretaceous chalks of the Charente, of Saumurois, in the chalky marls of the Garumnien, and a number of soils where carbonate of lime is abundant and soluble, all the forms of Rupestris are rapidly attacked by chlorosis, become stunted, and die. The Rupestris is one of the species most easily affected by chlorosis when in chalky soils, it turns yellow sooner than the Riparia. In compact clays (Rupestris du Lot excepted), in all humid soils, the other species are superior to it; it grows in the driest and most unfertile soils; and under these conditions it is superior to all other species, and to all other American grafting-stocks.

As we have seen from the figures already given, this species has a very high resistance to phylloxera; its vigour is very great, its trunk very strong, much stronger than that of the Riparia, without difference in thickness between the stock and the scion; the grafts are carried with great vigour, are fructiferous, and mature early; the affinity of its grafting to the European vines is nearly always equally good. Finally, the Rupestris grows well from cuttings or grafted-cuttings.

The soils where the V. Rupestris has succeeded, and will succeed, are very numerous in the vineyard districts of France. There are some districts which will be entirely reconstituted by the Rupestris, the Loire-Inferieure, and the Maine-et-Loire (Saumurois excepted), for example. In all the pebbly, pebbly-siliceous, or hard limestone soils, should they be on the rich or dry hills or slightly fertile 
plains, all the siliceous soils, with more or less large particles, will be reconstituted with the V. Rupestris; and soils of these natures are very numerous in the viticultural regions of France. Such are, for example, the soils of the Alpine diluvium, the diluvium of the Durance (Crau), and the dilivium of the Pyrenees in the south of France; the modern pebbly alluvium of the Rhône, those of the garigues of the Oxfordian and the Corallian, of certain hard limestones of the Molasse of the same region; those of the Silurian in the north of France, the hard and siliceous schists, the pebbly, hard limestone of the Carboniferous; those of the pebbly-granitic soils at the edge of the Central Plateau (Aveyron, Beaujolais); those of the hard limestones of the Jurassic, Oxfordian, and Corallian of the Rhône hills, and of the Bourgogne; the tertiary, pebbly sands of the Gironde, the graves, the ancient alluvia of the Charente and Rhône with hard calcareous and siliceous fragments mixed, etc.

The V. Rupestris, as already stated, grows well from cuttings or grafted-cuttings. It is possible, with special care, to arrive at as large a strike comparatively as with the most perfect grafting-stock, - the Riparia and Vialla, for examples. The successful strikes of grafts and grafted cuttings have reached, in many nurseries, from 80 to 90 per cent. Some nurserymen consider that the success of grafting with Rupestris is more perfect than with other grafting-stock, on account of the vigour of the grafts and the perfection of the knitting. However, the Rupestris is very difficult to graft when at an advanced age. In fact, to facilitate the growth of the cuttings and the grafted cuttings of the Rupestris, they must be carefully barked and the eyes. neatly excised on the part that is underground. We will specially insist on this when we treat of grafting.

The $V$. Rupestris, obviously ungrafted, is not subject to cryptogamic diseases of the leaves; the canes often exfoliate early at their base, but this is a natural phenomenon which is constantly observed of these vines in their wild state in America, but which has no action on the great vigour of this species. The black spots that are often observed on the leaves, and attributed to melanose, are only numerous on the less vigorous and valueless varieties, and never produce any weakening of the more perfect varieties. The Rupestris in a general way, is very subject to pourridie in damp soils; 
it is the most subject to it of all the American species, and on no account should be planted where there is stagnant water.* We will see the wide importance that the Rupestris had as an element in hybridization, on account of its primordial qualities of vigour and resistance to phylloxera.

But amongst the diverse forms of Rupestris that have been mentioned we must state precisely, from the aspect of adaptation and reconstitution, which are to be preferred in different soils. Only the Rupestris du Lot, Rupestris Martin, and Rupestris Mission should actually be cultivated. The Rupestris Ganzin, for example, is inferior to the Rupestris Martin as to vigour, but has the same qualities of adaptation. The Rupestris Metallica and most of the best forms of Rupestris de Fortworth are not equal to the Rupestris du Lot, which succeeds in the same surroundings.

The Rupestris Martin, on account of its great resistance to phylloxera, must a!ways be utilized in poor siliceous or pebbly soils, containing little or no limestone.

The Rupestris du Lot can actually replace Solonis and Jacquez in relatively calcareous and poor soils, or where formerly recourse was had to these grafting-stocks, and also the Vialla in compact siliceous soils.

The Rupestris Mission is preferable to Rupestris du Lot for relatively fertile soils, where the last-named, through its excess of vigour, urges the grafts to non-setting; or also in the soils where certain French vines, grafted on the Rupestris $d u$ Lot, are normally subject to non-setting, and do not yield a regular or abundant crop.

The Rupestris Metallica has a greater resistance to chlorosis than the Rupestris Martin or Rupestris Ganzin, - but is not equal in this respect to the Solonis.

\section{MONTICOLA:}

(a) Description (General Characters).--Stump little vig. orous, semi-climbing habit, trunk slender: wood of the year ramified, shining, of light-brown mahogany colour much striated, tendrils discontinuous. Leaves (Figs. 44 and 45) small, as wide as long, sub-cordiform, almost entire, slightly folded along the mid-rib; petiolar sinus deep, with overlapping sides; teeth blunt, obtuse, normal to the limb, which is thick and slightly undulating (bubbly): upper-face

\footnotetext{
*Rupestris has done well in soils where the water level is close to the surface 6 months in the year.-(Translations from a letter of L. Ravaz.)
} 
deep green, shining; under-face lighter green, as if $\mathrm{var}$ nished; young leaves rosy green. Bunch small berries submedium spherical, black or deep grey, taste clean and sweet. Seeds (Fig. 46) medium or large, sub-spherical; beak short and thick; chalaze sub-orbicular: $r$ a phe in the shape of a very prominent fine cord, distinctly separated from the chalaze. Roots hard, long, fairly slender.

(b) Varieties, Adaptation and Culture. - Until comparatively recently only a very few varieties of V. Monticola were known, or, on account of their feeble normal vigour were valueless for reconstitution. The recent explorations made by T. V. Munson in the extreme northwest of Texas enabled him to discover very vigorous forms in $189 \mathrm{I}$, and more recently in 1894 , in a new exploration he accomplished with Salomon, jun. The

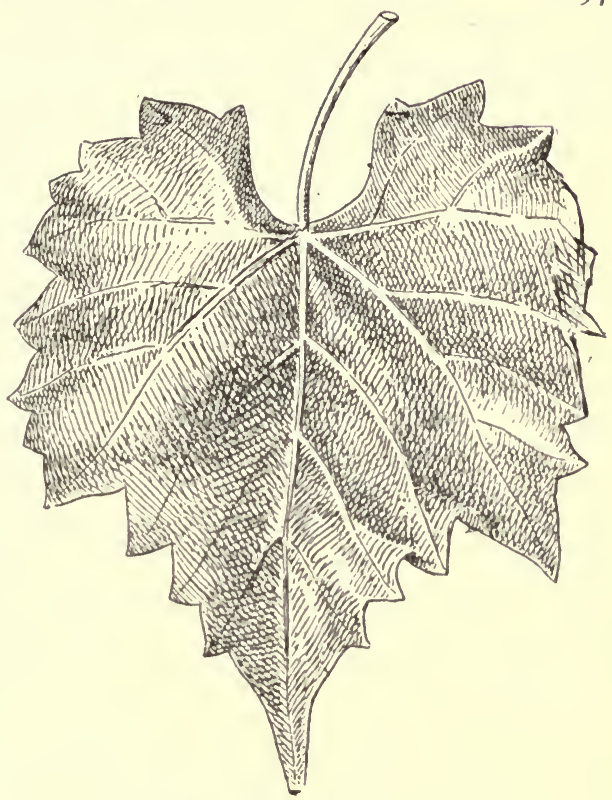

Fig. 44- -Leaf of V. Monticola (upper-face).

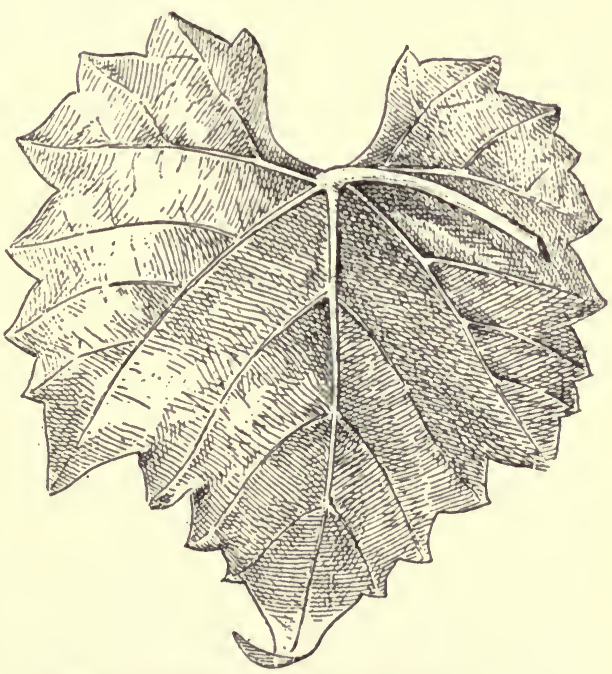

Fig. 45.-Leaf of V. Monticola (under-face). 
varieties which they brought back, and which have been cultivated since 1893 and 5895 , have a vigour and strength of development previously unknown in V. Monticola. We

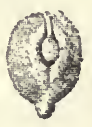

Fig. 46. - Seed of V. Monticola. cannot yet pronounce an opinion on their cultural value and adaptation, but on account of their qualities of resistance to phylloxera, chlorosis, and drought, which the species and the weak forms already cultivated in France have shown, on account, also, of the dry, unfertile, and calcareous soils, in which the vine grows in Texas, we may hope that the vigorous forms will, in future, have a great value for calcareous and chalky dry soils. The V. Monticola No. I, which has been cultivated at the School of Agriculture, Montl pellier, for three years already, shows an exceptional vigour, and remains of a fine green colour in a soiliable to cause chlorosis. The $V$. Monticola Salomon resembles it in its characters, but appears to be even more vigorous.

The V. Monticola (V. Texana or V. Foëxeana) occurs in a very limited geographical area in the centre of Texas, where it forms a circle in almost all mountainous country. The V. Monticola grows exclusively on low mountains, and only on the upper part of their slopes, or on the extensive table-lands crowning the hills of Texas. The climatic characteristics of these regions is an extreme drought; with a fall of temperature sometimes very great in winter, $-20^{\circ} \mathrm{C}$, and temperatures rising up to $42^{\circ} \mathrm{C}$. The $\mathrm{V}$. Monticola always remains, even in the most arid and unfertile soils, of a fine green shining colour.

The V. Monticola does not grow, like V. Berlandieri, in white chalky soft and friable soils, but if grows in soils where the percentage of limestone is fairly high, and which have an analogy with the Jurassic groies of the Charentes, in which most other grafting-stocks become chlorosed. The soil of the table-lands of the county of Bell, in Texas, where V. Monticola is most abundant, is constituted of laminated (or bladed) fragments of fairly compact limestone, of a lithographic texture, slight yellow or. whitish, with siliceous incrustations; they are intermixed with mellow blackish soil, containing numerous small fragments o soft limestone and a few siliceous concrteions. Acoording to analyses made by B. Chauzit, one of these Texas soils con- 
tained $6_{5}$ per cent. of stone and 25 per cent. of fine soil, containing:-

$\begin{array}{llllr}\text { Clay } & \ldots & \ldots & \ldots & 46.4 \text { per cent. } \\ \text { Sand } & \ldots & \ldots & \ldots & 3.5 \\ \text { Limestone } & & \ldots & \ldots & 48.9\end{array}$

The V. Monticola has probably a very great resistance to phylloxera, and seems rather difficult to propagate from cuttings.

The V. Monticola has yielded a fairly large number of wild hybrids with the species natural to Texas, which we will study. Some viticulturists have attributed to many vigorous forms of Rupestris an hybridizing influence of V. Monticola; this seems very difficult to admit generally, especially if we take into consideration that the V. Rupestris and $\mathrm{V}$. Monticola live, in their wild state, in regions very far apart.

The V. Monticola is, without doubt, an excellent element in the creation of Franco-American hybrids especially if combined with varieties of great vigour and strong development.

The principal forms of $\mathrm{V}$. Monticola selected and named in the collection at the School of Agriculture, Montpellier, are actually fairly numerous; we will only give the essential characters of the principal forms. Amongst these, the Monticola Salomon and Monticola Munson No. I are very vigorous, leaves intense grcen, canes strong and long, trunk stout. They appear to be the best, and are probably the most resistant to chlorosis.

Monticola Salomon.-Stump very vigorous; canes strong, long; rather numerous and erect ramifications; internodes fairly short, finely striated, of a light-green colour in the herbaceous state, of a brownish-yellow colour with deeper stripes when lignified; young leaves bright green, very shining; adult leaves (Fig. 47) relatively large, entire, excessively thick, sub-cordiform, very wide towards the petiole, terminal lobe triangular, well-defined, folded along the three principal ribs, with margins irregularly rising towards the top forming a cup: petiolar sinus very deep, with sides tangent or overlapping; upper-face intense green, as if varnished; under-face lighter green, very lustrous; ribs very stout, with fluffy hair at the points of bifurcation. Petiole very short, forming a right angle with the limb, with patches 


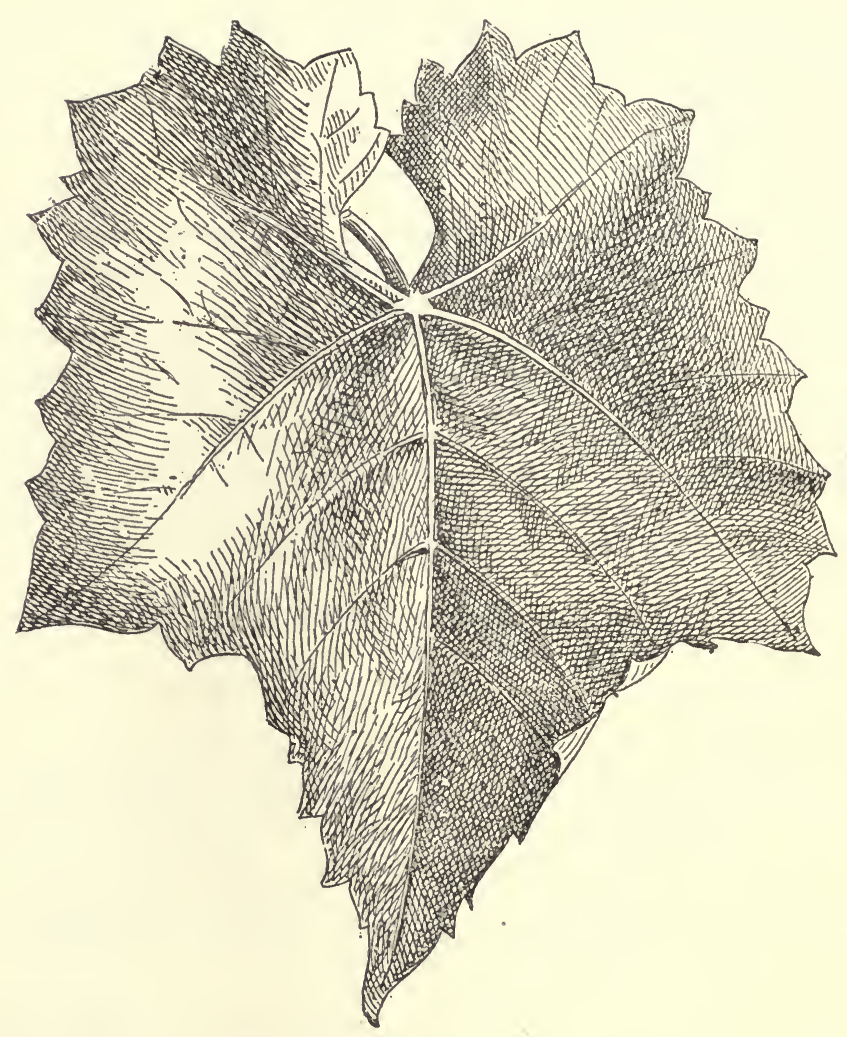

Fig. 47.-Leaf of Monticola Salomon.

of fluffy hairs disseminated on it; teeth short, wide, well defined, in two series.

Monticola Munson, No. I.-Vigorous form, differing from the preceding by its leaves (Fig. 48) having irregularly and unevenly undulating margins, limb relatively thick, deep green; numerous depressed hairs on the summit of the herbaceous shoots, giving a whitish tint to the plant.

Monticola Munson, No. 2.-This form closely resembles the preceding in the deep green tint of its foliage, and the general characters of the leaf, but is a little less vigorous. 


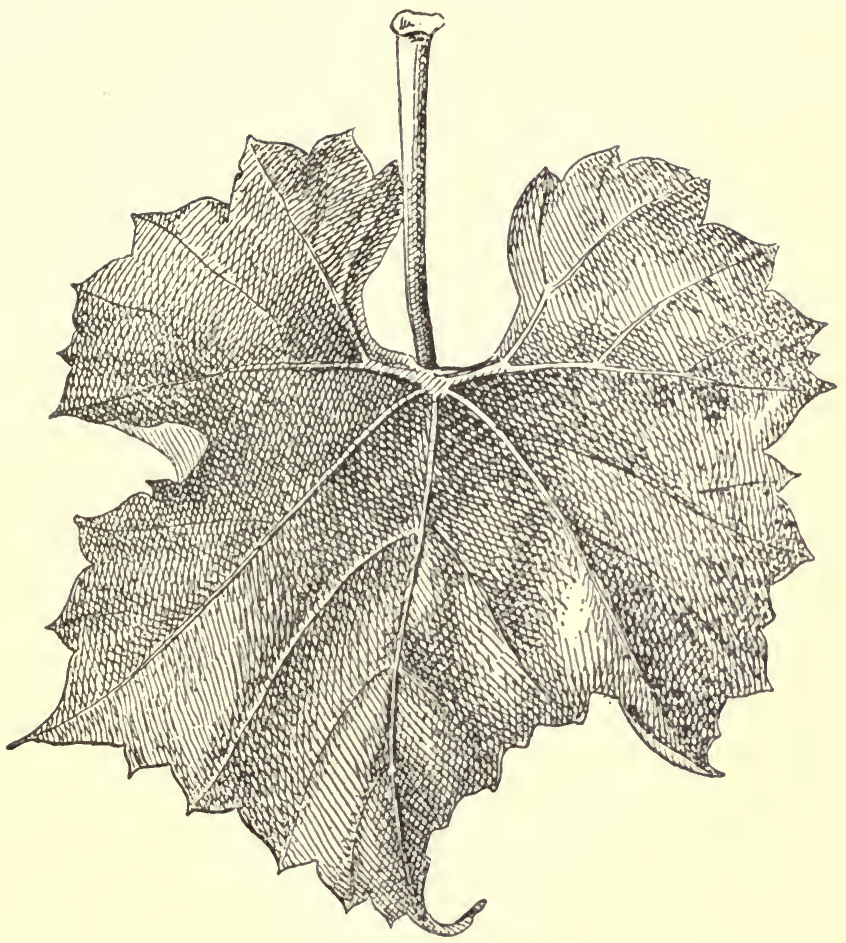

Fig. 48.-Leaf of V. Monticola Munson, No. ז.

Monticola Munson, No. 3.-A form of medium vigour, characterized by the general light tint of its leaves (Fig. 49) of a yellowish-green, elongated (like an arrow barb), flat, very lustrous.

Monticola Foexeana.-One of the first forms introduced into France; very inferior to those previously studied, on account of its small vigour; characterized by its relatively large leaves, thick, of a deep and very brilliant green, limb undulating; petiolar sinus almost closed; teeth wide and very short; wood purple-red when lignified.

Monticola Texana.-Type of the earlier introduced forms still in existence in France; of very feeble vigour and without cultural value. Leaves (Figs. 44 and 45) small, light yellowish-green, parchment-like; petiolar sinus open, almost flat; teeth relatively acute. 


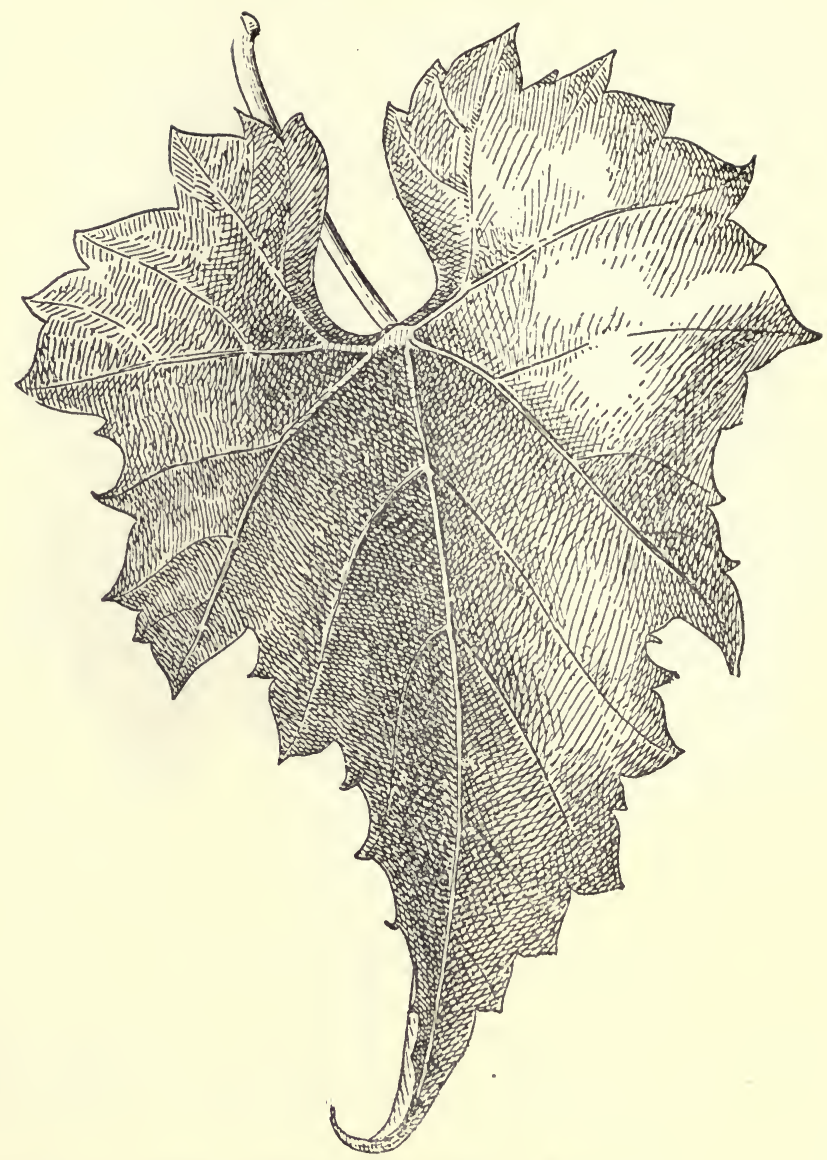

Fig. 49.-Leaf of V. Monticola Munson, No. 3.

\section{ARIZONICA.}

The $V$. Arizonica is not much known in France, and has not been used for reconstitution, although it has existed for a number of years in vine collections. This species resembles V Californica by its young leaves; its adult leaves (Fig. 50) glabrous, thick and small, and its bushy habit, gives it an appearance comparable to that of Rupestris; its seeds (Fig. 5I) distinguish it from V. Californica, but the numerous hybrids existing between V. Californica and V. Arizonica may often lead to confusion. 


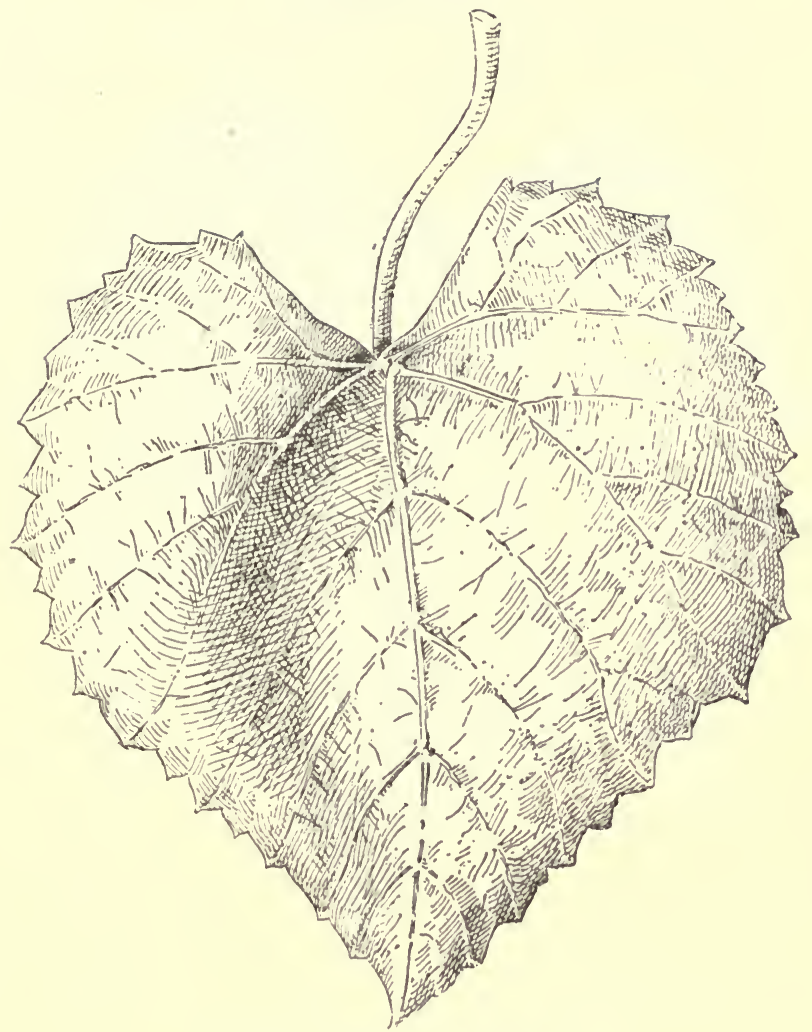

Fig. 50.-Leaf of V. Arizonica.

The V. Arizonica grows especially in the State of Arizona and New Mexico, from the banks of rivers to the highest and most arid lands, sometimes in very pebbly, dry. calcareous soils It has been propagated, as graftingstock, in the soils of a similar nature in California, where it is superior to V. Riparia. Cuttings and grafted cuttings root freely, and throw less suckers than V. Rupestris; its resistance to phylloxera is rather high, Fig. 5r.-Seed of and may be represented by the number 16 . V. Arizonica. In the chalky soils of the Charente, where V. Arizonica has been tried, it became slightly yellow, without, however, degenerating in cottis.* It is, therefore, from this point 


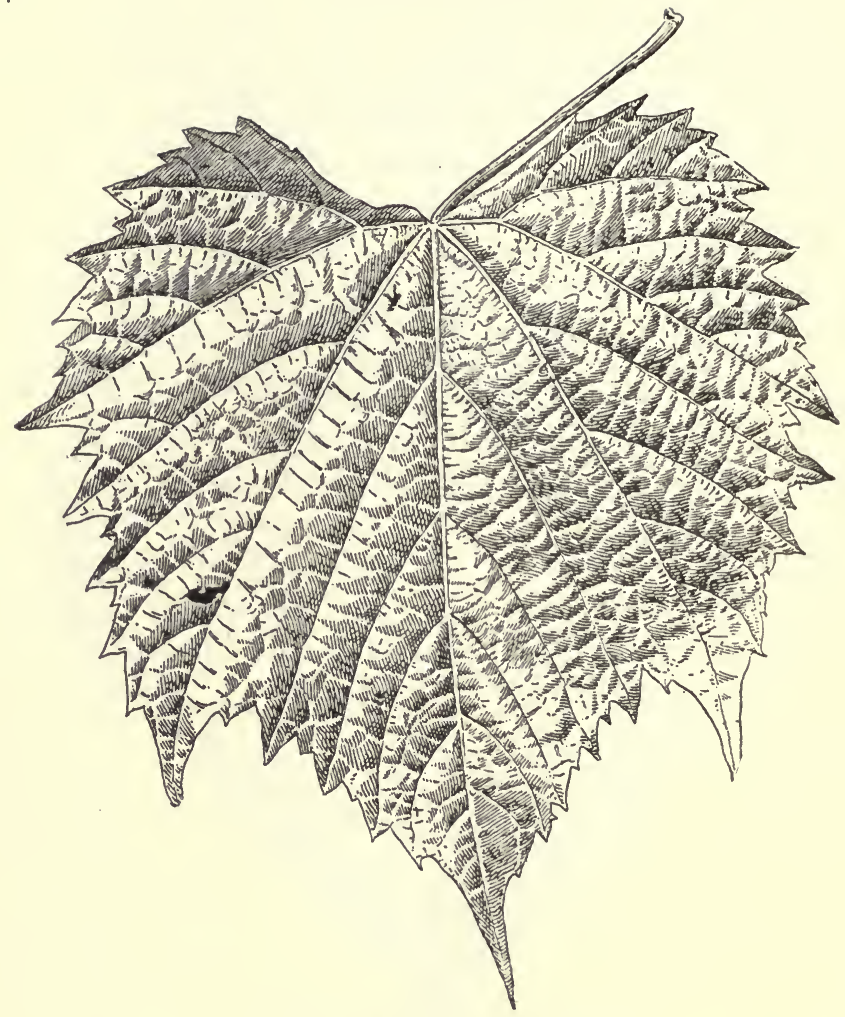

Fig. 52.-Leaf of Riparia Gloire.

of view, slightly superior to Riparia and much superior to V. Rupestris, but is very inferior to V. Berlandieri; as far as resistance to chlorosis is concerned, it may be classified after V. Monticola.

This species does not seem to be destined to a great future, as in the soils where it could thrive, the V. Berlandieri, V. Riparia, and V. Rupestris are always superior to it.

\section{RIPARIA.}

(a) Description (General Characters).-Stump vigorous, trunk medium, canes rather slender, varying in colour at complete lignification, from purple-red to ashy-grey; tendrils 
CÉPAGES.

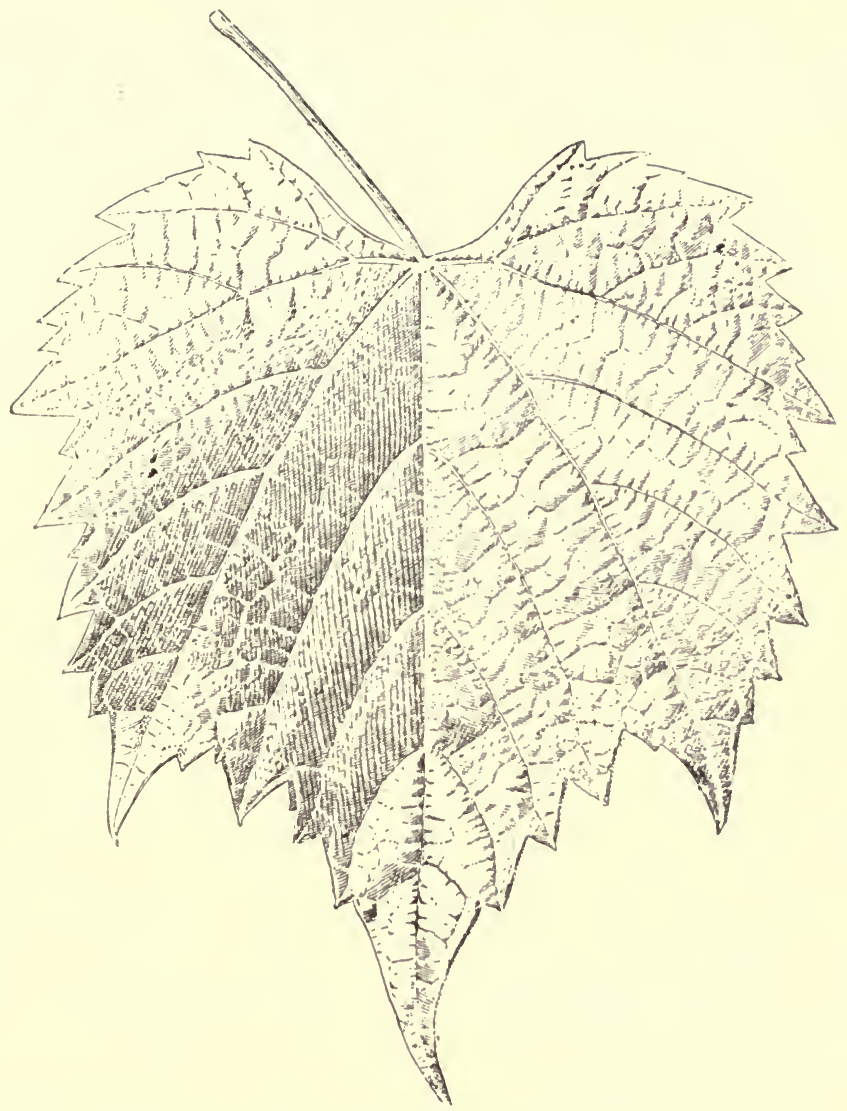

Fig. 53.-Leaf of Riparia Grand Glabre.

discontinuous. Leaves: young, unfolding slowly; adult (Figs. 52 and 53), medium or large, longer than wide, entire, the five lobes indicated by the teeth more developed; two series of acute and oblique indentations; dark-green colour on the upper-face, lighter green, glabrous, or slightly tomentose on the ribs of the lower-face. Bunch and berries small, spherical, darkbluish bloom, harsh. Seeds (Fig. 54) very small; chalaze slightly prominent, ending in a rudimentary raphe. Roots long, thin, Fig.54.- Seed of and slender, very ramified, hard.

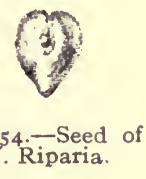


(b) Varieties.-The Riparia is certainly the American vine which has the greatest importance for the reconstitution of vineyards. It was Millardet who first, in 1874 , attracted the attention of viticulturists to this species. In conjunction with Despetis, he pointed out the importance of the selection of forms; its importation to France was due to Bush and Meissner. It is now well known that the individual variations of the Riparia are very numerous. The Riparia has a very widely extended area of distribution in America; its fruit ripens early and is easily disseminated by the rivers on the banks of which it grows, by birds, and even winds, which transport the seeds widely. The Riparia is, besides, mixed with many other species, and, as the period of florescence of certain Riparias is almost continuous during several months of the year, many hybrids have been formed; the better-defined characteristics of these hybrids will be studied. But many of them have only felt a slight hybridizing influence from other species and only present, in comparison with typical Riparias, quite insignificent differences. The Riparias with thick and shiny leaves are, probably, as indicated by Millardet, the result of hybridization with V. Cordifolia, which, as already stated, is nearly always found associated with V. Riparia. We consider these most meritorious forms equal to pure Riparias

It may be said that the selection of Riparias is nowadays settled amongst all the vineyards. Most of those which have been retained as cutting producers are varieties of value; the forms with small leaves, small trunk, and little vigour have been gradually eliminated, and are now almost entirely discarded.

Generally speaking, as applies also to the Rupestris, best Riparias are the most vigorous, and the most vigorous have nearly always a large trunk, thick leaves, large, shining (glabrous type), or a little dull (tomentose type). For reconstitution it is not indispensable to have recourse exclusively to the forms mentioned, although success is more assured with them, but we must rigorously exclude weakly-growing varieties with small thin leaves; this applies equally to the Rupestris.

The Riparias may be classed in two principal groups:-

\section{Tomentose Riparias.}

The short abundant hair on the branches and on the ribs of the under-face is especially characteristic; the leaves are dark dull-green on the upper-face; the teeth long, acute, 
and slightly oblique to the plane of the limb. Seeds small; berries covered with bloom; trunk much stronger than that of the glabrous Riparias. They comprise two subdivisions:-

rst. Tomentose Riparias with large leaves, the most vigorous, growing generally on the cool parts of river banks; they constitute excellent grafting-stocks. Ex.: Riparia Scribner, one of the most vigorous and meritorious. Generally speaking, these Riparias grow better in damp soils than the glabrous Riparias; their trunk is often very large. The forms having violet wood are more vigorous than those with grey wood.

2nd. The Tomentose Riparias with small leaves, which grow in dryer places, in the crevices of rocks; their leaves are thicker, of a less intense green, and dull on the upperface; they are little vigorous in the wild state.

\section{Glabrous Riparias.}

These are very varied, and comprise two sub-groups:-

Ist. Glabrous Riparias with lobed leaves.-The leaves have either three or five lobes, sinus deeply incised, generally small, ribs more or less deep rose colour. Ex.: V. Palmata of Vahl. In general, all the Riparias with lobed leaves have little vigour and are inferior for culture to other wild forms.

2nd. Glabrous Riparias with entire leaves.-The upper lobes are detached by the shallow lateral triangular sinus, the other lobes are indicated by a great prolongation of the extremities of the teeth. We divide this sub-group into:-

(a) Riparias with small leaves; leaves dull-green, slightly dark on the upper-face; teeth acute and oblique to the plane of the limb; parenchyma varying in thickness individually; very subject to chlorosis and punctuated anthracnosis, and without any value as grafting-stock.

(b) Riparias with large leaves, for the greater part grafting-stocks of much value, the most propagated in culture; they may be classed as follows:- (a) Glabrous Riparias with entire large leaves, dull; $\left(a^{\prime}\right)$ with thin leaves,-most of the forms of the north belong to this subdivision; they are sometimes very vigorous, but their trunk is of inferior size; $\left(a^{\prime \prime}\right)$ with thick leaves, the most vigorous and the best grafting- 
stocks of the glabrous Riparias with large dull leaves, amongst them are preferred the Riparia Baron Perrier, Riparia with bronzed buds, Riparia with violet wood, Riparias Nos. 6 and I 2 of the Meissner collection; (b) Riparias with large entire leaves, shining and always thick, subdivided into- $\left(b^{\prime}\right)$ Riparias with slightly round leaves, terminal lobe obtuse, teeth sub-acute, the Riparia of the Indian Territory; $\left(b^{\prime \prime}\right) \mathrm{Ri}$ parias with long and shining leaves, generally goffered in structure between the main ribs, such as Riparia Scuppernong, Riparia Grand Glabre, Riparia Portalis, or Gloire de Montpellier. The coloration of the wood, the acuteness and length of the teeth, and coloration of the ribs differentiate the forms of this second group. It must be mentioned that the nodes are frequently more flattened and the diaphragms thicker than in the Riparias with dull leaves, characters which, with the shining leaves, seem to suggest a cross with V. Cordifolia, with which they grow side by side. The Riparias with shining leaves, on account of their great vigour, have the highest value as grafting-stock in good soils.

The following table summarizes the classification of the different forms of Riparias:-

\section{TOMENTOSE RIPARIAS.}

1st. Large leaves. Ex.: Riparia Scribner, Riparia geant or tomentose of Mas de las Sorres, Riparia violet, etc.

2nd. With small leaves-

\section{GLABROUS RIPARIAS.}

1st. With lobed leaves. Ex.: V. Riparia var. Palmata, etc.

2nd. With entire leaves.

A. With small leaves.

B. With large leaves.

a. With dull leaves.

$a^{\prime}$ With thin leaves.

$a^{\prime \prime}$ With thick leaves. Ex.: Riparia Baron-Perrier, Riparia with bronzed buds, Riparia with violet wood, Riparias Nos. 6 and I2 Meissner, etc.

$b$. With lustrous and thick leaves.

$b^{\prime}$ With rounded leaves. Ex.: Riparia Indian Territory, etc. $b^{\prime \prime}$ With elongated leaves. Ex.: Riparia Scuppernong, Riparia Portalis or Gloire de Montpellier, Riparia Grand Glabre, or Riparia No. 13 Meissner, etc.

The following table shows the respective value of the principal forms of $\mathrm{V}$. Riparia as to their vigour and resistance to the phylloxera, from notes taken among the 
collection of the School of Agriculture, Montpellier. where these varieties of the same age are planted side by side in the same soil :-

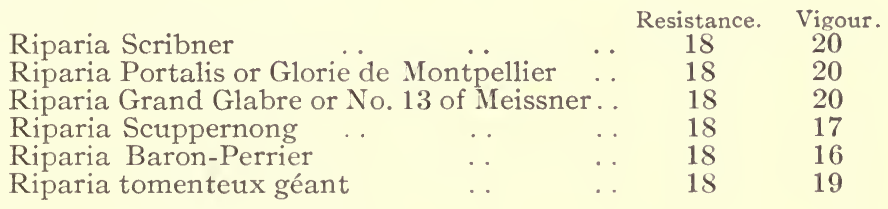

In the Despestis collection, growing in the same ground, under similar conditions, the Riparia Duc de Palban is similar to the Riparia Ginire de Montpellicr as to vigour and characters, the Riparia de Beaupré to the Riparia tomenieux géant, from the same points of view. The other forms are inferior. We will mention the Riparia Martineau or Gloire de Tourraine, which appear to us identical with the Riparia Gloire de Montpellier.

We will not describe the Riparia Fabre or Martin des Pailleres, for although it represents some good points it is not a unique form, nor the Riparia de las Sorres, which is included among the tomentose or glabrous and very vigorous Riparias. We must, however, point out among these last-mentioned a glabrous form selected by E. Durand, under the name of Riparia de las Sorres Selected, which is the most vigorous of all this group; this Riparia, planted in 1876, had attained a circumference of $45 \mathrm{~cm}$. (1 8 inches) at the level of the soil in r89 r.

We will only describe the Riparia Portalis or Gloire de Montpellier, the Riparia Grand Glabre or No. I 3 of Meissner, which are, with reason, the most esteemed and propagated, and would remind that among the tomentose Riparias, the Riparia Scribner seems to have an equal value to the above two varieties, and is even superior in compact soils.

Riparia Gloire de Montpellier (syn. Riparia Portalis, Riparia Michel, Riparia Saporta) was first mentioned by Louis Vialla. It is, along with the Grand Glabre and Scribner, the most vigorous, with rather large trunk. Canes spreading, long, internodes long, of medium thickness, a little bent at the nodes, light-hazel colour, smooth, slightly shinning, turning to bluish bloom near the nodes when lignified, young shoots light-purple tint. Leaves (Fig. 52) large or very large, thick. long, the lobes indicated by a 
great development of the limb, which is terminated by a long tooth - the tooth of the terminal lobe is slightly incurved underneath; regular goffered structure between the main ribs, which are of a vinous-red colour mostly at their origin; dark green, rather shining on the upper-face, paler green, light pink ribs with stiff hair on the under-face; petiolar sinus deep, like an open $U$; two series of acute teeth. Petiole strong, vinous-red.

Riparia Grand Glabre.-This variety was selected at Montagnac by G. Arnaud, and is identical with Riparia No. I 3 of Meissner's collection. Canes long, internodes long, medium thickness, of a purple tint during the herbaceous state; hazel-grey, slightly vinous with much bloom, and red near the nodes when lignified. Leaves (Fig. 53) medium or above medium, cordiform, lateral superior lobes each indicated by longer teeth, margins incurved underneath, lustrous dark green upper-face, yellowish-green, with stiff hair on the ribs of the under-face; teeth acute, slightly deep; petiolar sinus widely open, V-shape.

(c) Adaptation and Culture.-The V. Riparia is highly resistant to phylloxera; the grafts it bears are very vigorous, very fructiferous, and mature early. All the forms of the species take root very easily from cuttings or grafted cuttings: they can also be easily grafted when they have been in the ground a number of years, and bear most grafts of European vines fairly well.

The V. Riparia is also very resistant to cold, and can be cultivated in all the viticultural regions of Europe. This grafting-stock, which came after the Concord. Taylor, Clinton, at the begiming of the reconstitution with American vines, was certainly boomed excessively; it was a mistake to believe that on account of its vigorous, resistant. and producing qualities it could be successfully cultivated in all soils without exception. It was necessary, for this variety especially, to know the grounds in which it was growing in America. The Riparia was planted indiscriminately in the most siliceous as well as strongly calcareous soils. Consequently, complete failures were recorded, which resulted in a disbelief of the value of American vines and induced a reaction which resulted in the Riparia being discarded for some time. The properties of the Riparia are now well known, as this grafting-stock alone has served to reconstitute nearly I, I 36,400 acres (1895) out of a total of $1,730,000$ acres of American 
vines planted in France then; the Riparia is used, with good reason, as one of the best grafting-stocks.

The V. Riparia of all the American species spreads over the largest geograpaical area: it extends from the centre of Canada in the north, which is one of the coldest climates, to Texas and Louisiana in the south of the United States, and on the west to the Rocky Mountains. It is specially abundant in the Central States and those bordering the Atlantic.

In the northern limit of its geographical distribution, the Riparia withstands a cold of $-30^{\circ} \mathrm{C}$, and in the south resists the highest temperatures. On account of its early growth, its first buds are very subject to spring frosts, but, when frost bitten, large numbers grow on the trunk and base of the spurs; this is not a fault when it is grown for the production of cuttings, and has no importance when grafted, for we shall see when we study grafting that early budding does not force the graft to grow earlier.

The Riparia does not succeed in too dry surroundings, especially if little fertile; it has a poor growth in such soils, and the difference in size between the stock and scion, which occurs with all varieties, is then accentuated; we will discuss this further in the chapter on grafting. The Riparia is vigorous in the wild state in moist soils only, and it is especially on the sandy and fresh banks of rivers that it attains its greatest development in America. This applies also in France, where the Riparia grows much better in cool than in dry, sandy soils: but it does not like wampy or wet ground.

The Riparia grows in soils of very different kinds in the United States, belonging to the primitive formations or their derivatives, and to a less extent in secondary or tertiary formations. The recent alluvials, the rich siliceous or red clay siliceous soils (pebbly or not), the fresh and fertile sands, the soils formed of hard calcareous débris, but fresh and rich, are the surroundings in which it acquires a fine development. The Riparis imported into France by Meissner were selected on the banks of the Mississippi River where the soils are formed by clay-sandy alluvials, composed of fine particles, dark-grey colour, and great fertility, resting on hard calcareous or laminated banks of black-blue clay. As an example, one of these very fertile soils contained (physical analysis):-

Clay

Sand

Limestone

$\begin{array}{lll}\cdots & \cdots & \cdots \\ \cdots & \cdots & \cdots\end{array}$

65. 020 per cent. 
In Virginia, whence many Riparias were imported, the soils are clay-sandy, rich, of a red colour, mixed with siliceous pebbles. In the north of New York State, the Riparia soils were formed from the decomposition of Devonian schists, and constitute a clay-sandy soil with few pebbles and very rich; in Delaware and Maryland, the Riparias are in the very rich. red, grey, or grey-yellow humiferous sands. On the banks of the Great Lakes they grow in mellow soils which have been formed by the decomposition of hard calcareous rocks of the Devonian period, which are very fertile, although fairly calcareous. When, exceptionally, the calcareous pebbles are numerous and soft, the Riparias are not found; and if, by chance, a few vines are found in these soils they are poor, yellow, and stunted. The Riparias are very scarce, and affected by chlorosis in their wild state, in the yellow marls and limestones of Kentucky and the environs of Sandusky.

It is in the soft limestones and yellow or white calcareous marls of diverse formations in France that the Riparias have given most numerous failures. Sometimes they are found green and pretty vigorous in those surroundings when the soil is specially rich, but only while they are not grafted; as soon as they are grafted they get chlorosis, become stunted, and die rapidly. The V. Riparia is less subject to the effect of limestone than the V. Rupestris or V. Astivalis; but in soils where carbonate of lime is very plentiful, even if the soil is rich, it succumbs to chlorosis. In dry, unfertile, but non-calcareous soils, it has only a feeble development, and supports poor grafts, showing, as already said, a great difference in thickness between the stock and the scion. The Riparia is best suited by almost noncalcareous soils, naturally fertile, or enriched by plentiful manuring. Under these conditions, no other grafting-stock is superior to it; the numerous examples of resonstitution which actually exist in France prove this in an indisputable manner.

The Riparia must therefore, play a principal rôle as an element for reconstitution in the siliceous, clay-siliceous, clay-limestone, silico-limetones, deep, fresh, and fertile soils. When the subsoil is calcareous and hard, but covered with only slightly calcareous soil of 35 to $50 \mathrm{~cm}$. (I 4 to 16 inches) thick, it sticceeds very well, provided the soil has the necessary amount of fertility, and if in trenching care be taken not 
to disturb the subsoil or mix with it the top soil. A lesser thickness of non-calcareous soil, resting on a calcareous subsoil, is sometimes sufficient in moist regions, where there is no drought, or a drought of short duration, allowing the roots to live on the surface in the non-calcareous soil. It is the best grafting-stock to choose for the red, pebbly, or slightly calcareous soils, when the soil is at least $50 \mathrm{~cm}$. (I6 inches) in depth, and rich, mellow, and sound. These various kinds of soils are frequently met in French viticultural regions. Spraying the vines with sulphate of iron (method of Rassiguier) may serve to increase the area for the culture of V. Riparia in'fairly calcareous soils.

\section{RUBRA.}

The V. Rubra is a very rare species in America; it is limited to three or four points on the banks of the Mississippi and Merrimac Rivers, in the sandy, very rich, fresh, and moist alluvials, where it only acquires a small development. It exists in a few rare collections, and remains there. The V. Rubra has, however, a very great resistance to phylloxera, according to

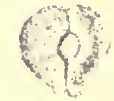
Fig. 55.-Seed of

Millardet, but its constant feeble vigour renders it valueless for reconstitution; it only has a certain value as far as hybridization is concerned. 


\section{II.-ASIATIC · SPECIES.}

The principal species of Asiatic vines are:-

V. Coignetie, Pulliat; V. Thunbergi, Siebold et Zucc.; V. Lanata, Roxburg; V. Pedicellata, Lawson; V. Romaneti, Romanet du Caillaud; V. Davidi or Spinovitis Davidi, Romanet du Caillaud; V. Amurensis, Ruprecht; V. Pagnuccir, Romanet du Caillaud.

All these species have, from the point of view of their adaptation and general characters, a great analogy with V. Labrusca. We know that the Behring Strait, separating Asia from America, is bordered in the two continents by soils belonging to the same geological formation (Tertiary); the diffusion of the same species in the two continents may have therefore taken place at a past epoch, and the actual types may originate from a common origin.

The Asiatic species are only slightly resistant to phylloxera; the following are the figures expressing the resistance of the three best known species:-

V. Coignetiæ

V. Amurensis

V. Thunbergi

$\begin{array}{lllll}\ldots & \ldots & \ldots & \ldots & 3 \\ \ldots & \ldots & \ldots & \ldots & 2 \\ \ldots & \ldots & \ldots & \ldots & 1\end{array}$

These species have grown well in France, when not destroyed by phylloxera, in rich, mellow, deep, fresh soils. They seem to require a moist atmosphere; in dry years their development appears to be checked, and their leaves fall early. They resist chlorosis almost as well as V. Labrusca, especially V. Thunbergi, V. Coignetiæ, and V. Amurensis, which is one of the most slender, having some of the characters of V. Vinifera, but greater resistance in limestone soils. These vines are evidently of no value whatever, even in very cold and humid regions, for which the V. Coignetiæ has been extolled.

We fear that these conclusions cannot be applied to the vines of Caplat resulting from Coignetiæ seedlings, and which from the preliminary trials in propagation would have given encouraging results in the extreme north of France. The origin of these vines allows us, however, to assert d priori their non-resistance to phylloxera. 


\section{III.-VITIS VINIFERA.}

It is useful, for what we have to say about the hybrids between V. Vinifera and American vines, to know what are the properties of adaptation and the resistance of this species, which has given all the European cépages actually cultivated.

The botanical characters of the V. Vinifera and the innumerable forms derived from it all reside in the seed. The characters of the trunk, cane, leaf, berry, are variable, and only offer slight distinctions. The seed (Fig. 56) varies in size, but has a constant characteristic. which is being elongated, with a well and clearly defined beak, relatively very long; the chalaze is depressed, slightly apparent, and always on the upper portion of the seed; these characters of prolonged beak and position of the chalaze are never found in other species.

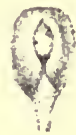

Fig. 56 - Vinifera.

Let us note also, as a contrast, the easy propagation from cuttings of all the cépages derived from V. Vinifera, the clean taste of their fruit, which is juicy, not pulpy and not foxy; sometimes they have a peculiar taste, as in Muscat, Cinsaut, Cabernet-Sauvignon. Finally, a very fixed and important character from the point of view of adaptation is that of the roots, which are large, tender, and fleshy. This characteristic of the roots being large explains why all the cépages derived from V. Vinifera generally grow well in very compact soils.

The V. Vinifera succeeds, however, almost equally well from a vegetative point of view, in soils of every class, from the most siliceous to the most calcareous. But in white, soft, chalky soils the cépages derived from this species become partially chlorosed, especially if the spring is wet. We have given some examples of this in the first part of this work. We have also shown that the chlorosis is only transitory, and of no importance. If we compare, from the point of view of their sensitiveness to chlorosis, the $\mathrm{V}$. Vinifera and other species, especially those of America, we are forced to the conclusion that the $V$. Vinifera are the most resistant; the $\mathrm{V}$. Berlandieri alone has almost the same resistance to chlorosis as V. Vinifera. 
The resistance to phylloxera of all the forms of $\mathrm{V}$. Vinifera, without exception, is nil. Certain cépages, owing to their inherent great vigour, last longer, such as, for instance, the Colombeau, Etraire de 1'Adhui, Psalmodi, etc., but they all finish by succumbing to the attacks of the insects. This non-resistance to phylloxera, as well as resistance to chlorosis, is transmitted to the hybrids resulting from V. Vinifera, and their selection, from this point of view, must be made with the greatest care. 


\section{IV.-HYBRIDS.}

\section{A.-HYBRIDIZATION.}

(a) Historical.-The vine hybrids, or product of the crossing of two different species, are extremely numerous and varied in the wild state, as will be evidenced in what follows.

The possibility of crossing two species, giving individuals of an infinite fecundity, was denied for a long time, and brought to light more especially by the work of Darwin. Millardet was the first to attract attention to the complexity and origin of certain forms of American vines, and to determine their hybrid nature; he insisted on this fact, that the hybrids between species were always fertile, and that the fertility was maintained almost indefinitely, even in most complex combinations. Not only hybrids of two species, but hybrids of three, four, or five species are fertile, and give seeds capable of originating fertile individuals again, a fertility which is maintained indefinitely.

The vine is certainly one of the plants in which these phenomena are most frequent in the wild state, and the most easy to produce artificially. The natural hybrids are so varied in America that one might classify between different species, series of forms with intermediate characters, which renders the specific elimination very difficult. It is very probable that the cépages derived from the $V$. Vinifera, fixed and selected by a long series of generations, are partly the result of different crossings. But, in a botanical sense, the crossing between two individuals of the same species yield metis and not hybrids. As very ably proved by Millardet, in a work on the hybridization of vines, ${ }^{*}$ there is no difference in the case of vines between a metis and a hybrid. When crossing takes place between two individuals of the same species, or two individuals of different species, the hybrids or metis resulting have an equal fecundity.

The creation of new varieties of vines by sowing or by hybridization has been tried for a very long time. Vibert. Rohert Moreau, Courtiller, Beeson, etc., in France, have made numerous seedlings with the object of improving table grapes. The sowing of vines has been practised for

*A. Millardet, Essais sur l'hybridization de la vigne. Revue des Pyrenees, I89r. 
a very long time in America. The vineyardists of the United States tried to produce new forms from seedlings, in the hope that they would be better adapted to climatic conditions, which they thought was the only cause of failure in vine culture. It was also with the same object that they tried later on to create new varieties by hybridization. Roger, Arnold, Underhill, Dr. Wylie, Allen, Rickett, Adlum, Bull, Bush and Meissner, Hermann Jæger, T. V. Munson, etc., obtained by these means numerous forms, some of which were introduced and multiplied in France; these will be studied later on.

In France, the first trials of hybridization or metization were carried out by Louis and Henri Bouschet; they commenced their researches in I828, and have given to the vinegrowers in southern districts cépages of great value (PetitBouschet, Alicante-Bouschet, Grand noir de la Calmette, etc). Louis and Henri Bouschet resorted to crossing, for the first time, with a defined object. They desired to infuse, by crossing, the intense colouration of the fruit of the Tinto to the heavy bearers of the south of France, and they succeeded in realizing the combinations aimed at.

But hybridization has assumed great importance on account of the phylloxera crisis, and the reconstruction with resistant vines forced on vine-growers. This importance has been and actually is the direct consequences of the results and failures obtained in the cultivation of American vines.

The first attempts at hybridization were made with the object of creating, by crossing American vines with varieties of V. Vinifera, fructiferous and resistant forms. On account of the inherent qualities of affinity to grafting which those hybrids were supposed to have, through their relation with $V$. Vinifera, it was desired to utilize the most vigorous and resistant of them as graft-bearers.

When the properties of adaptation of the American species and varieties were better known, the crossing was so directed as to unite the $\mathrm{V}$. Vinifera to American vines ving special qualities for given soils, and, therefore, to create resistant graft-bearers, with perfect affinity to grafting and pre-determined adaptation to certain soils.

On account of the difficulty of obtaining resistance to phylloxera by the combinations of European and American vines, the new lines followed, with reason, the creation of hybrids (Americo-American) between resistant vines en- 
dowed naturally with properties of affinity and varied adaptation which were tried to be amalgamated by hybridization.

Finally, we may succeed in creating direct producers of real fructiferous merit, adapted to diverse soils, resisting phylloxera and various cryptogamic diseases. But these possible successes seem very elusive. However, it is true that hybridization has entered a new path, which in the distant future may be full of results; some results may even be seen now.

An important fact, which would give hybrids of V. Vinifera a great superiority as graft-bearers, if their resistance to phylloxera was certain, is that resulting from the great affinity to grafting which those hybrids possess with regard to European vines. We have seen, in the first part of this work, the influence of grafting on the properties of resistance and adaptation of grafting-stocks. The hybrids of V. Vinifera possess these qualities of affinity in a much higher degree than pure American vines, and the affinity of the hybrids will be so much the greater as the American parents possess it to a higher degree themselves.

Artificial fecundation, practised with the object of obtaining direct producers and resistant graft-bearers of more extended adaptation, and of greater affinity to grafting, has been performed by several French viticulturists; its execution is easy, and may be performed by any one.

$\mathrm{We}$ will rapidly describe the principles and technicalities, having recourse to personal researches conducted by us in collaboration with G. Foëx, and to those of Millardet, who studied in detail and with undeniable authoritativeness, this question in all its phases. Previous to I880, when he started, in conjunction with de Grasset, hybridizations with different objects, Millardet had attracted public attention to the importance of the results which might be obtained in viticulture by the adoption of this process. Ganzin seriously studied artificial hybridization of vines at about the same date, and has since pursued it with success; he published the first work on this subject in $\mathrm{I} 88 \mathrm{r} . *$ We may state here that hybridization between American and European vines had been made at the School of Agriculture, Montpellier, by G. Foëx. in 1876 , and that it was continued

* Ganzin, De 1'Hybridation artificielle et des services qu'on peut en attendre pour l'avenier de la viticulture, Revue scientifique, r $88 \mathrm{r}$. 
in conjunction with the writers in the new direction indicated by the observation of facts.

Couderc has pursued the practical study of hybridization since I8So. We will mention amongst the hybridizators best known in viticulture-Davin, Castel, Malègue, Siebell, Terras, etc.

(b) Fecundation of the Vine.-The phenomena of fecundation of the vine, upon which hybridization is based, were studied in detail in I882, and more recently (I89I) by Millardet. E. Rathay completed, in I888, the first work of Millardet on the morphological organization of the flowers of diverse cépages. It has been asserted for a long time that the disposition of the flowers of vines prevented the phenomena of crossed fecundation. The five petals at the period of florescence, which begins at $15^{\circ} \mathrm{C}$. and is in full between $15^{\circ}$ and $20^{\circ} \mathrm{C}$. (Millardet), only become detached at their base of insertion on the receptacle, and always remain united at the apex, forming a cap (operculum) (Fig. 57).

It was admitted for a long time that

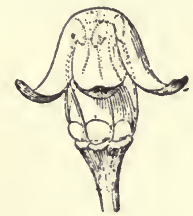

Fig. 57.-Normal at the moment the corolla became detached the operculum was lowered on the pistil, forcing the stamens on to it; the dehiscence of the anthers then occurred, and the pollen became deposited on the stigma. The action of pollen foreign to the flower was therefore prevented. With this interpretation of the phenomenon preceding fecundation, it would be difficult to account for the existence of spontaneous hybrids.

The phenomena take place in a different manner in the majority of cases, as observed by Millardet (Fig. 58). The
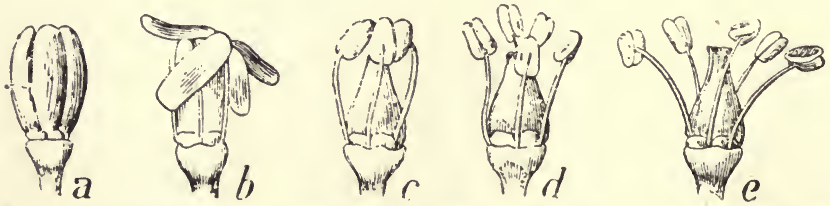

Fig. 58.-Different stages in the opening of a Chasselas Flower (after Millardet).

dehiscence of the corolla is the result of the erection of the stamens, thus lifting the operculum. At a convenient temperature the corolla becomes separated, and finally falls 
away. The stamens which are erected against the pistil, as soon as the corolla has dropped, slowly recede from the pistil and become obliquely disposed to it; five or ten minutes after "the anthers oscillate on their point of attachment so as to turn outwards the face which was previously in contact with the stigma, then the face of the anther bursts, with the result that the pollen becomes liberated." The pollen only falls out after the rotation of the anther has taken place. The auto-fecundation of the flower is therefore prevented by the physiological disposition of the floral organs, and crossfecundation therefore generally happens. Millardet has shown, however, some rare cases of special flowers, which he terms operculated (Malbeck, for instance), in which the corolla does not normally or accidentally fall away (nonsetting, owing to atmospheric conditions), and in which autofecundation does not take place. Rathay and the writers have often observed auto-fecundation.

The pollen is carried, by wind or by insects, from one flower to another on the same vine, or from one vine to another and is deposited on the stigma, wetted with a special liquid, in which it emits pollen tubes, which, travelling through the style, reach and fecundate the ovules.

According to Millardet the phenomena are similar for cultivated or wild vines. In the latter the recession of the stamens and the rotating movement of the anthers on the filaments are still more pronounced. This process of florescence is constant with all hermaphrodite flowers with long stamens.

The studies of Millardet and E. Rathay* have definitely determined these facts, previously observed by J. E. Planchon, on the difference of constitution of flowers. Many species in a wild state have male and hermaphrodite flowers. Many forms of Rupestris and Berlandieri, for instance, have exclusively male flowers (Fig. 59) ; the pistil is abortive and reduced to a small nipple, around which are erected long filaments (much longer than those of hermaphrodite flowers with long

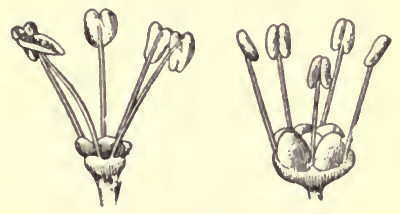

Fig. 59.-Male Flowers. stamens). The stamens remain erect after the florescence, 
and the anthers open outwards, offering a great and direct action to the wind, which carries away the pollen dust.

In cultivated or wild vines hermaphrodite flowers are divided into classes-those with long stamens (longer than the pistil) (Fig. 60), of the florescence and fecundation

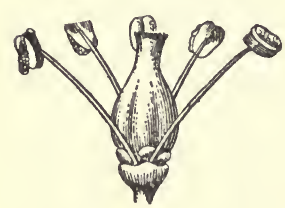

Fig. 60.-Flower with long stamens.

of which we have just given an idea, and others, less numerous, with short stamens. In the latter the stamens, shorter than the pistil, have their anthers in contact with the corona of the stigma. When florescence takes place the filament of these shortstamened flowers curves outwards, bringing the anthers in contact with the base of the pistil (Fig. 6I). According to E. Rathay the pollen of shortstamened flowers differ's morphologically from that of flowers having long stamens, and has no power of germination. Rathay concludes that they cannot be utilized for hybridization. Millardet reasons on results obtained with the pollen of male flowers, and does not consider this
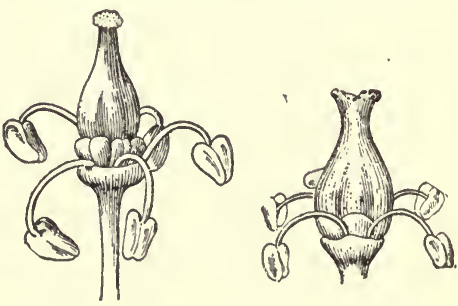

Fig. 61.-Flowers with short stamens. fact is constant.

According to Rathay the short-stamened flowers of cultivated vines are fecundated by the pollen of other vines with long-stamened flowers. If this were not so, nonsetting would take place. This was demonstrated very practically by the experiments of A. Jurie.* Short-stamened flowers are the rule in wild species with hermaphrodite fiowers. We will deduct conclusions' later on from these observations.

(c) Technique of Hybridization.-When we desire to cross two cépages, the flowering period of florescence of which is simultaneous, the operation is easy. But this case is the exception, especially in the hybridization between European and American vines. Certain American vines, such as V. 
Riparia, are in bloom a fortnight * or three weeks before the different V. Vinifera; others, such as V. Berlandieri, ten days to a fortnight after.

When the vine which is to furnish the male element flowers before the vine which is to be fecundated, we generally find flowers, resulting from late florescence (second crop), grown on secondary ramifications, which may furnish the pollen required for fecundating purposes. If the time between the periods of florescence were too great, it would be necessary to retard the flowering of the vine that was to furnish the male element. The best method, in this case, is to pinch back the shoots frequently; if this is done early enough new flowers are developed on the secondary shoots. We may also hasten the period of florescence of the female plant, or in other cases of the male plant (Berlandieri, Cinerea, etc.). For this purpose we may bring down the flowering shoots as close

*The tollowing are the extremes of flowering period observed for several cépages at the School of Agriculture, Montpellier-

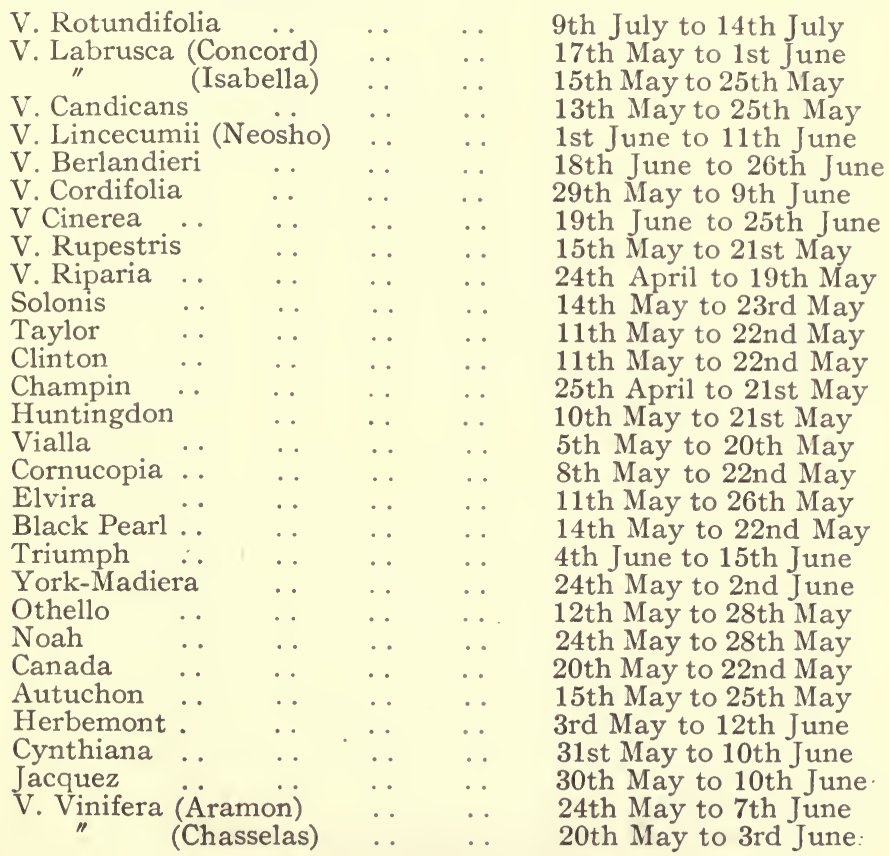


as possible to the ground, or place them under glass frames in the vineyard itself.

The simultaneousness of the florescence being assured, the male and female plants being decided upon, the bunch to be fecundated is chosen. It should be vigorous and normally developed, and when a few flowers begin to open, which are removed, is the best moment to proceed with the operation. We preserve, towards the centre of the bunch, 30 to 50 well developed flowers. With a small dissecting forceps, the cap of the corolla is seized, while exerting a slight pressure and pulling upwards at the same time. The petals become detached from their base, and, with a little skill, they are removed, together with all the stamens. If the petals were not removed by the first operation, they should be seized at their point of insertion, and successively disarticulated. When two or three petals are disjointed, the whole of the corolla is easily detached. We remove the stamens which did not become detached, and then ascertain, with a magnifying glass, that there is no pollen on the stignua. The operation being made on all the flowers, we remove that part of the bunch not used.

The bunches from the vine which is to act as male have been previously gathered in full bloom. They are shaken over the stigmas of the bunch to be fecundated, the stamens not naturally dehiscent are rendered so by exposure for a few moments to the direct rays of the sun (Millardet), we then ascertained, with a magnifying glass, if the stigmas are impregnated. The pollen, as shown by Millardet, may be gathered and dried in the open air for a few days previously, and preserves its fecundating power for ten days at least. This pollen dust may be spread over the stigmas of the prepared bunch.

The impregnated flowers may remain exposed to the open air, but it is better to take additional precautions. The bunch is isolated in a bag of gummed gauze, kept distended with a fine wire spirally arranged inside, so as to prevent foreign pollen from entering and affecting the results sought; for other pollen, with a greater sexual affinity, might fall on the stigmas and develop more rapidly. It is better to place in the gauze bag a fragment of the male flower, which would subsequently furnish pollen, if the fecundation had not taken place as desired.

A relatively short time is necessary for the pollen cell to germinate on the stigma, and for the pollen tube to travel 
through the short stylary channel of the pistil. Generally, as soon as the pollen tube has penetrated the ovule, the stigma and style die off. The gauze bag may, therefore, be removed soon after; but, as an additional precaution, it is allowed to remain on for a week. The fecundated branch is then isolated in a larger gauze bag until maturity, to avoid the destruction of the berries by birds, or accidents, etc.

It is not generally possible to recognise, from the berries themselves, if fecundation has taken place. As shown by Millardet, and often observed by the writers, the action of crossing on the fecundated flowers of different species is not apparent on the berries resulting from the fecundation. But this action takes place in the case of the crossing of two varieties of the same species (Metization), and was first pointed out by Henri Bouschet, who noticed that berries of Aramon and Chasselas, previously fecunclated with red juice cépages (Petit-Bouschet, Tinto), had red juices after fecundation, while the berries of the same grape, not fecunclated, still had white juice. The writers have themselves verified this fact with Rosaki and Chasselas fecundated with AlicanteBouschet; the fecundated berries of Rosaki and Chasselas, which are naturally white, had the juice in the skin reddish or red. These facts have not been observed in the crossing of two species (hybridization).

(d) Sowing and Selection.-The grapes are gathered when very ripe and left to dry, before the seeds are separated from the pulp. The following spring they are prepared by placing them in water to separate and select the seed; bad seeds float, good seeds sink to the bottom. They are removed, and left for 24 to 48 hours soaked in water, and are then stratified for twenty days in slightly damp sand.

It is better to sow the seeds in large flower-pots, filled with rich mellow soil, or with well decomposed mould. The seeds are thus easier attended to than when in a nursery, where other seeds might accidentally fall in the beds, and cause confusion. When numerous hybridization sowings are made, great care must be exercised in labelling, and the seeds of a given species should be isolated in one or several pots. The soil should be kept constantly moist, to assist the germination of the seeds, which are buried from $I \frac{1}{2}$ to 2 inches at most; the surface is covered with a mulching of partly decomposed stable manure. Germination generally takes place one month after sowing. If we can afford glass panes or glass houses the sowing should take 
place in February; if not, it should be done at the end of March or April. When the young plants are 2 or $2 \frac{1}{2}$ inches high they are hoed, to destroy weeds. The only care subsequently consists in maintaining the surface of the soil loose, and in giving during summer frequent but not abundant waterings. The young seedlings should be carefully protected from cryptogamic diseases by means of Bordeaux mixture and sulphur, as they are very sensitive when young.

The seedlings may acquire a relatively large development during the first year; they should be transplanted the following year, and planted at normal distances of 3 feet or, at least $2 \mathrm{ft}$. 6in. apart., We then begin to observe and select.

Selection, in view of obtaining graft-bearers, should be made with the objects of resistance to phylloxera, vigour, adaptation, affinity to -grafting, faculty of rooting from cuttings; and for direct-producers selections should bear on resistance to phylloxera, adaptation, fructification, productivity, taste, quality of fruit, precocity, and resistance to cryptogamic diseases.

Rooting of cuttings, affinity to grafting, vigour, resistance to cryptogamic diseases may be judged quickly and easily. Adaptation, as shown in the first part of this work, must be judged in the case of graft-bearers after they have been grafted, and this cannot be determined before the graft is three or four years old. The determination of the productivity takes longer, many seedlings only begin to bear fruit after $3,4,5$, or 6 years; but we may proceed more rapidly by grafting the shoots of young seedlings on vigorous stock, the grafting hastening the fructification. One may also, by selecting with care the most fructiferous shoots of hybrids with well constituted grapes, increase the productivity. It is also generally known that grafting on old stock is the most practical means of rapidly multiplying varieties which offer the sought qualities.

But, in any case, one of the most important studies is that of the relative resistance of hybrids to phylloxera, the main quality of any newly-created vine. Seven or eight years of close and attentive observation are required to judge perfectly the value of resistance of a cépage. Several methods have been proposed in order to arrive at this result rapidly. The most reliable method consists in planting the seedlings in soil naturally phylloxerated, or phylloxe- 


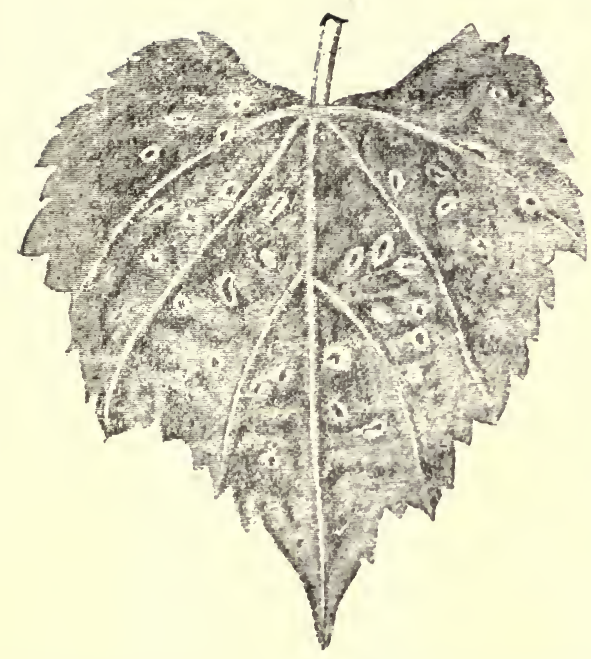

Fig. 62.-Upper face of a vine leaf, showing the opening of phylloxera galls.

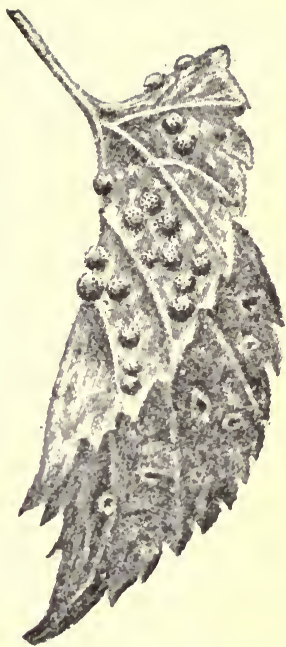

Fig. 63.-Side view, showing phylloxera galls.

rated artificially, by placing in the ground every year roots or leaves (with galls) covered with insects (Figs. 62 and 63 ). It is also necessary to plant at the same time rootlings of Rupestris, Riparia, Vialla, Solonis, Jacquez, York, etc., the resistance of which is known. This study must be carried out both in the open field and in artificial soils in pots. A comparative examination of the roots of the new cépages and those of the check known varieties enables an opinion to be formed on their resistance to phylloxera after a very short period. Only, before drawing definite conclu-sions, we must remember that many non-resistant vines have less nodosities on their hair roots than resistant vines. Every year the nodosities and tuberosities (Figs. 64, 65, 66, 67,68 ) of the roots of the young seedlings must be examined, to ascertain if they offer a sufficient guarantee of resistance. It is better, although not indispensable, to plant them in relatively dry soil, so that the action of the soil in no way interferes with that of the phylloxera. If, during several years, we notice that the roots have no tuberosities, but only nodosities, in presence of phylloxera, the resistance is almost certainly assured. It is certainly better to notice a few nodosities on the roots than no lesion at all, for this would prove that the insect had not been able to develop in the 
soils where the hybrids were tried. This is the more readily granted as the absolute indemnity of American vines and

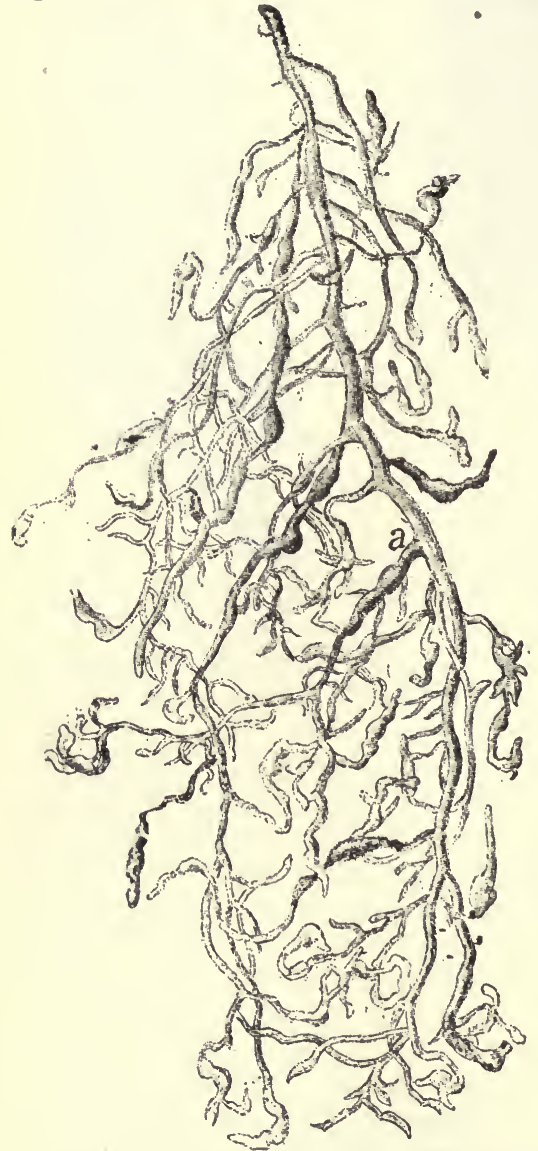

Fig. 64.-Nodosities and Tuberosities (a) on vine roots. therefore of their hybrids with $V$. Vinifera does not exist, except, perhaps, for the Muscadinia and Ampelosis.

(e) Crossings and Combinations.-Is it possible to give precise rules helping to forsee the results sought, and to direct the work of hybridization? The numerous works on this subject, made on different plants, by Darwin, Gärtner, Wichura, Decasine, Naudin, Nietner, Nægeli, Focke, etc., have only determined the general conditions of hybridization and the results obtained, but do not enable any fixed mathematical rule to be deducted, defining in what proportion the combination, fusion, or juxtaposition of characters and properties of plants united in individuals resulting from their crossings takes place. The result of the diverse combinations obtained by hybridizing vines is certainly difficult to indicate-_" It is yet a very obscure subject," says Millardet, " upon which we cannot throw light until many years' observation complete our actual experience."

There are, however, numerous facts definitely known, which may be foreseen almost with certainty, and which have been discovered by Millardet. We consider it useful to rapidly enumerate these, examining them from the point of view of 


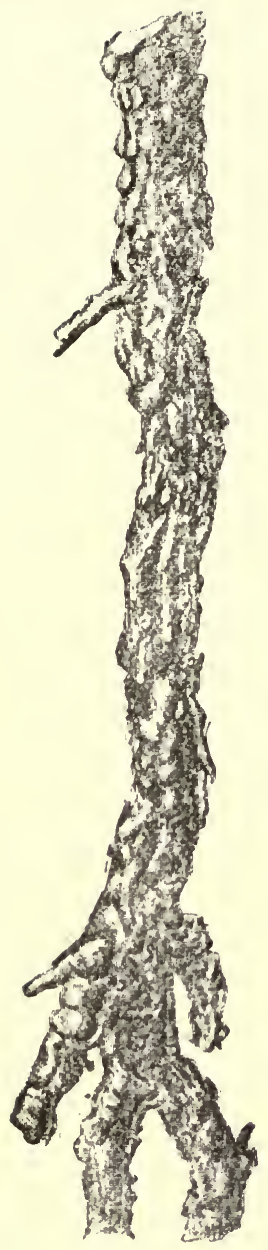

Fig. 65

Large penetrating tuberosities.

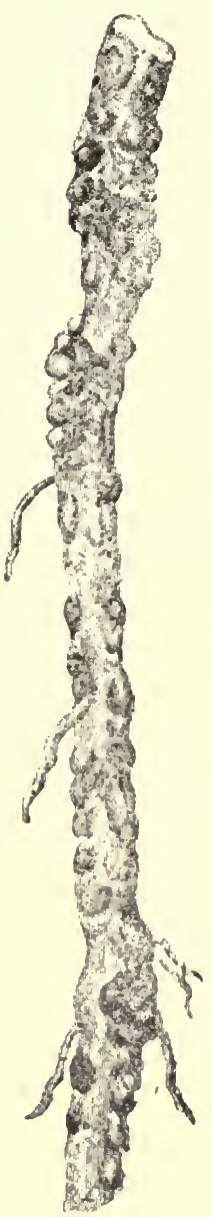

Fig. 66

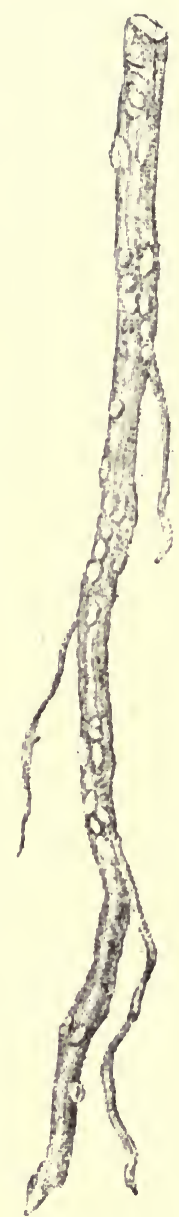

Fig. 67.

Large tuberosities.
Non-penetrating tuberosities.

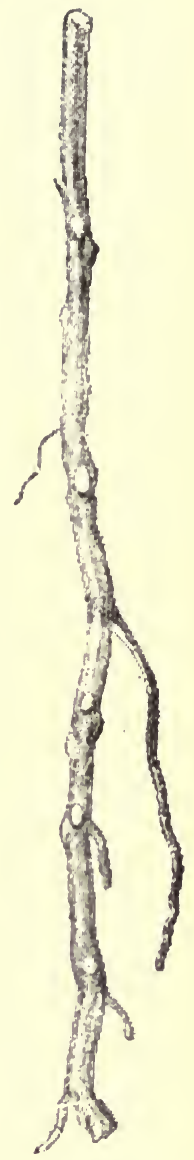

Fig. 68.

Non-penetrating tuberosities on Inroots of

American vines.

resistance to phylloxera, adaptation, affinity to grafting, and proclivity of hybrids resulting from crossings between American and European vines.

The first fact to be taken into account in hybridizations, is that relating to the sterility of the pollen of flowers with 
short stamens, that is to say, of all hermaphrodite flowers of wild vines. If the observations of $\mathrm{E}$. Rathay are confirmed, as they appear to be in a great many cases, the pollen of these flowers should not be used as male element in fecundation, as it seems probable that it is apt not to germinate.

Millardet has brought forward an important fact, confirmed by other experimenters, and which seems well established as far as the transmissions of resistance to hybrids is concerned. Firstly, it is evident that the resistance of Vinifera hybrids will always be inferior to that of the American vines used in the crossing, but that it will be more pronounced as the American vine used is more resistant; a Vinifera $X$ Rupestris should à priori be more resistant than a Vinifera $X$ Californica. There may be exceptions,-we will meet them in all the cases we are going to study; absolute fixity in the results obtained with the same elements of hybridization does not exist, but it is none the less true, however, that there is a relative fixity resulting from the elements entering into the combination. The most important fact to remember, from this point of wiew, is that relating to Americo-American hybrids. It is undeniable, and demonstrated by facts, that hybrids resulting from the union of resistant American species between themselves offer a constant guarantee of resistance, which is never the case when the element Vinifera enters into the combination.

What has been said for resistance applies, although in a less positive manner, to vigour. A given Vinifera united to a Rupestris and Mustang, or a Monticola and Estivalis, will give rise to products, Vinifera $\times$ Rupestris, Vinifera $\times$ Candicans, more vigorous than Vinifera $X$ Monticola, or Vinifera $X$ Estivalis; however, exceptions are more numerous in this case than in the above.

It is also well known that when an American vine, Rupestris, for instance, is used as a male element, the offsprings resulting from its union with a Vinifera are all the more resistant and vigorous as the pollen has been taken from an individual with male flowers, or, but to a lesser degree, from individuals with long stamens, if such exist among wild vines.

Finally, from the same point of view of resistance (the recent observations by Millardet, as well as those made by the writers on numerous hybrids at the School of Agriculture, Montpellier, throw new light on this subject), the combination of the two elements of hybridization has considerable 
importance. When the American resistant vine plays the part of male, the resistance is generally more pronounced than in the opposite case; a Vinifera $\times$ Rupestris is, as a rule, more resistant than a Rupestris $X$ Vinifera. In this latter case of hybridization, in which the Vinifera plays the part of male, the offspring are generally fecund and fructiferous.

The affinity of hybrids to the grafting of different varieties of Vinifera is so much the greater as the parents have themselves more affinity for those varieties. For instance, a Labrusca $\times$ Rupestris will have a more pronounced affinity than Rotundifolia $X$ Rupestris. All binary hybrids containing the element Vinifera will have more affinity for European vines than a pure American species or binary American hybrids, and so much the more that the American species has itself a greater affinity. A Labrusca $X$ Vinifera or a Berlandieri $X$ Vinifera would have more pronounced properties of affinity for Vinifera than hybrids Rotundifolia $X$ Vinifera or Lincecumii $X$ Vinifera.

As for adaptation, one may evidently foresee that the combined elements will give to the resulting combination their required properties. The study we are going to make of the hybrids will prove this conclusively. As the Vinifera grows under almost any conditions, we can forsee that the hybrids between Vinifera and American species will have a greater geographical area of adaptation than the species or hybrids between those species; for instance, a Vinifera $X$ Labrusca or a Vinifera $X$ Riparia will grow in a greater variety of soils than a Riparia $X$ Labrusca. And, again, a Vinifera $X$ Berlandieri will have to a greater degree the property of adaptation to chalky soils than a Vinifera $X$ Rupestris or a Vinifera $X$ Riparia for instance, and our numerous experiments prove that this is really a fact.

But here, as in any other case, exceptions may exist, the individuals resulting from crossing not only inheriting the properties of their parents, but also acquiring new properties. A few important cases will be studied in the chapter on adaptations (Solonis, Riparia $\times$ Rupestris, etc.).

$\mathrm{Up}_{\mathrm{p}}$ to the present we have only considered hybrids resulting from the union of two species or binary hybrids. As for hybrids produced by more complex combinations, by the union of three, four, or five distinct species, it is not easy to state definitely the results that would be obtained. We may expect that the predominant species will impress on the 
hybrids their specific properties. But here exceptions may still be more numerous than in the previous case, on account of variations resulting in the sowing of ternary, quarternary, or more complex hybrids, from phenomena of reversion and atavism.

Finally, there is a fact, shown, we believe, for the first time in I886, by Millardet, relative to the creation of resistant hybrid direct-producers. This fact is not so well proved as the former, but our observations, together with those of many hybridizators, seem to render it probable. We have stated that hybrids between European and American vines in which the American vine plays the part of male are generally little fructiferous and very resistant, and that, on the contrary, those in which the Vinifera plays the part of male are little or not resistant and more fructiferous. The fixation of the productivity in binary hybrids seems, therefore, difficult to obtain. Ternary or more complex hybrids, with Vinifera as dominant element, may, perhaps, allow us to attain this end, but their resistance seems very difficult to obtain, if we judge from results actually acquired.

It is, however, certain that sowing, without new hybridization, the seeds of hybrids individual to the first degree will enable us, more than any new hybridization, to obtain fructiferous and, perhaps, resistant individuals. The partial variations, resulting from numerous and complex phenomena of reversions and atavism, are produced in this case in a much higher degree and in greater diversity; it is, therefore, among these partial variations that we will with greater certainty obtain fructiferous and resistant vines.

\section{B.-HYBRIDS OF AMERICAN VINES.}

(Americo-Americans.)

Hybrids of V. Labrusca and V. Astivalis.-The hybrids of V. Estivalis and V. Labrusca are rare in America in their wild state; they are only vigorous in sandy and rich soils. They have not been introduced into France, and do not seem to present any cultural interest.

York-Madeira.-In this group we may mention, according to Millardet, the York-Madeira (Fig. 69), one of the first varieties imported into Europe, probably before the time of the invasion of oidium. It is almost unknown in the United States. Its 


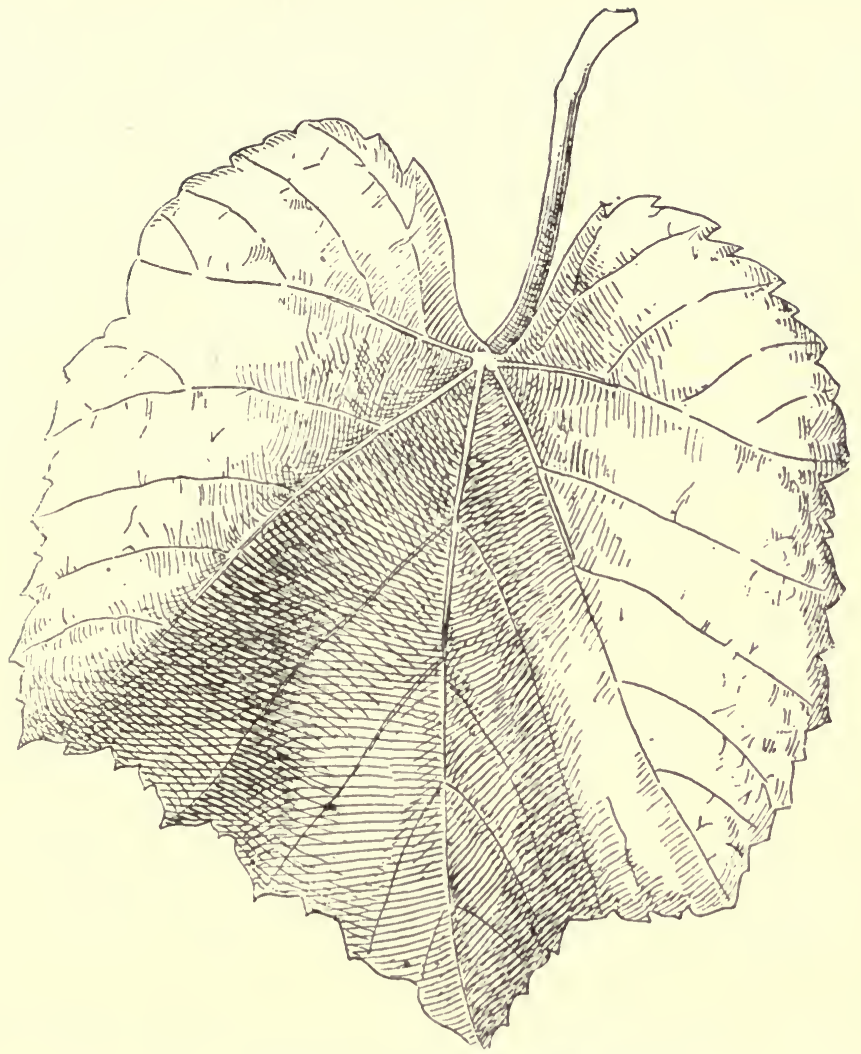

Fig. 69.-Leaf of York-Madeira.

resistance to phylloxera, contrary to what has generally been said, is not high, and may be represented by the number II. Its development is slow, even under conditions where the phylloxera does not check it. It only thrives well in northern regions, where it is an excellent graft-bearer, but only in fresh, pebbly soil, composed of siliceous or hard calcareous pebbles; it is equal in vigour to other graftbearers in stiff clay-siliceous soils. But, under these conditions, Rupestris is far superior.

In slightly fertile soil the York-Madeira remains very weak; its grafts are not vigorous, although they bear much fruit, but the fruit does not ripen well. In chalky calcareous 
soils it rapidly becomes yellow; it has, however, a certain resistance to chlorosis in good groies soils, but its vigour in such soils is too feeble to allow its utilization, notwithstanding its free rooting, and the perfection of the knitting it gives when grafted with almost all European varieties. It owes its facility of growing from cuttings to its parent, $\mathrm{V}$. Labrusca. To sum up, it is a graft-bearer which succeeds in the soils of the northern regions, where certain Rupestris varieties succeed also, with the advantage of being far superior. In warm regions phylloxera depresses it, except in fertile moist soils, where the Riparias are always far superior to it.

Its grapes are very foxy and harsh; it cannot therefore be used as a direct-producer. It is, however, cultivated for its fruit in some parts of Italy, where the rural population put up with it, for want of something better.

Hybrids of V. Labrusca, V. AEstivalis, and V. Cinerea.-In this group there are comprised, according to Millardet, cépages considered as pure Æstivalis, such as Cynthiana, Norton's Virginia, Hermann, Pauline. We will mention the three hybrids: Concord $\times$ Cynthiana, raised by T. V. Munson, Balsiger's (Cynthiana X Martha), Gold Coin (Cynthiana $X$ Martha). These three hybrids (Estivalis $X$ Cinerea $X$ Labrusca) are creations without interest for us.

Cynthiana, Hermann and Pauline are affected to a high degree by calcareous soils; they have therefore preserved the special properties of the two principal species they originate from and also that of V. Labrusca, if, as Millardet thinks, this species has played any part in their procreation. Their resistance to phylloxera is as follows:-

$$
\begin{array}{lllllll}
\text { Cynthiana } & \ldots & \ldots & \ldots & \ldots & \ldots & 14 \\
\text { Hermann } & \ldots & \ldots & \ldots & \ldots & \ldots & 10 \\
\text { Pauline } & . & . & . & \ldots & \ldots & 12
\end{array}
$$

Hermann and Pauline have never existed except in collections, but the Cynthiana has been propagated in some French vineyards, exclusively as a direct-producer, on account of its clean taste, and the deep and bright colour of its wine. In France it has only been a success in red pebbly siliceous soil; it is in soil of this nature that it is almost exclusively cultivated in America, more particularly in Virginia. But, in dry and warm regions, the Cynthiana, even when in such 
soils, does not grow; it requires a temperate, rather cold climate; for instance, it has given satisfactory results in the granite soils of the north of Drome, while it grows poorly in the Alpine diluvium of the south of France. This vine is practically abandoned nowadays, and will never be $t$ sed again for reconstruction. The Rupestris grow better in soils where the Cynthiana could succeed. It is difficult to grow from cuttings, as applies also to $\mathrm{V}$. Cinerea and $\mathrm{V}$. Estivalis.

Hybrids of V. Labrusca, V. Estivalis, and V. Rupestris.-These are crossings between York-Madeira and Rupestris. Obtained artificially in France, some of them possess a certain degree of resistance to phylloxera; but, like their procreators, they are greatly affected by calcareous soils, they become yellow the first year of planting out, and the second year, even when not grafted, have partially disappeared. This group of hybrids cannot, therefore, furnish any graft-bearers suitable for calcareous soils.

Hybrids of V. Labrusca, V. AEstivalis, V. Rupestris, and V. Riparia.-These hybrids are the result of the crossing of York-Madeira with Riparia $X$ Rupestris. The strain imparted to them by the Fstivalis and Labrusca lessens the properties of adaptation which might have been transmitted by the Riparia $X$ Rupestris. They become yellow rapidly in the calcareous soils of the Charentes, and are therefore useless.

Hybrids of V. Labrusca and V. Cordifolia.-A few of these hybrids are found, in a wild state, in places where the two species are mixed (rich siliceous soils), in the northern states of America and especially in Virginia. They have not been tried in France, but their origin enables us to assert that their value of adaptation would be inferior to that of other well-known graft-bearers.

Hybrids of V. Labrusca and V. Riparia.-These wild hybrids are very numerous in the forests of the littoral of the Atlantic, in America; very numerous also are those artificially created by hybridization. The former have not been introduced into France; and, further, they are of little value. Like Labrusca and Riparia, they grow in fertile siliceous soil. 
Amongst the cépages which, as shown by Millardet, are hybrids of $\mathrm{V}$. Riparia and $\mathrm{V}$. Labrusca, we will mention: Taylor and its seedlings:-Noah, Elvira, Faith, Transparent, Montefiore, Amber Queen, Etta, and Elvira No. Ioo of Jæger (the two latter are seedlings of Elvira); Clinton and its seedlings:-Vialla, Black Pearl, Bacchus, Ariadne, etc.; finally, Oporto, Blue Dyer, Uhland, Marion, Conqueror, Sack, Ironclad, Luty, Ferrand's Michigan, Missouri Riesling, Grein's Golden, etc.; and a series of forms which are certainly Riparia hybrids, and possess to a very great degree the characters of Labrusca, such as Catawba and its seedlings:-Diana, Iona, Mottled, Jefferson (hybrid of Concord $X$ Iona). We may also mention more complex hybrids, such as Empire State (Clinton $X$ Hartford Prolific), etc.

The V. Labrusca transmits through its hybrids a great affinity for grafting, 'a large trunk, but also a limited resistance to the attacks of phylloxera, the more limited as the influence of the Riparia is less pronounced (Ironclad, Luty, Missouri Riesling, Catawba, Diana). Most of them, however, are more resistant than V. Labrusca. The following, are the relative resistances of the principal of these:-

$\begin{array}{llr}\text { Taylor } & . & 13 \\ \text { Noah } & . & 14 \\ \text { Elvira } & . & 10 \\ \text { Clinton } & . & 8 \\ \text { Vialla } & . & 12 \\ \text { Black Pearl } & \ldots & 12 \\ \text { Bacchus } & . . & 8\end{array}$

$\begin{array}{llr}\text { Operto } & . & 12 \\ \text { Blue Dyer } & . & 9 \\ \text { Uhland } & . & 9 \\ \text { Marion } & . & 16 \\ \text { Catawba } & . & 4 \\ \text { Diana } & . & 4\end{array}$

These hybrids have larger roots (Taylor, Clinton, Vialla) than V. Riparia, owing to the action of V. Labrusca. Like the species they originate from, they do very badly in calcareous soils (Vialla), although better than V. Labrusca.

Taylor.-The Taylor has been much used as a graft-bearer; it constitutes important vineyards in the south of France, which are actually twenty-four years of age, and have been grafted twenty-two years. The cépage is an excellent graftbearer, knitting very well with most European varieties, having a large trunk, imparting good productivity and early maturity to the grafts it bears. When grown in suitable soils (free, fresh, rich marls, or blue clay) it constitutes an excellent graft-bearer, and phylloxera does not weaken it too much; but in dry, poor, calcareous soils it rapidly succumbs 
to the attacks of phylloxera. It is one of the cépages which are only sufficiently resistant when they are adapted to the soil; its large roots allow it to thrive better than Riparia in compact soils. The Taylor is now actually abandoned for other graft-bearers, which are superior to it in the rare soils to which it is entirely suited.

The Taylor is less affected by chlorosis than cépages derived from V. Labrusca; as long as it is not too much phylloxerated it resists chlorosis even better than Riparia and Rupestris, for this reason it must be a more complex hybrid than assumed by Millardet; perhaps it has a strain of Vinifera.

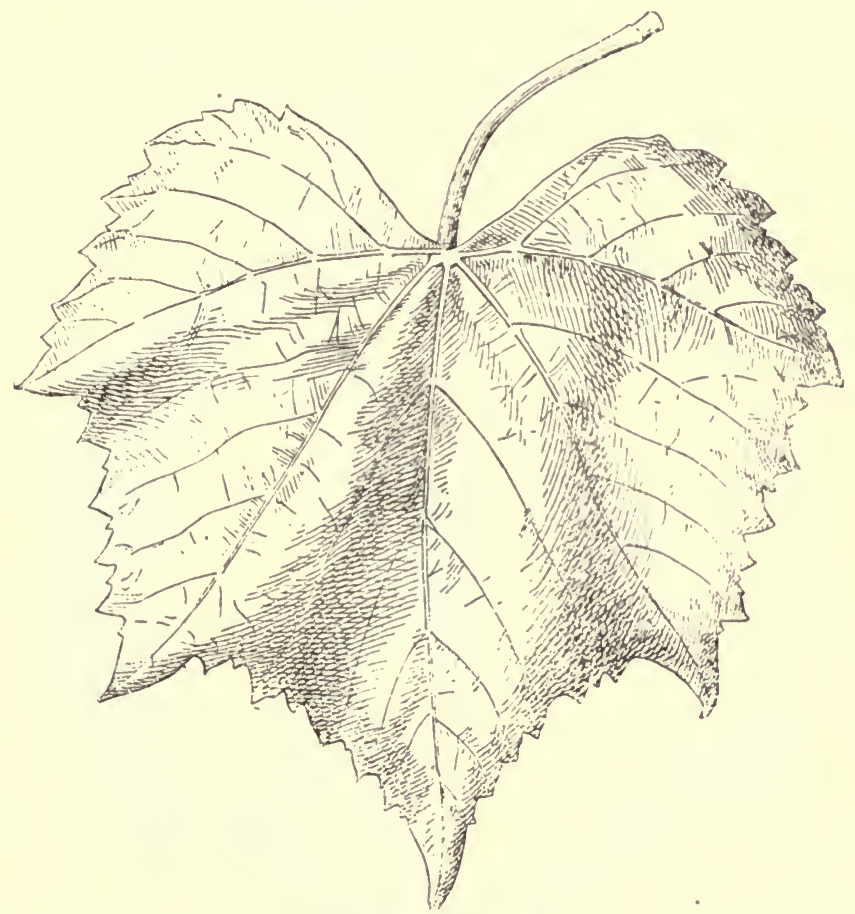

Fig. 70.-Leaf of Noah.

Noah.-A vigorous cépage (Fig. 70), having a large trunk, growing well in slightly compact, good, fresh soil, but greatly affected by chlorosis in calcareous soil, even when growing on its own roots. This is contrary to what is generally stated. As a graft-bearer it is much inferior to many others, and has no 
special merit. It is one of the most prolific American vines having white grapes, but its fruit is foxy, and the brandy made from its wine always retains a peculiar taste, which renders it unsaleable in commerce; as a cépage it is without actual value.

Elvira is still more productive than Noah, but its white grapes are foxy, and its resistance to phylloxera is very inferior; it is similarly affected by chlorosis in calcareous soil, and only thrives in very rich fresh soils, on account of its sensitiveness to phylloxera; it is, therefore, a valueless cépage, and has been long since entirely discarded. The Elvira No. IOO of Jæger is more prolific, but has the same original defects.

Clinton.-Before the knowledge and multiplication of Riparias, Jacquez, and Rupestris, etc., the Clinton (Fig. 7I)

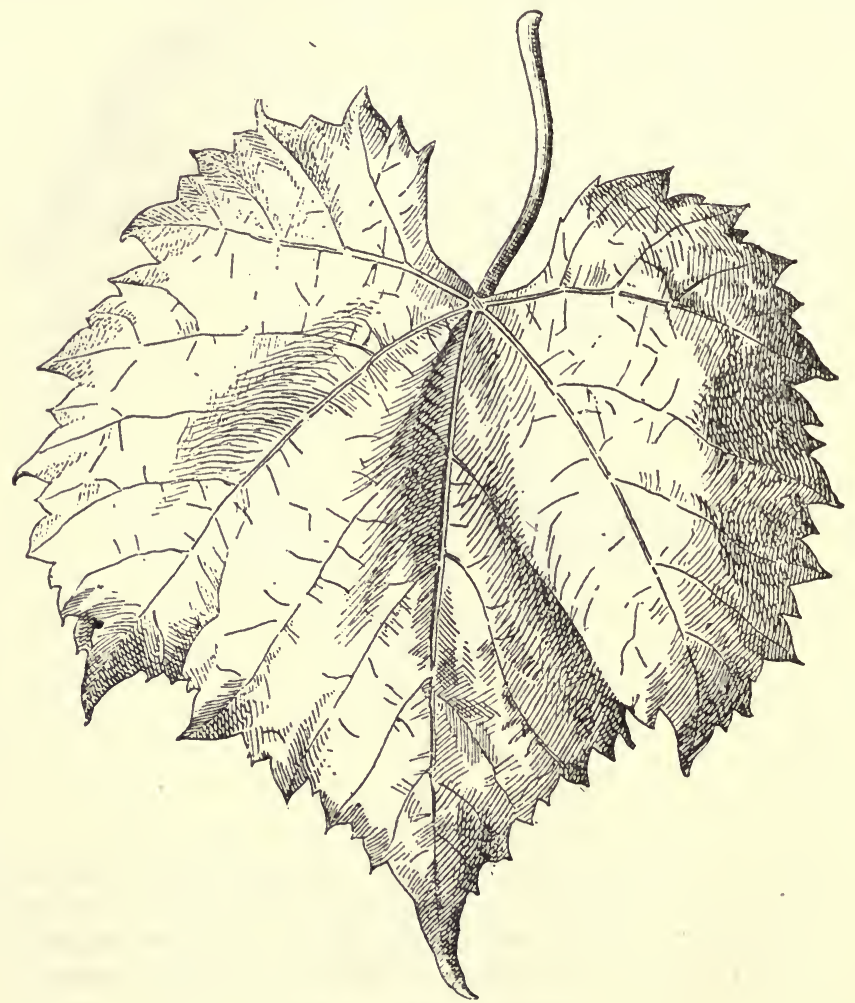

Fig. 7 r.-Leaf of Clinton. 
had been used as a graft-bearer in the south of France; it is now discarded, for in soils where it succeeds (mellow, fertile, deep, fresh, non-calcareous), Riparias are much superior to it, and much more resistant to phylloxera.

The Clinton furnished the first example of combined influence of adaptation and phylloxera. In calcareous and even in slightly fertile but dry soils, where its development cannot oppose the attacks of the phylloxera, it rapidly disappears. In soils to which it is perfectly adapted the insect. does not weaken it much. There are still in existence in the rich alluvials of the Hérault, grafts made on Clinton twentyfive years of age, generally very vigorous, except in very dry years, when the phylloxera is able to check its normal development.

The relative feeble action of the phylloxera accounts for the Clinton having been sold under the name of Plani Pouzin in certain non-calcareous regions of the Centre, and it has given fair cultural results as a direct-producer (Ardèche). It produces wines, however, which, although not very foxy, are inferior, and by grafting on Riparia we obtain, in regions suited to the Clinton, far superior results in both quality and quantity. The Clinton is now actually discarded in every region. Its sensitiveness to calcareous soils was noticed in America, in the islands of Lake Erie; it rapidly becomes distorted when in soft Devonian calcareous soils. In many regions in France, and especially in the chalky soils of the Charentes, it dies two years after planting out, even in the absence of phylloxera, and sooner than Noah or Vialla.

The Clinton roots freely from cuttings, and gives good knittings when grafted with most of the European varieties.

Vialla.-A cépage obtained from Clinton seedlings, propagated by Laliman, and named in honor of Louis Vialla (Fig. 72). Its hybrid nature was ascertained by Millardet. This graft-bearer has played an important part in the reconstruction of vines in the centre (France), and has been the standard, for instance, in the granitic and siliceous soils of Beaujolais; it thrives well as a graft-bearer in the north and centre, where its resistance is favoured by the climate and soil. In dry warm regions in the south of France, after a few successive dry years, the phylloxera weakens it, and may sometimes render its cultivation impossible; this was shown in the first part of this work. The Vialla was. limited to the centre, 
north, and south-west of France, and was exclusively cultivated in light siliceous soils. It was excluded, with good reasons, from all calcareous soils; amongst the graft-bearers which were most in use, it is the most affected by

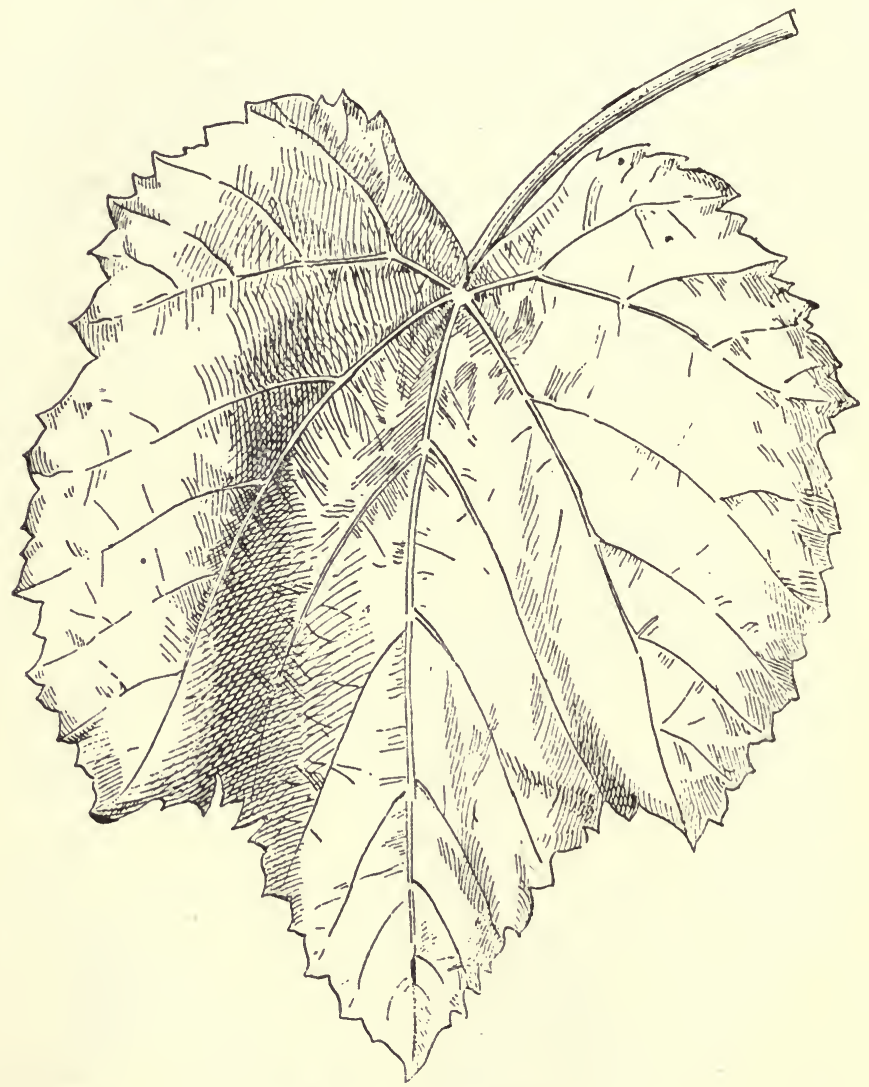

Fig. 72.-Leaf of Vialla.

calcareous soils. In siliceous and fairly fertile soil it has a very great vigour, and is one of those giving the best results; occasionally its excessive vigour causes non-setting. Of al! the American vines it roots most freely from cuttings, and the bench grafts give with it the highest percentage of knittings. 
The European scion knits well, the trunk remains large, the productivity is fairly great, and the maturation normal. It knits well with all French varieties, even with Gamay, which is known to be one of the most difficult to graft.

The Vialla has rendered undeniable services in siliceous or clay-siliceous soils, sound and rich, of the centre, north, and south-west of France, but the writers are of opinion that for the soils of these regions one may actually use graft-bearers having an equal adaptation and a much greater resistance to phylloxera,--Rupestris du Lot, Rupestris Martin, for instance.

Franklin greatly resembles Vialla, and has, from the points of view of adaptation and resistance, similar qualities and defects, but is inferior in vigour. Ferrand's Michigan is as vigorous as Vialla, and presents the same advantages; as also the Oporto, which is, perhaps, superior in vigour as well as in resistance to chlorosis, which its slight similarity to Riparia explains.

Several other hybrids of Riparia and Labrusca were obtained in France; they all have the same aptitudes as the former, as well as similar defects, varying in intensity according as they are nearer one or other of their procreators.

Hybrids of V. Labrusca, V. Riparia, and V. Rupestris.-Obtained artificially in France. Their resistance to phylloxera is greater than any of the previous, the Labrusca forming one quarter only in their constitution. They are not yet well known, and have so far only been experimented with in chalky soil, where they become very yellow.

Huntingdon is a hybrid of this group, propagated in several vineyards of the south-west and centre. This vine resembles the Rupestris very much by its leaves and habit, and the Labrusca by the disagreeable taste of its fruit. It is fairly fructiferous, but slightly vigorous only, and of no value whatever as a direct-producer. It is not too much affected by calcareous soils, and in some groies soils of the Charentes it grows vigorously, when not grafted, and unattacked by phylloxera. Its properties of adaptation results most likely from the combination Riparia $X$ Rupestris, which intervenes in its formation. 
Taylor-Narbonne.-This vine seems to be the result of a seed of Taylor, sown by Narbonne (Fig. 73). Despetis studied it with great care at his property, Yeuses (Hérault), where it gave indisputable results in calcareous soils, as fully explained in a detailed study published by Jules Pastre.

The general characters of the Taylor-Narbonne are very similar to those of Taylor. There has probably been a hybridizing influence of Riparia, endowing it with some of the characters of Riparia $\times$ Rupestris, which accounts for its relative resistance to calcareous soils.

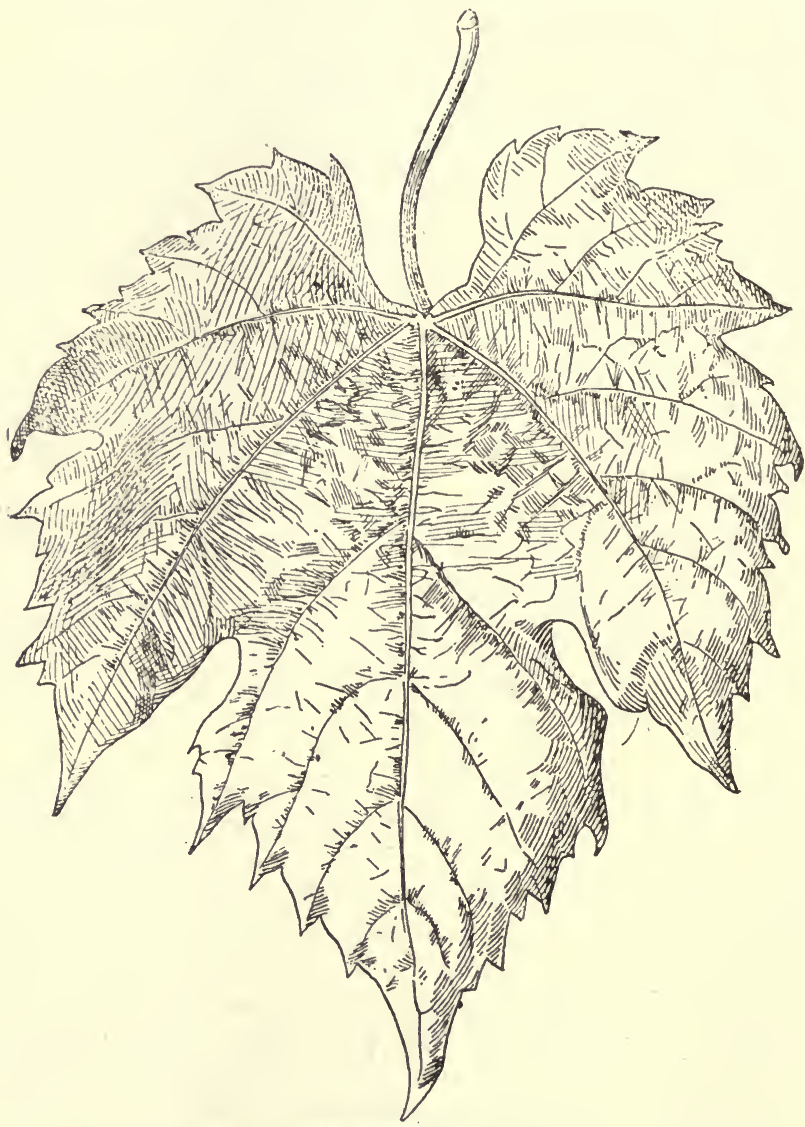

Fig. 73.-Leaf of Taylor-Narbonne. 
Whatever its real relations may be, the Taylor-Narbonne has a resistance to calcareous soils comparable and even superior to most Riparia $\times$ Rupestris. It may, therefore, from this point of view, be used in reconstitution. Despetis, who studied it during many years, thinks it has a high phylloxeric resistance; it is certainly superior to that of Solonis.

Figure 73 shows very clearly the characters of the leaf of Taylor-Narbonne, which are much more carved out than that of Taylor. This cépage is vigorous, its cuttings root freely, knit well with most European vines, and give fructiferous grafts. If its resistance to phylloxera is proved, it will ultimately be used in the same surroundings as Solonis was formerly and also in poor sandy soils free from salt.

Hybrids of V. Californica and V. Arizonica.-These hybrids are very numerous; a scale of successive forms intermediate between the two species has been found. They have almost always been introduced into France under the name of pure Californica or pure Arizonica, and have remained in collections; they are inferior in vigour to the Californica, and in resistance to the Arizonica. They seem to require richer soil than the latter, and are, therefore, of no interest. They succumb to chlorosis, like the Rupestris.

Hybrids of V. Candicans and V. Berlandieri.On account of the co-existence of Candicans and Berlandieri on the banks of the rivers and hills of Texas, on account also of the almost continuous florescence of the latter, a great number of hybrids have been produced in the wild state, between these two species. Intermediate between these two species are found, and almost in infinite number, many forms of Berlandieri, with abundant woolly hair on the young leaves and young shoots, considered thus far as pure; they are only hybrids of Candicans more or less defined. The Berlandieri Planchon is an example of this.

These hybrids are occasionally isolated on the chalky hills of Texas, where they are generally found in rich and fresh soils; a certain number, especially those which have preserved to a high degree the characters of the Berlandieri, are sometimes found in dry and slightly fertile soils, but rarely in marl and bluish-grey soils. And, what is more, the influence of the Mustang has diminished the resistance to chlorosis of the Berlandieri; this explains why the hybrids experimented with in the chalky soils of Cognac have been rather 
sensitive to chlorosis. The Mustang has also diminished the natural resistance of the Berlandieri to phylloxera but has endowed it with great vigour.

Certain hybrids of Berlandieri and Candicans (form Barnes) are vines of extraordinary vigour.

The Berlandieri $\times$ Candicans inherit the strong roots of the Mustang, and from both species the defect of not being easily multiplied by cuttings. T. V. Munson has, however, isolated three forms, named Berlandieri $\times$ Candicans No. $I$, No. 2, and No. 3, striking fairly well from cuttings and fairly vigorous. The following table gives the relative vigour and resistance to phylloxera, in fairly calcareous soils, for the principal forms of Berlandieri $X$ Candicans :-

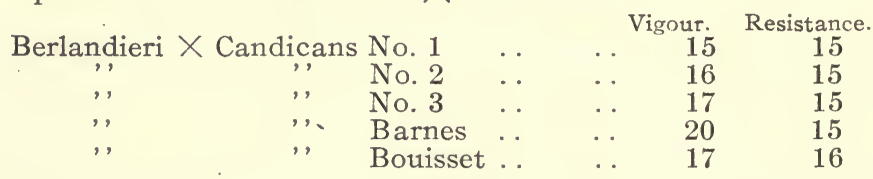

Experiments made in the chalky soils of Cognac have shown, what was to be foreseen, that these cépages have only a limited resistance to chlorosis. They should only be tried

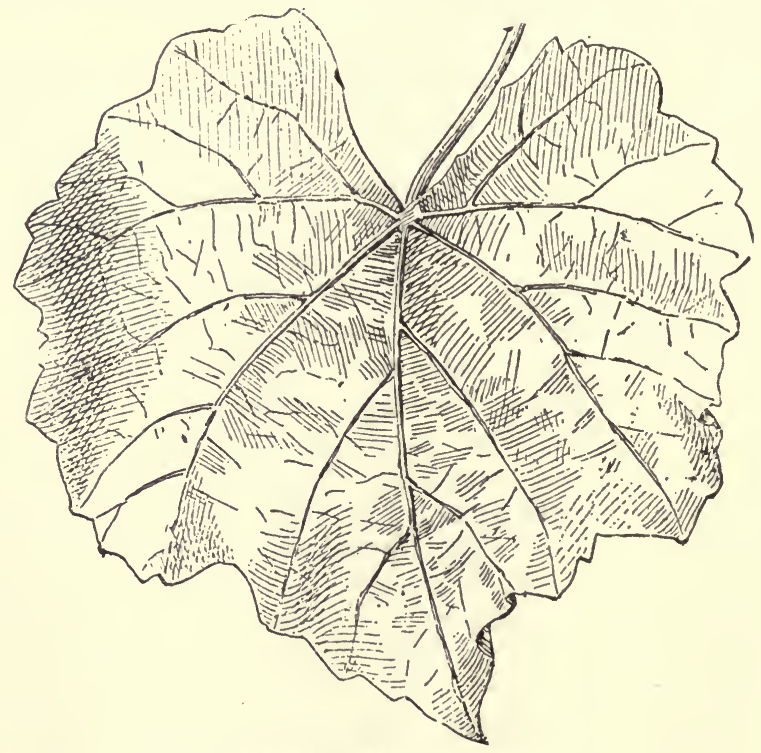

Fig. 74.-Leaf of Barnes. 
in certain whitish marly soils, in which the proportion of carbonate of lime is not too high.

Barnes.-A form isolated by T. V. Munson, growing badly from cuttings, of extraordinary vigour, with large trunk, strong canes, slightly fluted, of a blackish-brown colour. Leaves (Fig. 74) medium, very thick, sub-cordiform, slightly folded along the mid-rib, very green and lustrous; petiolar sinus open, deep $\mathrm{V}$ shape; under-face of a dull green, with fluffy hair on the principal ribs, which are strong and deprived of the stiff hair of the Berlandieri; teeth only slightly indicated by a mucron. Most of the Berlandieri $X$ Candicans have no stiff hair on the ribs. This form becomes yellow during the first year of planting out in the chalks of Cognac.

Berlandieri $\times$ Candicans Bouisset.-A form isolated and named by $T$. V. Munson; according to him it roots freely. This form is certainly a hybrid of Berlandieri and Mustang; it seems to be only slightly vigorous, and has become very yellow in the chalks of Cognac. Its habit is bushy; canes with short internodes, dull hazy colour, with slightly indicated flutings; numerous woolly patches of hair on the young shoots. The leaves are small, very thick, slightly folded along the mid-rib, sides plane, rudimentary teeth; petiolar sinus $\mathrm{V}$ shape, deep, wide; upper-face deep green, shining; under-face glabrous, lighter green, almost dull; petiole slender, with woolly hair.

Lady-Love.-A form isolated by T. V. Munson, and possessing many of the characters of the Mustang; canes fluted, similar to V. Berlandieri. Leaves medium or large, thick and plane, dull; petiolar sinus deep, lozenge shape: principal ribs covered with long woolly hair, and white on the under-face. This cépage has not been experimented upon in France, but does not seem to be superior to Mustang; it roots freely.

Hybrids of V. Candicans and V. Rupestris-These hybrids have existed for a long time in France; they were first isolated by J. E. Planchon, under the name of $V$. Champini or Champin vines. Their general characters are very similar to those of Monticola $X$ Candicans and ?erlandieri $\times$ Candicans. The Rupestris $\times$ Candicans comprise a very numerous series of forms intermediate between Rupestris and Candicans; some have the bushy habit, the small, shining, folded leaf of the Rupestris, others have the 


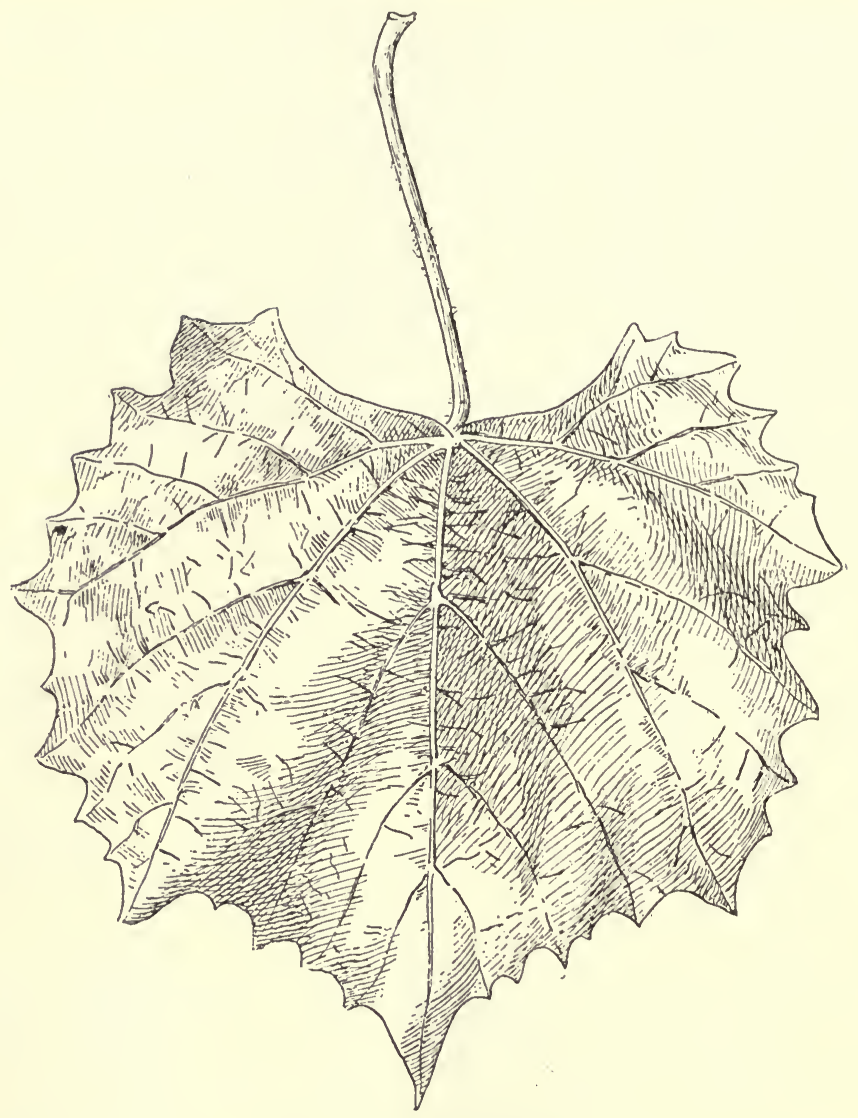

Fig. 75.-Leaf of Champin.

plane, thick, rather large leaf characteristic of the Mustang; they all have the fluffy hair on the young leaves and shoots peculiar to the Mustang. The forms with small shining leaves may be grouped under the name of glabrous Champin (Fig. 75); those with large tomentose leaves under the name of tomentose Champin. The former have a resistance of 14 : the latter, more vigorous, have, however, less resistance, due to the Mustang, which may be represented by I2. All these forms do not root freely from cuttings; the glabrous forms, however, root easier than the tomentose, which seems due to the predominance of Rupestris. They may, however, be 
very easily multiplied by summer layering, which has often been successfully done. Champin isolated five forms; four different forms were isolated at the School of Agriculture, Montpellier.

The Champins grow in Texas (environs of Cleburne), in cretaceous soils, blackish and pebbly, and also fairly rich and calcareous, with a subsoil composed of calcareous rock, hard and laminated, with reefs of bluish or white clay, or of the blue marl alternating. The following is the physical composition of these soils, analyzed by B. Chauzit:-

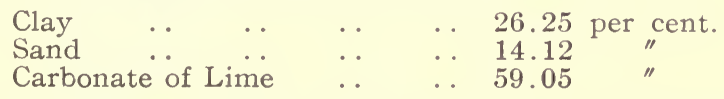

But the Champins have never been found in chalky soils.

They have resisted chlorosis in France much better than Riparias, or even Jacquez in fairly calcereous soils; in chalks, they become yellow without getting stunted, but soon die when grafted. In certain yellowish marls of the miocene of the south of France, the most vigorous forms have been grafted with different varieties since fourteen years ago. They have always given good results where Riparia and Jacquez disappeared under the action of chlorosis.

To sum up, the Champin possess a certain resistance to phylloxera very much inferior to Berlandieri or its hybrids; and, as they are less resistant to phylloxera, as their vigour is only equal or below that of the latter, there is no need for propagating them.

Hybrids of V. Candicans and V. Monticola.-These are as varied and as vigorous as the Berlandieri $X$ Candicans. "They grow in less rich soils than the latter, sometimes even in fairly calcareous soils, but they have never been found growing in the wild state in chalky limestone; they grow naturally in blackish-red soils, more or less deep, resting on fissured lithographic limestone. In such soils, dry and slightly fertile, one of the most interesting forms of these hybrids. the Monticola $\times$ Candicans of Belton, has an extraordinary vigour and trunk of wonderful dimensions. The characters of these hybrids present the whole scale of intermediates between the Mustang and Monticola. It is evident that the greater the influence of the Mustang the smaller the resistance to chlorosis, the greater that of the Monticola the less vigour. 
T. V. Munson has isolated two forms of these hybrids. One, the Gwyn grape, of the County of Lampasas, has medium, thin, lustrous leaves, with small patches of fluffy hair on the ribs of the under face, wide triangular sharp teeth. The other, the Sanford grape of the County of Bell, with small, thick, slightly tri-lobed, elongated leaves, plane, with very abundant whitish tomentum on the petiole and shoots, long hair on the principal ribs of the upper-face, and, araneous patches of hair on all the veins of the under-face. These characters show that in these two forms which root freely from cuttings, according to T. V. Munson, the Mustang predominates, which may throw doubt on the value of these cépages which have not been tried in France.

Belton.-This is the most interesting hybrid of this group, although it is rather difficult to propagate by cuttings. Its resistance to phylloxera is superior to that of

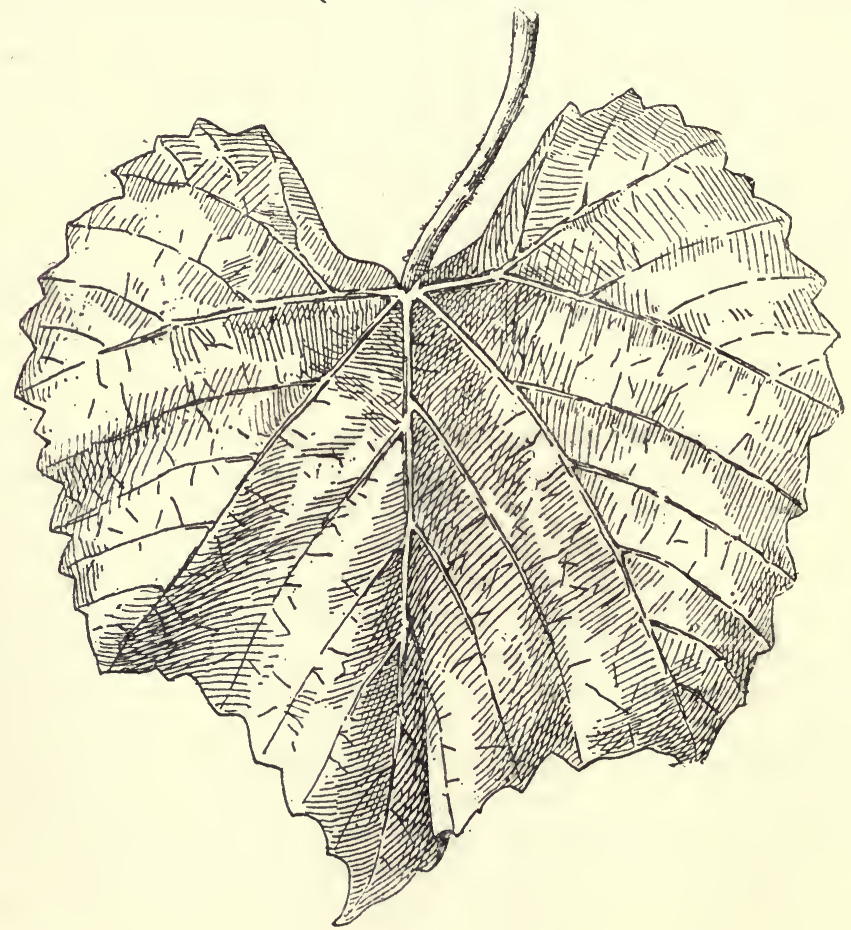

Fig. 76-Leaf of Belton. 
Solonis, and may be expressed by the number I6; its vigour, as already mentioned, is higher than that of the majority of American vines. In the chalks of Cognac this hybrid became yellow, although not grafted, but without becoming stunted. Its resistance to chlorosis is certainly inferior to that of V. Berlandieri, but it might be of some value for compact, fairly calcareous marls, for which it would seem to be indicated on account of its strong roots.

The Belton has strong, cylindrical canes, with numerous whitish, fluffy hairs. Its leaves (Fig. 76) are plane, thick, tough, the lateral lobes indicated by longer teeth, the terminal lobe triangular; teeth sharp, normal to the limb, like Monticola; upper-face dull-green, araneous hair on the principal and secondary ribs of the under-face. The consistence of the parenchyma and the aspect of the leaf seem to indicate a hybridizing action on the Berlandieri which would make the Belton, therefore, a ternary hybrid.

Hybrids of V. Candicans and V. Riparia.-These hybrids were indicated by Millardet and discovered by H. Jæger. Numerous wild forms of it are to be found in the north of Texas, on the banks of the Red River, in very fertile, sandy, red alluvials. It acquires, under these conditions, a very great development of the canes, and fairly large dimensions of trunk. An individual vine, cultivated since I888 at the School of Agriculture, Montpellier, has always had a remarkable development in a blue non-chlorosing clay. This hybrid may be of some value for compact clayey, but only slightly calcareous, soils. It roots freely and has a large trunk. Its leaves (Fig. 77) are large, plane, thick, orbicular, the five lobes indicated by longer teeth; petiolar sinus widely open, with straight sides; upper-face deep-green, varnished; underface dull-green, with numerous patches of long, araneous hair on ribs, petioles, and canes. Canes stout, vinous-brown, straight.

Hybrids of V. Candicans, V. Riparia, and V. Rupestris (?).-Certain forms of this numerous group of hybrids are connected with Riparia $\times$ Candicans, in a very distinct way, in their ampelographic characters; they constitute what T. V. Munson considered as a species, the $V$. NovoMexicana, and amongst them Solonis.

The Novo-Mexicana of Munson comprises a group of vines, rather than a unique form; most of them are similar to 


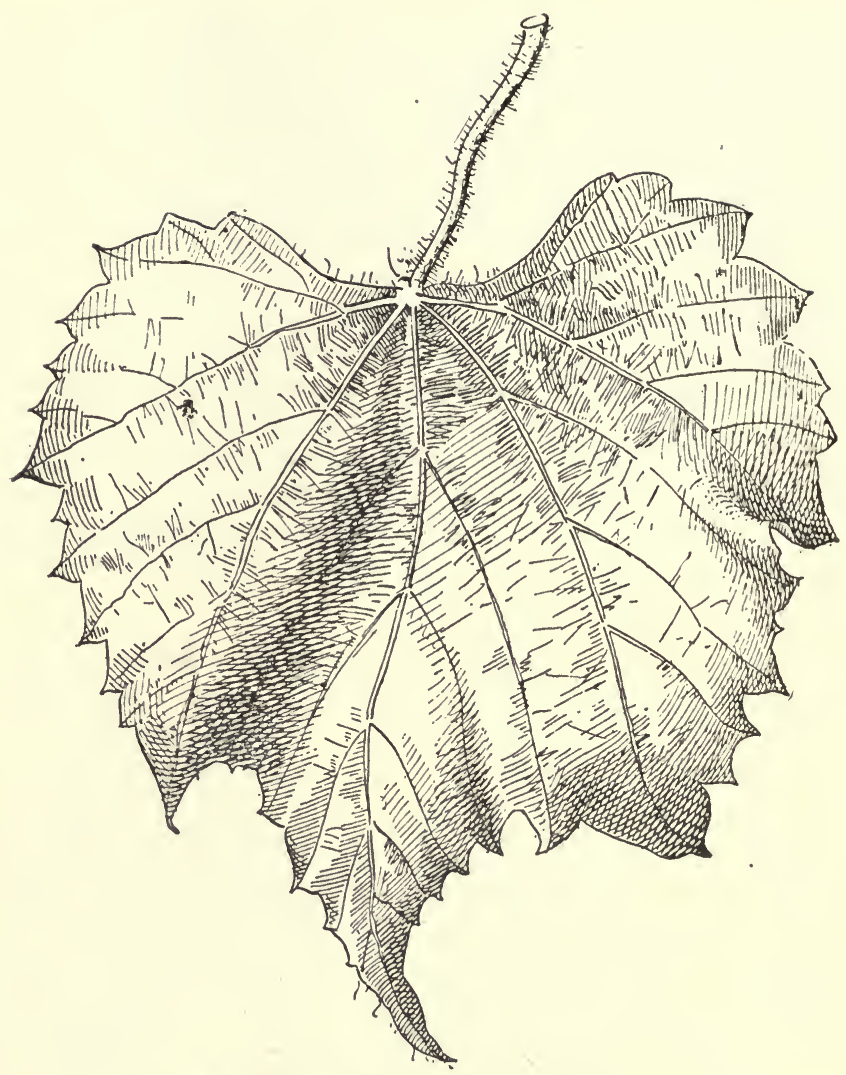

Fig. 77.-Leaf of Riparia X Candicans.

Solonis, and others differ only by the less dense tomentum or by the complete absence of hair; the general shape of the leaves, the acuteness and direction of the teeth are always those of the Solonis type. Certain forms of Novo-Mexicana only differ insignificantly from Riparia $X$ Candicans; they always have thinner leaves.

These hybrids remain fairly constant in their characters in the wild state over a fairly large zone. Their seedlings preserive the general characters rather well, which induced $T$. V. Munson to consider them as a species. They are obviously hybrids, in which the characters of V. Riparia and V. Candicans are easy to detect. Millardet considers, perhaps 
with reason, that these are ternary hybrids, into which Rupestris also enters. The Rupestris is not to be found in regions where the Novo-Mexicans grows, but Millardet gives an instance of Solonis seedlings with Rupestris characters. A forns of Novo-Mexicana, the Mobeetie, has very decided characters of $\mathrm{V}$. Rupestris.

The Novo-Mexicana and Solonis have been found growing together on the banks of the Red River, extreme north of Texas, in cretaceous soils. The soils of the banks of the Red River are generally rich, red, sandy, often moist, and always fresh; the subsoil is composed of white calcareous concretions, fairly hard, fissured, through which the roots penetrate. T. V. Munson has observed the Novo-Mexicana in lithographic limestones and in rather hard chalky soils, covered with a layer of rich blackish soil, of a thickness of I 4 to 16 inches. The Solonis and Novo-Mexicana grow naturally in soils containing a moderate percentage of carbonate of lime.

The Solonis is the only form of Novo-Mexicana experimented upon in France since the invasion of phylloxera, that is to say, since 30 years, and is one of the American vines which succeeded best in calcareous soils, with relatively low percentages of carbonate of lime, which accounts for the importance it had at the beginning of the reconstitution. In chalky, soft, and white limestone it generally develops well, as long as it remains ungrafted. It never becomes chlorosed to any extent, but when grafted it rapidly becomes stunted. In ground, the soil of which is calcereous, but fresh and deep ( I6 to 20 inches), resting on a chalky or white marly subsoil, where all other vines (Rupestris, Riparia, Vialla) become chlorosed and die rapidly, the Solonis has always given good results. Upon the whole, many calcareous regions have been reconstituted with success on Solonis, regions which it would have been impossible to reconstitute with any other then known cépage. Such were the Blayais, Charentes, south of France, Dordogne, etc. In moderately calcareous, but fresh and fertile soils, its grafts are fine, very fructiferous, ripening early. Many vineyards planted under these circumstances have now been grafted for nineteen to twenty-one years. And, moreover it is the best graft-bearer for damp or brackish soils; in the latter soils no other graft-bearers are superior. Graft-bearers are actually in existence (Riparia $\times$ Rupestris, Rupestris du Lot) almost equal to the Solonis so far as 
resistance to chlorosis is concerned, and possessing a high degree of resistance to phylloxera. They are to be preferred to Solonis, except in the case of damp or brackish soils.

The Solonis and other forms of Novo-Mexicana do not owe their resistance to chlorosis to the species they originate from; we are therefore forced to admit that this property is an independent character, acquired by an actual selection in the surroundings where they naturally grow.

All this group of hybrids comprise forms which root freely from cuttings, are vigorous, and have a large trunk. Their resistance to phylloxera is certainly not very high; the Solonis have even been used as a limit in the study of resistance to the insect. It bears numerous nodosities and tuberosities, sometimes penetrating, followed by grave consequences. The phylloxera weakens Solonis to such an extent that sometimes in dry and only slightly fertile soils it occasions its death. In soils to which this cépage is well adapted, phylloxera has practically no action on it. Vineyards of seventeen to thirty years old, which were grafted from thirteen to nineteen years ago, are still in existence in the Hérault, Gironde, Dordogne, where they still remain fine and vigorous. To sum up, Solonis has only withered when grafted in very calcareous, very poor, or very dry soils.

We consider it necessary to give the distinctive characters of the principal cépages of this group. The description of Solonis will serve as a term of comparison.

T. V. Munson selected, amongst Novo-Mexicana, many interesting forms of great vigour, more resistant than Solonis and of perhaps equal resistance to chlorosis. The two principal are the Novo-Mexicana Hutchison and the Novo-Mexicana Mobeetie. The Hutchison has great analogy to the Solonis, but is more vigorous; the Mobeetie has characters approaching closer to Rupestris than any other form of this group. The Novo-Mexicana forms D, Microsperma, No. 43 and $C, N o .56$, and Solonis Microsperma, are of much inferior vigour to the other three forms. We will mention also in this group a form which seems to be rather a hybrid of Riparia $X$ Candicans than a Riparia $\times$ Rupestris $\times$ Candicans, a form which T. V. Munson considered to be a species, the Doaniana.

The following is the comparative scale of resistance and 
vigour of these forms, studied in a collection planted in clayey-calcareous soil at the School of Agriculture, Montpellier, the vines being of the same age :-

Solonis

Solonis with lobed leaves

Hutchison

Mobeetie

Doaniana

$$
\begin{array}{llcll} 
& \multicolumn{3}{c}{\text { Vigour. }} & \multicolumn{2}{c}{\text { Resistance. }} \\
\ldots & \ldots & 18 & \ldots & 14 \\
\ldots & \ldots & 19 & \ldots & 13 \\
\ldots & \ldots & 20 & \ldots & 15 \\
\ldots & \ldots & 17 & \ldots & 16 \\
\ldots & \ldots & 12 & \ldots & 12
\end{array}
$$

Solonis.-Stump vigorous, habit spreading, trunk strong. Canes long cylindrical, with patches of whitish hair, lightbrownish grey when lignified. Leaves (Fig. 78) medium,

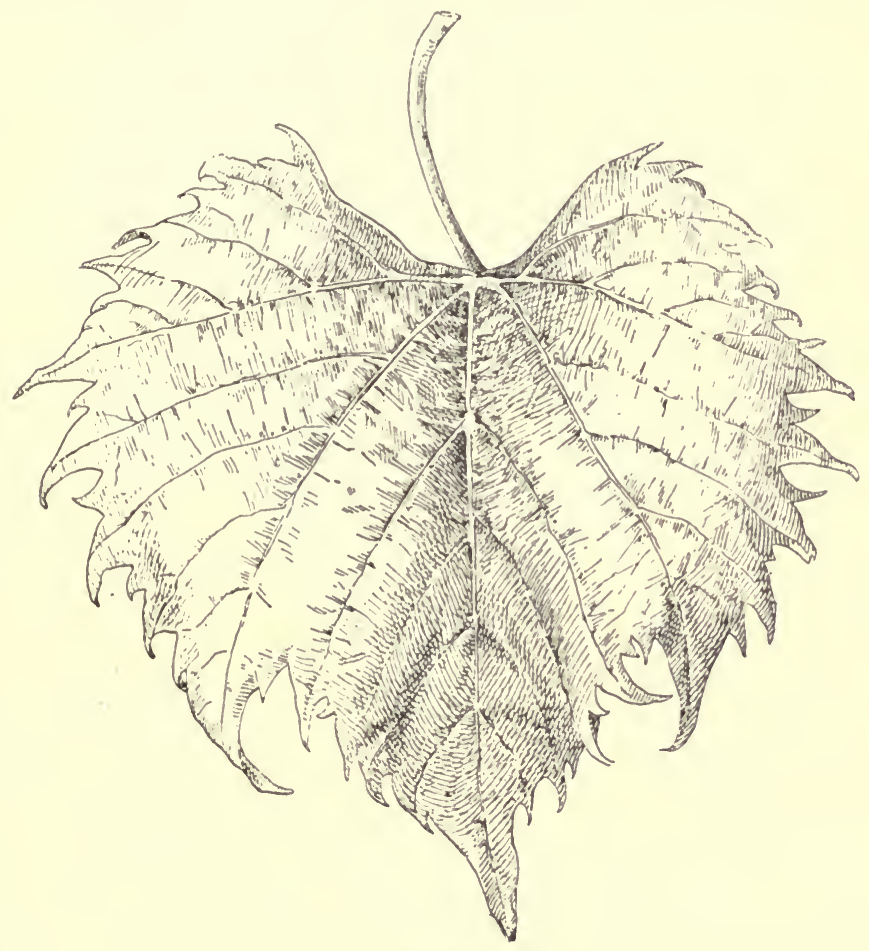

Fig. 78.-Leaf of Solonis.

entire, teeth acute, in two series; the longer ones indicating the lobes; those of the two inferior lobes converging towards the axis of the leaf, which is folded along the mid-rib, the 
extremity of the terminal lobe curved underneath; petiolar sinus shallow, widely open; limb glabrous on both faces, stiff whitish hair on the veins of the under-face, disseminated patches of fluffy hair on the petiole and the veins of the upper-face, upper-face glaucous green, under-face paler green. The Solonis with lobed leaves differs in its three lobed limb, and less acute teeth; it is not superior in vigour or facility of adaptation, to the true Solonis type, and its resistance is less. We will also quote, according to Vermorel, the Solonis Feytel which is not of greater value than the Solonis.

Hutchison.-Stump very vigorous, trunk very strong. Canes straight, medium size, grey-cinnamon colour; young shoots purple rose colour, covered with a white woolly tomentum extending on to the petioles, tendrils, and upperface of young leaves. Adult leaves, thick, longer than wide, slightly folded along the mid-rib, teeth acuminate, in two series like the Solonis, but the curve being less pronounced at the summit of the lobes; upper-face greyish-lustrous green with a few patches of araneous hair; under-face light lustrous green, with prominent ribs; petiolar sinus widely open, $\mathrm{V}$ shape.

Mobeetie.-Stump vigorous; canes long, straight, cylindrical, dull cinnamon-red colour, with well defined fluting. Leaves (Fig. 79) large, orbicular, as long as wide, entire, the terminal lobe longer, slightly folded along the mid-rib, fairly thick; upper-face glaucous green, lustrous, with disseminated patches of araneous hair; under-face lighter green, lustrous, with numerous stiff hairs on principal and secondary veins; petiole long and slender, with patches of white araneous hair; petiolar sinus deep, open U shape.

Doaniana.-T. V. Munson discovered and named the Doaniana, in 1887 , in the north of Texas (Panhandle), where this vine grows mixed with Candicans hybrids, especially Novo-Mexicana. As he found this vine growing over a considerable area and with constant characters, he thought it constituted a species, which he named $V$. Doaniana.

The various forms of Doaniana have, it is true, very peculiar and definite characteristics, the habit, for instance, and the character of the leaves recall certain French cépages. When the ampelographic characters of the Doanianas have been carefully studied in detail, one cannot doubt any longer of their hybrid nature; their relationship with Mustang is very positive in the characters of the fruit, the seed and the 
tomentum of the leaves (Fig. 80); the form which T. V. Munson named Later Doaniana is very close to Mustang. The leaves of this form and of another variety, the most

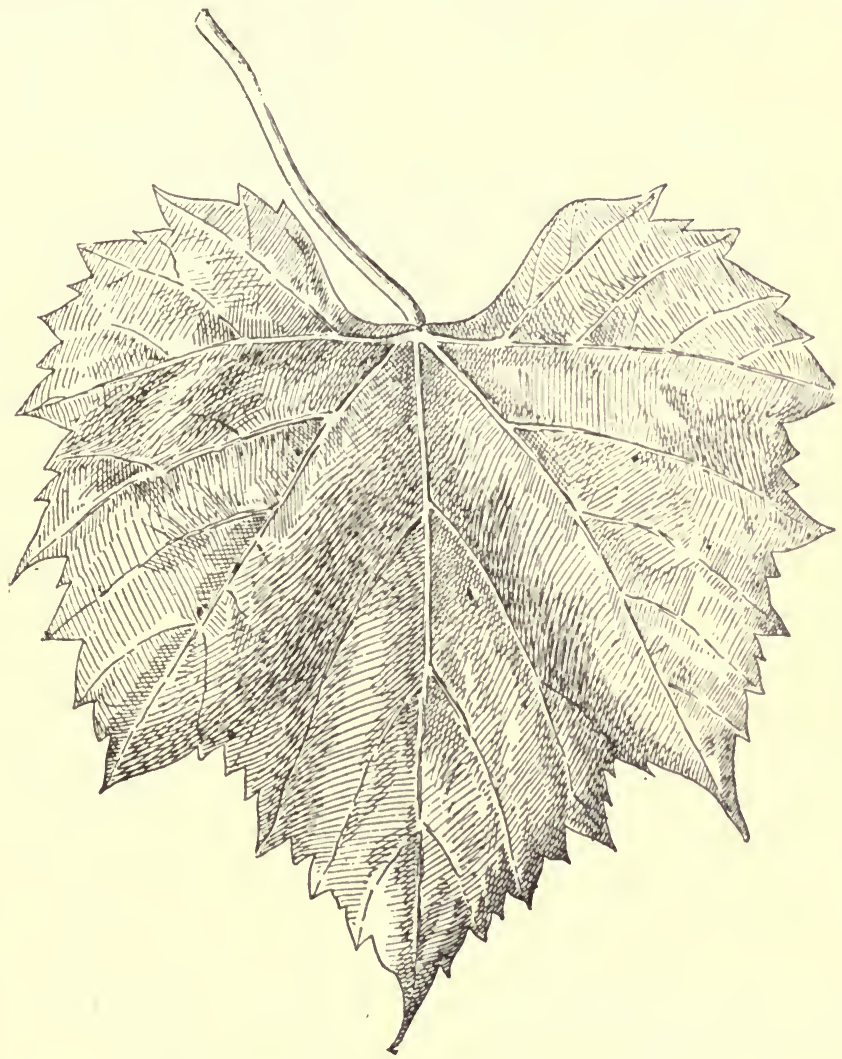

Fig. 79.-Leaf of Novo-Mexicana (Mobeetie).

characteristic and most common, selected by T. V. Munson, and named by him Early Doaniana, resemble certain vigorous forms of Novo-Mexicana so closely that they are readily confused; finally, the erect habit of the Early Doaniana seems to indicate an effect of the Rupestris. Munson expected a future for these hybrids as direct producers and graft-bearers. Their fructification is not abundant, and the characters of the Mustang are too pronounced in the 


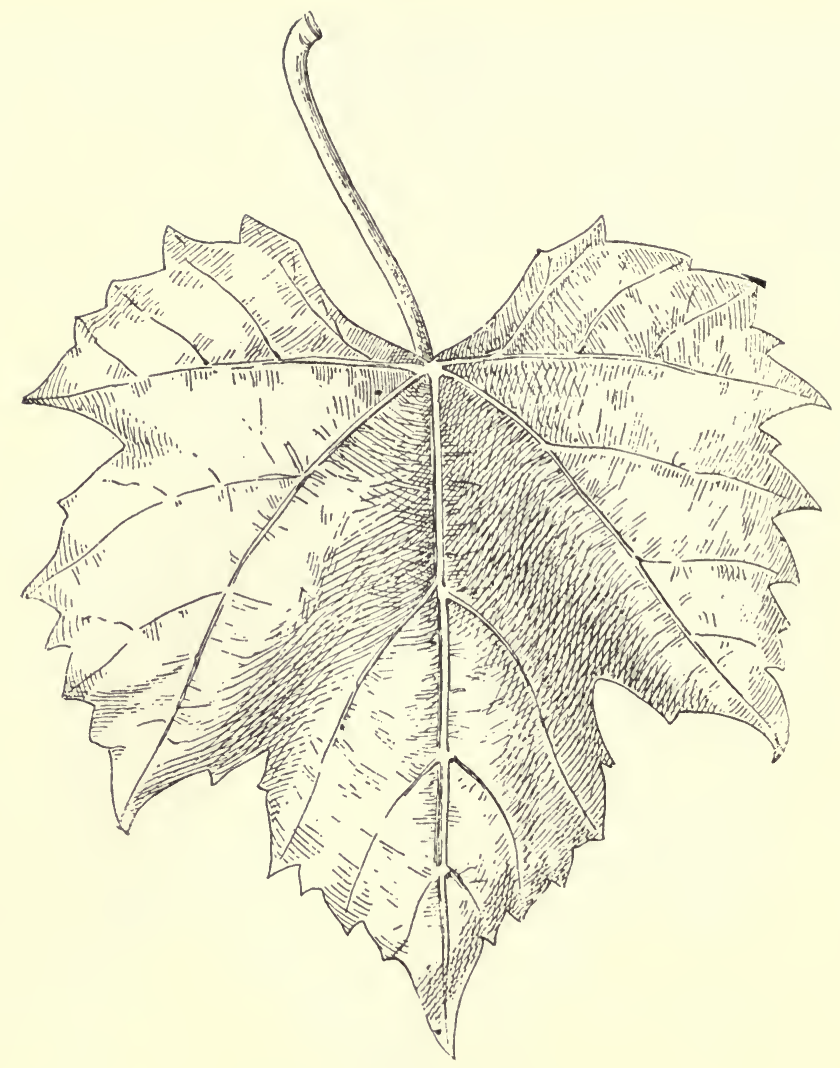

Fig. 80.-Leaf of Doaniana.

fruit for them to have any value in Europe. As graft-bearers they are without interest.

The Early Doaniana is much less vigorous than any other forms of Novo-Mexicana, its resistance to phyiloxera, when three years old, is only 12 . It roots freely from cuttings.

The Early Doaniana has an erect habit, like the Espar (Mataro), for instance; canes short or medium, cylindrical, rugose, dull, deep-hazel colour; internodes short, nodes prominent; young shoots light pink with abundant araneous tomentum on the summits. Leaves rather small, almost entire, symmetrical, pentagonal, elongated; terminal lobes well detached, triangular, elongated; limb very deeply and 
regularly goffered along the secondary and ternary veins; teeth in one series, wide, indentations shallow and obtuse; petiolar sinus deep, slightly open; upper-face light lustrous green, with disseminated patches of araneous hair; underface duller green, with well-defined veins covered with a number of stiff brush-like hairs.

The Late Doaniana differs from the above form by its very marked Mustang characters; it has fluffy tomentum even on the lignified canes. Leaves often tri-lobed, vaguely goffered, with margins sometimes curved underneath, underface regularly covered with numerous short araneous hairs; teeth wide, well defined.

Munson found a hybrid in the wild state, on the banks of the Red River, which he considered to be a Cinerea $\times$ NovoMericana, bearing many points of resemblance to Doaniana; according to him, it has a large and very vigorous trunk: its leaves recalling those of Novo-Mexicana, but being less thick and more tomentose. This hybrid has not been introduced or experimented upon in France. Finally, amongst other hybrids of this group, we mention Solonis $\times$ Riparia No. ${ }_{16} I_{6} 6$ and I6I5, of Couderc; having a resistance to chlorosis equalling that of Solonis, and, according to Couderc, having a greater resistance to phylloxera: the $161_{5}$ is the most vigorous.

Hybrids of V. Candicans and V. AEstivalis;-of V. Candicans and V. Cordifolia;- of V. Candicans and V. Cinerea.-The Estivalis $X$ Candicans are scarce; Millardet only mentions one form. The Cordifolia $X$ Candicans and Cinerea $X$ Candicans are rather numerous, in the wild state, in the north of Texas: they are generally vigorous in the rich alluvials of river banks; they have not been introduced or experimented upon in France. Their procreators may have transmitted to them a great difficulty of rooting from cuttings, and a feeble. resistance to chlorosis; but have endowed them with a large trunk and great vigour; their resistance to phylloxera may be small, as is the case in all other hybrids of V. Candicans. The Cordifolia $\times$ Candicans would offer a greater guarantee of resistance.

Hybrids of V. Lincecumii and V. Astivalis;-of V. Lincecumii and V. Candicans;-of V Lincecumii and V. Cinerea;- of V. Lincecumii and V. Cordifolia. -These various groups of hybrids are very numerous, 
in the wild state, in all the regions where the V. Lincecumii grows mixed with these other species (Missouri, Indian Territory, Arkansas, and north of Texas); they are of no interest, for they are generally very difficult to propagate from cuttings and only grow well in siliceous, fertile soils. The Cordifolia $X$ Lincecumii are the most vigorous. T. V. Munson isolated two forms of these hybrids which he named Black Jack and Ninon, they are rather fructiferous, but of no value for our vineyards.

Hybrids of V. Lincecumii and V. Rupestris.-Frequently met with in the south-west of Missouri, where H. Jæger studied them carefully. He also created a very great number of forms, with the object of obtaining direct producers resistant to black rot and mildew; his numbers 43,70 , and 72 are the most interesting, but the wines they produce are too inferior in quality and quantity to interest us; they always retain the harsh taste characteristic of the Lincecumii grape. Most of the vigorous forms of these hybrids are difficult to propagate from cuttings, and are inferior to the fine Rupestris varieties, even as far as vigour is concerned; they seem to thrive well only in soils where the latter also grows well. However, the V. Lincecumii is a species with large trunk, great development, and some wild or artificial Lincecumii and Rupestris hybrids might be of value in Rupestris soils.

Hybrids of V. Bicolor and V. Riparia.-Munson is the only one who has observed this hybrid in Canada. It is a tomentose Riparia, with leaves bluish on the under-face, similar to $\mathrm{V}$. Bicolor, and has only an interest as a curiosity. The same applies to the AEstivalis $\times$ Bicolor, which are numerous in Pennsylvania and Ohio, and have no cultural value on account of their poor vigour.

Hybrids of V. AEstivalis and V. Cordifolia-One of these hybrids was first discovered by J. E. Planchon; they are very numerous in the centre and extreme south of the United States, and are only slightly vigorous, contrary to what would have been supposed, on account of the influence of $\mathrm{V}$. Cordifolia. They have the general characteristics of the small-leaved variety of $\mathrm{V}$. Cordifolia, with patches of araneous rusty-coloured hair on the veins. These hybrids have not been tried in France; we may infer from the properties of their procreators that they have only a feeble resistance to 
chlorosis. For dry or rich siliceous soils they would be inferior to other graft-bearers on account of their small vigour.

Hybrids of V. AEstivalis and V. Cinerea,-The wild forms are rare. Millardet and de Grasset isolated one of them in I882, and Munson found one in Georgia. These vines are generally of little vigour; their value of resistance and adaptation is not known, but we may assume that they are not meritorious.

Hybrids of V. Astivalis and V. Rupestris.-Exist in a wild state in the south of Missouri and Indian Territory. They generally have a strong trunk and great vigour, but only grow in dry siliceous soils, the soils for Rupestris. The forms tried in France, amongst others, the Rupestris Taylor and Rupestris de Lézignan, grow vigorously in Rupestris soils, and in good garrigues soils of the south of France; in calcareous and chalky marly soils they become stunted after the first year's planting out. They are not suitable varieties for chalky soils, but they make very good graft-bearers, and are vigorous in all soils where the Rupestris could be cultivated, especially in pebbly-siliceous, poor and compact soils. Millardet and de Grasset have selected a few Rupestris and Estivalis, which become yellow in cretaceous chalks like the wild forms.

Rupestris Taylor.-Form isolated at Mas de las Sorres; not much affected by phylloxera. Stump very vigorous, trunk strong, habit exclusively spreading. Canes sinuous, strong, deep-chestnut colour, nodes covered with vinouscoloured bloom. Leaves large, wider than long, orbicular, thick, fleshy, goffered structure, deep green, slightly shining on the upper-face, light glaucous green and dull on the under-face; ribs strong, covered with stiff hair; petiolar sinus deep, lyre-shaped. Seeds same character as V. Estivalis. Resistance, I6.

We will also mention the Rupestris de Lézignan, which is a very vigorous hybrid of Rupestris and Estivalis. According to Millardet, this hybrid selected by Marron-Martin and Joulia, of Lézignan, is distinguishable from Rupestris Taylor by the character of its wood-" That of Rupestris Lézignan is round, while that of Rupestris Taylor is flat, and has very marked flutings between the nodes." 
Hybrids of V. Astivalis and V. Riparia.-The Riparia and Estivalis are numerous in the United States, in the centre states bordering the Atlantic; they have a very great vigour and a very great development of trunk and canes, in red, fertile, generally siliceous soil. Although the wild forms have not yet been tried in France, it is to be presumed that on account of their origin they are not resistant to chlorosis. They would, however, the most vigorous forms exclusively, make excellent graft-bearers for Riparia soils on account of the size of their trunk.

Azémar Hybrid.-Millardet has named and made known a hybrid of Estivalis $X$ Riparia, which was accidently obtained from seeds of Estivalis, sown in 1879, by Azémar of Perpignan. According to Millardet, it is a very vigorous vine, with large trunk, rooting freely from cuttings, and knitting well with almost all European varieties without forming any pronounced pad of knitting tissue; and further, it is very resistant to phylloxera. In the chalky soils of Cognac it succumbs to chlorosis and becomes stunted very rapidly, even before grafting. It is not, therefore, suitable for marly or chalky soils, but makes an excellent graftbearer, superior to certain Riparias; in light siliceous or claysiliceous soils it does not equal in value the most vigorous forms of Riparia. Millardet considers it a good graft-bearer for clayey, but not damp, soils.

Here are the general characters, according to Millardet:" Stump very strong; young shoots violet-grey pubescent: canes with medium internodes, deep-mahogany colour; covered with bloom. Leaves large, cordiform or polygonal-subcordiform, vaguely tri-lobed, slightly goffered structure, margins revolute, terminal lobe acute; teeth fairly regular, sub-acute. Upper-face of a fine deep green, with a few cobwebby hairs; under-face with a few short hairs on the main and secondary ribs.

Hybrids of V. Berlandieri and V. Rupestris.-T. V. Munson isolated two wild forms of these hybrids which were imported into France in I888; they are still growing fairly vigorously in rather calcareous soils. One of these (No. I) is, we think, an hybrid of $V$. Berlandieri $\times$ Candicans; its vigour compared with the known forms of Berlandieri $X$ Candicans may be represented by 19, but its resistance to phylloxera is only I2. The other form, which is alone 
considered by us as a Berlandieri $X$ Rupestris (No. 2 ) is rather vigorous (I8) and fairly resistant (I6). Contrary to No. I, it has no white tomentum on the young leaves. The canes are a little more slender, the internodes longer, of a dull vinous-brown colour. Leaves medium, very thick, as wide as long, orbicular, folded along the mid-rib, slightly goffered along the main ribs, of a deep lustrous green, almost glabrous on the under-face; petiolar sinus $U$ shape. This form roots freely from cuttings, but is inferior, as far as vigour is concerned, to the artificial hybrids of the same group ; it is therefore without cultural value.

Millardet, de Grasset, and Malègue have created several artificial hybrids of Rupestris $X$ Berlandieri. They are generally fairly vigorous, and inherit from the Berlandieri a high resistance to chlorosis. Their resistance to phylloxera is very good. They are excellent graft-bearers, not suitable, however, for strongly chalky soils, but for all those similar to the groie soils of the Charente and Bourgogne, that is to say, pebbly.*

Hybrids of V. Berlandieri and V. Monticola.-In the few regions where the $\mathrm{V}$. Monticola grows in Texas, the $\mathrm{V}$. Berlandieri is invariably associated with it; the wild hybrids of these two species are therefore rather numerous. They are more vigorous, in a wild state, than most forms of $V$. Monticola, and grow like them on barren hills formed of fairly hard limestone, the $\mathrm{V}$. Berlandieri endows them with extra vigour. But a rather constant fact observed for all the forms introduced into France up to I894 is that their resistance to phylloxera is less than that of either of the two species they are derived from. Amongst the eight forms introduced at the School of Agriculture, Montpellier, the most vigorous (No. I) has a resistance of 14 , like the Solonis; the No. 6 has the same resistance, but is inferior to Solonis in vigour; finally, the No. 8 died from phylloxera. A curious fact, corrobating what has been said in the first part of this work, takes place with this form, $i$. $e$, the weakening due to phylloxera manifesting itself externally, without the leaves becoming chlorosed, although the vine is growing in calcareous soils. The origin of this hybrid explains this relative resistance to chlorosis even under the action of phylloxera.

* Amongst the best forms we may mention the Rupestris X Berlandieri, Millardet No, $301 \mathrm{~A}$ and No. $2 \mathrm{IgA}$, as being very 'vigorous and very resistant to chlorosis. and phylloxera. (P. V. I900.) 
The most vigorous and resistant hybrids of Berlandieri $x$ Monticola, may have a certain value for moderately calcareous soils (Jurassic, and groie soils); but this value can only be assumed, for they have not yet been sufficiently experimented with in those soils. Certain forms of very fine vigour were introduced in I895 into our collections.

Hybrids of V. Berlandieri and V. Cordifolia;-of V. Berlandieri and V. Cinerea;-of V. Berlandieri and V. Lincecumii. - A few rare hybrids of $V$. Berlandieri and $V$. Cordifolia were indicated as existing, in a wild state, in America, and were introduced into France as pure Berlandieris. They possess a certain resistance to chlorosis, but very inferior to that of pure Berlandieri, and are recognisable by their very varnished-like leaves, with regular and well-defined teeth. In the numerous consignments of Berlandieri made in latter years, many hybrids of Berlandieri and Cinerea have been introduced, easily distinguishable by their leaves, which are cordiform, elongated, finely goffered in structure, of a deep dull green on both faces, with numerous short greyish hair on the ribs of the under-face, and by their fluted canes. Certain individual forms have a very great vigour, but are far inferior to Berlandieri for chalky soils; they seem, however, to have a certain value for very compact and damp clayey-calcareous soils; they root from cuttings more freely than Berlandieri. A few hybrids of Berlandieri and Cinerea have been created by Millardet and de Grasset, and by Conderc; they root badly from cuttings, and are much affected by chlorosis. Hybrids of Berlandieri and Lincecumii also exist in a wild state, but have not been introduced into Europe.

Hybrids of V. Berlandieri and V. Riparia.-The hybrids of Riparia and Berlandieri seem à priori, on account of their procreators, to have real value for calcareous and chalky soils. The Riparia is vigorous, slightly resistant to chlorosis, and very resistant to phylloxera; it roots very freely from cuttings, and when grafted the grafts are very productive. The Berlandieri shares these qualities, but to a very much higher degree, especially as far as productivity and resistance to chlorosis are concerned, but normally it does not root from cuttings. It would seem that by uniting it to Riparia one might endow the offspring with the properties of rooting freely, while maintaining the essential qualities of 
resistance to chlorosis in chalky soils. The experiments made at the Viticultural Station at Cognac confirm thesc anticipations. The hybrids of Riparia and Berlandieri root from cuttings almost as well as the Riparias themselves, and their resistance to chlorosis, without, perhaps, being as high as that of pure Berlandieris, is very greatly superior in any case to that of V. Vinifera or V. Rupestris. Assuming that Berlandieris were not practically utilizable on account of the difficulty of their propagation (which is not so), and that the Franco-Americans remain without value on account of their doubtful resistance to phylloxera (which might be), it is certainly the hybrids between Riparia and Berlandieri which would, we consider, be the solution of the problem of reconstitution of vineyards in many chalky soils. We also think that Berlandieri $X$ Riparia are destined to a great future for many soils where the Riparia, without getting stunted, becomes chlorosed, and gives comparatively small yields, and where Solonis and Rupestris du Lot are not sufficiently resistant to chlorosis.

Millardet and de Grasset, Couderc, Malègue have aiready artificially created many of these hybrids which are certainly promising.

At the School of Agriculture, Montpellier, sowings made in $\mathrm{I} 890$ with seeds gathered from Berlandieris originating from the calcareous and chalky soils of the extreme north of Texas have given us forms of Rerlandieri, and very distinct forms of hybrids between Riparia and Perlandieri. Amongst the latter we selected two forms, one glabrous (No. 33) the other tomentose (No. 34), of very great vigour, resistant to phylloxera, and rooting freely. We cannot vet fix their real value in respect to resistance to chlorosis in chalky soils; this resistance, however, seems probable. and the trials now being made in the chalky soils of Champagne and Cognac will shortly settle this definitely*: meanwhile, here are the principal characters of the two forms:-

Bcrlandieri $\times$ Riparia No. 33 Ecolc.-Stump strong and vigorous, spreading habit; canes straight, cylindrical, thick and strong. little ramified, internodes rather short, ribs vaguely indicated and deeper in colour on the lignified canes,

* Since this second edition appeared ( 1806$)$ the Riparias X Berlandieris have proved to be of great value all through France for calcareous soils containing less than 35 per cent. of carbonate of lime; these stocks are actually in great use, specially the 34 Ecole, $420 \mathrm{~A}$ Millardet and I57-I I Couderc. (P. V. I900.) 


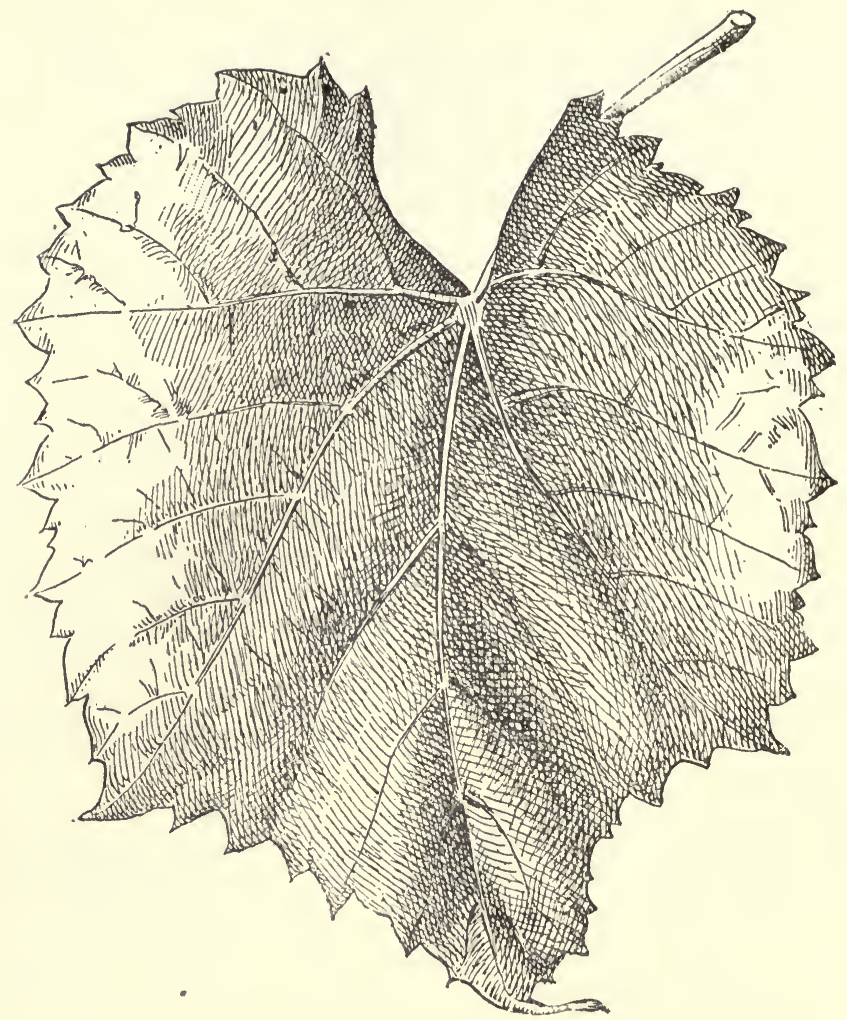

Fig. 81.-Leaf of Berlandieri X Riparia, No. 33 Ecole.

which are of a light fawn-brown colour; young shoots glabrous yellowish-green, pinkish along the ribs. Leaves (Fig. 8I) medium, entire, terminal lobe, long and acute, cordiform, very thick; principal ribs strong, with a few disseminated patches of hair; upper-face deep lustrousgreen, goffered structure between the ribs; under-face varnished appearance, light green; petiolar sinus deep $\mathrm{V}$ shape, with a few hairs on the edges; incientations shallow, teeth in two regular series; the petiole prolonged rin a line with the mid-rib.

Berlandieri $\times$ Riparita No. 34 Ecole. - Stump vigorous, trunk strong; canes cylindrical, wide striations, with we!l marked ribs on shoots of medium size, deeper in colour at 


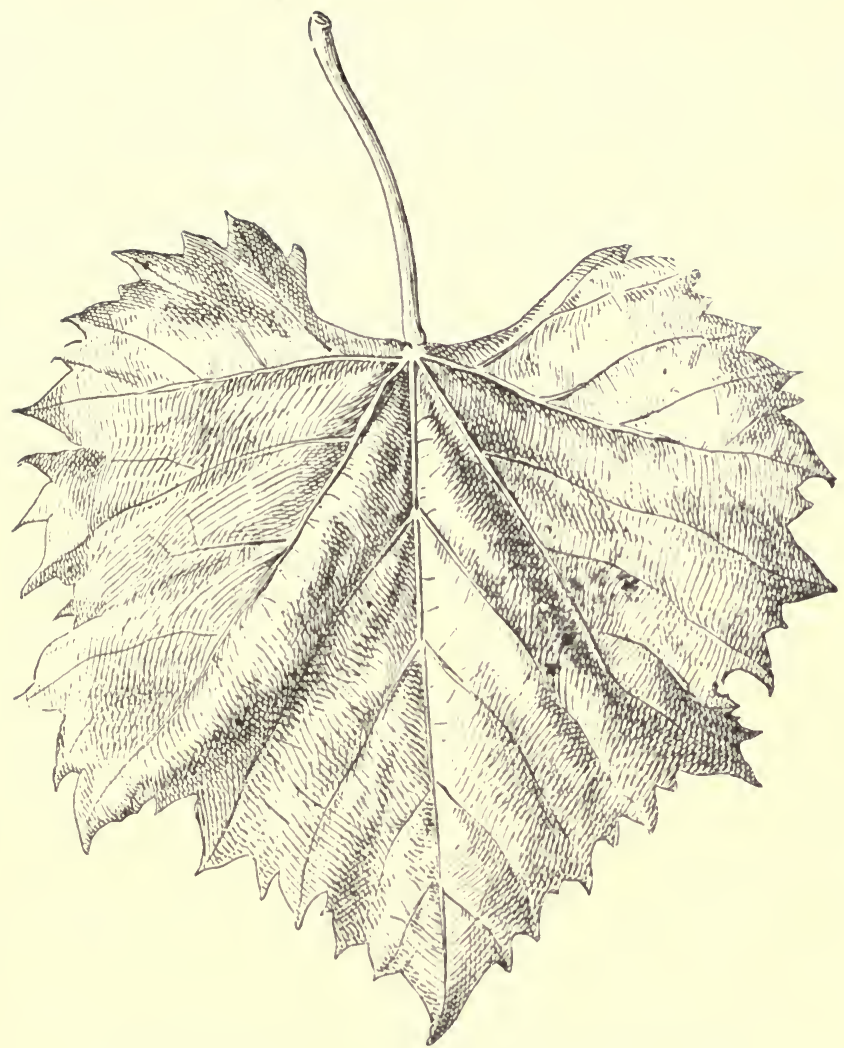

Fig. 82.-Leaf of Berlandieri X Riparia, No. 34 Ecole.

complete lignification, internodes medium; young shoots tomentose, covered with very numerous short hairs over the whole surface, hair extending to the tendrils and petioles, of a vinous fawn-brown at lignification. Leaves, adult (Fig. 82), large, very thick, sub-orbicular, entire, terminal lobe fairly well defined and curving underneath, margins revolute; upper-face deep green, as if varnished; under-face lighter and duller in colour; main and secondary ribs covered with short regular brush-like hairs; teeth in two series, scarcely defined; petiolar sinus $\mathrm{V}$ shape, widely open, fairly deep.

Hybrids of V. Cordifolia and V. Cinerea.-These hybrids are common in the south-west of Missouri, and on 
the banks of the Red River, in Indian Territory and Texas. They are vigorous, but generally less so than the species they are derived from. They have not been tried in France, and even if they preserved, from the point of view of adaptation, the qualities of their procreators, they could not possess their value for poor lands.

Millardet has indicated a hybrid of V. Cordifolia and V. Rubra, which is, however, of no cultural interest.

Hybrids of V. Cordifolia and V. Rupestris.These were propagated for the first time in France, in I880, by de Grasset. Millardet advocated them in I882, in the hope that they would prove excellent graft-bearers for bad soils. H. Jæger, who discovered them in the United States, differentiated 80 forms in Missouri, Indian Territory, and Arkansas, where the Rupestris and Cordifolia grow together.

The Cordifolia $X$ Rupestris grow in the same soils and situations as the Rupestris, consequently in non-calcareous soils, and in the more fertile parts of the Rupestris regions. In such soils the Cordifolia $X$ Rupestris have a great vigour and large trunk. One of the best forms studied by Millardet, the Cordifolia $\times$ Rupestris de Grasset No. I, roots well from cuttings, and bears very fructiferous and very vigorous grafts; the trunk is very strong, and its resistance to phylloxera is 18 .

In calcareous chalky soils, in yellow marls, the Cordifolia $X$ Rupestris rapidly becomes stunted, and dies from chlorosis the first or second year after planting out, without being grafted. These vines, on account of the size of their trunk, of their resistance, and their vigour, might be cultivated in rich Rupestris soils, or in deep friab!e Riparia soils; but nothing has yet shown that the Cordifolia $X$ Rupestris are superior to these two species in such soils. They must, in any case, be excluded from all soils where soft limestone predominates.

Among the Cordifolia $\times$ Rupestris selected by Millardet and de Grasset, the No. I is the most vigorous; amongst those isolated by Jæger the most meritorious are the numbers I, 4 , and 5 .

Hybrids of V. Cordifolia and V. Riparia.-We have already said that the forms of Riparia with thick lustrous leaves might be considered as hybrids of Riparia and Cordifolia. Well characterized hybrids of this nature 
are frequent in the centre of the United States; they are generally very vigorous, and live in the same soils as the Riparias, from which they get their properties of adaptation and resistance. Millardet and de Grasset created many hybrids of this nature.

Hybrids of V. Cinerea and V. Coriacea-The varied forms of vines, to which Munson gave the name of $V$. Simpsoni, and which he found in the south-west of Florida, are only hybrids of Cinerea and Coriacea. These vines, like the $\mathrm{V}$. Munsoniana, do not offer any cultural interest for us, on account of their originating in a tropical country; they were introduced into France in I888; they grow badly in slightly calcareous soils, without, however, becoming yellow.

T. V. Munson discovered a wild hybrid of Simpsoni and Labrusca, the Wofford's Winter Grape, which grows in Georgia, together with a hybrid Simpsoni $X$ Cordifolia growing in Florida. These forms are of no more interest than the Simpsoni itself. The same may be said of a few hybrids of Cordifolia $X$ Coriacea and Estivalis $X$ Coriacea observed in Florida.

Hybrids of V. Cinerea and V. Riparia.-They are not frequent in a wild state, and were imported into France as Riparias. Some are very vigorous, and have a larger trunk than that of Riparia, from which they are distinguished by their leaves being thicker and by the very numerous short hairs on the main and secondary ribs of the under-face; in some forms the canes are fluted. They have not been seriously studied from the point of view of adaptation. They must be very sensitive to chlorosis, if the characters of their parent have been transmitted; but may, perhaps, have some value for damp and compact soils.

Hybrids of V. Monticola and V. Rupestris.-No hybrids of this nature have yet been observed in a wild state; they might, perhaps, exist, but would certainly be exceptional, for the two species do not generally grow in the same regions or in similar soils. It has been wrongly surmised that certain vigorous forms of Rupestris, with light lustrous small leaves, were hybrids of Monticola and Rupestris; this opinion is only founded on hypothesis, especially as far as Rupestris du Lot is concerned.

Hybrids of V. Monticola and V. Riparia.-These hybrids are still very little known. It is probable that their 


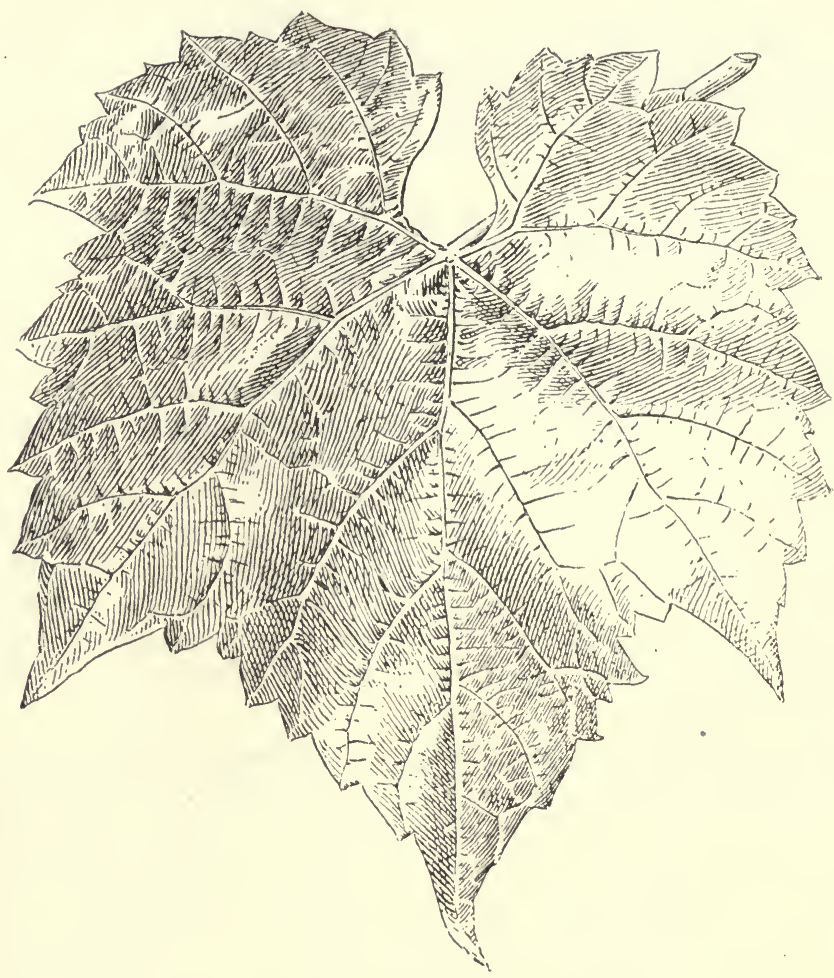

Fig. 83.-Leaf of Colorado.

resistance to phylloxera on the whole is good, and that their resistance to chlorosis is superior to that of Riparia. This is so, however, for the natural hybrid of these two species, which is known under the name of Colorado. There are many Colorados. Many have no doubt no relationship with Monticola. It is not so with that shown in Fig. 83. The leaf has most of the characters of V. Monticola. This vine has a resistance to chlorosis superior to that of Riparia or Riparia $\times$ Rupestris. It only bears a few more nodosities than the Riparia Grand Glabre. It can, therefore, be utilized for soils causing chlorosis of medium intensity. It roots freely from cuttings, and the grafts knit well.*

* The few forms of Riparia X Monticola created in France did not give the results expected from them, and they seem very inferior to Berlandieri X Rupestris for dry an 1 calcareous soils where they could be made use of. P. P. I900/ 


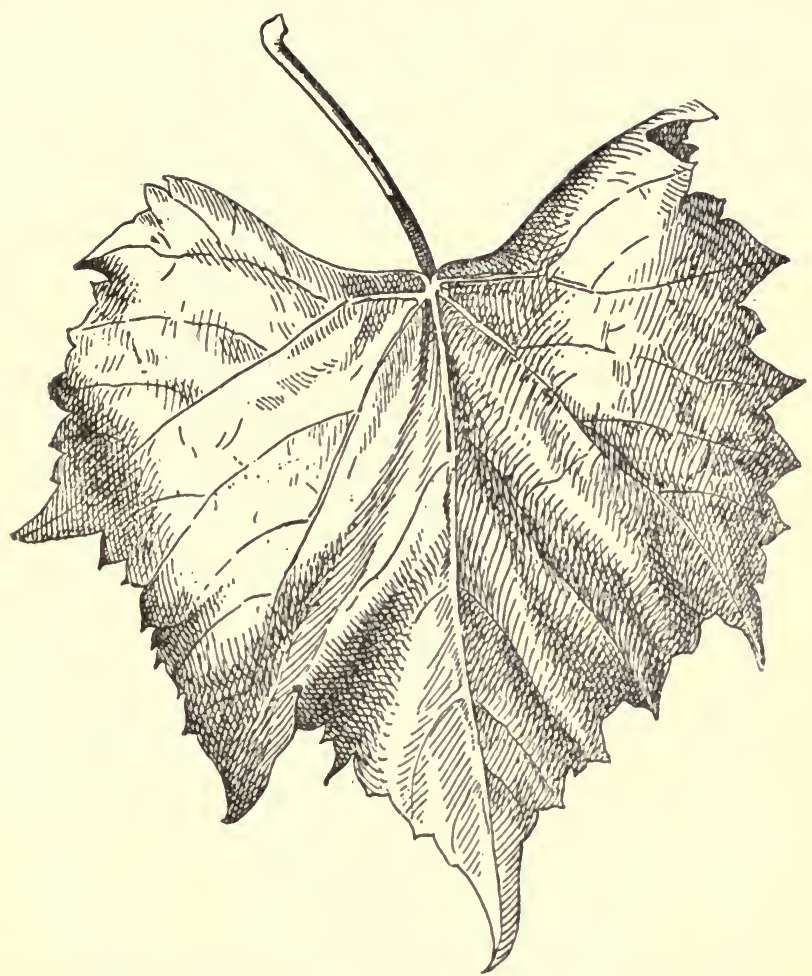

Fig. 84.-Leaf of Riparia X Rupestris, Nos. Ior $\times 4$, Millardet and de Grasset.

Hybrids of V. Cinerea and V. Rupestris.-Rare in a wild state: only found in the Indian Territory and north of Texas. They grow in the same soils as the Rupestris, and, on account of their specific origin, it was to be assumed that they would be affected by limestone soils; this actually occurred in the chalky soils of Cognac. In a wild state the Cinerea $X$ Rupestris have rather great vigour, although inferior to that of Cordifolia $\times$ Rupestris; they grow, however, in drier and poorer soils than the latter. One of the forms isolated by Munson has a resistance to phylloxera equal to I7. H. Jægar created two very vigorous hybrids of Cinerea $X$ Rupestris. They do not succeed in chalky calcareous soils, and seem to be inferior to Rupestris in all soils in which the latter can be cultivated. Their rooting from cuttings is only middling. 
Hybrids of V. Rupestris and V. Riparia.--These were discovered by H. Jæger in the forests of the tribes of Senasqua, Wyandotte, Modoc, Shawnee, Quapaw, Paola, Ottawa, and Miami, of Indian Territory. The most interesting forms of these hybrids have been classified; they are very numerous in the wild state, and over Ioo forms have been selected, some of which have real value.

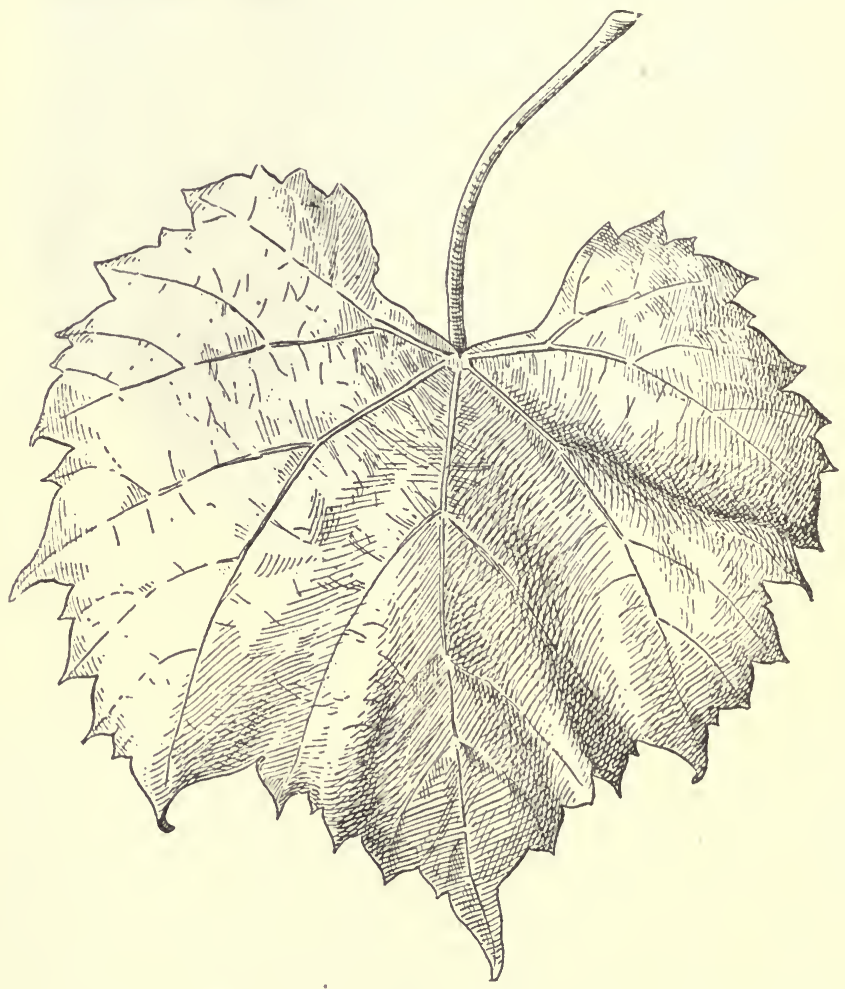

Fig. 85.-Leaf of Riparia X Rupestris, No. 3306, Couderc.

In America, the Riparia $\times$ Rupestris grow, more especially on the banks of the Great River, in hard calcareous fissured rocks, the interstices of which are filled with soil derived from the plateaux. They attain there considerable dimensions, sometimes 6 to 8 inches in diameter. In general they are more vigorous than their progenitors, they rapidly increase in diameter and the canes become longer and stouter, and, moreaver, accommodate themselves to poorer soils than 


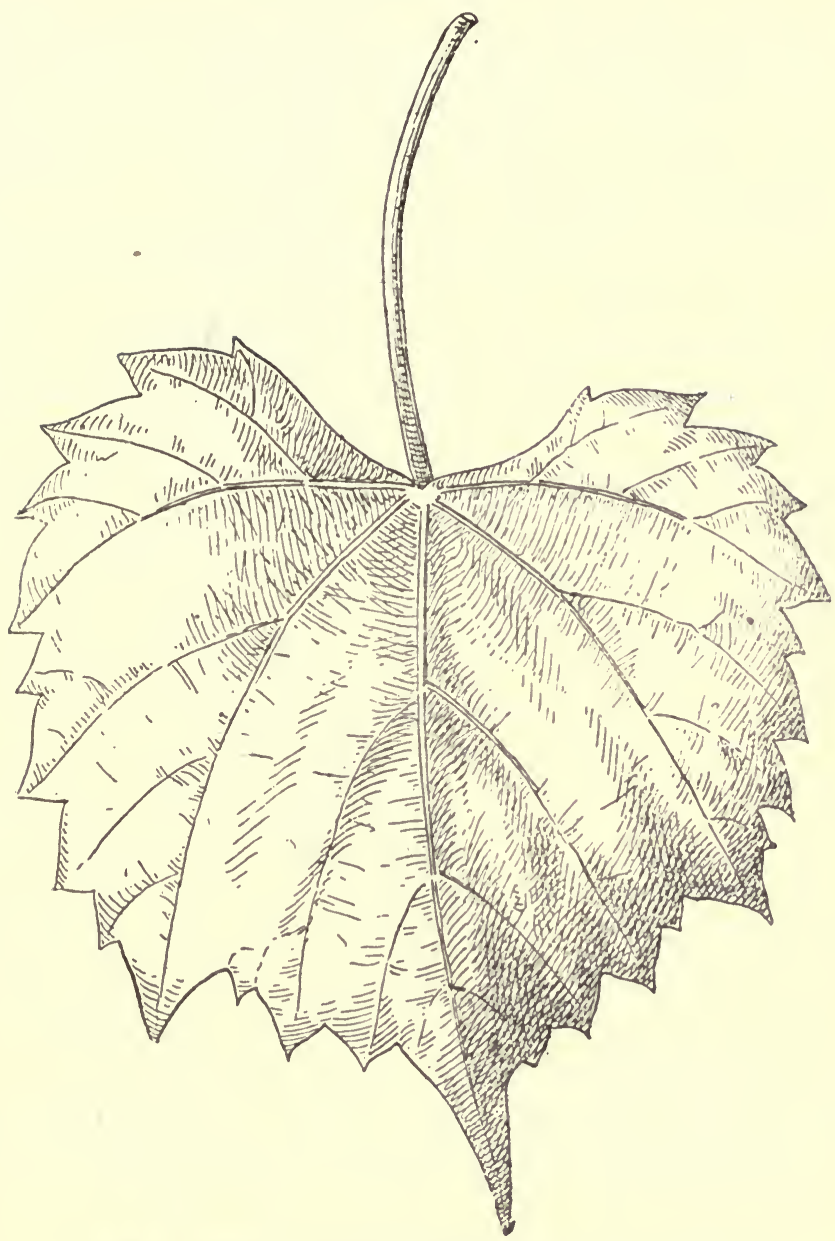

Fig. 186.-Leaf of Riparia X Rupestris, No. 3309, Couderc.

Riparia or Rupestris. In calcareous soils, where the two latter species became slightly yellow, some of their hybrids remain green and vigorous when grafted and their grafts are very fructiferous. In the chalky soils of the Charentes they die, but not so rapidly as the species they are derived from; in certain groie soils, not too calcareous, certain forms resist chlorosis effectually. In many viticultural regions certain Riparia $X$ Rupestris assume a vigorous 
development when planted in the place of Riparias or Rupertris which had died from chlorosis. These hybrids have, therefore, a greater geographical area of adaptation than their procreators, being also more vigorous and possessing the same resistance to phylloxera; they, therefore, constitute remarkable graft-bearers.

In France, many hybrids of Riparia and Rupestris have been obtained artificially. They have the same properties as the wild hybrids, similar resistance to phylloxera (I8), similar facilities of adaptation. Moreover, as they have been well selected, and cultivated for a very long time in presence of phylloxera in very diverse soils, they may now be used without fear as graft-bearers. Amongst them we will mention Nos. IOI-I4 of Millardet and de Grasset (Fig. 84), Nos. 3309 and 3306 of Couderc (Figs. 85 and 86), which remain green when grafted, in groie soils of the Charentes slightly liable to cause chlorosis.

All the Riparia $\times$ Rupestris are not equally good; and it does not suffice for a vine to be a hybrid of this group to possess the general most important properties. Some of those we have cultivated are too deficient in vigour to render any service, and must be discarded. Others too closely resemble their parents, and may have their defects too strongly pronounced; the most vigorous varieties only, should therefore be cultivated, those that have been submitted with success to the trial of poor soils. The most meritorious forms are those we have mentioned (IOI-I4, 3309, and more especially 3306) $; *$ and amongst the varieties selected by Jæger, the Riparia $\times$ Rupestris Gigantesque, which, however, is less resistant to chlorosis than the previous.

These vines, which give remarkable fertility to the grafts they bear, are excellent graft-bearers for all Riparia soils, and even for soils where this vine suffers slightly from chlorosis.

\section{'C.-HYBRIDS OF V. VINIFERA.}

\section{(Franco-Americans.)**}

The hybrids created by the union of European varieties with different American species are very numerous and are increasing in number every year. The complexity in the union of pure forms already hybridized by crossing of one

* These hybrids are found to-day in California nurseries and Agricultural Experiment Stations.

** Or Vinifera X Americans. (Trans) 
or more species, renders their study extremely difficult; we will, however, endeavor to indicate and study most of the groups created by simple or complex hybridization. The hybrids of V. Vinifera and American Vitis have, from the points of view of their affinity and adaptation, unquestionable qualities rendering them generally superior to the pure American vines which contributed to their formation. They would, therefore, from this point of view have great merit.

Unfortunately, the property of resistance to phylloxera seems difficult, if not impossible, to fix in these hybrids, if we judge from the results obtained so far. Hybrids, such as No I60 of Millardet and de Grasset (Gros Colman $\times$ Rupestris), No. $50 A$ (Riparia $X$ Rupestris $\times$ unknown cépage), Gamay-Couderc (3Io3, Colombeau $\times$ Rupestris of Couderc), No. 333 Ecole (Cabernet $\times$ Berlanderi), etc., which were thought to possess a very high resistance to phylloxera, have ended by succumbing to attacks of the insects in soils favorable to their development.

We may, therefore, wonder whether other hybrids of $\mathrm{V}$. Vinifera, upon which great hope is placed, will not have the same fate. And we may conclude at the outset of this study of Franco-American hybrids that whenever we have the choice for reconstituting our vineyards between pure American species and hybrids of American species between themselves (Americo-American), the resistance of which appears a better guarantee, we must not hesitate to use the latter. We think it is possible, nowadays, to reconstitute all vineyards with pure American vines or their hybrids.

Hybrids of V. Vinifera and V. Rotundifolia.-Millardet and de Grasset tried experimentally the hybridization of Vinifera and Rotundifolia, and, although the botanical differences of these two species are strongly accentuated, they obtained forms which seemed to be hybrids of Vinifera $X$ Rotundifolia. One of these vines shows distinct Rotundifolia characters in its seeds, but externally the Vinifera character predominates. The Vinifera seems always to communicate to its hybrids with $\mathrm{V}$. Rotundifolia a negative resistance to phylloxera.

Hybrids of V. Vinifera and V. Labrusca - The Americans attempted numerous hybridizations of the different varieties cultivated in their territory, mostly Labruscas with various 
European cépages, with the idea of improving the quality and productivity of indigenous vines. They created and are still creating constantly a considerable number of these hybrids. Here is a list of the best known, with their origin, and their value of resistance to phylloxera:-

Triumph (Concord and Muscat-Chasselas No. 6, Campbell)-Resistance, 4 .

Senasqua (Concord and Black Prince, Underhill)-Resistance, 5 .

Black Defiance (Black St. Peter and Concord, Underhill) -Resistance, 5 .

Agawam (Labrusca and Black Hamburg No. I5, Rogers) -Resistance, 6.

Campbell (seedling of Triumph, Munson).

Herbert (Labrusca and Black Hamburg No. 44, Rogers).

Highland (Concord and Muscat No. 57, Ricketts).

Irwing (Concord and White-Frontignan No. $8^{\circ}$, Underhill)-Resistance, 5 .

Lindley (Labrusca and Golden-Chasselas No. 9, Rogers).

Gärtner (White-Chasselas and Labrusca No. I4, Rogers).

Black Eagle (Labrusca and Vinifera No. $8^{12}$, Rogers) -Resistance, 3 ; etc.

The non-success obtained in the culture of European cépages in America was exclusively attributed, before the discovery of phylloxera in France, to the action of the climate. It was with an idea of endowing the European cépages with a greater faculty of adaptation to climate that hybridization was first undertaken. It was easy to foresee (a fact which the American hybridizers overlooked) that the crossing of a $\mathrm{V}$. Vinifera of negative resistance and $\mathrm{a} V$. Labrusca with very limited resistance would produce a vine of little resistance. This is what actually occurred. The resistance, given above, of the principal of these hybrids is very small. On account of this fact alone, these hybrids, especially those which have had a certain fame in France (Triumph, Senasqua, Black Defiance), have no value whatever. They could only succeed and thrive in rich, fresh, sandy soils, especially in northern regions, where the phylloxera would not have much effect upon them, and where they. could easily and rapidly produce new roots. In dry and unfertile soils, particularly in the south of France, these three cépages rapidly succumb to the attacks of phylloxera. In rich soil their grafting on more resistant 
vines would always give superior cultural results. Moreover, though possessing a relatively high productivity, their very foxy fruit gives very inferior wines to those yielded by cépages originating from Vinifera. The Labrusca endows its hybrids with the very strongly accentuated foxy taste peculiar to its pulpy fruit. The white berries of the Triumph, large and abundant, are not only very foxy but also burst at maturity. The Black Defiance is the least foxy, but its red wine, like that made from Senasqua, always retains an after taste of the same nature.

The Labrusca communicated to all this group great sensitiveness to black-rot and mildew, but also a relative re-. sistance to oïdium and anthracnosis.

All these cépages are now discarded, with good reason, but they are interesting from the point of view of adaptation to calcareous soil. The Vinifera impressed them (and we will see that this phenomenon is constant) with a certain resistance to chlorosis. The Triumph, for instance, thrives better than pure Riparia, Rupestris, or Labrusca in soils containing a certain amount of limestone, and in the chalky soils of the Charantes; this property of adaptation, which does not belong to Labrusca, has been imparted by the Vinifera to these hybrids. This fact must not be overlooked.

Hybrids of V. Vinifera and V. Californica.-These two non-resistant vines cannot give resistant hybrids; their offspring are therefore without interest.

Hybrids of V. Vinifera and V. Candicans.-These hybrids generally have very great vigour. Their fruit, when they bear any, always has a harsh taste, similar to that of Nustang; their resistance to phylloxera is usually small. In calcareous soils they become a very yellow; they therefore offer very little interest for the reconstitution of vineyards. They root freeiy from cuttings.

Hybrids of V. Vinifera, V. Labrusca, and V. Estivalis-Among these hybrids we will mention, together with their resistance to phylloxera,-

Eumélan-Resistance, 3.

Centennial (Eumélan and Delaware, seedling of Marwin).

White Delarvare-Resistance, 3.

Grey Delaware-Resistance, 3 . 
Croton (Delaware and Chasselas of Fontainebdeau, seedling of Bull)-Resistance, 3 .

Duchess (Concord and Delaware, seedling of Caywood)-Resistance, 2.

Beauty (Delaware and Maxatawny, seedling of Rommel)-Resistance, 3.

None of these hybrids are of any value for reconstitution, on account of their feeble resistance to phylloxera. Several were used at the commencement of the introduction of American vines (Eumélan), but were quickly discarded: others, which are very fructiferous (Beauty, Delaware), bear foxy fruit, and should not be used under any circumstances. The Delaware is one of the most widely cultivated cépages in the north of the United States, where the phylloxera, on account of the soil and climate, only has a comparatively slight effect. We will note, however, a few interesting facts so far as adaptation is concerned. These cépages are more resistant to chlorosis in calcareous soils than Estivalis or Labrusca; the Delaware is more resistant than Eumélan, and possesses the characters of the Vinifera to a greater degree. In this group of hybrids, the Croton is best adapted to calcareous soils, in which it thrives as well as Othello, as long as it is not attacked by phylloxera; the Croton has two Vinifera elements in its parents (Estivalis $X$ Labrusca $X$ Vinifera and Vinifera).

All the cépages of this group obtained and experimented upon in France are the result of the crossing of YorkMadeira with V. Vinifera. Their composition is as follows:V. Estivalis 1/4, V. Labrusca 1/4, V. Vinifera 1/2. But the Ylork-Madeira; like its progenitors, does not resist chlorosis; if, therefore, its hybrids with $\mathrm{V}$. Vinifera have a large geographical area of adaptation, they cannot thrive in very calcareous soils; in the chalky soils of Charentes they become yellow and stunted very rapidly. Moreover, their resistance to phylloxera and vigour is small. Among these hybrids are Nos. I304, IIO6, 2I02, and 904, or Cognac of Couderc. The latter, which has foxy grapes, is so sensitive to limestone, in the Charentes, that it dies the first year of planting out.

Hybrids of V. Vinifera and V Cinerea.-The V. Cinerea thrives well in compact damp soils deficient in limestone. Crossed with V. Vinifera, this species would give 
"graft-bearers of great value for such soils." But other hybrids of Rupestris, Riparia or Cordifolia with Vinifera, which have a more powerful root system, would thrive equally well in similar soils. However, the Cinerea hybrids could only rencler services in such soils if they were resistant to phylloxera.

One of the progenitors of $\mathrm{V}$. Cinerea is very sensitive to chlorosis, and the strain of Vinifera contained has not endowed them with a very high resistance to that disease, therefore they are useless for the chalky soils of the Charentes. All those tried in these soils became yellow the first year of planting out, and, when grafted, rapidly succumbed. They root freely and knit well.

Hybrids of V. Vinifera, V. Labrusca, V. Astivalis, and V. Cinerea.-Millardet assumes that the Alvey is the result of the union of four species. The cépage is only slightly resistant to phylloxera (resistance, 7 ) and is now only to be found in collections. It is without interest. Let us note that its resistance to chlorosis is small, inferior to that of Jacquez or Blue Favourite, which is no doubt due to the predominance of its American progenitors.

Hybrids of V. Vinifera, V. AEstivalis, and V. Cinerea. - This group contains very well-known cépages of great interest: the following list shows their resistance to phylloxera :-

Jacque -Resistance, I2.

Saint-Sauveur (Jacquez $\times$ Bouschet-Hybrid, seedlings of G. Bazille)-Resistance, 3 .

Jacquez d'Aurclle (seedlings of Jacquez Nos. I and 2, of Aurelle)-Resistance, 9.

Jacquez. with large berries (cuttings of Jacquez Nos. I and 2, of Aurelle)-Resistance, 9.

Herbemont-Resistance, I3.

Dunn (seedlings of Herbemont, of American origin). Exquisite (seedlings of Herbemont, of American origin).

Harwood (seedlings of Herbemont, of American origin)-Resistance, Io.

Yoakum (seedlings of Herbemont, of American origin).

Hariard (seedlings of Herbemont, of American origin). 
McKee (seedilings of Herbemont, of American origin). Herbemont, of Aurelle (seedlings of Herbemont No. I and No. 2, or Aurelle)-Resistance, 3. Herbemont Touzan, (Herbemont Touzan, of Lauze)-Resistance, Io.

White Herbemont (seedlings of Herbemont, of Malègue)-Resistance, Io.

Black July-Resistance, I I.

Blue Favourite-Resistance, Io.

Cunningham-Resistance, I2.

Rulander-Resistance, 2.

Carpar (seedlings of Rulander), etc.

The hybrid nature Vinifera $\times$ Estivalis (Jacquez, Rulander) of these cépages was ascertained by numerous experimenters. Millardet indicated, from their ampelographic characters, their relationship to Estivalis, Cinerea, and Vinifera. This ternary relation is more especially marked in Jacquez. Blue Favourite and Rulander; and less marked in Herbemont, Black July, and Cunningham, but, in all of them, the Estivalis predominates in their ampelographic characters, particularly in the characters of seed, berry, and leaf, except, perhaps, for the Rulander, in which the Vinifera has had more influence, which is decidedly evident in the character of its seeds; on the other hand, it also possesses the least resistance to phylloxera. Herbemont and Cunningham, which show the least influence of Vinifera, also evidence decided influence of $\mathrm{V}$. Cinerea. We shall see, when studying their adaptation, that the predominance of some of their progenitor species explain these differences.

The origin of these different cépages, particularly Jacquez and Herbemont (their descendants excepted), is very obscure. Munson includes them in a general group corresponding to the old Estivalis group of the south, of Engelmann, and considers it as a species, which he named V. Bourquiniana in honour of G. Bourquin of Savannah (Georgia), who tried to determine the origin of this group.

G. Bourquin held from his ancestors, who cultivated them for more than I50 years, and according to him imported them from Europe, two vines: Blue French grape and Brown French. grape. Munson considers the former would be the Jacquez and the latter the Herbemont. According to these two American viticulturists the Jacquez and Herbemont were 


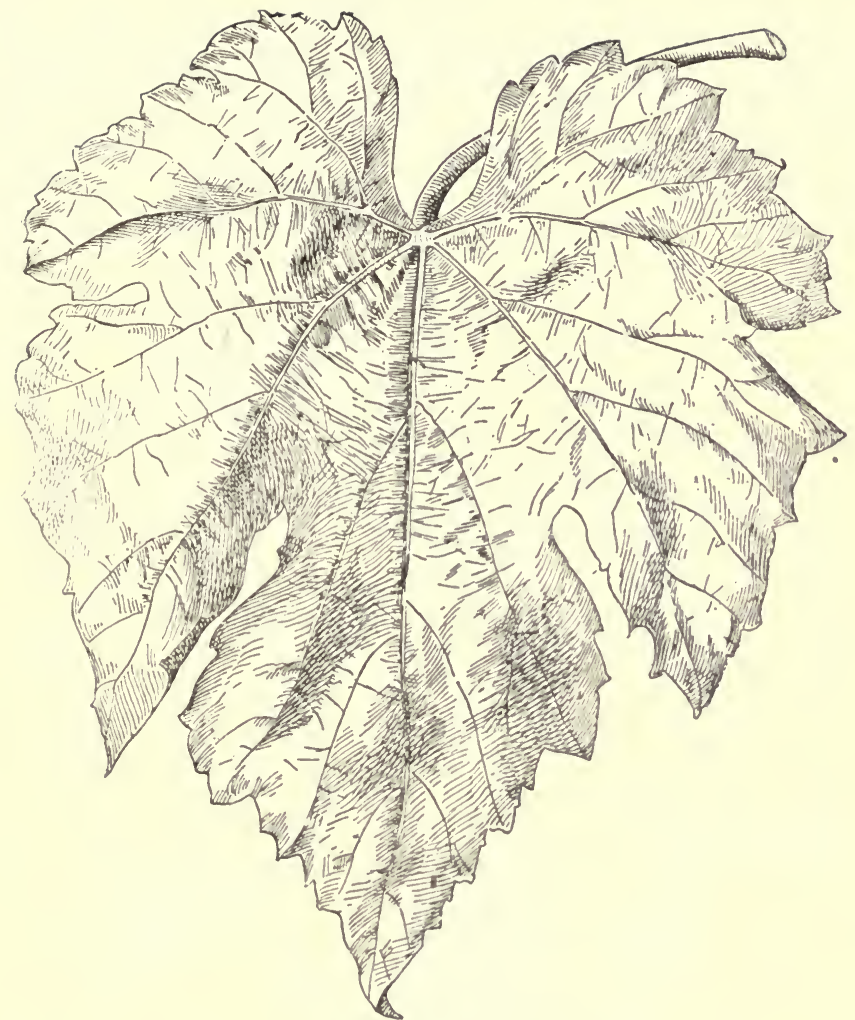

Fig. 87.-Leaf of Jacquez.

imported from Europe to Savannah at the time of the firs: colonization in that country; Munson thinks " the same" applies to Black July, Rulander, and a few other vines of this type which have also an obscure origin which leads us to suppose that they were imported via the Madeira Islands." The relationship with Vinifera can only be explained in the above manner.

Certain historical facts which we have not been able to check have come under our notice, they would, if verified, give more weight to this new idea, as the Jacquez and Herbemont cannot have been hybridized with Vinifera in America, for they were known in the south of Texas, from whence they were distributed all over the United States, from as far back as Ioo years ago, long before any cépages of 
European origin had been imported into the country. The vineyards in the Madeira Islands would have been destroyed long before the invasion of oidium; at that time importations of vines from Virginia and the Central States would have taken place. Accidental hybridization might have been produced in the Madeira vineyards between imported American cépages and indigenous vines, and these hybrids would have subsequently been imported into the United States by the colonists. If this was the case, vines of their nature should be found in the south of Europe. Munson thinks he has discovered Herbemont, or forms very similar to it, in the seeds of a vine recently imported from the province of Valencia (Spain) into Texas.

The Jacquez (Fig. 87) only exists exceptionally in Texas; its cultivation has never extended on account of the great sensitiveness of its leaves to mildew and black-rot. Various attempts at culture of this vine on a large scale had to be abandoned, and Herbemont has replaced and is still replacing Tacquez in the few districts where it is cutivated. The Herbemont (Fig. 88) is, in effect, very resistant to mildew and black-rot, which, until recently, was the greatest obstacle in the culture of vines in the United States. As for the Cunningham, Rulander, and Black July, they are almost unknown in America. The Cunningham, which was cultivated in a few restricted places, was quickly discarded; this also applies in France to Rulander which succumbed to the attacks of phylloxera. The Black July has always been kept in collections, for its productivity was thought to be inferior to that of Jacquez, and because these two cépages were until lately considered only as direct-producers. The Cunningham on account of its great vigour has been grafted and extolled as a graft-bearer in marly, rather calcareous: soils; the results obtained are very conflicting.

Cunningham and Herbemont are less resistant to chlorosis than any others of this group, although their resistance is superior to the American species they originate from; they are, from this point of view, very inferior to Jacquez and Rulander. We consider they derive these characters from $\mathrm{V}$. Cinerea which predominates over V. Vinifera in Jacquez. and Rulander.

All these cépages, especially Herbemont and Jacquez which interest us most, have great affinity to grafting with European vines, properties which also result from their 
relationship with Vinifera. As we shall see when studying grafting, this concordance of affinity accounts for the production of grafts upon Jacquez or Herbemont being normal and equal to that of the French cépages when ungrafted; it accounts also for the maturation of their fruit not being hastened, as takes place in the case of grafts upon Riparia

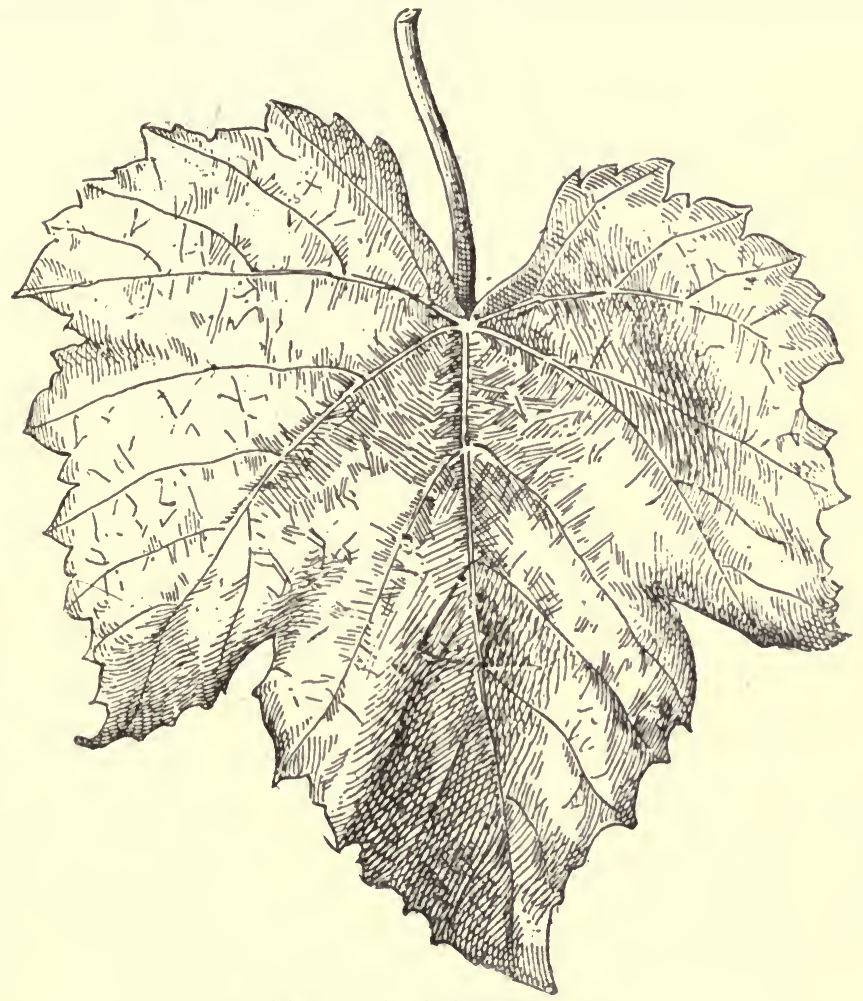

Fig. 88.-Leaf of Herbemont.

and Rupestris, which are also more fructiferous. This is caused by the difference of affinity existing between these graft-bearers and European vines.

These cépages do not root as freely from cuttings or grafted-cuttings as French vines, or Riparia, Vialla, etc., but the proportion of strike is, however, high, and often attains, with ordinary barked cuttings, 80 to 85 per cent. When the nurseries are established carefully, when the grafts are well 
made and well attended to, one obtains with Jacquez and Herbemont quite as good knittings, and a proportion of strike quite as great as with other graft-bearers. It was wrongly supposed that the Jacquez presented great difficulty from this point of view.

All these cépages accommodate themselves perfectly to the climates of the various viticultural regions of France, as has already been said in the first part of this work; there is no danger of the grafted Jacquez or Herbemont being injured by winter frosts. This is certain so far as Herbemont is concerned. The cold during the winter of I890-9I did not injure grafted Jacquez even in regions where the fall of temperature was very considerable $\left(-30^{\circ} \mathrm{C}\right.$. ; Isère). In Maineet-Loire, Jacquez vines twenty-five years old are still in existence; some, twelve years of age, are to be found in Vendée, and in the Charentes of from fifteen to sixteen years. In Virginia and Missouri, where the thermometer falls to $-25^{\circ}$ and $-28^{\circ} \mathrm{C}$., the Jacquez has never been affected by the frost. It is now positively ascertained that Jacquez and Herbemont succeed well, as far as climate is concerned, in the coldest regions in France. It is certain, however, that Herbemont grows better in the north than in the hot dry districts of the south, while Jacquez grows almost everywhere.

The resistance of Jacquez and Herbemont (12) is not of the highest degree, but is sufficient for many soils in the centre, west, and north of France. In warm and dry regions, in very poor soils, phylloxera destroy a great proportion of the hair roots, and produce nodosities and tuberosities, important enough to injure the vine, but the weakening seen in this case is less noticeable in rich, or fresh well-manured soils. The cases of weakening and exhaustion of Jacquez, in dry and poor soils, is far from being constant; the cases of certain and durable success are numerous. There are still in existence, in the Gard and in the south-west of France, Jacquez 30 years of age, which are still quite as vigorous as when first planted out. Jacquez plantations twenty to twenty-five years of age, grafted three to four years after planting out, are not uncommon in the south of France in fresh soils of medium fertility.

But we must admit that there is no reason for Herbemont to be used as a graft-bearer and still less as a directproducer. The Jacquez, which renders some service for reconstitution in fairly calcareous soils where Riparia did 
not thrive, must now be replaced by more resistant cépages possessing the same properties of adaptation, such as Riparia $X$ Rupestris, Rupestris du Lot, Berlandieris, and Berlandieri $X$ Riparia.

The Jacquez, which have been used for reconstitution in fresh and rich soils where phylloxera has not a very intense action, and where they may easily recuperate their hair-roots, are always very vigorous, grafted or not, and we have no reason to doubt their stability.

Jacquez has been used for a very long time in the south of France, where its grapes ripen well when it is grown as a direct-producer, on account of the intense colour and high alcoholic strength of the resulting wine. Its wine always retains, notwithstanding special treatments, a violet colour, which seriously interferes with the sale. But it was, until recently, very much used as graft-bearer in the south of France as well as in northern regions. It was, along with Solonis, a common graft-bearer, which accommodated itself best to rather calcareous soils. It becomes yellow and stunted in white marls and in chalky limestone, but when grafted can withstand an amount of limestone in which Riparia, Rupestris, Vialla, etc., rapidly succumb. In the south of France, for instance, it is green and vigorous in marly laminated limestone of the Miocene, where Riparias become affected by chlonosis and die a few years after being grafted.

Further, the Jacquez thrives well in blue clay, bluish marl, calcareous marls, and generally in all compact and fresh soils where Riparia and Rupestris, although not chlorosed, have little vigour. The Jacquez, on the contrary, is very vigorous, and its excessive vigour sometimes brings about non-setting, but this defect can be easily remedied by long pruning. The Jacquez, like European vines, knits well when grafted at a certain age (between six or seven years old or more), which is not the case for Riparias and Rupestris.

We will not insist on the value of Jacquez seedlings, such as Saint-Sauveur, Jacquez d'Aurelle, Jacquez with large berries, Herbemont, d'Aurelle, Herbemont Touzan, White Herbemont. All these cépages succumb to the attacks of phylloxera, and have deen discarded.

The seedlings of Herbemont, of American origin (Dunn, Harwood, McKee), have the same qualities and defects as 
Herbemont. Finally, let us note that the Blue Favourite has the same properties of adaptation as the Jacquez, and is more vigorous but less resistant to phylloxera.

Hybrids of V. Vinifera and V. Cordifolia.-The V. Cordifolia has very great vigour and attains considerable dimensions. This quality reappears in its hybrids with Vinifera, which are very strong and vigorous plants, possessing a powerful root system. If resistant to phylloxera, they would constitute graft-bearers of great value for all non-calcareous soils. They become very yellow in chalky or calcareous soils, and are of no value in such. Their cuttings root freely, and their grafts knit well. They might, therefore, be multiplied in compact, clayey, or damp soils, as also in dry, poor, but non-calcareous soils.

Hybrids of V. Vinifera and V. Berlandieri.-These hybrids have all been obtained in France. These vines offered, $\dot{a}$ priori, the greatest interest for the reconstitution of vineyards in calcareous soils. Their progenitors are, as a matter of fact, the two species of vines which thrive best in such soils. We may recall the development which FolleBlanche, Pinot, Colombeau, etc., all vigorous varieties of V. Vinifera, attain in the chalky and very calcareous soils of being too weak, or on account of the variety of $V$. Berlandieri, as already stated, is the American species which thrives best in soils of this nature. Non-grafted, its finest varieties are as resistant to chlorosis as Folle-Blanche. Its hybrids, therefore, must possess a high resistance to chlorosis, and the numerous experiments conducted by the writers prove this in an incontestable manner.

All the hybrids of this group cultivated in the Charentes have always remained green when non-grafted, even greener than Folle-Blanche planted side by side with them. Several grafted with Folle-Blanche have never shown a trace of chlorosis, even in the second year, which, as we have shown, is the time when the disease reaches its greatest intensity. Others, on the contrary, have become yellow on account of being too weak, or on account of the variety of V. Berlandieri intervening in the crossing being itself too weak, or incapable of thriving in calcareous soils. We should always choose the most vigorous of these hybrids, as applies to all cépages. 
As already said, it is not sufficient for an American vine to thrive vigorously, when non-grafted, in chalky soils, for it has to constitute a good graft-bearer. Many of them have a fine development in such soils when non-grafted, but when grafted the whole appearance alters; they turn yellow and become stunted. The reason of this phenomenon will be-

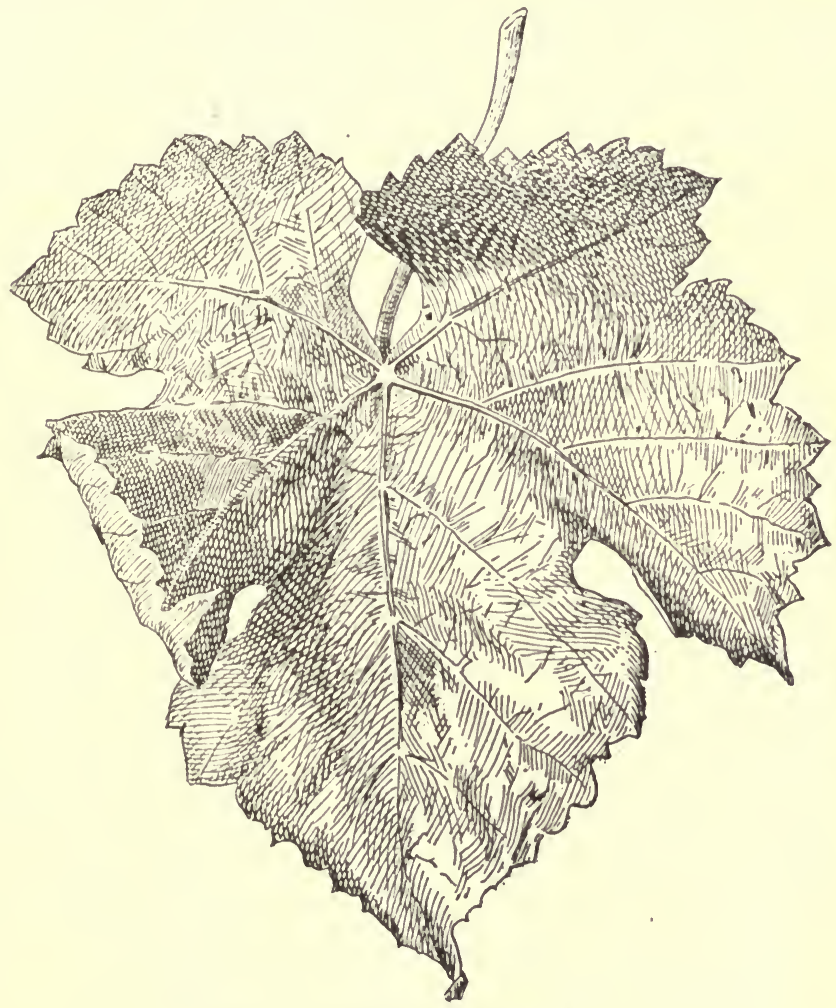

Fig. 89.-Leaf of Cabernet X Berlandieri, No. 333, Ecole.

given later on (see page 2I4). The graft-bearers must not suffer from the operation of grafting, and, therefore, must be as similar as possible, in their physiological functions, to the scions they are to bear. The Vinifera strain which the Berlandieri hybrids contain increases their facility of adaptation, and diminishes also the ill-effects. of grafting. For these two reasons the hybrids Vinifera 
$X$ Berlandieri would be preferable to pure Berlandieri if they possessed good phylloxera-resistant qualities.

We know how difficult it is to multiply this species from cuttings; its hybrids, on the contrary, are very easily multiplied by this means; they knit perfectly, are very fructiferous, and do not present any pad of knitting tissue at the joint.

Among these hybrids we will mention the Tisserand (Cabernet $\times$ Berlandieri No. 333 of the School of Agriculture, Montpellier) (Fig. 89), which has always remained green

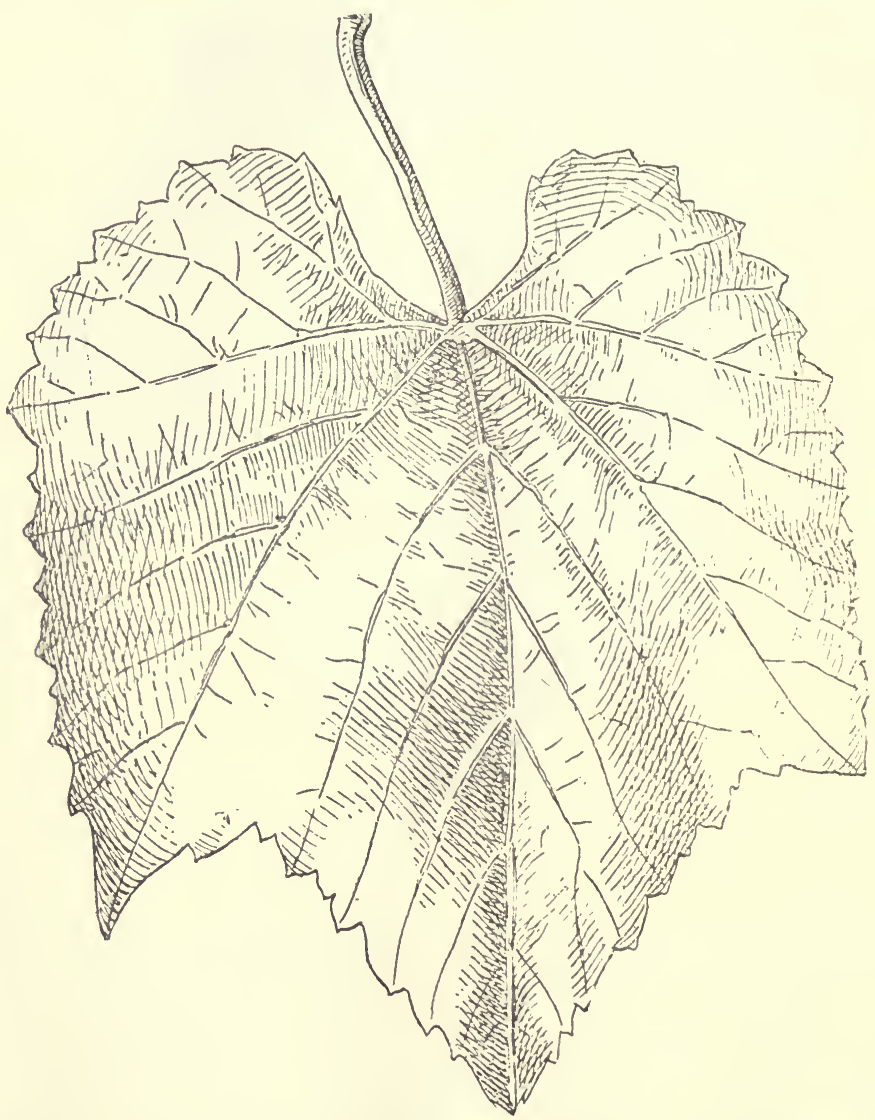

Fig. 90.-Leaf of Chasselas X Berlandieri, No. 4I, Millardet and de Grasset. 
when grafted in the strongly chalky soils of the Charentes; unfortunately, it has not realized expectations as far as phylloxera is concerned. The Chasselas $\times$ Berlandieri No. 4I, of Millardet and de Grasset (Fig. 90), is also very remarkable in its resistance to chlorosis, even in strongly calcareous soils; Millardet considers it resistant to phylloxera.

Hybrids of V. Vinifera and V. Monticola.-Several of these hybrids are of fairly great vigour. Their faculty of adaptation for calcareous soils, although not equal to that of Vinifera $X$ Berlandieri is rather high. Couderc has created a few complex hybrids of Vinifera, Rupestris, and Monticola, which present a certain amount of interest.

Hybrids of V. Vinifera and V. Rupestris.-These are, along with Cordifolia hybrids, the most vigorous vines in existence. Their trunk increases in size very quickly and yields canes occasionally so large that a portion of the cane cannot be used for grafting. The root system is also very powerful.

They strike easily from cuttings, as easily as European varieties; but, like Rupestris, grafting on the growing stock does not succeed unless all the eyes on the stock are removed previous to the operation. Their grafted cuttings succeed well if the precautions indicated further on for Rupestris, are taken.

These graft-bearers are, therefore, interesting. But what is their faculty of adaptation? We know that V. Rupestris is largely affected by chlorosis. Its hybrids, on account of their Vinifera strain, become less yellow, and when ungrafted in the most chalky soils of the Charentes they have a linxuriant vegetation, although sometimes at the second or third year after planting out a slight yellow tint becomes apparent here and there. But, when grafted, they become more yellow in such soils and are quite valueless. In groics soils where chlorosis has less gravity some of them thrive well and remain green and vigorous whether yrafted or not.

To sum up, the Vinifera $\times$ Rupestris hybrids have a geographical area of adaptation much more extended than the Rupestris or Riparia. In the Experimental Station of Cognac, where they are planted side by side, the Rupestris has a resistance to chlorosis represented by 4 , the Riparia by 5 , the maximum being 20 ; the hybrids Vinifera $X$ 
Rupestris vary between 7 and 16 . These figures show how great the influence of $\mathrm{V}$. Vinifera is on the faculty of adaptation of American vines.

The grafts existing on these hybrids are very vigorous, very fertile, and their fruit ripens early.

Several hybrids of Vinifera and Rupestris have been advocated as direct producers. Most of them yield poorly and bear non-foxy but tasteless grapes. The berries are generally small, sometimes very intense in colour. However, the grafting with European varieties diminishes their faculty of adaptation. It is certain that most of them would grow well in calcareous soils, but the poor quality of their truit does not enable them to be utilized.

As a certain number of these hybrids are already in the hands of the vine-growers, we will now study them.

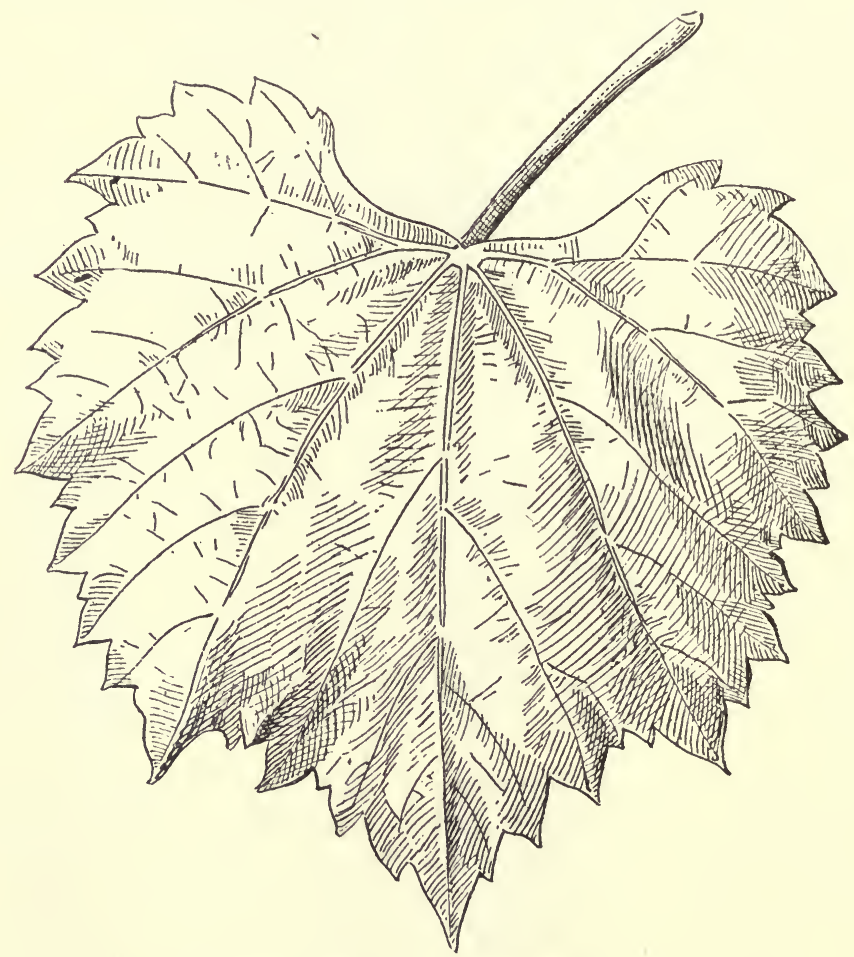

Fig. 9r.-Leaf of Aramon X Rupestris, Ganzin, No. I. 
Aramon $\times$ Rupestris Ganzin No. I (Fig. 9I).--Obtained by Ganzin. This is one of the most resistant to phylloxera and chlorosis; it has the qualities of most of the hybrids of $V$. Vinifera and Rupestris. Quite useless for chalky soils, becoming yellow also in groies soils. This graft-bearer would, therefore, only be of use in slightly calcareous or damp and compact soils.

Aramon $\times$ Rupestris Ganzin No. 2.-Becomes more yellow than the previous hybrids in calcareous soils; its vigour is similar. It knits well when grafted, like all cépages of this group.

Gamay Condere or Colombeau $\times$ Rupestris Martin No. 3103.-Obtained by Couderc, who fecundated the Colombean (a Provence cépage), with Rupestris Martin. This cépage has a fairly powerful growth, and was considered as proof against phylloxera. Unfortunately, its resistance is far from being good, at least, in the collection at the School of Agriculture, Montpellier, where its roots bear numerous nodosities and some tuberosities; phylloxera weakens it, and the vine soon becomes completely stunted in the clay calcareous soi! in which these collections are growing. Under these circumstances, we consider it would be unwise to multiply them as graft-bearers in clay-calcareous, calcareous, dry, and unfertile soils, especially in the south of France. As direct producers they yield very poorly, and the berries are too small. Their faculty of adaptation is the same as that of other hybrids of the group; they are useless for the chalky soils of the Charentes, and become slightly yellow in groies soils.

Mourvèdre $\times$ Rupestris No. I202.- Is more vigorous and less affected by calcareous soils. Would probably be one of the best Rupestris hybrids for poor soils; we must, however, recognise that it withers away like the Gamay-Couderc, as the result of the attacks of phylloxera, in the collection of the School of Agriculture, Montpellier.

We will also mention a few others created by Couderc.

Bourrisquou $\times$ Rupestris Martin Nos. 60I, 603, 604.

Chasselas $\times$ Rupestris Martin Nos. 901, 200I, IIO3.

Mourvèdre X Rupestris Ganzin No. I203.

Rupestris $\times$ Petit-Bouschet Nos. 503, 504.

Rupestris $\times$ unknown No. I206 as direct producers, and Gamay X Rupestris Ganzin Nos. IOOI, IOO2.

Pineau $\times$ Rupestris Martin No. I305, as graft-bearers. 
Millardet and de Grasset also obtained a great number of similar hybrids.

Gros Colman $\times$ Rupestris No I6o are more vigorous than the Rupestris hybrids so far tried in the chalky soils of the Charentes; they also become less yellow, although useless for those soils. They root very freely from cuttings, the grafts knit well, and are very fructiferous. In the groies soils of the Charentes they are better, and do not become yellow, whether grafted or not. The development of their grafts is very satisfactory; but Millardet has ascertained that their resistance to phylloxera is not sufficient.

Cabernet $\times$ Rupestris No. 33 are also very vigorous and fairly resistant to chlorosis.

Alicante-Bouschet $\times$ Rupestris No. I39 are less well adapted to chalky soils, and become yellow in groies soils.

Alicante-Bouschet $\times$ Rupestris No. 136 of the School of Agriculture, Montpellier. Has a powerful vegetation, but is not adapted to calcareous soils, and could, therefore, only be cultivated in compact, siliceous, and non-calcareous soils, for which the pure species is still superior. 'These hybrids seem to be the best as far as resistance to phylloxera is concerned.

We might, again, mention many other hybrids of Vinifera and Rupestris obtained by Millardet, de Grasset, Couderc, Castel, the School of Agriculture, Montpellier, Terras, etc. As a matter of fact considerable numbers of these hybrids have recently been created; the Rupestris, on account of its great vigour, has been much utilized as a hybridizing agent in binary, ternary, or more complex combinations. What has just been said will suffice to give an idea of the general properties of adaptation of this group. We cannot study all its forms.

A few, however, have been advocated as direct producers, such as Franc's Hybrid, Alicante $X$ Rupestris Terras No. 20 , etc. These vines are relatively fructiferous as far as the number of grapes is concerned, but the yield is always small compared with that given by the European vines, and, moreover, the quality of their wine is inferior to that of the most common French wines. The colouring matter of the wine from these hybrids is sometimes very intense; but it has the defect of all Rupestris produce, that of rapidly attenuating. Their resistance to phylloxera has not yet been ascertained. 
Ganzin created by the union of Aramon $X$ Rupestris Ganzin No. I with large Clairette, a hybrid which he named Golden Clairette Ganzin. It is a cépage with white grapes, very fructiferous, ripening late, giving sweet fruit, and relatively good wines. The Alicante-Ganzin was obtained by the fecundation of Aramon $X$ Rupestris Ganzin No. I with Alicante-Henri Bouschet. It is a very fructiferous cépage with coloured juice, giving a very fine wine, but it is also a hybrid containing Vinifera strain, and its resistance, like that of Colden Clairette Ganzin, seems very doubtful.

Hybrids of V. Vinifera, V. Labrusca and V. Rupestris. - Only one of these hybrids (Triumph $X$ Rupestris) has been tried by the writers in the chalky soils of the Charentes. Its composition is as follows:- $\mathrm{V}$. Vinifera, $1 / 4 ; \mathrm{V}$. Labrusca, 1/4; V. Rupestris, 1/2. The slight strain of Vinifera it contains has not endowed it with resistant qualities to chlorosis, it becomes very intensely yellow, and is therefore of no interest for reconstitution of vineyards.

Hybrids of V. Vinifera, V. Rupestris, and V. Lincecumii. - Seibel, of Aubenas, obtained many hybrids of this group, which are very fructiferous, and would give a wine of good quality (Seibel Hybrids). We doubt their resistance to phylloxera, and their resistance to chlorosis is unknown.

Hybrids of V. Vinifera and V. Arizonica.-None of these hybrids (if obtained in France), have been, so far, experimented upon. We cannot therefore state precisely their qualities of adaptation. We can however presume, after what has been said of $\mathrm{V}$. Arizonica, that it is probable that these hybrids would resist chlorosis better than those of Rupestris, without however possessing their great vigour.

Hybrids of V. Vinifera and V. Riparia.-The V. Riparia resists chlorosis better than $V$. Rupestris. We may therefore expect that its hybrids with Vinifera will be less subject to chlorosis, and this is actually the case. In the experimental plots of the Viticultural Station of Cognac, the green tint of the Riparia hybrids is readily distinguishable from that of the Rupestris hybrids; and they seem superior to the best of the latter. 
Although very vigorous, their vegetation is slightly less. than that of the Rupestris hybrids, they are however remarkable cépages with a trunk increasing in size almost as rapidly as that of the scion; the pad of callus at the knitting. point is comparatively insignificant. Their grafts are very vigorous and very fertile.

They would be useless for chalky soils, for when grafted they become yellow. They remain greener in the groie soils of the Jurassic. Their resistance to phylloxera is doubtful.

The Aramon $\times$ Riparia, Nos. I43 and I4I, of Millardet and de Grasset, possesses the same qualities, but cannot be recommended for chalky soils, as applies to all the cépages of this group.

The following cépages possess the same quality of adaptation:-Petit-Bouschet $\times$ Riparia Nos. $300 I$ and 3002, of Conderc, Colombeau $\times$ Riparia Nos. 250I, 2502, PetitBouschet $\times$ Riparia No. I42, of the School of Agriculture, Montpellier, which is more fructiferous and bears finer grapes than the Hybride-Franc; but the quality of its wine is inferior and its resistance to phylloxera is very uncertain.

Hybrids of V. Vinifera. V. Labrusca and V. Riparia. - These ternary hybrids which were created in America are varied and interesting. In a general way, the two elements, Labrusca and Vinifera, have endowed them with an inferior resistance to phylloxera, as will be seen by the figures quoted hereafter; the Riparia corrected this important defect in only very rare cases (Autuchon). The more the Vinifera predominates the weaker the resistance (Canada Secretary), but the less foxy the taste of the fruit is. The resistance to mildew and black-rot is very slight, which is due to the influence of the Vinifera and Labrusca (Canada, Secretary, Othello). The forms, the foliage of which has the greatest similarity to that of V. Riparia have also the greatest resistance to mildew (Autuchon, Cornucopia).

But the influence of $\mathrm{V}$. Vinifera is most pronounced in the characters of adaptation, endowing these hybrids with a relatively high resistance to chlorosis. We will insist on this point when studying a few of these hybrids which had, but fortunately have not, actually, a great importance in France. 
The following are the principal, with their origin and resistance to phylloxera. We will note that they are mostly hybrids of Clinton (Riparia $\times$ Labrusca) and European vines :-

Othello (Clinton $\times$ Black Hamburg No. I, Arnold $)-$ Resistance, 6.

Advance (Clinton $\times$ Black Hamburg, Ricketts).

Canada (Clinton $\times$ Black St. Peter No. ı6, Arnold) Resistance, 4.

Brandt (Clinton $\times$ Black St. Peter No. 8, Arnold)Resistance, 4 .

Cornucopia (Clinton $\times$ Black St. Peter No. 2, Arnold) -Resistance, 4 .

Secretary (Clinton $\times$ Muscat Hamburg, Ricketts)Resistance, 2.

Autuchon (Clinton $\times$ Golden Chassels, Arnold)Resistance, 7.

Naomi (Clinton $\times$ Muscat, Ricketts).

Waverley (Clinton $\times$ Muscat, Ricketts).

Alma (Bacchus $\times$ Vinifera, Ricketts).

August Giant (Black Hamburg, Marion).

Rommel (Triumph $\times$ Elvira, Munson), etc.

Othello has never had any importance in America, where it was discarded on account of its great sensitiveness to mildew, black-rot, grey-rot, brown-rot, and sunstroke. The Othello is generally attacked by these parasites in France; in dry and warm regions it often loses its leaves when the season is unusually hot, and its fruit frequently becomes sunburnt.

The resistance of Othello to phylloxera (6) is relatively weak; therefore, in soils favorable to the multiplication of the insect and in warm regions, the phylloxera may weaken it and bring about its death after four or five years (numerous cases in the south of France, one case in the nursery at Fontenay-le-Comte in poor soils, different case in the Côte d'Or in unfertile soils). The Othello can only resist phylloxera in temperate and cold climates, where the insect progresses slowly, and in fresh rich soils, which check the development of the insect and favour the development of numerous hair-roots. But in such soils the grafting of French varieties on resistant and well-adapted graft-bearers will always give results superior to those which might be 


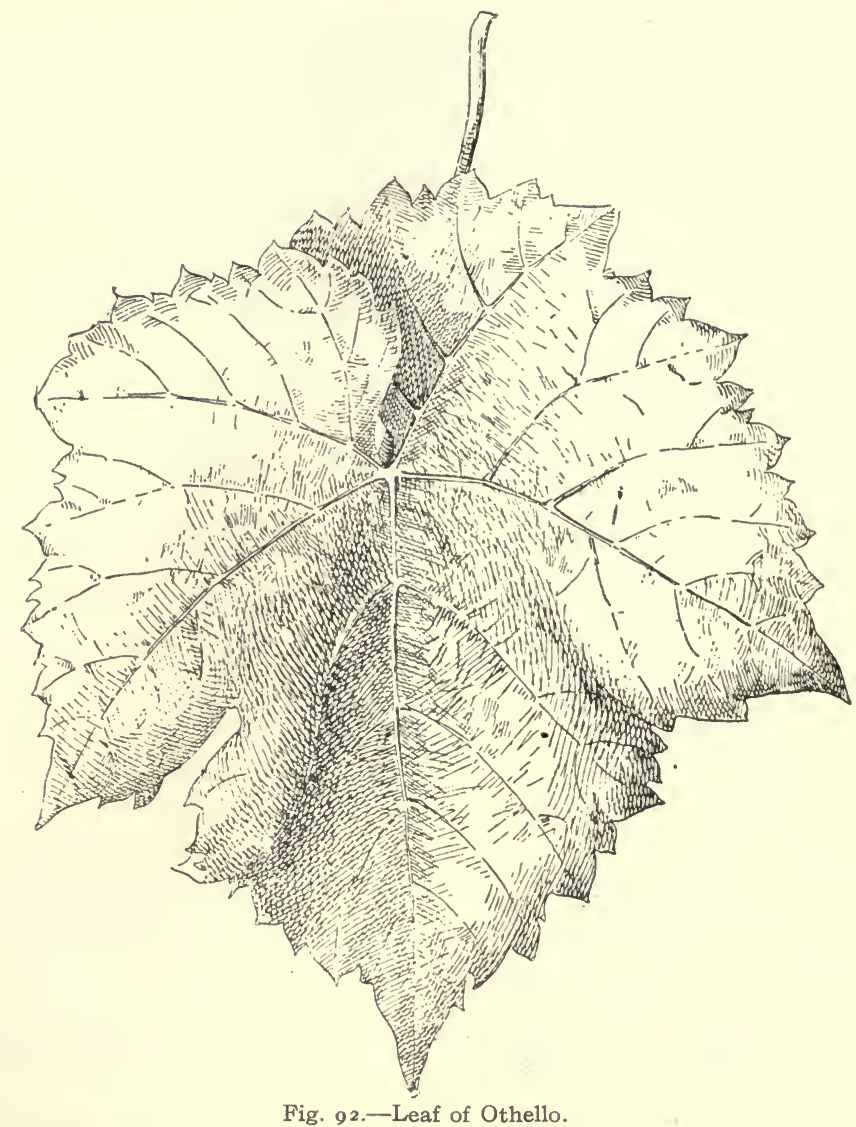

obtained by cultivating Othello. This cépage possesses, however, great fertility, yields of 900 gallons of wine per acre have been obtained in certain rich soils; moreover, its maturity is precocious, which renders its culture possible in the most northern vine-growing countries. But the wines made from Othello, as all those made of other American direct-producers actually known, are inferior to the most ordinary wines made from European cépages. They always retain, the Othello particularly, a foxy after-taste, so much the more pronounced as the wine originates from a warmer climate. In northern regions the foxy taste attenuates rápidly, and may even disappear after a few rackings. 
The Othello has certainly been too much propagated in France, for the different reasons above-mentioned, and actually it must now always be discarded.

It has been noticed that, when ungrafted, Othello possessed a certain resistance to chlorosis. B. Chauzit pointed out this fact that Othello grew without becoming attacked by chlorosis in soils containing up to 50 per cent. of carbonate of lime. Similar facts have been noticed elsewhere. The writers were the first to point out that this resistance to clorosis was due to its relationship with $\mathrm{V}$. Vinifera. Othello has been known to remain green in chalky and marly soils where Noah, Riparia, Rupestris, and Vialla quickly become yellow and stunted. If, however, these soils are favorable to the action of phylloxera, it only lives a few years. Let us remember this fact-that Othello resists chlorosis; it is the only quality it inherits from $\mathrm{V}$. Vinifera.

Canada, Brandt, Secretary, Cornucopia, Autuchon.-The same phenomena of adaptation to calcareous soils which have been pointed out for Othello also apply to these cépages. This is again due to the influence of V. Vinifera.

We have shown, at the beginning of this work, a special case with reference to Cornucopia. Let us notice that the Secretary, the most influenced by Vinifera and therefore the least resistant of these hybrids, is also the least affected by chlorosis in calcareous soils. Canada, Brandt, and Autuchon have the same faculties of adaptation as Othello.

Autuchon is the most resistant of all of these to phylloxera (7); this explains its greater vigour in certain marly calcareous rather poor soils. It bears white non-foxy grapes, with a special agreeable taste, but has very slight productiveness, and is therefore without cultural value.

The Secretary derives from the Muscat Hamburg large fruit, juicy, with a slight Muscat taste; it is fructiferous, but its resistance is only slightly superior to that of varieties of V. Vinifera. Canada and Brandt are less resistant, and less resistant than Othello, but their fruit has a clean taste.

As for the Cornucopia, it not only produces less than the latter (Othello), but its fruit is almost as foxy; it is, however, the most vigorous of all.

None of these cépages can render any service: their culture should be entirely abandoned everywhere. 
Among cépages of this group we will mention the Canada Riparia Nos. $240 I$ and 24I2, which are graft-bearers advocated by Couderc.

Of the hybrids of this group, obtained in France, which we have studied, some have $1 / 4$ Vinifera strain (Canada $X$ Riparia), some $1 / 2$, others $3 / 4$.

One of these, Oporto $\times$ Colombeau, No. I 40 I of Couderc, has been recommended as a direct-producer. It gives, it is true, fruit of a fairly large size, but foxy taste. Its resistance to phylloxera is slightly superior to that of York; but its area of adaptation is very limited. It can only be cultivated in siliceous or slightly calcareous soils, where grafted American vines grow very well. 


\section{PART III.}

\section{CULTURE.}

(a) Conclusions (Choice of V arieties).-From what precedes, it results that the first quality required from a grafting-stock, or direct-producer, is a high resistance to phylloxera; and, in every case that a soil is equally suited to all the American vines, only the most resistant should be planted.

The following table summarizes what has already been said from this point of view for most of them; we will indicate their resistance in the order in which we studied them, and draw attention that the maximum resistance or absolute indemnity is represented by the figure 20 :-

\section{Scale of Resistance to Phylloxera.}

Absolute immunity, 20.

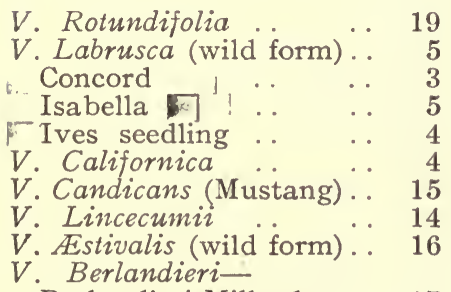

Berlandieri Millardet . . 17

Berlandieri Planchon .. 17

Berlandieri Vialla .. 17

Berlandieri de Grasset . . 17

Berlandieri Ecole .. 17

$V$. Cordifolia $\quad . \quad \ldots 18$

$V$. Cinerea (form studied) 15

$V$. Rupestris-

Rupestris Mission .. 18

Rupestris du Lot $\quad \ldots 16$

Rupestris Ganzin . . 18

Rupestris Martin . 18

Rupestris, with violet shoots 18

Rupestris, with metallic leaves $\quad . \quad \quad \ldots \quad 18$

Rupestris Ecole $\quad$. 18

Rupestris of Fortworth 18

Rupestrisof Kansas (Jæger) 18

Rupestris No. $62 \quad \ldots \quad 18$

Rupestris Arkansas .. 18
Rupestris Cleburne . 18

Rupestris No. $66 \quad \ldots \quad 18$

Rupestris of Texas . 18

Rupestris No. $64 \quad$. 18

Rupestris No. $66 \quad \ldots \quad 18$

Rupestris $x$ (Couderc) $\ldots 18$

Rupestris Y " . 18

$V$. Monticola .. $\quad \ldots 17$

$V$. Arizonica . $\quad \ldots 18$

V. Riparia-

Riparia Gloire de Montpel-

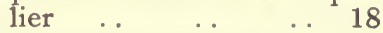

Riparia Grand Glabre . . 18

Riparia Scuppernong .. 18

Riparia Baron Perrier 18

Riparia Tormenteux

$\begin{array}{llll}\text { géant .. } & \text {. } & \text {. } & 18\end{array}$

Riparia Ramond . 18

Riparia Martineau .. 18

V. Rubra A $\quad$. $\quad$.. 18

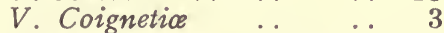

$V$. Amurensis $\quad . \quad \quad \ldots \quad 2$

$V$. Thunbergi $\quad . \quad$. 11

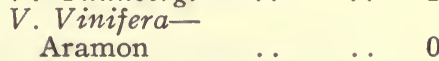

$\begin{array}{llll}\text { Aramon } & \cdots & \cdots & 0 \\ \text { Pineau } & \cdots & \cdots & 0\end{array}$

$\begin{array}{llll}\text { Chasselas } & \cdots & \ldots & 0\end{array}$

Grenache $\quad \ldots \quad \ldots 0$

Etraire de la Dhui .. 1

$\begin{array}{llll}\text { Colombeau } & \text {.. } & \text {. } & 1\end{array}$ 
SCALE OF RESISTANCE TO PHYLLOXERA-continued.

Psalmodi

Ugni blanc

Cabernet Sauvignon, etc. 0 Various Hybrids-

York Madeira .. . . 11

$\begin{array}{llll}\text { Cynthiana } & \ldots & \ldots & 14\end{array}$

Hermann . . . 10

$\begin{array}{llll}\text { Pauline } & \text {. } & \text {. } & 12\end{array}$

$\begin{array}{llll}\text { Taylor } & \ldots & \ldots & 13\end{array}$

Noah $\quad$. $\quad$. 14

Elvira $\quad$. $\quad \ldots \quad 10$

Clinton $\quad$. $\quad \ldots 10$

$\begin{array}{llll}\text { Vialla } & \ldots & \ldots & 14\end{array}$

Black Pearl .. $\quad . .8$

Bacchus $\quad \ldots \quad$. 12

$\begin{array}{llll}\text { Oporto } & \ldots & \ldots & 12\end{array}$

Blue Dyer $\quad \ldots \quad$. 88

$\begin{array}{llll}\text { Uhland } & \ldots & \ldots & 9\end{array}$

$\begin{array}{llll}\text { Marion } & \text {. } & \text {. } & 14\end{array}$

$\begin{array}{llll}\text { Catawba } & \ldots & \ldots & 4\end{array}$

$\begin{array}{llll}\text { Diana } & \ldots & \ldots & 4\end{array}$

Huntingdon $\quad \ldots \quad \ldots 10$

Berlandieri X Candicans-

$\begin{array}{llll}" & \text { No. } 1 & . . & 14 \\ " & \text { No. } 2 & . & 14 \\ \text { " } & \text { No. } 3 & \ldots & 14\end{array}$

Barnes .. $\quad . . \quad \ldots 14$

Berlandieri Bouisset . . 16

Champins glabrous .. 14

Champin tomentose .. 12

Belton .. . . . 17

Candicans X Monticola-

No. 35 Ecole .. . . 17

Candicans X Riparia . . 16

Solonis .. $\quad$. $\quad \ldots \quad 14$

Solonis, with lobed leaves 14

Hutchison .. .. 15

$\begin{array}{llll}\text { Mobeetie } & \ldots & \ldots & 16\end{array}$

Doaniana $\quad \ldots \quad \ldots 13$

Rupestris X Taylor .. 16

Rupestris de Lézignan 16

Azémar
Berlandieri X RupestrisNo. 1 ... . .

Berlandieri X RupestrisNo. 2

Berlandieri X Manticola-No. 114

No. 615

No. 810

Cordifolia X Rupestris de Grasset No. $1 \quad \ldots \quad \ldots \quad 18$

Cinerea X Rupestris (Munson) 16

Triumph $\quad . \quad \ldots \quad$. 44

$\begin{array}{lllll}\text { Senasqua } & \ldots & \ldots & \ldots & 5\end{array}$

Black Defiance $\quad . \quad \ldots \quad 5$

$\begin{array}{lllll}\text { Agawam } & \text {. } & \ldots & \ldots & 6\end{array}$

$\begin{array}{lllll}\text { Irwing } & \ldots & \ldots & \ldots & 5\end{array}$

Black Eagle . . . . . . $\quad$. . 3

$\begin{array}{lllll} & \text { Eumelan } & . & & \\ \end{array}$

Delaware white $\quad . . \quad \ldots .3$

$\begin{array}{llll}\text { Delaware grey } & \ldots & \ldots & 3\end{array}$

$\begin{array}{lllll}\text { Croton } & \text {. } & \ldots & \ldots & 3\end{array}$

$\begin{array}{lllll}\text { Duchess } & \ldots & \ldots & \ldots & 2\end{array}$

$\begin{array}{lllll}\text { Beauty } & \ldots & \ldots & \ldots & 3\end{array}$

$\begin{array}{lllll}\text { Alvey } & \ldots & \ldots & \ldots & 7\end{array}$

$\begin{array}{lllll}\text { Jacquez } & \ldots & \ldots & \ldots & 12\end{array}$

$\begin{array}{llll}\text { Saint-Sauveur } & \ldots & \ldots & 3\end{array}$

Jacquez d'Aurelle-No. 1 . 9

Jacquez, with large berries 11

Herbemont $\quad . \quad \ldots \quad 12$

Harwood . . $\quad . . \quad \ldots 10$

Herbemont d'Aurelle $\quad . \quad 3$

Herbemont Touzan $\quad$. 12

$\begin{array}{llll}\text { Black July } & \text {. } & \text {. } & 11\end{array}$

Blue Favorite $\quad . .969$

$\begin{array}{llll}\text { Cunningham } & \ldots & \ldots & 12\end{array}$

$\begin{array}{lllll}\text { Rulander } & \ldots & \ldots & \ldots & 2\end{array}$

$\begin{array}{lllll}\text { Othello } & \ldots & \ldots & \ldots & 6\end{array}$

$\begin{array}{lllll}\text { Canada } & \ldots & \ldots & \ldots & 4\end{array}$

$\begin{array}{lllll}\text { Brandt } & \ldots & \ldots & \ldots & 4\end{array}$

$\begin{array}{lllll}\text { Cornucopia } & \ldots & \ldots & \ldots & 4\end{array}$

$\begin{array}{lllll}\text { Secretary } & \ldots & \ldots & \ldots & 2\end{array}$

$\begin{array}{lllll}\text { Autuchon } & \ldots & \ldots & \ldots & 7\end{array}$

In grouping the principal and best known varieties we arrive at the following table, showing their scale of resistance, the maximum being 20 :-

No. 20.-Absolute immunity (?).

No. 19. $-V$. Rotundifolia.

No. I8.- $V$. Riparia, $V$. Rupestris, $V$. Cordifolia, Riparia $\times$ Rupestris, Cordifolia $\times$ Riparia, Cordifolia $\times$ Rupestris. 
No. 17.-V. Berlandieri, V. Monticola (?), Riparia $\times$ Berlandieri, Riparia $\times$ Monticola, Rupestris $\times$ Berlandieri.

No. I6.-Rupestris $d u$ Lot, Rupestris de Lézignan, Cinerea, Rupestris, Riparia $\times$ Estivalis.

No. I 5.- $V$. Cinerea, $V$. Estivalis, $V$. Candicans.

No. I4.-Vialla, Solonis, Novo-Mexicana, Noah.

No. I3.-Taylor, Michigan.

No. 12.-Jacquez, Herbemont.

No. II.-York-Madeira.

Nio. Io.-Elvira.

Numbers below Io.-Othello, Autuchon, Concord, V. Labrusca, Senasqua, Black Defiance, Croton, Duchess, etc.

The numbers 16 to 20 correspond to a sufficient resistance for all soils; the numbers I4 and I $_{5}$ express a resistance sufficient for sandy and damp soils, where the phylloxera does little harm; No. I3, and under, should be totally discarde:l from vineyards.

However, there are cases where the choice of a vine cannot be altogether subordinated to its resistance to phylloxera. We have already mentioned, in the first part of this work, the example of the Cornucopia and Solonis, and could add several others.

For sandy and damp soils, where the phylloxera multiplies but little, vines of medium resistance, but well adapted to these soils, should be preferred to other more resistant cépages, which would not develop as well.

In the choice of a variety numerous circumstances, which are of influence on the growth, must be taken into account.

These circumstances have been studied at length in the first and second parts of this work. Here we will only recapitulate the general points, and indicate, for each of them separately, the comportment of the American vines. It goes without saying that in each circumstance these influences operate in varying proportions; the growth of American vines is, therefore, determined by their combined influence; on this the choice of a vine depends.

Several American vines of only slight resistance grow well, for example, in dry soils; but frequently phylloxera has a very intense action, and they have to be excluded from these soils. Others have a very fine growth in a given soil, but for some reason or other they do not set properly, and, 
in this case again, they have to be discarded. These examples will guide the reader in the interpretation of the following indications.

It is evident that in the choice of a vine for reconstitution we must consider:-

Ist The resistance to phylloxera, already discussed.

2nd. The influence of the soil, which is associated with:-

(I.) Humidity.- The vines which accommodate themselves best to this condition are-Cinerea, Mustang and its hybrids, hybrids Vinifera $\times$ Cinerea, Rupestris du Lot, Jacquez, Herbemont, Vialla, Solonis, hybrids of Vinifera $X$ Rupestris, Vinifera $\times$ Riparia, York; then, Riparia, Rupestris; amongst the direct producers, Othello, Canada, Autuchon, Cornucopia, Herbemont, Noah, Elvira, etc., which are not affected.

(II.) Compactness.-For this the American vines may be classed in the same order as the preceding item.

(III.) ARIDITY.- -The Rupestris is the vine which does best in poor soils; then come-Hybrids Vinifera $\times$ Rupestris, Jacquez, Herbemont, hybrids Vinifera $\times$ Riparia, Vialla, Cordifolia $\times$ Rupestris, Riparia $\times$ Rupestris, Solonis, Riparia.

(IV.) Predominance of Silica.-(a) Under the form of fine sand-Vialla, Rupestris du Lot, hybrids Vinifera $\times$ Rupestris, hybrids Vinifera $\times$ Riparia, Jacquez, Herbemont, Rupestris, Solonis, Riparia, and the least resistant vines. (b) Under the form of coarse sand-Hybrids Vinifera $X$ Rupestris, Rupestris du Lot, hybrids Vinifera $\times$ Riparia, Rupestris, Riparia, Jacquez, Solonis.

(V.) Amount of Limestone in the Soll.-From this point of view the American vines may be classed as follows:

In the foremost place-Hybrids Vinifera $\times$ Berlandieri, and the Berlandieri, Riparia $\times$ Berlandieri, Rupestris $\times$ Berlandieri, the hybrids Vinifera $\times$ Riparia, hybrids Vinifera $\times$ Rupestris, Jacquez, Solonis, Rupestris du Lot, Riparia X Rupestris. Finally, the less suitable-Riparia, Rupestris, York, Vialla. Amongst the direct-producers-Cornucopia, Othello, Autuchon, Canada, Brandt, not much affected by limestone; Noah, Elvira, much affected.

In writing down a scale of resistance to chlorosis, we obtain for the value of the various graft-bearers:-

No. I7 and above, $-V$. Vinifera, Chasselas $\times$ Berlandieri or 4IB (Millardet and de Grasset), Tisserand or Cabernet $X$ 
Berlandieri No. 333 (School of Agriculture, Montpellier), many of the Vinifera $\times$ Berlandieri.

No. I6. $-V$. Berlandieri.

No. I5.-Riparia $\times$ Berlandieri.

No. I4.-Rupestris $\times$ Berlandieri.

No. I3.- $V$. Monticola (?).

No. I2.-Vinifera $\times$ Rupestris.

No. I I.-Vinifera $\times$ Rupestris.

No. Io.-Riparia $\times$ Monticola, Taylor $\times$ Narbonne, Colorado.

No. 9.-Vinifera $\times$ Cordifolia, Vinifera $\times$ Cinerea, Othello, Jacquez, Canada, etc.

No. 8.-Novo-Mexicana, Solonis.

No. 7.-Riparia $\times$ Rupestris (IOI ${ }^{14}$ Millardet and de Grasset, 33IO and 3309 Couderc), Riparia-Ramond, Taylor, etc.

No. 6.-Riparias (Gloire de Montpellier, Martin des Paillères, Tormenteaux, Grand Glabre, Scribner), Riparia $\times$ Cordifolia $\times$ Rupestris.

No. 5.-Rupestris (Rupestris Fortworth, Ganzin, Martin), $V$. Arizonica, Riparia $\times$ Rupestris Gigantesque.

No. 4.-Rupestris $\times$ Astivalis, Herbemont, Riparia $\times$ Cordifolia.

No. 3.-Labrusca $\times$ Riparia, Vialla, Noah, Clinton, Elvira ; Cordifolia $\times$ Rupestris, Rupestris $\times$ Cinerea, Triumph.

No. 2.- $V$. Asstivalis, $V$. Cordifolia, $V$. Cinerea, $V$. Candicans, $V$. Labrusca.

The foregoing numbers, in reference to chlorosis, are established in such a manner that each of them corresponds to a percentage of chalky limestone almost equal to the figure representing it multiplied by the co-efficient 2.5 .

We must also consider-

(VI.) The Vigour of the Grafts.-The American vines are classed thus:-Hybrids Vinifera $\times$ Rupestris, Rupestris $d u$ Lot, Vinifera $\times$ Cordifolia, Vinifera $\times$ Riparia, Berlandieri, Rupestris, Jacquez, Herbemont, Vialla, hybrids Vinifera $\times$ Berlandieri, Solonis, Riparia, York.

(VII.) Their Affinity with the European vines grafted on them.-Foremost come the hybrids Vinifera $\times$ Berlandieri and the Vinifera $\times$ Rupestris, hybrids Vinifera $\times$ Cordifolia, Berlandieri, Jacquez, Vialla, Herbemont, the hybrids Vinifera $\times$ Riparia, Rupestris, Solonis, Riparia, York. 
(VIII.) Fer'Tllity of Grafts.-The Berlandieri, Riparic. and Rupestris bear the most prolific grafts; then follow Vinifera $\times$ Berlandieri, hybrids Vinifera $\times$ Riparia, Vinifera $\times$ Rupestris, York, Solonis; then Vialla, Herbemont, Jacque:. Cunningham.

(IX.) EARliness of Ripening of FRUit.-The earliest ripening fruit is of the grafts on Riparia and Berlandieri, Rupestris, Solonis; then hybrids Vinifera $\times$ Riparia, Vinifera $\times$ Rupestris, Vinifera $\times$ Berlandieri; later still, Vialla, Herbemont, Jacquez, Cunningham, York.

(b) Deep Cultivation.-As we have already stated in the first part of this work, the vine, like all plants, prefers a deeply loosened soil. Trenching is therefore necessary, and, if not indispensable (for all American vines can grow in untrenched ground), is at least of the greatest utility for such varieties as the Riparia, most of the Rupestris, etc., which grow very slowly in compact soils. Trenching, however, obtains in many vine-growing regions for the varieties of the $V$. Vinifera, and in many places not a single vine is planted without previously trenching the ground to a depth of 20 inches or even 3 feet.

The vine grows more vigorously during the first years in trenched ground, and bears fruit at the third leaf; while in non-trenched ground it does not bear crops till the fifth or sixth year; an advantage of two or three good crops is thus derived. It is always important to gather a crop as soon as possible, to cover the considerable expenses incurred in planting a vineyard; trenching, therefore, is more than ever necessary; it hastens the growth of the vine, and places it in better condition for its future development.

It is especially necessary for grafted rootlings. These young plants, often weakly at the time of planting, and with a root system always weaker than that of ordinary rootlings, often remain sickly when planted in soils which are not favorable; thorough trenching greatly facilitates their early growth.

Generally trenching to a depth of about 20 inches is sufficient for American vines, a greater depth, however, suits them better. It may be done either by hand or plough. If. in both cases, the soil is not very calcareous, the subsoil should be brought to the surface, where it improves by contact with the air and under the action of successive 
manurings; thus augmenting the thickness of arable soil. Further, as this is devoid of grass seeds, the vineyard may be easily kept free from weeds for several years.

On the other hand, in calcareous soils, or when the subsoil alone is very calcareous, the latter must not be brought to the surface, or even mixed with the arable soil. We all know that carbonate of lime is detrimental to the vine; consequently, it is useless to mix it with the organic claysiliceous or other soils in which the roots grow well, or even to place it on the surface, where the rain would carry it to the roots. Such a trenching would cause the leaves to turn yellow, and consequently prove its harmful effect. It is better in such cases to subsoil.

Trenching under suitable conditions frequently removes the excess of water from damp soils, diminishes their coldness, and renders assimilable the matters which otherwise could not have been utilized by the vines.

(c) Manuring and Planting.-Manuring may be done at the same time as trenching; this method is very good. It may also be done, when planting, with farm manure, or chemical fertilizer; the quantity used being guided by requirements.

In selecting manures care must be taken not to use on already very calcareous soils, road sweepings of calcareous material or débris from old buildings; they induce chlorosis, as has been often proved.

If grafted rootlings are used, further manuring should be done when planting. It is important that the young grafted rootlings should attain as great a development as possible during the first year, in order that the joint may become perfect, and the roots fully established. Those grafted vines which, for some reason or other, are weak during the first year of planting, generally remain so. Therefore, it is always necessary after the land has been trenched to dig holes large enough to allow all the roots to be preserved; they must not be planted with a dibble, as the roots, being left only $\mathrm{I} / 2$ or $\mathrm{I}$ inch in length, are reduced then to the state of ordinary cuttings.

In transplanting, the various organic manures (guano, oil-cake, etc.) are preferable to chemical manures, as they tend to keep the soil loose and friable round the roots. Chemical manures, when in too close proximity, often burn the roots and stem, considerably affecting the welfare of the 
new plantation. On the other hand, if too far away the effect is not felt, or comes too late.

When stable manure is used, I or 2 inches of soil should be placed over the roots before applying it, and a thicker layer, 2 to 4 inches, in the case of chemical manures. The hole is then filled up with soil, which is earthed up so as to cover the whole of the old wood of the scion. In warm climates the joint is placed $I / 2$ to $I$ inch above the surface of the soil, in cold climates a little below.

Planting should be done between November and April. The vines planted before or during the winter are earthed up to the fifth or sixth eye of the scion, which is later on pruned level with the top of the mound. In spring planting, the mounds need not be so high,- to the second or third eye of the scion is sufficient; but it is an important and essential condition for the success of the rooted-grafts that the old wood of the graft be completely covered with soil. The effect of the earthing up is to prevent the evaporation of moisture by the action of the sun and wind on the stem, which, had it been exposed, the rootlets would have been unable to replenish, being deprived of their absorbing extremities. The mounds should not be less than 16 inches in diameter, and each vine should be securely tied to a stake.

In July the mound is removed, and the roots which have grown on the scion cut off; the soil is then slightly earthed up; later on, in August or September, the joint should be exposed to the air. The reason for this will be shown later on.

The following years the joint is exposed by hoeing in spring time; this effectually prevents any rootlets forming on the section.

In wet compact soils the planting of rooted-grafts should only be done after the ground has been well drained. The soil should be firmly tamped round the plant, so that water will not accumulate and remain around the vine, preventing the formation of roots.

For the planting of cuttings and ordinary rootlings the precautions indicated by current practice should be taken.

Can vines be planted where vines have already been growm and uprooted?-It is well known that, except in cases where vines have died from cryptogamic diseases (Pourridié, etc.), we may establish the new vineyard directly after the uprooting bf the old one. If the soil has been too much 
impoverished, its fertility must be recuperated by more abundant manuring; but it is quite useless to let the ground rest for several years, or to cultivate annuals on it.

But if the uprooted vines have been strongly infected with phylloxera, and the roots abundantly covered with the insects, it would be absurd to replant with other than American vines of the highest resistance. Feebly-resistant vines, especially when young, cannot withstand a rapid or strong invasion.

(d) Ploughing.-The object of ploughing is to loosen the surface of the soil, and to prevent the growth of weeds; it should therefore be repeated as frequently as possible. The first ploughing (bareing) and the last (earthing up) must be fairly deep ( 6 inches); all others are more superficial, and done with scarifiers rather than with ploughs; this is above all indispensable for calcareous soils. We know that deep ploughings in spring frequently cause vines to become yellow and that in all soils they bring about non-setting of the grapes, if done at bloom time. The reason of this is that the plough, by destroying the roots living on the surface, that is to say, in less calcareous soils, forces the vine to derive its nourishment from deeper layers, placing it therefore in unsuitable conditions for growth, augmenting the chlorosis, checking the nourishment of all organs, and therefore of the bunches, which consequently do not set.

(e) Distance between Vines.-No improvement can be made on the old local customs. It was thought that the American varieties required more space than the V. Vinifera, but this is not true. Attention is now drawn to the fact that closely-planted vines, while young, give a better yield, and also produce wine of a better quality than those planted at a greater distance apart. Moreover, in ground in which the subsoil is very calcareous, vines planted closely together, having a more limited root development, live more in the upper layers, and are therefore less liable to become yellow ; in this particular case, which applies to very important vineyards, the adaptation to soil is rendered easier by close planting.

( $f$ ) Layering.-The layering of vines is a common method of cultivation in some of the large vineyard districts (Bourgogne, Champagne, Ermitage, Côte-Rôtie, Côtes-du-Rhône, 
etc.), and it is said that the quality of the wine in those districts results from that method of culture. Sometimes the layering is done annually, and all over the vineyard, as in Champagne (Marne); at others only partially, as in Bourgogne, Ermitage, etc. In the latter case the whole stump is layered when the vines become weak, and the layers are heavily manured. The motive for layering in Champagne is to bring the pruning wood close to the soil, and consequently the grapes, and also to develop the roots in the superficial layers of the soil.

From numerous studies and comparative information that we have been enabled to gather, we are of opinion that it is not an indispensable operation for the improvement of the quality of wines; besides, the secondary aim of layering (suppression of the lengthening of the bearing-wood, closeness of the grapes to the soil, etc.) may be obtained without having recourse to this process, the details of which we will not discuss now. We believe that in vineyards planted with grafted American vines this method will be discarded.

But, should we desire to have recourse to it with grafted American vines, the operation is possible, as seems to result from trials made in this direction. The liberation of the scion is, it is true, possible with grafted vines which are completely buried when young (one to two years old), but the abundant growth of roots and their vigorous development on the scion is not to be feared if the vines are older and the knitting perfect. In layering, by completely burying the stump (verified by experiments), vines of three or four years old or more, the liberation of the scion and the indirect diminution of vigour of the stock are not to be feared. We may therefore, if layering is regarded as an indispensable operation (Champagne), practise it, only starting it on knitted vines three or four years old. The roots growing annually on wood of the year layered, do not attain very great development, for they are generally destroyed by phylloxera. Layering, in soils containing a high percentage of soluble limestone, can but favour adaptation. In the chalky soils of the Charentes, grafts on Riparia remain green if a few rootlets are left on the scion; those growing on the layered wood, which always remains weak, attenuate chlorosis.

Trials on layering by complete burying or by simple layering were made at Ermitage, Côte-Rôtie, and different parts of Côtes-du-Rhone. They show the possibility of the 
operation with grafted vines. Foëx has had annual layerings of Pinot grafted on Taylor made at the School of Agriculture, Montpellier. The layering started in I879, when the vines had only been grafted one year, and have been continued ever since; the grafts always retain the same vigour, and have not become liberated from the stock; the rootlets grown on the wood annually layered always remained weak, and were destroyed by phylloxera two or three years after.

( $g$ ) Quality of Wine from Grafted Vines.-We think it is better to discuss this question here rather than when studying grafting, for from this point of view it is only of secondary importance.

At the beginning of the reconstitution of vineyards with American vines, peculiar ideas were formed as to the effects that would result when they were grafted with European vines. It was said, for instance, that red varieties could not be grafted on white kinds (for example, Taylor), and especially that French grafts made on Labrusca, Landicans, Riparia, etc., would produce wines with a foxy, acrid, or harsh taste. The numerous experiences known by agriculturists and arborculturists should have at once condemned that opinion; and facts have since proved it erroneous.

It is now admitted, without dispute, that wines produced from grafted vines are not only of equal, but of appreciably superior quality (particularly in alcoholic strength) to those produced by the same varieties when not grafted. This superiority is due, in most cases, to the earlier ripening of the grapes, as will be explained later on.

But for the finest wines (grands crus) the influence of grafting is still disputed. Some people doubt if, in the districts producing the finest wines, the grafted vines vield as perfect a quality as that obtained before the reconstitution by American stocks, and, for example, that the grafted vines require excessive manuring, and that this treatment. though raising the quantity of wine produced, must indirectly diminish its quality. We have said on several occasions, and the fact is now well known, that some American vines are not more exacting in the matter of fertility than the European varieties. And again, numerous comparisons that have been made in the vineyards producing fine wines (Burgundy, Beaujolais, and Médoc) have fully proved that the quality of the wine from grafted vines is equal, if not 
superior, to that from non-grafted vines. It is evident that, in order to arrive at a serious deduction in the comparison, the fact that old vines give wine of a superior quality to young vines must be taken into account. Conclusions on this point are only of value when the wines compared have been made from vines of equal age, the same variety, grown in similar soils, and submitted to the same methods of culture.

We know, and it is a classical fact, that grafting generally improves the quality. The varieties of the pear, peach, apple, etc., when grafted, bear more luscious and sweeter fruit than those which have not been grafted, and grafted vines form no exception to this general rule. In the Beaujolais, grafted vines, eight, ten, and twelve years old give wines equal, if not superior in quality, to those produced before the phylloxera invasion by vines of the same age. In the Blayais, comparisons of the wines from grafted vines eight or ten years old have been made with great care; the wines produced are of high quality, and do not concede any points to those made formerly. The same may be said of several vineyards (de grands crus) in the Haut and Bas-Médoc, and also of the Saint-Emilionnais, the Libournais, Ermitage, Côte-Rôtie, Côtes-du-Rhône, Châteauneuf-du-Pape, Nerte, Saint Georges (Hérault), where comparisons of the wine from grafted and ungrafted vines five to sixteen years old have been made. Everywhere, and without exception, the quality has been maintained, if it has not even been found superior.

We have only studied here the cultural questions with regard to their direct bearing on reconstitution with American vines and their adaptation. With regard to the complete study of ordinary processes of culture (pruning, ploughing, manuring, diseases and their treatment, etc.), we refer to general treatises on those subjects, and to special works for the various viticultural regions of France. 


\section{PART IV.}

\section{GRAFTING AND NURSERIES.}

The grafting of the vine has been known for centuries; the Roman agriculturists gave very precise indications as to the manner of performing it. The same methods are in use now.

In our French vineyards it has always been a common practice, in order to change the variety, as was done in Languedoc, when, after the advent of railway communication, TerretBourret vineyards had to be transformed to Aramon vineyards; or in order to substitute fertile varieties for non-setting varieties; or to enable delicate and weak varieties to grow in poor soils; and, as often done now, as a means of rapidly multiplying rare cépages.

But it is especially since the use of American vines for the reconstitution of vineyards that grafting has become a general practice. In I869 M. Laliman, at the Congress at Beaune, and afterwards Gaston Bazille, first demonstrated its great importance. Now it is a cultural operation with which every vigneron is familiar. And out of the $1,687,000$ acres of American vines cultivated in France in I895 at least I,446,000 acres were grafted.

\section{I.-ANATOMY AND PHYSIOLOGY OF THE GRAFT.}

We are not going to make a detailed and complete study of this question. Its importance, however, is very great. If we knew exactly how the tissues of the joint knit, the conditions which favour or check the knitting, the phenomena which take place between the stock and the scion, which, while they preserve their individual characters are obliged to live in common, the knowledge would be of the greatest utility, particularly if the desire be to obtain a larger percentage and better joints, and for the choice, when it is possible, of a grafting-stock which would best suit a given European vine. This, however, is completely unknown. We will endeavour to explain how to understand, from known facts, the phenomena of grafting. 
(a) Knitting Tissue.-If the lower section of a cutting bearing one or two buds is placed under suitable conditions of heat and moisture, there appears on its side, as in the case of any other cuttings, small protuberances, termed callus (Fig. 93), which are nothing but masses of healing tissue. They are more numerous and more developed towards the lower end of the section (Fig. 93); and on the splice of a

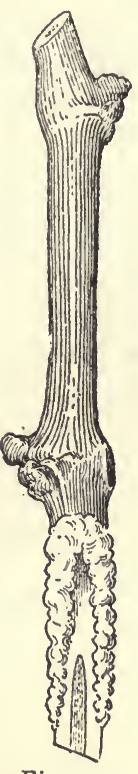

Fig. 03. scion cut in the whip-tongue method the callus appears first at the lower end of the splice; on the side and upper extremity it only develops later on. The object of these tissues is to cover the wound made by this cut by a kind of suberous (corky) layer, and to act as a protection against outside influences (decay, etc.) affecting the living part of the graft (the cambium layer, liber, and bark). The juxtaposition of a corresponding section of the scion on the stock modifies its natural destination.

The wood has nothing whatever to do with the production of healing tissue; its action is nil, and it is never subjected to cellular alteratives. But all parts of the bark (liber), the cells uniting the medullary rays to the fibro-vascular bundles, the layers of medullary rays, the cells which permeate the sieve tubes of the liber, the sieve tubes themselves, the cambium layer Callus or Knitting Tissue (the libriform fibres and exterior layer of developed on a scion. cork excepted), contribute to its formation. But the principal part in the formation of callus devolves on the cambium layer. The mechanism of its formation is as follows:-

The cells in immediate contact with the surface of the section belonging to the parts named become more active, subdivide, multiply, and become elongated in a direction approximately perpendicular to the surface of the cut. The, liber cells and the soft liber become transformed into soft, thin, and non-lignified cells; they subdivide and multiply, and reunite with those produced with the activity of the cambium layer, and constitute the layer or pad of healing tissue. Later on the exterior cells of the callus become 
transformed into cork, and, in one or more layers, form a corky protective envelope, more or less resistant, completely surrounding each protuberance, and generally unite with the corky layers of the cane.

On the upper section of the stock the same phenomena occur, but are not so apparent, and appear much later. The reason of this is that the cane has no tendency to protect wounds on its upper extremity. The same applies to the whole vine. The exposed section made on a cane when pruning never gets covered with callus, the surface of the cut dries up for a variable length, its channels get blocked with gum, etc., but the living cells do not form any cork or other tissue. Every one has seen that cuttings stratified in cool sand or earth form callus excrescences at their base; it is seldom that there is any at the top. It is only when placed in contact with another section that the healing tissue is produced more abundantly. In all cases it is produced in the same manner as on the scion, or on the base of the cutting, and at the expense of the same cellular layers.

If an excision be made on the side of a cane, the knitting tissue at first forms on the upper part of the excision, then on the sices, and finally lower part; it is formed in greater abunciance on the part of the excision looking downwards, following the sides, and later on with more difficulty forms on the part looking upwards.

A longitudinal cleft from the top downwards, on a vinecutting squarely cut off (such as is prepared for an English cleft graft), forms knitting tissue on the lateral sides, but none, or scarcely any, on the transverse section from which the cleft starts. On the oblique section of the splice of a stock prepared for the whip-tongue graft, the knitting tissue seems to form with as much difficulty as on a transverse section

Finally, the knitting tissue forms with greater ease and in greater abundance near the node than on the internode.

These protuberances of healing tissue knit when brought in contact with each other, by the juxtaposition of the sections of stock and scion. The younger they are when brought in contact, that is to say the less suberfied the external cells are, the more perfectly the knitting takes place. It results from this that the two sections must be brought as close together as possible. The cells directly produced by the multiplication of the generative layers knit. One of their 
layers is transformed into a generative layer, knitting with the generative layer of the scion. From this moment the whole plant grows normally above, below, and at the knitting point; and wood inside, liber outside, are formed in the normal way. The cells produced by the other regions of the liber and bark knit also, and become transformed, so as to reconstitute the tissue from which they were derived.

If the pads of callus are only brought in contact when older, the knitting takes place under unfavorable conditions; it takes place, however, in the above-described manner, but only after the external layers of corky cells have become transformed and regenerated.

The tissues resulting from the new generative layer get differentiated, so as to form fibro-vascular bundles, or medullary rays, etc., corresponding to those of the stock. However, more or less numerous anastomoses, arranged in the form of entangled network, are produced at the knitting point. The channels of the wood and liber, newly formed at the joint, are therefore in direct communication with those of stock and scion; the circulation of the sap takes place in almost the same manner as in a non-grafted plant.

If layers of the bark other than the generative layers intervene in the formation of the joint, the part the latter play is by far the most important. The generative layers must exist in the knitting tissue to form the wood inside, which will support the stem and liber outside. The joints in which the liber alone knits (this sometimes happens), are of only temporary duration, unless a generative layer forms to join the generative layers of stock and scion together. We know, as a matter of fact, that every year the liber of the preceding year exfoliates, and becomes detached from the cane in thongs, more or less thick, constituting what vinegrowers commonly call bark.

Such is, roughly, the mechanism of knitting.

In all that precedes, we have assumed that the stock was a portion of cane more or less old. Roots, or portion of root, if large enough, may also be used. Large vine roots have (with the exception of a few liber fibres) practically the same structure as a two or three years' old cane. The knitting therefore takes place in the same manner.

The healing or knitting tissue is not produced as readily by all varieties, whether used as stock or scion. This also applies to many other plants. Some produce no or very 
little callus; others produce it in great abundance. The same facts have been observed with different varieties of vines; some, and these give the greater percentage of takes when grafted, produce callus freely and abundantly (Berlandieri, Cinerea, Rupestris du Lot, Vialla, CabernetSauvignon); others (Solonis, Folle-blanche) always produce it slowly, and in small quantity; the latter evidently do not knit as free or as easily.

But, independently of the nature of each variety, the formation of the knitting tissue also depends on the influence of certain external circumstances. According to Millardet, it is produced more frecly and in greater abundance at a temperature of $20^{\circ} \mathrm{C}$. According to recent researches by Gouirand, it is between $25^{\circ}$ and $35^{\circ} \mathrm{C}$; ; above $35^{\circ} \mathrm{C}$. the graft suffers. Between $\mathrm{I}^{\circ}$ and $2 \mathrm{O}^{\circ} \mathrm{C}$. the formation of callus is very slow. In short, what is required is a fairly high and, above all, even temperature. This explains why scions stratified in light warm soil, deep enough for the temperature to be subject to only slight fluctuations, bear the largest pads of callus.

The degree of humidity of the soil has a very marked influence. If cuttings, or even scions, have their lower extremities immersed in water, no knitting tissue will ever form. Scions stratified in sand, kept very damp by frequent watering, will develop buds, but no or very little callus will form. This frequently happens when grafted cuttings are stratified in too damp moss. In almost dry but fresh sand, on the contrary, enormous pads of callus develop rapidly. Excessive humidity around the joint prevents the formation of knitting tissue; and it is in soils containing from 5 to Io per cent. of water that it is most easily formed.

On the other hand, aeration considerably accelerates its development. The cells in course of rapid growth respire abundantly, they therefore require well aerated surroundings, rich in oxygen. This explains why cuttings buried deeply in compact soil do not form any callus at their base, and why grafted cuttings planted in stiff soils do not succeed well. When the joint of a newly-made graft is enclosed in an indiarubber tube, preventing access of air, the scion sometimes grows for a long while, although no knitting tissue is produced.

(b) Effects of Grafting.- "Affinity."-Connection being established between the vascular bundles of stock and scion, 
let us try to explain what then takes place. In what way will the scion be affected by roots that are not its own, and in what way will the stock be affected by shoots and leaves foreign to it?

In the majority of cases we notice (except, however, when stock and scion belong to the same variety) an almost constant weakening of the scion. We also notice (and more so for cépages where the weakening is more marked) an increased fructification, a greater number of closer set grapes with larger berries, more juicy and frequently richer in saccharine matter, an earlier ripening, only a slight non-setting if any, a diminution in the vigour of the root system, and a greater sensitiveness to phylloxera and chlorosis; finally, we frequently notice the formation of a voluminous pad of knitting tissue at the joint.

Lucien Daniel noticed still more accentuated effects with other plants. "The stock influences the scion and the scion influences the stock in such a way as to modify in a reciprocating manner their physiological properties and anatomical structure." This is, however, very rare. Strasburger pointed out the passage of atropine from scion to stock in a graft of belladonna (Atrophia) on potato (Solanum tuberosum). Daniel also noticed changes of taste due to grafting. The most striking example of this is the Milan cabbage which, when grafted on the turnip cabbage, acquires a decided turnip taste. We also know that cherries differ in taste according to whether they are grafted on Mahaleb or wild cherry. Finally, quite recently, according to a communication made to the National Agricultural Society (France), a horticulturist has succeeded in obtaining a new variety of potato by grafting. This experiment was made with the Richter Imperator as stock and other varieties as scions. The tubers of the Richter Imperator produced under these circumstances were smaller than those produced from the same plant not grafted; but after two or three generations of repeated sowings they attained satisfactory dimensions, retaining a taste quite different to those of Richter.

This instance shows that grafting may be used in order to obtain new varieties. L. Daniel only lately enriched agriculture with a new variety of forage cabbage by this method. To attain this result he started from the principle, established by him, that seeds furnished by scions grafted on stocks of other varieties often gave rise to plants which participate, in 
a greater or lesser degree, of the characteristics of stock and scion.

Grafting would, therefore, seem to have in some cases an action similar to that of hybridization. These facts are, nevertheless, contradicted by Warming. With vines, however, no action of this kind has ever been observed. Berries of vines grafted with Labrusca, Clinton, Taylor, etc., have the same taste as if they were grafted on Jacquez, or on their own roots, or even not grafted at all.

The effects of grafting are the same as those of the annular incision. We know that trees or branches submitted to this operation become more fertile, set better, and bear larger fruit, ripening earlier, than branches not submitted to this operation. This induced some agriculturists to think that the mode of action was similar. In reality it is not. Annular incision only acts as long as the tissues are not knitted; it only increases the fertility while the communication between the tissues of the bark of the branch is interrupted. But directly those tissues knit and the liber at the top of the incision reaches that of the bottom, the effect of the incision disappears; the branch ceases to be more fertile, or to give sweeter fruit, ripening earlier; in fact, the branch resumes its normal functions. Nothing of the kind happens with grafts, except, perhaps, during the first or second year. As long as the knitting is incomplete, the effects may be compared to those of a partial annular incision or, better, to those of any wound. But once the knitting is completed, once all the tissues of the scion are in direct communication with those of the stock, there is no further similarity between grafting and the annular incision.

We are of opinion that this process operates in a different manner. The effects of grafting do not result from mechanical action; they are not due to the operation itself, but they are a consequence of the new conditions under which the grafted plant has to develop; and, therefore, the cause is rather of a physiological order.

There seems to exist, if we may so express it, perfect harmony between the different organs of a plant. Each of them contribute to the development of the others under the best possible conditions. Grafting breaks this harmony. The new stem works under conditions different to that of the stem it has substituted; the matters it elaborates do not 
altogether suit the stock, which, being therefore placed under unfavorable conditions, develops less, suffers, and becomes weaker.* The disturbances manifested after grafting are, therefore, the result of the internal or external individual physiological differences existing between stock and scion. These disturbances can only be noticed in varieties differing from each other, but never occur in the case of a variety grafted on its own roots. The Folle-blanche, grafted on its own roots in difficult soils, behaves exactly as if ungrafted; it is not more affected by chlorosis, its development and fructification are identical. Therefore, the greater the analogy existing between the functions of stock and scion and their mode of living, the less marked will the effects of grafting be. We have seen that European varieties grafted on the species of Muscadinia are successful, but that, grafted on Ampelopsis or Cissus, they die soon after knitting. With Riparia, etc., the physiological functions of which are so different to those of European vines, these phenomena are still very marked; they are less marked with other stocks which, for some reason or other, are more closely related to Vinifera, and this explains why these disturbances are greatly attenuated with Franco-American graft-bearers.

It is very difficult to define exactly the differences of affinity of various American stocks for a given scion, as also to ascertain if the differences of vegetation are due to pro-

* Lucien Daniel (Comptes Rendus, 21st September, $\mathrm{r} 89 \mathrm{I}$ ) arrives at similar conclusions for plants other than vines:

"It seems strange to see plants similarly closely related to the genus Taraxacum, such as Barkansia, Lettuce, and Chicory, behave differently; the first grafting successfully, the two other knitting well, but dying if their adventive roots are removed.

"Anatomical studies may explain this anomaly. The roots of the Taraxacum are gorged with inuline; this substance passes through the membranes of the Barkansia, which assimilates it, as may be ascertained by microscopical examination of tranverse and longitudinal sections of the graft; both stock and scion contain inuline.

"But inuline does not penetrate the scions of Lettuce or Chicory; it has never been detected in them. Therefore, they wither or die, if supplementary food is not given to them through their adventive roots. This is not an isolated case. We may understand that the membranes of some scions are impermeable to certain matters elaborated by the stock, in the same way as Lettuce and Chicory are impermeable to inuline. The failure of many grafts may thus be easily explained by a phenomenon of insufficient nutrition, without having recourse to problematic affinities between genera and species."

These remarks by Daniel apply still more forcibly to the vine and its grafts. It is because the matters elaborated by the scion cannot be assimilated by the stock that the latter remain weak, and eventually its weakness affects the whole plant. But is it simply because the membranes of the stock do not allow these substances to pass through that they remain unassimilated? If it is so, it is apparent that before the grafting these substances were unnecessary to the stock, and that afterwards they become inimical to its development. 
perties of adaptation to soil rather than reciprocal action between stock and scion. We can ascertain it by studying the chemical composition of grafted vines. Those suffering least from grafting are evidently those the composition of which is closest to that of the same vines ungrafted. The chemical composition of Folle-blanche grafted on its own roots and of the same vine ungrafted is identical. There is more nitrogen and less starch above than below the joint, and similarly in the ungrafted vine there is more nitrogen and less starch above than below the collar. With European vines grafted on pure American stock the phenomena is just the reverse. Grafted Franco-Americans have an identical chemical composition to Vinifera grafted on their own roots or ungrafted. This is an indirect proof of their great affinity to European vines.

The various American stocks in use show considerable differences of "affinity" with varieties of V. Vinifera. These differences have been studied for each of them. Let us remind that V. Labrusca varieties have the greatest affinity to European vines. The Vialla, Taylor, Noah, YorkMadeira, provided their resistance to phylloxera and adaptation to soil are not taken into consideration, associate well with European varieties, and do not appear to suffer from grafting; Labrusca and Vinifera present, in fact, great analogy in their development.

But the diverse European varieties do not all behave in the same manner with a given American stock; some are very vigorous, others remain weak. Table No. I clearly indicates these differences.

The figures given to each graft-bearer must be read vertically; they only indicate in what manner the various European varieties experimented upon behave in regard to a given graft-bearer; they do not allow comparisons to be made between the affinities of different graft-bearers, as the growth of the latter, represented by the figures, is not only the result of their affinity with the scions they bear, but also the effects of phylloxera and influence of soil.

Tables Nos. 2, 3, and 4, condensed in tables Nos. 5 and 6, which were communicated by Professor E. Durand, of the School of Agriculture, Montpellier, indicate the comparative differences of fructification of two French vines, Aramon and Carignane, when grafted on various American stocks. Table No. 7 shows the comparative circumferences of stock and 
scion. We will not insist on these differences, as the figures show them clearly, but point out, however, that grafts on Berlandieri are the most fructiferous, and that this cépage does not show any difference in diameter between stock and scion.

TABLE No. 1.

EXPERIMENTS ON GRAFTING AFFINITY, MADE AT THE SCHOOL OF AGRICULTURE, MONTPELLIER.

(Age of stock 15 years. Age of scion 14 years.)

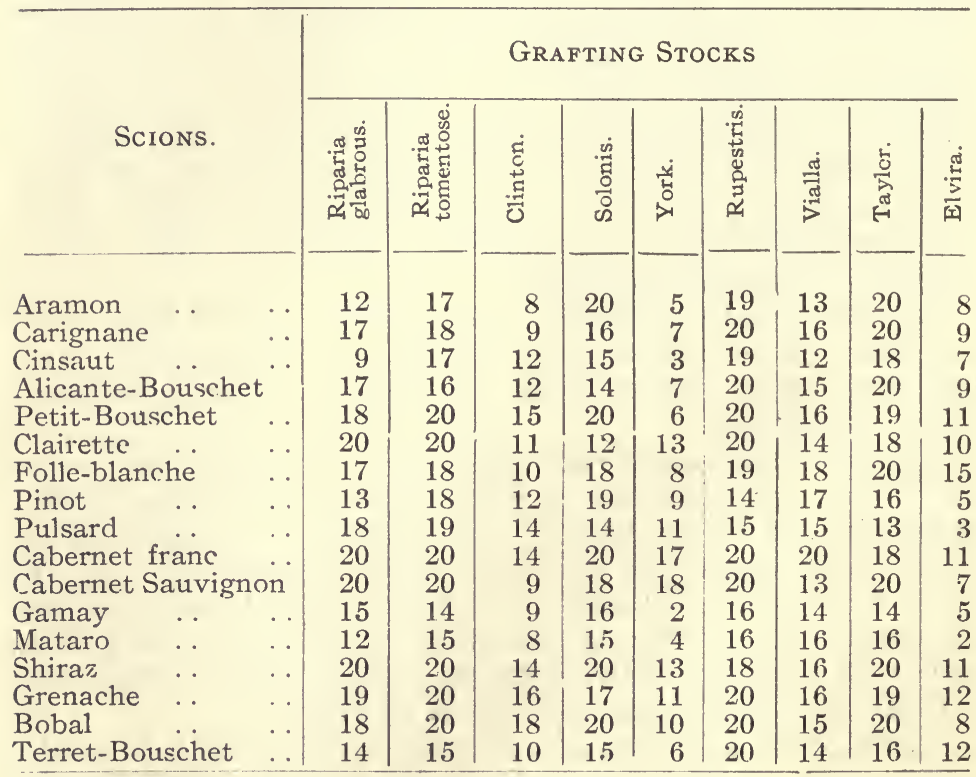




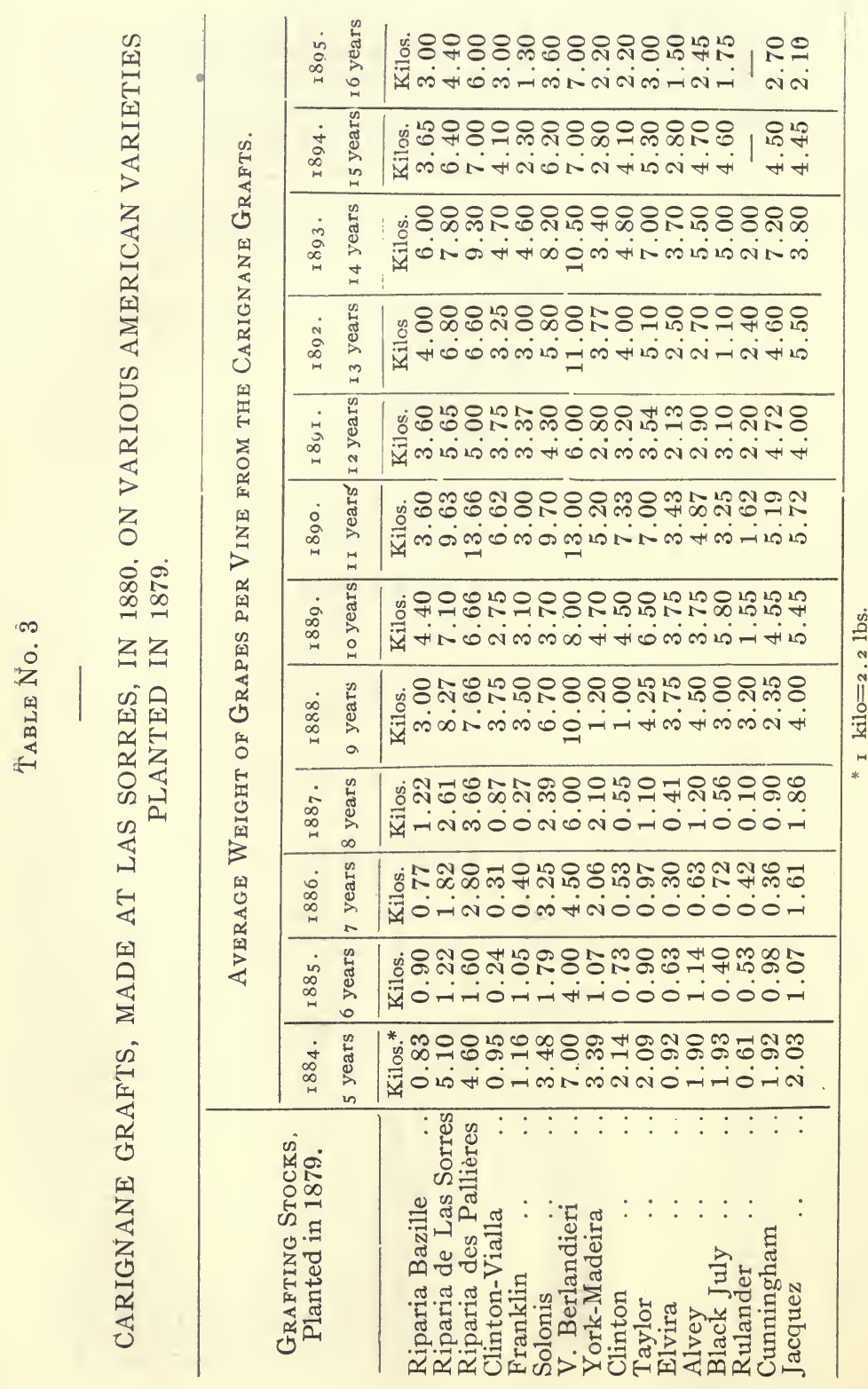


Table No. 4.

ARAMON AND CARIGNANE GRAFTS, MADE AT LAS SORRES, IN 1890 AND 1891, ON VARIOUS AMERICAN VINES PLANTED IN 1889.

(Comparative Weights of Grapes per Vine.)

\begin{tabular}{|c|c|c|c|c|c|c|}
\hline \multirow{2}{*}{ Grafting Stock. } & \multicolumn{3}{|c|}{ ARAMON. } & \multicolumn{3}{|c|}{ CARIGNANE. } \\
\hline & 1893. & I 894. & I 895. & 1803 & I 894 & 1896. \\
\hline $\begin{array}{l}\text { V. Berlandieri } \\
\text { Riparia Gloire } \\
\text { Rupestris Martin . }\end{array}$ & $\begin{array}{r}\text { Kilos.* } \\
5.60 \\
5.00 \\
4.40\end{array}$ & $\begin{array}{l}\text { Kilos. } \\
6.20 \\
5.10 \\
6.20\end{array}$ & $\begin{array}{l}\text { Kilos. } \\
5.60 \\
3.50 \\
3.40\end{array}$ & $\begin{array}{l}\text { Kilos. } \\
5.80 \\
5.00 \\
280\end{array}$ & $\begin{array}{l}\text { Kilos. } \\
5.60 \\
4.80 \\
4.60\end{array}$ & $\begin{array}{l}\text { Kilos. } \\
2.00 \\
1.50 \\
1.00\end{array}$ \\
\hline
\end{tabular}

* I kilo=2 2.2 lbs.

TABLE No. 5

COMPARATIVE FRUCTIFICATION OF BERLANDIERI AND OTHER GRAFTING STOCKS.

\begin{tabular}{|c|c|c|c|c|}
\hline \multirow{2}{*}{ Grafting Stock. } & \multicolumn{2}{|c|}{ ARAMON. } & \multicolumn{2}{|c|}{ Carignane. } \\
\hline & $\begin{array}{c}\text { Tctal } \\
\text { for I } 2 \text { years } \\
\text { for one Vine. }\end{array}$ & $\begin{array}{c}\text { Average } \\
\text { for I } 2 \text { years } \\
\text { for one Vine. }\end{array}$ & $\begin{array}{c}\text { Total } \\
\text { for i } 2 \text { years } \\
\text { for one Vine. }\end{array}$ & $\begin{array}{c}\text { Average } \\
\text { for I } 2 \text { years } \\
\text { for one Vine }\end{array}$ \\
\hline 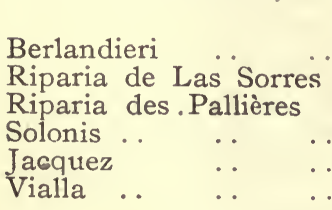 & $\begin{array}{l}\text { Kilos. } \\
96.35 \\
83.67 \\
78.91 \\
73.30 \\
52.97 \\
34.60\end{array}$ & $\begin{array}{l}\text { Kilos. } \\
8.03 \\
6.95 \\
6.57 \\
6.19 \\
4.41 \\
2.88\end{array}$ & $\begin{array}{l}\text { Kilos. } \\
94.00 \\
62.90 \\
74.55 \\
61.12 \\
42.66 \\
35.30\end{array}$ & $\begin{array}{l}\text { Kilos. } \\
7.83 \\
5.24 \\
6.21 \\
5.09 \\
3.55 \\
2.94\end{array}$ \\
\hline
\end{tabular}


TABLE No. 6.

COMPARATIVE FRUCTIFICATION OF BERLANDIERI, RIPARIA GLOIRE, AND RUPESTRIS MARTIN.

\begin{tabular}{|c|c|c|c|c|}
\hline \multirow{2}{*}{ Grafting-Stock. } & \multicolumn{2}{|c|}{ Aramon. } & \multicolumn{2}{|c|}{ Carignane. } \\
\hline & $\begin{array}{c}\text { Total for } \\
3 \begin{array}{c}\text { years for one } \\
\text { vine. }\end{array}\end{array}$ & $\begin{array}{c}\text { Average for } \\
\begin{array}{c}\text { years for one } \\
\text { vine. }\end{array}\end{array}$ & $\begin{array}{c}\text { Total for } \\
3 \text { years for one } \\
\text { vine. }\end{array}$ & $\begin{array}{c}\text { Average for } \\
3 \text { years for one } \\
\text { vine. }\end{array}$ \\
\hline $\begin{array}{l}\text { Berlandieri } \\
\text { Riparia Gloire .. } \\
\text { Rupestris Martin }\end{array}$ & $\begin{array}{l}\text { Kilos. } \\
15.40 \\
13.60 \\
14.00\end{array}$ & $\begin{array}{r}\text { Kilos. } \\
5.13 \\
4.53 \\
4.66\end{array}$ & $\begin{array}{l}\text { Kilos. } \\
13.40 \\
11.30 \\
8.40\end{array}$ & $\begin{array}{l}\text { Kilos. } \\
4.46 \\
3.76 \\
2.80\end{array}$ \\
\hline
\end{tabular}

TABLE No 7.

COMPARATIVE CIRCUMFERENCES OF THE SCION AND STOCK WITH VARIOUS GRAFTING-STOCKS.

\begin{tabular}{|c|c|c|c|c|c|c|c|c|}
\hline \multirow{2}{*}{ Grafting-Stock. } & \multicolumn{2}{|c|}{ Aramon. } & \multicolumn{2}{|c|}{ Aramon. } & \multicolumn{2}{|c|}{ Carignane. } & \multicolumn{2}{|c|}{ Carignane. } \\
\hline & Stock. & Scion. & Stock. & Sciòn. & Stock. & Scion. & Stock. & Scion, \\
\hline Grafts of $16 \mathrm{ye}$ & $\mathrm{Cm} *$ & $\mathrm{Cm}$. & $\mathrm{Cm}$. & $\mathrm{Cm}$ & $\mathrm{Cm}$ & $\mathrm{Cm}$ & $\mathrm{Cm}$. & $\mathrm{Cm}$. \\
\hline $\begin{array}{l}\text { Berlandieri } \\
\text { Riparia des Pallières } \\
\text { Riparia de Las Sorres } \\
\text { Riparia Bazille }\end{array}$ & $\begin{array}{c}30.0 \\
15.5 \\
17.0 \\
-\end{array}$ & $\begin{array}{l}26.5 \\
21.0 \\
18.5 \\
11.0\end{array}$ & $\begin{array}{l}17.5 \\
- \\
-\end{array}$ & - & $\begin{array}{l}18.0 \\
12.5 \\
15.0 \\
11.0\end{array}$ & $\begin{array}{l}20.0 \\
15.0 \\
15.0 \\
140\end{array}$ & $\bar{z}$ & - \\
\hline Grafts of 6 years- & & & & & & & & \\
\hline $\begin{array}{l}\text { Berlandieri . } \\
\text { Riparia Gloire } \\
\text { Rupestris Martin }\end{array}$ & $\begin{array}{l}11.5 \\
12.5 \\
11.5\end{array}$ & $\begin{array}{l}11.5 \\
11.7 \\
12.5\end{array}$ & $\begin{array}{r}12.5 \\
9.0 \\
10.5\end{array}$ & $\begin{array}{l}12.5 \\
10.0 \\
12.5\end{array}$ & $\begin{array}{r}15.0 \\
9.5 \\
12.0\end{array}$ & $\begin{array}{l}14.5 \\
13.0 \\
12.5\end{array}$ & $\begin{array}{r}14.5 \\
8.0 \\
14.0\end{array}$ & $\begin{array}{l}14.0 \\
14.5 \\
13.0\end{array}$ \\
\hline
\end{tabular}

${ }^{*}$ I inch $=2.53$ centimetres. $\mathrm{I}$ centimetre $=0.30$ inch. 
Besides the indications given in the above tables, every grower may gather others as the result of personal experience.

In the south of France, the Cinsaut grafted on Riparia does not grow well, and remains weak; Carignane grows better than Aramon, on Jacquez or Riparia. Aramon has a medium affinity for American stock; on Riparia it leaves nothing to be desired. Clairette is one of the least affected by grafting; it remains green in calcareous soils where other varieties die from chlorosis, it has even been known to attenuate the chlorosis of Herbemont when grafted on it. This may be so, and yet not be the result of the affinity for scion stock. The Alicante-Bouschet, as well as the Alicante, from which it is derived, do not live long when grafted. In this respect the Petit-Bouschet is superior. The Espar (Mataro) grows poorly when grafted, especially if on Riparia; it does better on Rupestris. It is very sensitive to chlorosis in calcareous soils, and in the Charentes, where it was extensively cultivated, it had to be discarded from all soils liable to cause chlorosis. Grenache has a medium affinity. The Terrets (Terret noir, Terret gris, Terret-Bouschet) are rather weak and sensitive to chlorosis when grafted. The Aramon-Teinturier-Bouschet is still poorer, and rapidly becomes stunted. The Morrastel is not much affected by grafting. The white Ugni or SaintEmilion of the Charentes remains vigorous, but is affected by chlorosis to the same extent as Folle-blanche. The Muscats, as also Colombeau or Saint-Pierre, the Picquepouls, and Grand Noir de la Calmette do well when grafted.

The Cabernet-Sauvignon remains vigorous when grafted. although rather sensitive to chlorosis. This also applies to Cabernet-Franc, Carmenère, Verdot, and Saint-Macaire. Malbec is more sensitive to chlorosis than Cabernet.

Merlot is little affected by chlorosis; it may even be said to improve the growth of the stock, but this fact has not been sufficiently proved. Grafted on Vialla, it remains green in soils where the Vialla itself is affected by chlorosis. In the Saint-Emilionnais district, it is cultivated in calcareous soils where Cabernet and Malbec suffer from chlorosis. The Castets grafted on Riparia leave much to be desired. At first they develop normally, but soon become stunted with short-jointed canes and poorly developed jagged leaves; This does not occur in deep, rich soils suitable to Riparia; 
but is frequently noticed in poor calcareous soil, especially in spring time, and results in complete non-setting. In summer the vegetation becomes normal again, so that grafted Castets have, at the end of summer, a peculiar appearance; the base of the canes having short internodes and jagged leaves, the top bearing leaves and internodes normally developed. The Grappu does well on Riparia and Jacquez. According to Girard, the Béquignol and Quésan must be placed in the first rank. Sauvignon and Muscadelle do well on American stock; Sémillion is not so satisfactory.

Folle-blanche when grafted has a medium growth and suffers slightly from the operation, less, however, than Balzac or Mataro; planted side by side with Merlot in the same soil it becomes yellow, while the latter remains green. The white Jurancon turns even more yellow, and has little vigour. The Saint-Emilion is vigorous, and is affected in the same manner as the Folle. The Blanc-Ramé grows well when grafted. The Blanc-Limouzin is very vigorous and not very subject to chlorosis; it does badly on Solonis, becoming stunted in spring time like Castets. The SaintPierre remains vigorous, and is little affected by chlorosis. Colombard does not turn as yellow as Folle, and becomes green again sooner; it is also more vigorous, may be cultivated in p.oor soils, and does well on Riparia. The Petit Noir is rather less vigorous, and turns yellow after grafting. Mataro is very liable to chlorosis. The Saint-Rabier is a little less vigorous than Malbec.

The Muscadet of the Loire-Inférieure grows regularly, and bears well on Solonis, Jacquez, and Riparia, turning only slightly yellow. The white Chenin and black Chenin are good grafts.

The Pinot is more sensitive to chlorosis than Gamay. The black Gamay non-grafted has little vigour, but is not subject to chlorosis. The white Gamay always remains green. The Pulsard is rather less vigorous when grafted. The Enfariné remains vigorous and green.

The Syrah (Shiraz) grows luxuriantly when grafted. It is one of the vines that is least affected by grafting and does well on Riparia. The Mondeuse grows well when grafted, but is rather liable to chlorosis. Etraire, Persan, Durif, and Corbeau do well on American stock, as also the Roussanne. Marsanne, black Mornin, and Viognier, are not so 
satisfactory. Among vines not impaired by grafting may be mentioned Rosaki, Sultanieh, Sainte-Marie, etc.

If weakening of the vine, as the result of grafting, is produced in most cases, occasionally it has the opposite effect. We may see weak chlorosed vines become vigorous after grafting. The Herbemont, which so quickly turns yellow in calcareous soils, remains green when grafted with Clairette; the Merlot on Vialla, in the calcareous soils of the Vendée, remains green and vigorous, while the Vialla alone turns yellow and become stunted in the same soil.

In general, the graft increases the fertility, although it reduces it in a few particular instances. These facts may be explained by reasons of the same order as those given above, we need not, therefore, repeat.

The phenomena that have been recorded with regard to the vine have been observed to apply to all fruit trees.*

\section{II.-SYSTEMS OF GRAFTING.}

It is scarcely possible for us to describe all the different systems of grafting, some of which have been experimented upon more or less, and are very ingenious indeed. Among

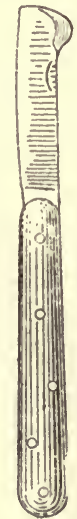

Fig. 94 Grafting-knife.

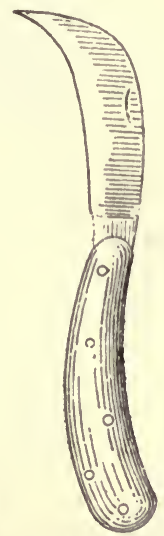

Fig. 95 . Grafting-bill

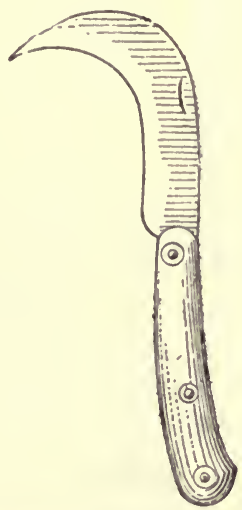

Fig. 96 .

Grafting-bill with curved blade.

the latter, the whip-tongue graft and the English cleft-graft are the better known; we will limit this study to them.

* See F. Sahut Les vignes Americaines; J. E. Planchon, Conference sur le greffuge, Bulletin Soc. d'Agr. de l'Hérault. ז870; Decaisne, .4mateur des jardins et furdin fruitier du Museum, etc., etc. 
(a) Whip-tongue Graft.-Stock and scion are both spliced in the same manner (Fig. 97); both sections should have

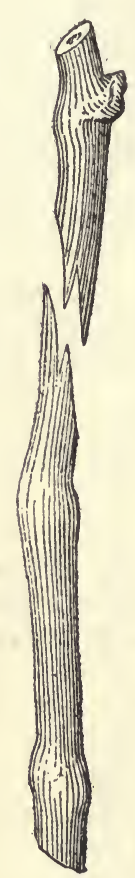
perfectly corresponding outlines and surfaces, therefore stock and scion should be of the same diameter. The stock, rooted or not, is cut level at its upper extremity as close as possible to the node, for, as we have already said, it is at that point that the knitting tissue is formed with the greatest facility. The length of the splice depends on the size of the cane. Generally, the section is made at an angle of $\mathrm{r}_{4}$ degrees for thin canes, so as to allow it to be long enough to secure a strong grip, and I7 degrees for stout canes. It is usually made by hand with a graftingknife (Figs. 94 to 98), the section being cut neatly and without bruised edges. It can also be made by means of special machines, which all have the capital fault of requiring, like the knife, a long apprenticeship from the operator, without greatly increasing the rapidity of the work, and generally giving defective sections and bruising the tissues. When made with the knife, the sections must be cut with one sweep, if not, the section is more or less irregular or bruised; concave must be preferred to convex surfaces, for they render the

assemblage easier and firmer. The splice

Fig. 97. - Stock and Scion prepared for the whip-tongue graft. once made, a longitudinal slit parallel to the fibre of the wood, and $6 \mathrm{~mm}$. ( $1 / 4$-inch) at least in depth, is made with the same knife. When taking the blade out of the slit, a slight rotary movement is given to the knife so as

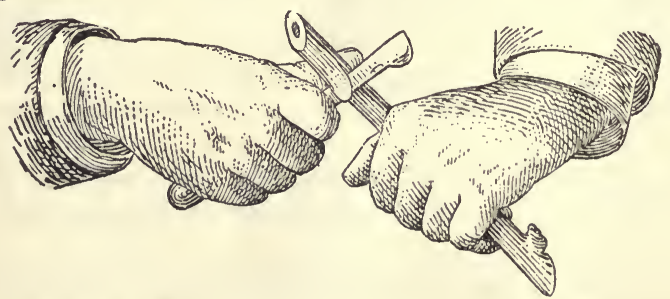

Fig. 98.-Preparation of Stock for the whip-tongue graft. 
to leave the slit open and facilitate the insertion of the tongue. The object is to consolidate the assemblage, but it also facilitates the production of callus. For, as already

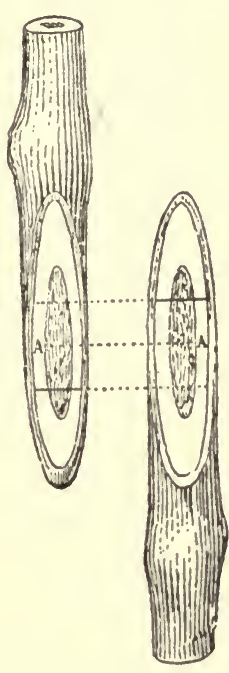

Fig. 90.

Sections of Stock and Scion.

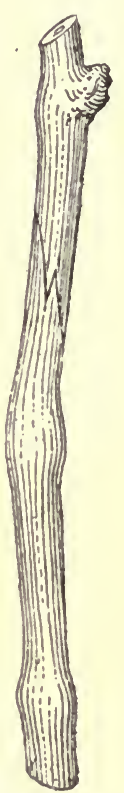

Fig. 100 .

Joint of whip-tongue graft.

explained, callus will be produced in greate ${ }_{i}$ abundance on a longitudinal than transverse section. Further, the callus first appears on the inner walls of the slit.

The point where the slit is made has not very great importance, and the pith need not enter into consideration. The pith, contrary to the old belief, does not play any part in the life of the plant; it can be removed without inconvenience. But what is more important is that the point where the slit begins and the point where it ends be at an equal distance from the centre of the section, so as to allow their exact juxtaposition (Fig. 99). Therefore, the closer to the centre the shallower the slit will be. If it is not made in the way indicated, the adjustment will be defective; if too short, the sections could not cover each other: if too long, the joint will lack in strength. 
The scion, with one or two eyes, is cut in a similar manner at its base. To make the joint, the tongue of the scion is inserted in the slit of the stock, the tongue of the stock in the slit of the scion, forcing a little, till the juxtaposition of the two sections is perfect (Fig. IOO), the whole is then firmly maintained together by means of a ligature.

The whip-tongue graft is that which gives the best knitting; stock and scion being cut exactly alike the juxtaposition is perfect, and leaves no portion of the section exposed to the air, there is, therefore, no scar, and the circulation of the sap takes place almost in the same manner as in an ordinary cutting. The outside surface in this case is smooth, and in many cases it is impossible to detect, by superficial examination, the point where the graft was made.

On the other hand, if the

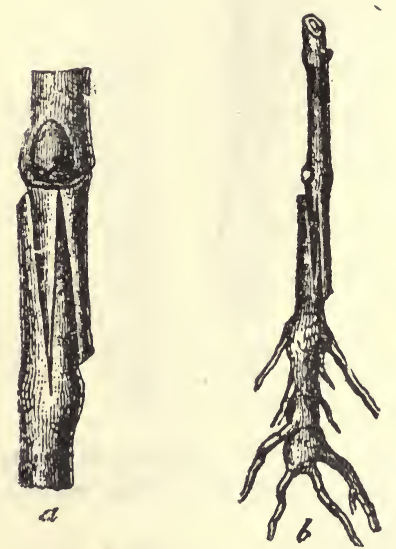
whip-tongue graft gives the best knitting, it gives less takes. The reason for this is, that the oblique section of the stock produces callus with difficulty, as already explained; the walls of the slit produce it in greater abundance it is true, that is why it must be made deeper than is customary, that is to say, it begins further from the centre of the section.

The "Champin Graft" (Fig. IOI) is only a modification of the whip-tongue; it is more difficult to perform, it gives less satisfactory knittings, for

Fig. xor.-Champin Graft.

a part of the section is exposed to the air; and, moreover, it facilitates the growth of roots on the scion.

The whip-tongue graft can only be used when stock and scion are equal in diameter; when the stock is larger than the scion, the ordinary cleft-graft is used.

(b) Ordinary Cleft-Graft.-The stock, always larger than the scion in diameter, is cut horizontally with a handsaw (Fig. I02), or with a secateur;* the section is then freshened with a grafting knife. It is then split, but on the side 


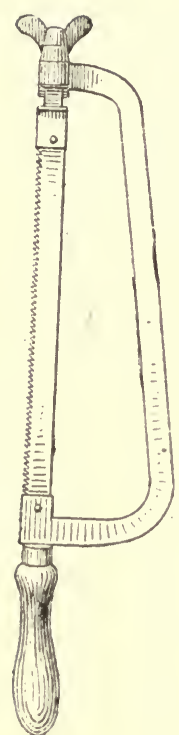

Fig. 102.

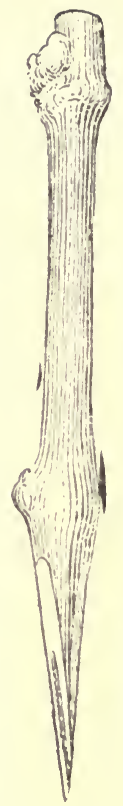

Fig. 103.-Wedge-shaped Scion for ordinary cleft-graft.

only; the chisel used for this operation is held with the handle upwards and inwards, the blade downwards and outwards, it is then struck with a mallet so as to obtain a split 3 or 4 centimetres ( $\mathrm{I}$ to $\mathrm{I} / 2$ inches) in depth, which is kept open by means of a small wedge inserted near the centre. The preparation of the scion is then proceeded with.

The scion, which should have at least two eyes, is cut wedgeshape (Fig. I03); the two lateral sections, for reasons already indicated, must be as close as possible to a node, and form an angle, so that the whole of their surface will be in

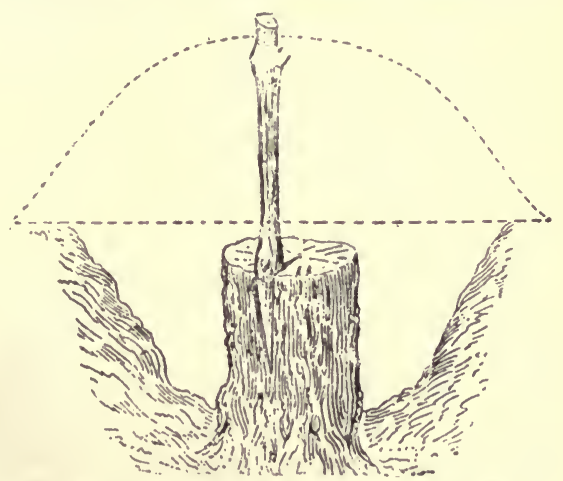

Fig. r $0_{4}$-Ordinary Cleft-Graft on old Stock. 
contact with the walls of the slit. The generative layers are made to coincide with those of the stock (Fig. IO4), and are then bound.

(c) Double Cleft-Graft.-The stock is prepared as above, the slit is made along the diameter with a strong knife

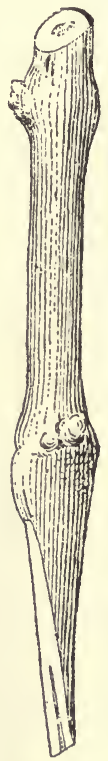

Fig. I05. or chisel, and is kept open by a wooden wedge placed at the outer edge of the slit. The scions are cut in a wedge shape, as shown in Fig. 105. The lateral sections starting from the same level and intersecting along the axis of the cane, and not outside the pith, if not the contact of the generative layers of scion and stock will not take place throughout their length.

On large stocks, two parallel or perpendicular slits may be made, in each of which two scions are inserted. The strike is thus better assured. Again, when the stock is very large, the scions may be placed as shown in Fig. I06. This is a side cleft-graft, the stock not being split along its diameter.

(d) English Cleft-Graft.-The English cleft-graft is made on stock of one to two years old, either equal or smaller in diameter than the scion they are to bear. Wedge-shaped Scion for In the cleft-graft above described one

English Cleft-Graft. side of the scion only knits with the stock; in the English cleft-graft the knitting takes place on both sides and is, therefore, more perfect.

The stock is cut horizontally, and, if necessary, the cut is freshened with a knife. It is split along the axis to a depth of 2 or 3 centimetres $\left(3 / 4\right.$ to $1 \frac{1}{4}$ in.) The scion, with one or two eyes, is cut in the shape of a rather long wedge, the two lateral sections being very close

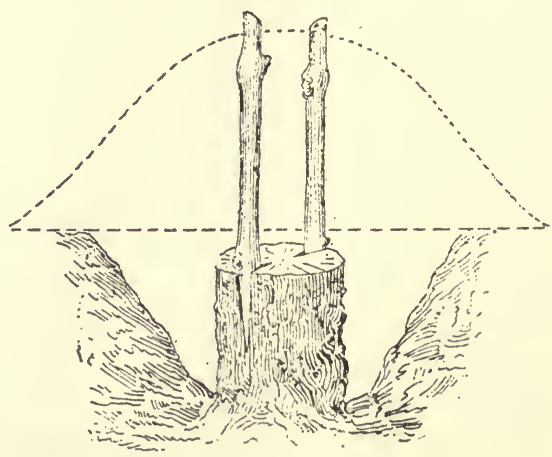

Fig. I06.-Double Cleft-Graft on old Stock. 
to a node and starting from the same level; they intersect exactly on the axis of the cane (Fig. I05). The scion prepared in this way is introduced in the slit of the stock, kept open by the point of the grafting knife (Fig. IO7).

Canes are not generally cylindrical, but more or less flattened. Consequently, stock and scion must be cut in a wedge-like shape or split along the larger diameter. It is

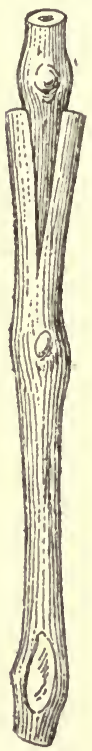

Fig. 107.

English Cleft-Graft Stock and Scion joined.

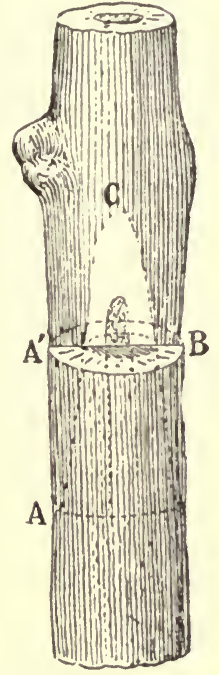

Fig. 108.

Showing the disposition of generative layers on Stock and Scion.
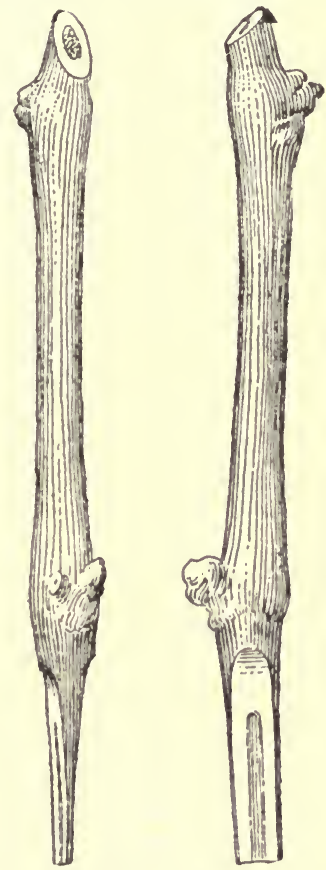

Figs, roo and rio. Shouldered Cleft-Graft prepared with grafting-knife.

in fact along this diameter that the canes have developed most, it is there that the generative layers are most active, and, consequently, that knitting takes place most perfectly.

As already pointed out, the zones along which knitting takes place must be in perfect juxtaposition; they are parallel on the stock, they should, therefore, be parallel on the scion. But the generative layers of a scion-cut wedge are disposed (Fig. IO8) according to a parabola A, B, C; 
the contact can only, therefore, take place at two points, A and $\mathrm{B}$, and consequently the knitting is defective. There are different means of bringing the sides of the scion parallel to one another, and to bring them into juxtaposition for the whole of their length with the generative layers of the stock.

Ist. By using scions larger than the stock, the contact of the generative layers takes place, in this case, nearer the top of the slit, the lower portion of the wedge slightly protruding from the slit in the stock; but as the two tongues are very thin and separated only by the pith, which has no resistance, the binding brings them close together inside the slit, and so makes them coincide exactly with the generative layers of the stock.

2nd. By making the lateral section as close as possible to a node; at this point the dimensions of the canes used as scions are larger, the edges of the section do not form an exact parabola, and are closer for the greater part of their length, at least, to the parallelism sought.

3 rd. By making two shoulders on the scion (Figs. Iog to II2), rendering the lateral section of the wedge almost triangular in shape, and, therefore, its edges almost parallel. By combining these three means, we may obtain an almost perfect parallelism of the surfaces brought in contact, and, consequently, a more perfect knitting. The shoulders may be made with a very narrow-bladed knife; they are in this case slightly rounded (Figs. IO9 and IIO); or, better, by means of special machines. Their object is not only to facilitate the knitting and strengthen the joint, but also to diminish the extent of the wound which always exists in an English cleft-graft (Figs. I I I to II3).

The cleft-graft, shouldered or not, never gives as perfect a joint as the whip-tongue, especially during the first year. The knitting only takes place along a longitudinal slip equal to the thickness of the part of the wedge inserted into the stock, therefore, the circulation of the sap can only take place through that strip, and not through the whole circumference (Fig. II3); on each side are large wounds or more or less extended portions of dead wood, which only become completely healed a few years after. This perhaps has not very great importance for fine growing vines grafted by the English cleft system are to be seen everywhere. And, again, if theoretically the whip-tongue graft is perfect, practically it rarely attains that degree of perfection. 
Actually, in all the south-west regions of France, the English cleft-graft is made with machines; the rapidity of the work is greatly increased, and the knitting is quite as good. The shouldered cleft-graft and the aglet cleft-graft are generally used; the latter seems to us preferable. The scion is cut as shown in Fig. I I4, the upper extremity of the stock being limited by two oblique sections intersecting each other along its greater diameter, and then split along that diameter. The wedge of the scion is then inserted in the slit of the stock, the two aglets exactly covering the two oblique sections of the stock, leaving no portion of the sections
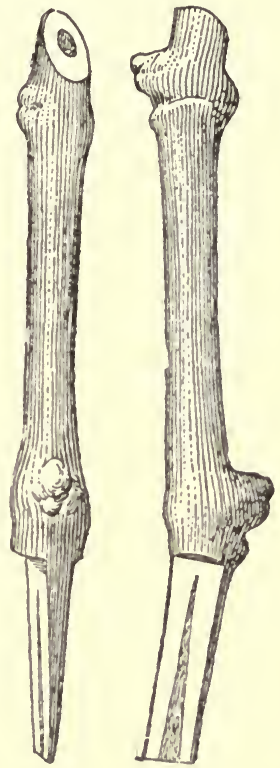

Figs. III and I 2 .

Shouldered Cleft-Graft prepared with a grafting machine.

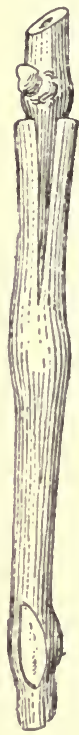

Fig. I 3

Shouldered Cleft-Graft joined. exposed to the air. This is one of the advantages of this graft, which is also stronger than the ordinary cleft, the aglets preventing the joint from becoming dislocated in case
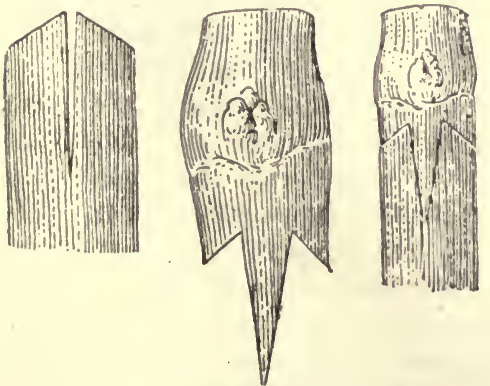

Fig. I I 4.-Aglet Graft, Stock, Scion, and Graft united. of the binding or ligature rotting too rapidly.

The hollowed cleft-graft can only be made with a special grafting machine; the sections are almost always defective, clumsy, and bruised; the scion is cut in the shape of a very short wedge; the joint is wanting in solidity and it is difficult to obtain it perfect. This graft is now discarded. 
The saddle graft (Fig. I I5) is the reverse of the cleft-graft; the stock is cut wedge shape; the two oblique terminal
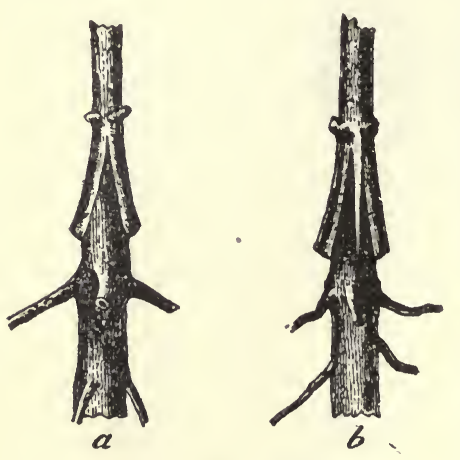

Fig. $115 .-$ Saddle Grafts. sections form callus sparingly for reasons already given; the knitting takes place badly, and, in addition, the scion developes many roots.

The dovetail graft can only be made with machines, it gives a fairly good joint, but has so far been very little used.

(e) Binding and Waxing. -Of the numerous systems of binding, several are very good, others have been discarded; those in which raffia is used are most generally adopted. What is required of the binding is to retain the two parts in firm contact until the tissues of the joint are knitted and become lignified. Therefore the binding should last a sufficient length of time; it should not be made so tight as to hinder the expansion of the parts becoming united, or, in other words, there should be no strangulation of the joint (Fig. I 16 ).

There are two means of attaining this object: first, by bindings which resist decomposition for a long time and expand (elastic bands or tape of indiarubber); second, those which soon become rotten, or are easily removed when the solidity of the joint renders them unnecessary. Raffia* has, at least under certain circumstances, both these qualities; hence the indiarubber tape or band, although very good, has been discarded in favour of the less costly raffia.

When the grafting has been done early in the season the raffia rots a little too soon, and the sections of the graft have a tendency, through the expansion of the callus, to split asunder. By soaking the raphia in a solution of sulphate of copper (blue vitrol), I5 to 45 grains per pint of water, its durability is much increased, and if it is found,

* Raffia, or Raphia, is the thin strong cuticle of the leaf of Raphia Ruffia, a palm, native of Madagascar; Raphia Tadigera, or Jupati-palm, a Brazilian species is also exported to Europe. and helps to make up the bulk of the Raffia of commerce. (Transls.) 
when removing the surface roots, that the ligature is too tightly bound, it should be cut with a knife. But sulphate of copper is a very caustic compound, and "burns" the tissues with which it is in contact, even when in small quantity, and checks the division and multiplication of the cells in the stages of their development; it is, therefore, a great obstacle to the formation of the knitting tissue, and corisequently to the success of the graft. Some nurseries have often had extensive failures through the use of bands containing too much sulphite of copper. It should, therefore, be used with caution, and, in order to diminish its caustic effect, the bands should be washed carefully with water to remove the excess of sulphate of copper; enough will remain fixed in the tissues to preserve the bands from too rapid decay. Or, better, the graft may be separated from the sulphated raffia by a thin sheet of lead or tin (Figs. II7 to I2I); then when removing the roots in July or August the bands which have not rotted should be cut.

The lead foil does not facilitate the knitting nor does it appear to prevent

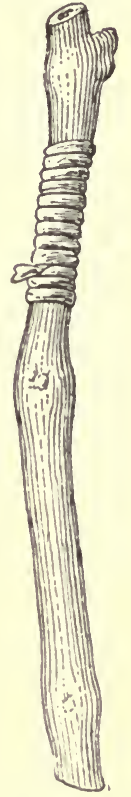

Fig. I 6.

Raffia Ligature. the growth of roots at the base of the scion; but it is rather an obstacle to the formation of callus, first, in preventing the contact of air with the cells during the process of division and multiplication; second, and also perhaps by penetrating the new tissues in the form of carbonate of lead, which is a poison. But its action in that sense is practically nil, and need not be taken into account. On hundreds of thousands of grafts made as above with lead foil we have not noticed any check. In any case its action is incomparably less than that resulting from the direct contact of the sulphate of copper with the knitting tissues. The foil prevents the entrance of water at the base of the scion; this is an advantage in wet soils, but rather a nuisance in dry soils. Anyhow, its use is more and more discarded, except in damp soils, where its employment is an advantage. 
The ligature may be made in any form, whether lead or tinfoil be interposed or not; the most simple and rapid of execution, being at the same time the strongest and best, is

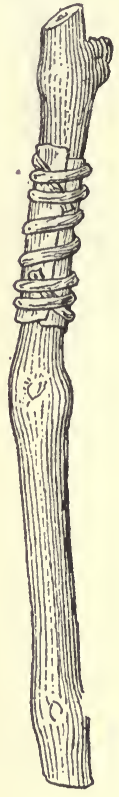

Fig. I 17 . Whip-tongue Gratt Ligature.

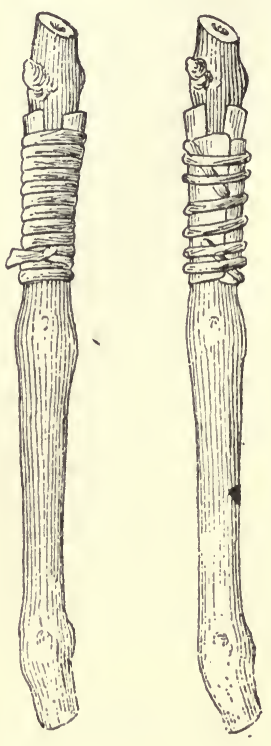

Figs. I 8 and I 10.

Shouldered Cleft-Graft
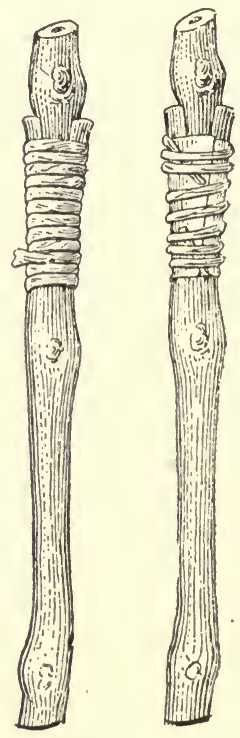

Figs. I 20 and $\mathrm{x} 2 \mathrm{I}$. Ordinary Cleft-Graft.

that described by L. Rougier in his excellent manual on the Reconstitution des vignobles, as follows (see Fig. I22) :- "The operator, after having verified the fit of the grafted cutting, holds it firmly with the left hand and commences the binding at the top. One of the ends of the raffia is kept fixed on the graft with the thumb of the left hand, while the other fingers hold the stock, the raffia is then wound round from right to left, so as to hold the end of the binding which was under the left thumb.

"The left hand, being now free, is used to hold the two parts of the graft in the required position. Continue to wind the raffia with the right hand, stretching and twist- 
ing it slightly, so as to increase its strength. The strands should not touch one another, and as they are wound down the graft the left hand is moved to make room for them.

"When the bottom of the joint is reached, the next thing is to tie the raffia. The best way of doing this is to fix the last strand with the index finger of the left hand underneath. With the right hand, a large loop is formed with the rest of the raffia, fixing the extremity of the raffia with the left thumb in front of the joint.

"The right hand now being free, the portion of the raffia that was held by the index finger of the left hand is taken and brought over the extremity held by the left thumb.

"Then turn the loop twice over the end held by the thumb, passing it each time over the free end of the scion. Finally, while the last turn is held in position by the left index finger, the end of the raffia released from the left thumb is pulled tight with the right hand, the loop disappears and the ligature is thus secured."

Other methods, of course, may be adopted, especially when the grafts are being made on a growing stock. The main point is to secure sufficient solidity, so that any shock the graft is likely to be subjected to may be withstood. It has already been said that the strands or spirals of raffia should not touch each other (Figs. II7 to I2I). Between these intervals the callus, not being compressed, develops in large masses, which insure from the start the formation of a good joint.

The use of cork sheathing has been recommended, in place of lead-foil, but, although good, it is expensive and its use troublesome. Finally, corks (Fig. I23) perforated along their axis, and cut in halves, have been used. The joint is completely surrounded by the cork, which is held in position by iron wire. The execution of this binding is tedions; it is very expensive, and, although it gives great solidity to the joint, it prevents its increase in diameter, and therefore the 
formation of knitting tissue; it also prevents, when performed underground, the lignification of the knitting tissue.

This method of binding is only

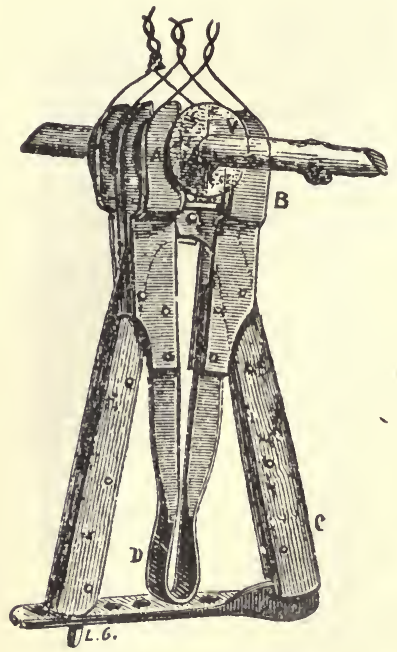

Fig. I 23.-Cork Graft. advisable for grafts made above ground.

Corks simply perforated constitute an excellent but expensive binding.

Other methods of binding may be used. All those are good which allow the access of air and the increase of the joint in diameter (for the thicker the layers of wood and liber are, the more perfect the knitting is), and resist rotting sufficiently, or are easy to remove at opportune times; which are not detrimental to the young cells of knitting tissue in the formative stage, and, finally, cheap and easily applied. Raffia seems to us to possess all the required qualities, if, according to circumstances, precautions are taken as indicated above. Consequently, early grafts should be tied with sulphated raffia, washed with water to remove the excess of sulphate of copper, or, again, lead or tin foil may be interposed between the ligature and the joint (Figs. II7 to I2I). For late grafts, made in April or May, non-sulphated raffia should be used without lead or tin (Figs. I I6, I20).

To increase the solidity of the joint, and to guard against the too rapid decomposition of the ligature, a lead ring 3 or $4 \mathrm{~mm}$. wide ( $\mathrm{I} / \mathrm{s}$ inch) may be fixed around the joint by bringing its two extremities together.

Grafts stratified in moss may do without ligatures; however, no inconvenience results from consolidating them by means of a few turns of raffia. Finally, the solidity of the joint may be increased by means of an iron dowel introduced into the pith of both stock and scion. This method of grafting is called the End-to-End or dowel graft. Both stock and scion are cut slantingly; the dowel or piece of galvanizediron wire is introduced into the pith of stock and scion, 
and the two bevels exactly juxtaposed. This graft succeeds fairly well, but we do not think it is more meritorious than the whip-tongue or English cleft-grafts.

All the waxings which have been tried are now totally abandoned. They are not only useless, but even detrimental. If we recall what was said when studying the formation of knitting tissue, this detrimental effect can be easily explained. It prevents the air, and, therefore, oxygen from reaching the joint, and, in the case of grafts made on rooted plants, when the sap begins to rise, it maintains around the joint an excessive humidity, which is a very great obstacle to the formation of knitting tissue.

III.-GRAFTING ON GROWING STALKS AND BENCH GRAFTING

The various grafts studied may be executed-Ist, on the growing stocks in the vineyards or in nurseries; 2 nd, indoors on cuttings or rootlings (bench grafting).

\section{A.-Grafting on Growing Stocks.}

(a) Time of Grafting.-Grafting on growing stocks is generally performed during the months of March, April, and May. But, during this period, is there any more favorable time which can be fixed? If it were not for the risk the scion runs of rotting or drying, we are of opinion that early grafts have better chances of success, and that those made in February or March should give a better number of strike than those made later on, in April or May. It has been noticed, in fact, that grafts made when the stock is in full sap do not generally knit, and there is a common saying to the effect that the sap drowns the scion. The sap drozm.s nothing at all. If we place a portion of a cane or a scion in water it will grow, especially if the water contains nutritive matters, and it will not be "drowned." The sap surrounding the scion is, after all, water, with several other substances dis-solved in it, which are also nutritive matters; they seem, however, to be injurious to the scion. It is, as established previously, that water (or the sap) opposes the formation of knitting tissue. Callus pads will never develop on the base 
of a scion or the upper extremity of a stock planted under these conditions. We see, therefore, that grafts made when the stock has not begun to bleed will have the best chances of success.

Later on, when the bleeding is already abundant, the success may be quite as great, for the channels conveying the sap become closed at their extremity by gum or bacterial colonies (we have, in fact, all observed that after a few days the section of a cane or spur does not allow the sap to flow, and that a new section made about $1 / 2$ inch below it bleeds abundantly); if this moment coincides with the start of growth of both scion and stock, or, better, precedes it, knitting tissue forms easily, and the knitting takes place. But if (and this is the case for late grafts made in April or May, according to the district) the scion starts growing before the flow of sap has ceased, the slightest check in its development, due to change of temperature or to active evaporation, compromises the strike, the knitting tissue not having been able to form to guard against that check in the growth.

Finally, still later on, when the vine has ceased to bleed, in June for instance, the knitting takes place under better conditions.

This explains the beneficial effect of cutting the rooted stocks a few days previous to grafting; the fatal influence of heavy rains during the period of grafting maintaining the grafts in too damp surroundings; of the too great compactness of the soil placed around the joint preventing the escape of excess of sap; and it explains also the good strike often obtained in grafting growing stocks in cold regions of the south-west, centre, and east of France, and also in certain seasons in the south.

For the knitting tissue to be produced with certainty at the moment the scion starts to grow, or, better, a little before, the surfaces in contact must not be in too damp surroundings; this result may be obtained at any time by cutting the growing stock previously, so as to only proceed with the grafting when the vine has ceased to bleed.

(b) Operation of Grafting.--The stocks, whatever their age may be, are previously decapitated, the soil is removed from around the stump to facilitate the operation. They are decapitated by a section made perpendicular to their axis, generally a little above ground, at the time when the graft has to be done, or, better, a week or a fortnight before, 
especially when the plant is bleeding, for reasons already stated. The stock thus prepared is grafted, if very large, with the ordinary or double-cleft graft (Figs. IO6 to I08); if small in dimensions, and one or two years old only, with the English cleft or Whip-tongue graft. The English cleftgraft gives the greater number of unions, for reasons already given, and also because it allows the sap to escape easier than the whip-tongue.

The point where the stock is grafted may be level with the ground, especially in cold districts of the centre and the east of France, never below; but preferably $3 / 4$ or $I \frac{1}{4}$ inches above the surface in the hot regions of the south. Under these conditions the roots of the scion are more easily removed; and, later on, being always above ground, roots never grow at the base of the scion, so that the ultimate liberation of the scion is not to be feared; the knitting tissue being also exposed to the air lignifies better, becomes hard and resistant, and, therefore, less affected by frosts and knocks.

Acording to the season, the joint is bound with sulphated raffia, isolated by tin or lead foil, or with ordinary raffia. Fine loose soil is then earthed up around the stump. In very stiff soils it is better to use sand to cover up the scion, for reasons already given.

The mound should be 40 to $45 \mathrm{~cm}$. (I 4 to 16 inches) in diameter at its base; it must cover the scion completely, in such a way that after the mound has settled down the top eye be covered with $1 / 4$ inch of soil only before it starts growing. The mound maintains the graft at an even temperature, prevents it from drying, and also from being knocked out by wind, etc. To guard against the latter accident, it is advisable to place a stake at the foot of each graft, to which the shoots may be tied as they grow.

The graft on old stocks of large dimensions is less successful than on stocks of smaller diameter. This cannot be due to their structure, which is always similar whatever their age may be; but it is more likely due to the great quantity of sap escaping from the section.

(c) Severing the Roots.-When the knitting is almost complete, that is to say, in July or August, according to the district, the roots which have developed on the scions should be removed. All shoots grown from the stock having been removed as they appeared. 
The roots growing on the scion are not, after all, a very great hindrance to the knitting; and if their development, as everybody knows, is in reverse ratio to the production of callus, they are generally the result of knitting which has been slowly effected. Their removal in July or August is too late to appreciably improve the knitting, but it is important, however, to stop their further development; they should

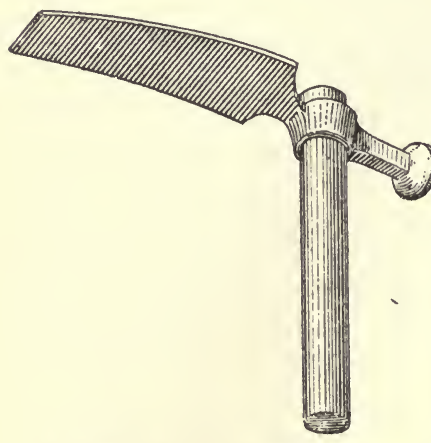

Fig. 1 24.--Mattock used for severing the roots. therefore be removed. As a matter of fact, when the scion is nourished partly by the roots of the stock and partly by its own, the stock, only bearing a limited part in the growth of the plant, dwindles, remains slender, and can only partially contribute to the solidity of the knitting; its roots remain small and slender; in a word, they waste away, so much the more as the roots of the scion, growing under much better conditions of soil and situation, assume more rapid development. The stock ceases to be useful to the scion, which henceforth becomes liberated and grows independently. This is shown in Fig. 125; a scion growing on its own roots. The roots of the scion are not, therefore, an obstacle to the herbaceous growth; on the contrary, they favour it, especially in calcareous soils (calcareous soils of the Charentes). Vines grafted on Riparia nourished both by the roots of the scion and stock are the only ones resisting chlorosis; but this only lasts as long as the phylloxera is not on their roots.

If the removal of the roots of the scion is effected too late in the season, the vine is placed in a bad condition for nutrition; the dwindled root system of the stock is not sufficient to nourish it any longer, and if the soil is unsuitable it withers and dies.

The severing of the roots must be done as early as possible, in order to furnish the plant with the substance necessary to its existence.

According to regions this operation is done in July or August in France. The soil is earthed up again, but not 
quite so high; in September the roots are removed a second time, if necessary, the raffia which has not rotted away is cut, and the joint is left completely exposed to the air and sun so as to lignify and harden.

(d) Care to be given to Grafts.-At the beginning of winter the joint may be left exposed to the air, especially if well lignified. But it is preferable to earth up the soil again, so as to guard it against the possible effects of winter frosts. This precaution is specially necessary in the cold regions of the centre and east of France, where the grafts grow tardily, and are not always well lignified when the first winter frosts appear.

In the following spring the soil is removed from the stump, and the joint left exposed to theair.

The stock is frequently smaller than the scion in diameter, especially for Riparia, Solonis; and, for this reason, it is liable to be broken by wind. A wellknitted graft never breaks at the joint, but always below. This accident may be avoided by tying the plant firmly to a stake.

Pinching is useless, although harmless.

It goes without saying that the young shoots, which are tender, and therefore very sensitive to cryptogamic diseases, should be carefully treated, to prevent mildew.

In nurseries, grafting on- growing stocks is performed in the same way, and the same care and attention are necessary.

We have assumed in the foregoing that the stock had been

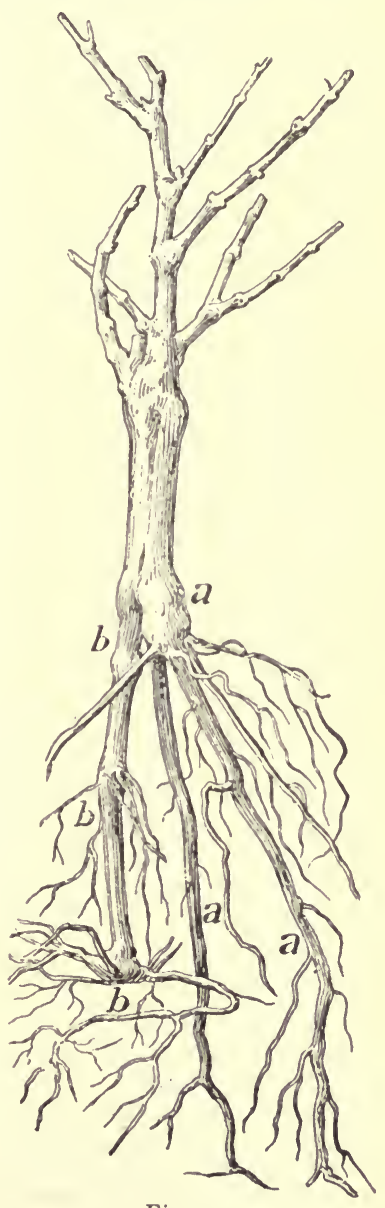

Fig. 125.

Liberated Graft. (a) Strong scion roots. (b) Weak roots of the stock. 
planted out for at least one year. Rooted cuttings are sometimes planted out in autumn, to be grafted in the following spring. Here, again, the operation is performed in the same way, using the whip-tongue or English cleft-grafts. But frequently better results are obtained by this method than with stocks that had been planted out for one year, at least in the cold regions of the south-west and centre.

How can this be explained? The graft is not better made in one case than in the other. It is that rooted cuttings do not bleed as much, and also that stock and scion are not surrounded by an excess of water, and are therefore placed under better conditions for the production of callus.

This method, which can only be applied to vigorous rootlings, allows a rapid and cheap reconstitution to be made, but gives rather weak grafts, at least during the first year following the grafting.

(e) Selection and Preservation of Scions.-We need not insist on the selections of scions. They should only be cut from those canes which have borne the most fruit, and from the most fertile vines. They should never be taken from young vines, which always have a tendency to produce wood instead of fruit, and which are never well lignified; nor from vines affected by cryptogamic diseases, which are always deficient in reserve material, and consequently incapable of forming much callus.

For early grafts (February) the scions may be taken direct from the stump and used immediately; for late grafts they should be cut beforehand, previous to the start of growth, preserved in a cool place exposed to the north, and completely buried in almost dry sand. For, as already saici. the stock always forms callus with difficulty; hence it is important that its growth should be more advanced than that of the scion.

(f) Autumn Grafts.-Grafting on growing stocks can also be performed in autumn, in the manner already indicated; the scions are taken from well lignified canes, and the graft should be well earthed up. The results have proved unsuccessful almost everywhere.

Finally, it may also be performed in summer, without decapitating the stock. In this case the Cadillac and Gaillard systems of grafting are used. 
Cadillac Graft.-Cazeaux-Cazalet, who promoted this method, describes it as follows:- "The stump is not decapitated. Its growth is not interrupted, and it remains healthy the following spring, much more so than if it had been cut down, and may be grafted again, if the graft has missed, with the same chance of success as if it had not been grafted at all. An English cleft or whiptongue graft is $\mathrm{mad}$ e laterally. Here are a few details with regard to the method of execution-

"First remove the soil and form a little basin round the stump. Then a cleft is made laterally from top to bottom, 3 or 4 inclies above the level of the ground, a straight section is madedescending obliquely towards the pith (Figs. I26 to I28); this cleft must be made with a thin-bladed knife, commencing at $a$ (Fig. 126), horizontally (sharp e d g e downwards) proceeding downwards and communicating to the blade a slow sawlike movement to-

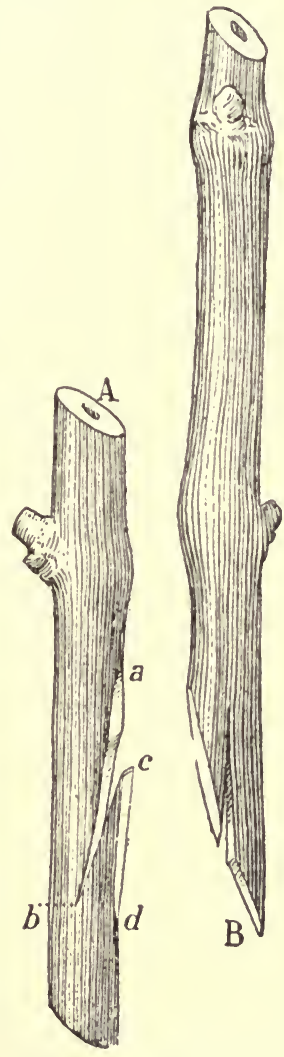

Figs. 126 and 127 . Cadillac Graft. (a) Stock. (b) Scion.

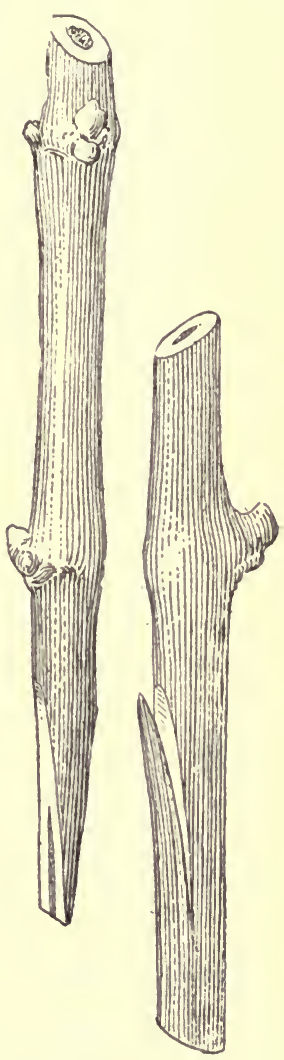

Figs. 128 and 129. Cadillac Graft. (a) Stock (b) Scion.

wards $b$; the section should be $\mathrm{I} / 2$ inches in depth; the scion is cut like that of an ordinary cleft-graft (Fig. I28), and introduced in place of the knife. The scion should be chosen of such a size that the liber of stock and scion be 
in exact contact at least at the bottom of the cleft. The stock may be prepared with one eye as shown in Fig. I30 (Cazeaux-Cazalet graft). The scion in this case must be a little smaller than the cleft for contact to take place at $a, b, c, d$.

"To make the lateral whip-tongue graft, a longitudinal slice of $\mathrm{I}$ or $\mathrm{I} / 2$ inches is removed from one side of the stock at the

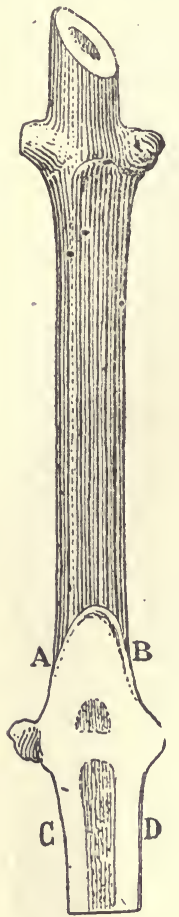

Fig. 130 . Cazeaux-Cazalet Graft. same height as for the cleft (Figs. I26, $a, d$ ), cutting a little deeper than the bark; at a point three-fourths of the distance from the bottom of the slice, a small oblique cleft, $c, b$, is made, similar to that of an ordinary whip-tongue graft; the scion, cut like that of the latter (Fig. 127, b) of a diameter equal to the cleft of the stock, is inserted in that cleft, taking care to secure contact of the liber at least towards the lower part of the sections.

"The scion should have at least two eyes above the joint.

"The cleft should always be oblique, especially for the side cleft-graft, and straight, to avoid a curved section, as shown in Fig. I3I, for it renders the juxtaposition difficult, the ligature forcing the scion to bend; and, if the ligature breaks during winter, the weight of the scion dislocates the joint, and the scion hangs on the tongue, which is too weak to support it.

"As far as possible, the graft should be made without removing the stake from the stock; the section of the scion must always be as close as possible to a node.

"The joints are tied with raffia alone, or raffia and lead bands rolled over and the two ends twisted together.

"The scions should be made with wood of the year, well lignified, and taken from the vine just when required for grafting; although scions preserved in sand have been used with success. The scions must be well lignified, if they are not they may knit, but are liable to dry off in summer, especially if the season is too dry. 
" The knitting begins at a few points of contact before the autumn, but the scion remains with dormant eyes; its. buds burst the following spring, at the same time as those of the stock. This early start necessitates sheltering the grafts during the first year, in districts liable to early spring frosts.

"The graft may be performed in summer, with equal chances of success, using scions which were stratified in dry sand during winter; but the scions grow during the same summer and produce insufficiently lignified wood, easily affected by the inclemency of winter; consequently, the following spring they are in less advantageous circumstances than the scions of the year.

"The soil is then earthed up so as to completely cover the scion. When the soil is not sufficiently mellow, it is preferable to use sand for immediate contact with the scion. For this operation a metal cylinder or piece of down-piping split along its side is placed around the scion

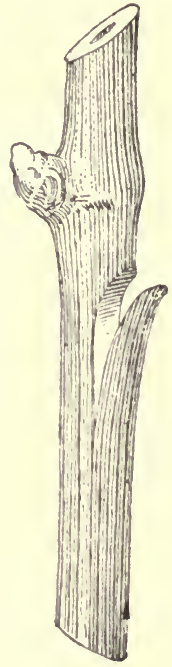

Fig. I 3 I. Defective Cleft. and filled with sand; the soil is then earthed up around it and the cylinder lifted out.

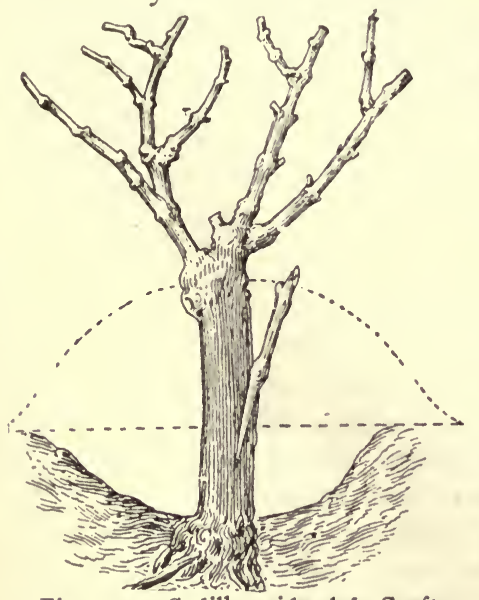

Fig. 132.-Cadillac side-cleft Graft.

"As an alternative a small basin may be made with soil around the scion and filled with sand, finishing the mound with soil.

"During winter the grafted stock is pruned in the ordinary way.

"For the pinching or suppression of the shoots of the stock, cut the stock with a secateur an inch or two above the joint, when the buds begin to shoot; or carefully pinch all the shoots on the stock as they develop. The latter method requires. 
more labour than the former, as it necessitates the operation being frequently repeated.

"The effect of this operation is very remarkable. The knitted scion immediately starts growing, and, when the shoots on the stock have been pinched

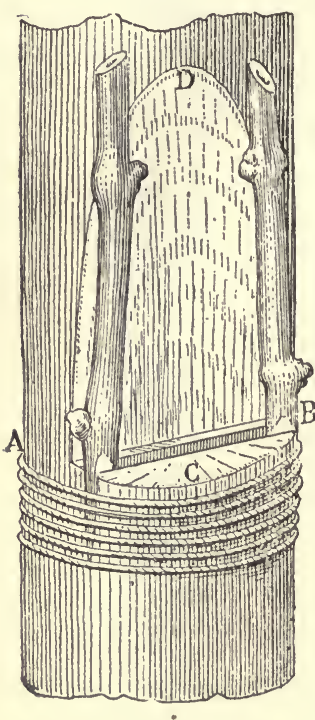

Fig. 133.

Gaillard Graft. two or three times, the shoots on the scion develop rapidly.

"The roots and ligatures of the scion should be removed when its branches are 40 to $50 \mathrm{~cm}$. (I6 to 20 inches) in length. The latter should be tied to a stake to prevent the frequent strong winds of spring from breaking the joint. After this is done, the graft does not require any further special care. Ploughing and scarifying are proceeded with as usual."

Gaillard ·Graft.-Fig. 133 shows very clearly the method of making this graft, which requires the same care as the above.

Grafting on growing stocks gives very variable strikes; sometimes 90 per cent. or more, sometimes 50 , or even 25 per cent. only. In the majority of cases, vineyards reconstituted by this method are patchy; the misses have to be replaced by grafted rootlings; and the yield is put back two years in the case of the replaced vines.

For this reason, in the cool regions of the south-west, centre, and east, and even in the south of France, it has been discarded in favour of bench grafting.

\section{B.-Bench Grafting.}

(a) Grafting on cuttings.-The canes of American vines destined to be used as stock, and which should be at least $6 \mathrm{~mm}$. ( $\mathrm{x} / 4$ inch) in diameter at the small end, are cut in lengths of 25 or 28 centimetres (IO to II inches). The bottom section is made under and as close as possible to a node (Figs. II8 to I22); for we know that the roots grow stronger and more abundantly on a node than on an 
inter-node; this is indispensable for Berlandieri and all cépages rooting with difficulty. The upper section is made 3 or $4 \mathrm{~cm}$. ( $\mathrm{I}$ to $\mathrm{I} / 2$ inches) above a node-we have already shown why; and for the English cleft-graft the joint is strengthened, the cleft being limited at the bottom by a node.

The American canes are therefore used on all their length as long as the minimum diameter is not less than a quarter of an inch; one cane may in this way furnish eight to ten stocks. It would, no doubt, be better to use, as in the old days, the base of the cane only, where the nodes are closer together; the chances of rooting would be increased and the vine would be more robust; but the present high price of American stock does not allow this selection to be made.

Is it necessary to bark the stock? When we have to deal with cuttings of Herbemont, Solonis, Jacquez, etc., which do not strike easily, yes; for the barking facilitates the penetration of the tissues by water, and, replacing that constantly evaporated at the top of the cutting exposed to the air, hastens the production of roots. But grafterl cuttings are always completely covered with soil, and, consequently, no active evaporation takes place. Anrl further, on the barked part, strong pads of callus, identical with the knitting tissue, appear, and they might be formed at the expense of the latter.

The usefulness of barking, really apparent for cuttings having their upper part exposed to the air, does not seem so evident in the case of grafted cuttings, except perhaps when they have become dried before planting. However, whether barked or not, the results have been practically identical.

A far more important operation is that which consists in cutting off all the buds of the stock. It is not sufficient to remove them with the finger-nail or to cut them above the ring of latent buds; for, in this case, three or four buds burst all round, living at the expense of the plant, and preventing the development of the knitting tissue. Stocks bearing their own shoots have no tendency to knit with the scion.

This precaution is specially indispensable for Rupestris and its hybrids.-This stock is said to give insignificant strikes when grafted by the bench method; as a matter of 
fact, this is simply because the buds of the stock are not removed in a proper way. It is not sufficient to remove them, as is done for Vialla and Riparia, by cutting the base of the main bud; a large cut of at least half-acentimetre ( $\mathrm{I} / 4$ inch) in diameter must be made, as shown in Fig. I34; in doing so the principal as well as the latent buds are removed. With this pre-

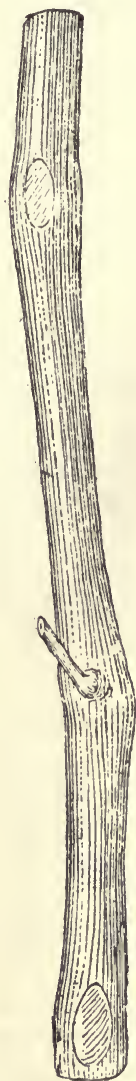

Fig. 134 .

Showing the way of removing the eyes of stocks. caution, grafts on Rupestris succeed better than on any other stock; and recently 45,000 Rupestris grafted cuttings gave 115 80 per cent. strikes, and over 60 per cent. good knittings. It is preferable to remove the buds only when planting out.

The scion bears one or two buds; one is sufficient when the nursery is established in loose fresh soil, for in this case the joint, even if close to the surface, is not liable to dry. In dry soils the joint should be buried much deeper, otherwise it would dry; but if the bud is too much covered with soil it does not grow well. It is therefore rather difficult, in these soils, to place it under the most favorable conditions for growth. If the scion bears two eyes, on the contrary, the joint is always placed deep enough to prevent its desiccation; and the upper bud of the scion, which alone develops, is covered with $1 / 4$ inch of soil at most.

Stock and scion thus prepared are joined as previously described.

The grafts made before April are tied with sulphated and washed raffia, isolated from the joint by lead or tin foil; after April non-sulphated raffia may be used, without lead or tin foil. The strands should not touch each other (Figs. II7, II9, I22), and no wax should be used.

(b) Stratification and callusing. - The grafted cuttings are planted out immediately, if prepared at the end of April; otherwise they are preserved till the moment of planting out. In this case; they are tied in bundles of ten to twenty, and placed 
in fresh sand, outside, taking care, however, to shelter them from frosts and variations of temperature, which might damage the joint. In a word, grafted cuttings should be preserved, as was formerly done in the case of ordinary cuttings. This method is the simplest and most effective. The grafts, being in a moist surrounding, do not lose the water necessary to their growth; the temperature is higher and more constant, especially if the heaps of sand are placed in a sunny place against a wall; this induces the formation of knitting tissue, and often, when the time of planting out has arrived, the knitting is partially effected, and roots have developed on the stock.

An excess of humidity must be avoided; it hastens, it is true, the formation of roots, but opposes the formation of knitting tissue. If the sand is too damp, the callusing is defective. The sand should not contain more than 5 to io per cent. of water. It is therefore necessary to shelter it from heavy rain.

When all these precautions are taken, the knitting is almost completed after a month's stratification, and both stock and scion begin to develop. This is the best time to plant them out in the nursery. Grafted cuttings may also be callused in moss. The results are good if water is not present in excess. But the use of moss presents certain difficulties which do not apply to sand. It has to be watered often to prevent drying; the water is often in excess, and grafted cuttings stratified in this material develop without knitting.

(c) Preservation of stocks and scions. - The canes to be used as stocks are preserved in the same way (if not cut and used directly). Sand is to be preferred to earth, as it does not soil them.

The scions may be cut from the stump until the end of February; after that they are preserved in almost dry sand, in a shed exposed to the north, as already explained. When they are to be used, the section of the bark should be of a bright green colour. If it is whitish, it indicates that they have become too dry. 


\section{IV. - NURSERIES.}

(a) Selection and preparation of soil.-Almost any ground may be converted into a nursery, with more or less success. Dry, pebbly soils which cannot be watered often result in failures; the growth of the roots takes place slowly, and the joint is liable to dry. Compact or very damp soils are not much better; for whatever may be the length of the shoots, the roots always remain small and slender, and the knitting is defective. As in the case of most plants where rapid development is required, the grafted cuttings need a very friable, sandy, fresh, and, above all, fertile soil. Recent alluvials are, generally, very suitable for the establishment of a nursery, as also warm siliceous soils where heath grows naturally; in fact, all soils remaining moist at a certain depth and becoming easily warmed on the surface, but without baking hard. We should, as far as possible, avoid establishing nurseries in soils the surface of which forms a crust after rain; the buds remaining imprisoned cannot shoot through the hard crust, and therefore die off.

The neighborhood of trees must be avoided; whatever care may have been taken in cutting their roots when trenching, grafted cuttings never develop well in the vicinity. of trees or forests, on account either of the shade or the exhaustion of the soil by their roots.

Trenching or subsoiling by hand should be preferred, the work being done in summer. Manuring with fertilizers, or preferably with stable manure, should be done freely.

(b) Plantations.-The planting of the nursery is done in April or May, the cuttings are planted in lines, the distance apart of which varies according to the size of the plot. But for the cultural care, the removal of the roots, etc., to be easily performed, the lines should be at least 50 to $60 \mathrm{~cm}$. apart (20 to 24 inches). Again, they may be arranged two by two, $20 \mathrm{~cm}$. ( 8 inches) apart, each group of two being separated by an interval of I metre ( $3 \mathrm{ft}$. 3 in.). The distance apart of the cuttings in the line may vary between 5 and 15 $\mathrm{cm}$. ( 2 to 6 inches). It goes without saying that the further they are apart the better.

The planting may be done with a dibble, a fork, or in a trench.

When planting with a dibble (Fig. I35), the land should be previously manured. The grafted cuttings are buried in 
such a way that the joints be below the general surface, although this is not of very great importance. What is more important is that the soil should be rammed round the cutting, and above all that the upper eye of the scions be exactly on the same level, so as to be covered with an even thickness of soil.

The application of this rule is the best guarantee of success; for if the more or less perfect execution of the joints is an important element of success, the way in which the planting is performed is even of greater importance; and many failures attributed to the bad quality of the joint, etc., were simply due to badly carried out planting. It is of the utmost importance, as already pointed out, for the eye to be covered with a thin layer

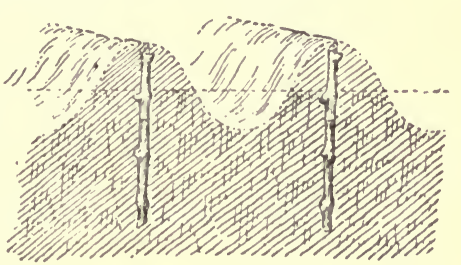

Fig. 135.-Grafted Cuttings planted with a dibble. of soil $(\mathrm{r} / \mathrm{4}$ inch $)$ and not left bare, in orcler to develop well. If the eyes are not all on the same level after the earthing up, some will naturally be too much covered and will not develop, or others, insufficiently covered, will become dry.

With a fork, the operation is more rapidly carried out, but this method can only be applied to very friable light soil.

With trenches the operation is quite as rapidly performed. The trenches are dug $35 \mathrm{~cm}$. (I4 inches) in depth and 50 to $60 \mathrm{~cm}$. (20 to 24 inches) apart. One of the walls is cut sloping, the grafts are placed against it, in such a way that the top

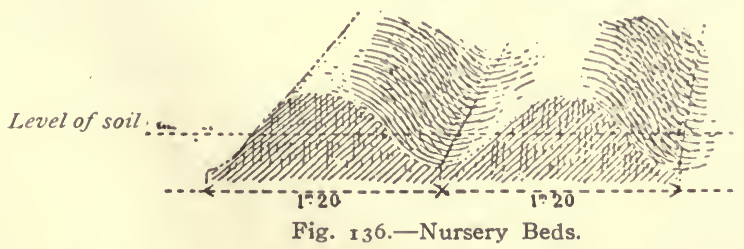

eyes be all at the same level. The manure may be placed at the bottom of the trench, at the opposite angle. The soil taken from the slope is left at the bottom of the trench, and used to cover the manure, and it is in that loose soil that the base of the cutting is placed, the soil being then lightly 
pressed with the foot. The manure or fertilizers may also be placed on the first layer of soil, but always at a certain distance (a few inches) from the stock, so as not to burn it.

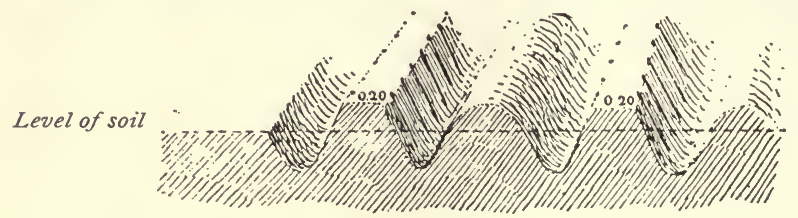

Fig. 137.-Grafted Cuttings placed in nursery rows.

The trench is then filled in with soil from the next trench; and the earthing up done with looser soil, as already explained.

Another arrangement which has given us good results may be adopted.

The planting is done in double rows, $20 \mathrm{~cm}$. ( 8 inches) apart, each group being separated by an interval of one metre ( $3 \mathrm{ft}$. $3 \mathrm{in}$.). The land is previously worked in ridges (Fig. I36). When the time for planting has arrived, the top of the ridge is flattened with a spade, and a slope cut out on

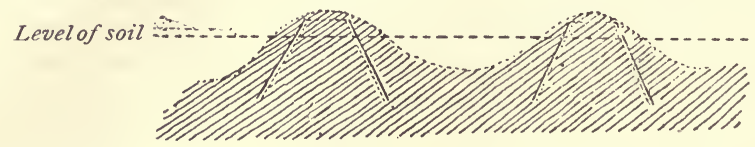

Fig. 138-Arrangement of the soil.

both sides: the ridge becomes a prism, the section of which is a trapezoid, the upper side of which measures $20 \mathrm{~cm}$. ( 8 inches), and the lower about $50 \mathrm{~cm}$. (20 inches). The soil resulting from this operation is rendered very friable, and placed in the interval separating two consecutive ridges (Fig. I37); the grafted cuttings are placed on each side

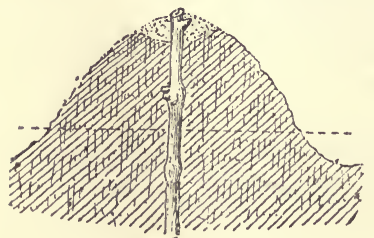

Fig. 139.-Showing arrangement of the sand around the top eye. against the slopes, with the eyes level with the top angle. Manure may be placed at the foot of the cuttings, but not touching them, and the soil resulting from the excavation (Fig. I38) earthed up against them. This arrangement has the advantage of facilitating the working. 
The earthing up in compact and clayey soils is not always easy; the soil wetted by rain hardens and forms a crust, preventing the shooting of the bud. This can be remedied by placing sand round the top eye as shown in Fig. I39, covering it entirely. Covered in this way, the eyes develop normally, and success is assured.

The earthing-up does not retard the development of the buds; it hastens it, on the contrary, and does not impoverish the scion in reserve matters. It only prevents-and this is its only use-evaporation from the scion by sheltering it from wind and sun. The water it contains is necessary to the production of callus and the development of all the tissues.

(c) Cultural care.-The only cultural care required is hoeing and scarifying when necessary. Above all, we must prevent weeds from growing, as they injure the grafts, not only with their roots, but also by choking the buds when they come out.

Watering may be performed when required. But care should be taken not to allow the water to reach above the joint, so as not to favour the liberation of the scion, or to hinder the formation of callus.

When watering, we may spread over the soil chemical manures (nitrates, superphosphates, etc.), or any other manure acting rapidly; this will improve the growth of the grafts. For knitting to be perfect, it is indispensable that the increase in diameter of both stock and scion be as rapid as possible; a joint constituted by only five or six layers of cells will evidently be weaker than one constituted by fifteen or twenty layers. We should,

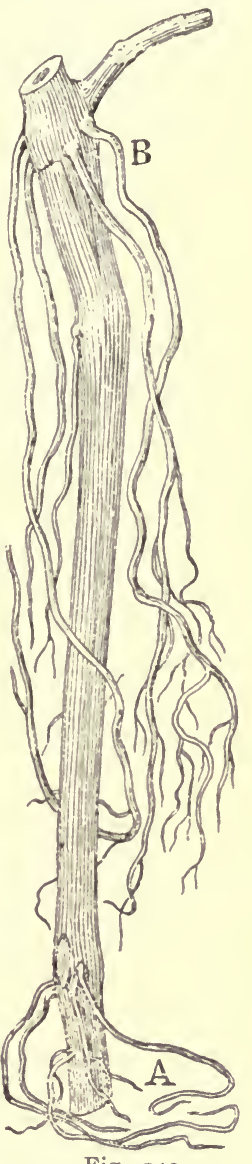

Fig 110

Grafted Cutting. (a) Slender roots of the stock. (b) Strong roots of the scion. therefore, use every means of increasing the growth of the grafted cuttings. This result is attained by watering in dry weather, and by abundant manuring with very active fertilizers. 
(d) Removal of roots from the scion.-In the month of July the roots growing on the scion are cut off, and the soil earthed up again, although not quite so high. This operation is of great importance. We know that liberated scions obtain the bulk of their food through their own roots; and that those of the stock, becoming useless, cease to develop (Fig. I40). The stock remains weak, and consequently the joint is defective. It is important to have strong numerous roots on the stock, together with as strong a joint as possible; this is obtained by the removal of roots from the scion. In the month of September the ridges are completely leveled, and the joints exposed to the air to lignify. We know that the parts of the vine buried underground are always tender and affected by cold. At the same time, new roots which may have developed on the scion are cut off, together with the ligatures which might strangulate the graft.

However, for grafted cuttings where the stock develops roots slowly (Berlandieri*), it is indispensable to only sever them later on. The roots of the scion serve to nourish the plant, while the stock forms its own roots; they should therefore only be removed when the stock has rooted.

\section{(e) Lifting grafted cuttings.-The grafted cuttings may} be lifted in November and preserved in bundles completely covered with soil. But if they are left in the nursery till the date of planting out, care must be taken to earth them up to the fifth or sixth eye of the shoot, to guard tender herbaceous shoots against spring frosts.

Well-rooted plants knitted on both sides are alone used. These are known as "first selection"; those knitted on one

* If the development of the grafted cuttings of Berlandieri is attentively watched from the planting till the end of summer, the following changes are easily noticed:- First, the knitting tissue begins to be formed between the stocks and the scion, and the scion commences to grow. This stage is common to all grafted cuttings, whatever grafting stock may be employed. Soon after, voung rootlets appear at the base of the scion, and nothing on the stock except a more or less pronounced pad at the lower section, formed of healing tissue. The plant then grows with the roots of the scion until July. Late in July or August the stock begins to form, just above the pad, a few fine rootlets. The rootlets increase very rapidly, and soon make up for their slowness in forming. The herbaceous development of the scion has thus for two months depended on its own roots. The knitting tissues continue to be progressively formed at the expense of the material elaborated by the scion. The reason that grafted cuttings grow better than ungrafted cuttings of Berlandieri is probably due to the active life of the scion the stock thus receiving, through the action of the knitting tissue, the elaborated materials necessary to assist in it the formation of roots.

If the roots on the scion are cut too early before those of the stock have formed, the growth is, arrested, and both stock and scion die. 
side only will always be defective. Finally, those well knitted but with short slender shoots and badly developed roots should be left in the nursery; they are termed "second selection."

Grafting of rooted cuttings.-Benchgrafting on rooted cuttings is performed in the same way. The cultural care is similar. The shoots are stronger, the knitting better, and therefore there is a greater number of plants of "first selection."

Essential recommendation. - Remove carefully, as above directed, all the eyes of the stock.

(f) Diseases.- The enemies of the nursery are numerous.

First, white grubs. They frequently do considerable damage in nurseries, by eating the green bark of the stock, which slowly dies.

Bisulphide of carbon, applied with an injector, in quantities of 800 to 1000 kilos per hectare (about 8 cwt. of bistlphide per acre) before planting, kills most of them. But it is best to

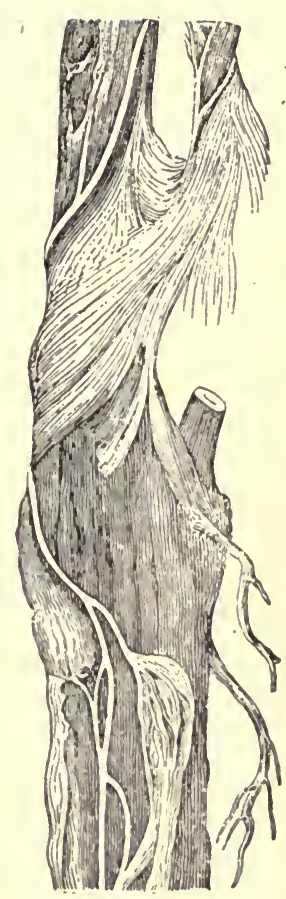

Fig. 1 4 I

Pourridie. select a situation for the nursery where there are no grubs.

J. Perraud states that an acarian, the Tetranychus tellarius, does damage, but there is no known method of destroying it.

When the roots of the scion are cut too late, the roots of the Berlandieri grow very slowly. Those on the scion obtain a preponderance, and it grows independantly. The growth of the stock becomes arrested, and when the roots of the scion are removed, the slender roots of, the stock are insufficient to nourish the grafted cutting, and it dies slowly.

We see that the roots of the scion must be severed neither too soon nor too late. Success with grafted cuttings of Berlandieri depends only on attention to these details

It is easy to state precisely the proper time to sever the roots. which should not be before the end of July In various regions, the southern for instance, the time for cutting them varies from the 20 th July to 2oth August (in France). But for greater security. it is better to ir:spect the butts of a few grafted cuttings and only cut the roots off the scion when they have commenced to grow on the Berlandieri stock also.

The time for severing the roots is not the same for all vines. The Carignane scion, for example, whose roots are produced very strongly and rapidly, requires to be cut much earlier. In so doing with grafted cuttings on Berlandieri, it yields quite as large a percentage of takes, with well-developed roots on the stock as with the Riparia and the Rupestris. 
Coniothyrium diplodiella, or white rot, grows sometimes on the young shoots and kills them. It is easily treated with Bordeaux mixture.

Pourridié (Fig. I4I) causes great damage in nurseries. $\mathrm{Up}$ to the present there is no real remedy. As soon as detected in a nursery, it is best to discontinue planting in that spot for two or three years.

Mildew is also serious, as it causes the leaves to fall prematurely, and stops the growth of the plant, the formation of knitting tissue, the maturing of the shoots, and the development of roots. As the tender shoots of the young plant are very sensitive to its action, Bordeaux mixture should be used frequently (six or eight times during the summer).

Fibrillaria (Psathyrella ampelina) grows sometimes between the surfaces of the sections at the joint, in the form

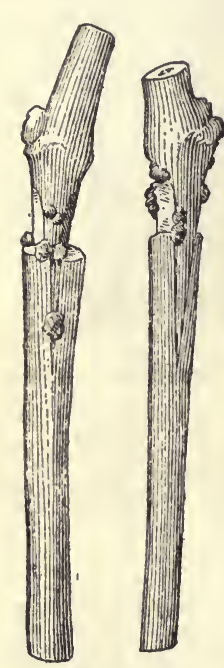

Fig. 142.

Botrytis Cinerea. of a thick white coat, thus preventing the healing tissue of the scion reaching the stock, and vice versâ. Its damages are not very considerable. It is easily checked by watering the stock with a ro per cent. solution of sulphate of iron.

Sclerotinia Fuckeliana (Fig. I42), or Botrytis cinerea, does a little harm to the grafted cuttings when stratified in wet sand. To avoid this it is only necessary to use dry sand for stratification. The Scl. Fuckeliana forms at the level of the tongues and clefts, hard black warty nodules, about one-eighth of an inch thick. They are wedge-shaped, and by their intrusion between the joints prevent the latter adhering to each other. The surfaces become dry, and the formation of knitting tissue prevented. The grafting stock may form roots in the nursery, but the scion soon becomes dry.

The Botrytis cinerea sometimes attacks branches preserved in too damp soil. Its mycelium pentrates their tissues and kills them. 


\section{V.-HERBACEOUS GRAFTING.}

According to Hermann Goethe's work, from which we extract the following, herbaceous grafting has been a common practice in Hungary for the last half-century, although exceptionally used in connection with vines.

The cultivation of American vines drew the attention of viticulturists to this method, which belongs rather to the

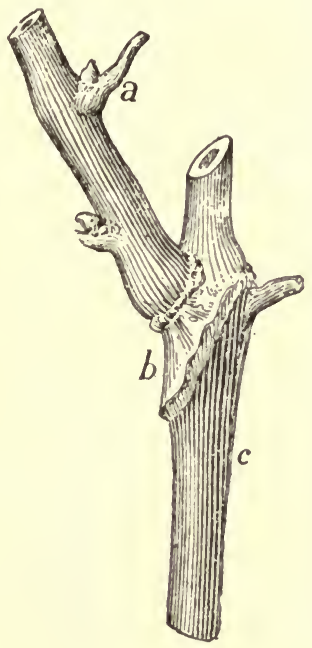

Fig. 143.

Herbaceous Graft knitted. The scion dereloped a shoot $(a, h)$. (After H. Goethe.)

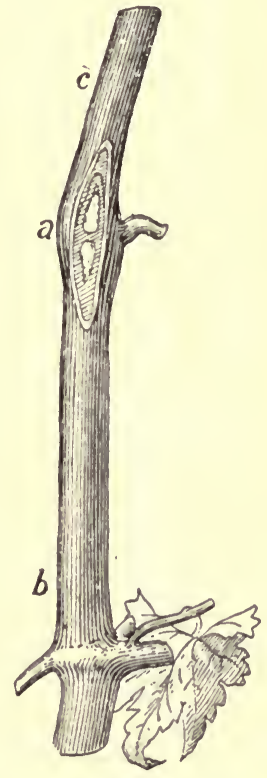

Fig. 144.

Stock prepared for the herbaceous graft. (After H. Goethe.)

domain of horticulture, and it is now applied on a large scale for the reconstitution of vineyards destroyed by phylloxera. The results obtained are good, the percentage of strikes often reaching 90 per cent.

It has been tried in France in several districts, but the result has not always been very satisfactory, and for different reasons, which we cannot study here, it has generally been discarded. 
Figs. I43 to I48 show the mode of execution of this graft.

Ist. The stock (growing) and the scion, both herbaceous, are prepared in the same way as for a whip-tongue graft; they are joined in the same way and ligatured with rubber.

2nd. Or again, they may be prepared as for an ordinary splice graft and ligatured as above.

3 rd. Or again, a kind of side cleft-graft is made, pinching the shoot above the joint. (Figs. I43 and I44.)

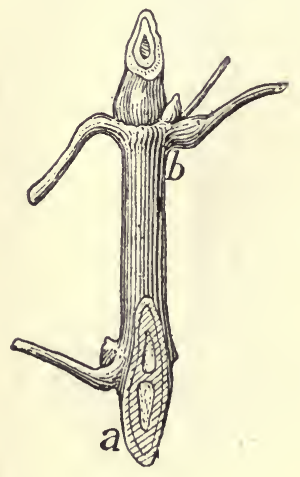

Fig. 145 . Herbaceous Graft Scion. (After H. Goethe.)

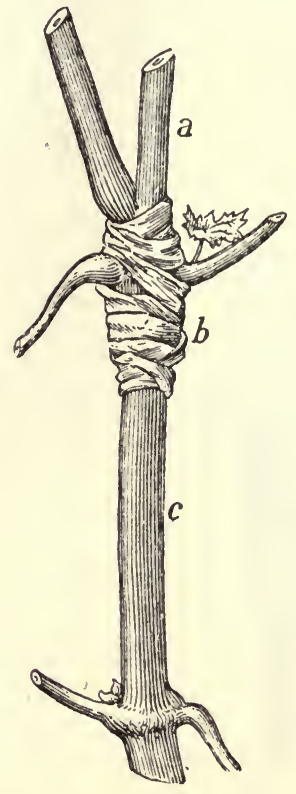

Fig. 146 . Same ligatured. (After H. Goethe.)

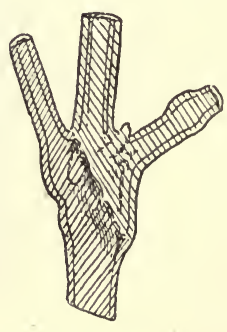

Fig. 147.

Section showing the Union (After H. Goethe.)

The sections of both scion and stock are made on a node; this increases the strike, for reasons given above.

These grafts are made in June, selecting the most vigorous shoots as stock. Two or three weeks later the eye of the scion bursts, and the wood ripens normally.

Budding.-Herbaceous budding has not been much applied to vines. It has been modified lately, and complete details, which we cannot give here, will be found in Bulletin 
No. I46 Ag. Exp. St., Berkeley, Cal. They tend to render the operation more practical, but it is always rather delicate of execution. The operation is performed in the following manner (Figs. I48-I50) :-

"The bud is excised with a sharp grafting knife from the shoot of the variety to be multiplied. This is done when the shoot reaches its complete development, that is to say when the length is at least a foot. The buds of the apex of the shoot cannot be used, as they are not as vigorous as those of the base and mean part. We may also, in July, excise buds from secondary shoots developed after pinching. The bud must be herbaceous and well formed.

"The shield is about $I$ to $I / 4$ inches in length. A layer of cellular tissue $I$ to 2 mms. in thickness is preserved under the bark to prevent the bud from drying. This wood must be preserved under the whole shield; without this precaution the desiccation of the bark would be inevitable. The length and width of the shield vary according to the size of the stock.

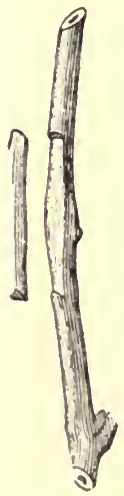

Fig. 148

Preparation of the Shield.

"A certain number of scions can be prepared and used during a few hours, being careful to preserve them in damp moss, or better, in water. The leaves are cut at the middle of a petiole.

"The stock is a shoot of the year, well developed, and in a suitable position.

"On a herbaceous internode at the base of a bud a longitudinal incision is made $I \frac{I}{2}$ to 2 inches in length, the two sides of the incision being raised with the haft of the grafting knife.

"The scion or shield is then inserted in the slit of the stock. This is done by inserting first one side of the shield under the bark of the stock, then raising the bark with the haft of the grafting-knife and inserting the other side in the same way. This operation is rendered very easy by slightly bending the shoot inwards. The graft is bound with wood or cotton.

"The knitting requires from ten to twelve days, and may be recognized by the fresh state of the scion and the union 
between the cambium of both stock and scion. At this stage the ligature is removed.

"When budding is performed during the first months of vegetation, that is to say with growing eye, we obtain the first year a straight shoot, which may bear fruit the follow-

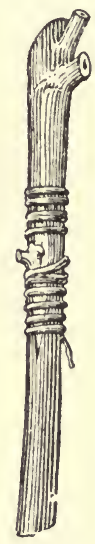

Fig. 140

Salgues Budding.

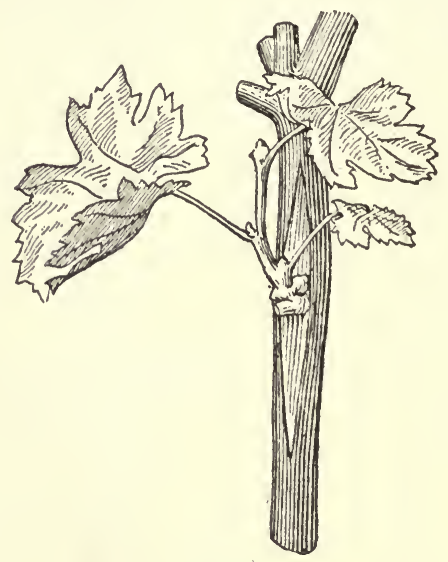

Fig. 150 .

Knitted bud after ligature is removd.

ing year. In this case one should shorten the stock 5 to 6 inches above the graft as soon as the latter is knitted. If, on the contrary, budding is only performed in July or the beginning of August, that is to say with dormant eyes, this latter operation is useless, as the bud only starts growing the following year."*

Budding might render great services with varieties not rooting freely, such as Berlandieris. The canes of this cépage might be budded on a layer, thus giving a grafted rootling.

* J. Gabarret: De la greffe en ecusson de la vigne: Greffe Salyues. 


\section{APPENDIX.}

TABLE No. 1.

COMPARATIVE STATISTICS OF AMERICAN VINES AND INSECTICIDES IN FRANCE.

\begin{tabular}{c|c|c|c|c|c}
\hline Years. & $\begin{array}{c}\text { American } \\
\text { Vines. }\end{array}$ & $\begin{array}{c}\text { Carbon } \\
\text { Bi-sulphide. }\end{array}$ & $\begin{array}{c}\text { Sulpho-carb. } \\
\text { of Potassium. }\end{array}$ & Submersions. & $\begin{array}{c}\text { Annual } \\
\text { increase of } \\
\text { American Vines }\end{array}$ \\
\hline & Acres. & Acres. & Acres. & Acres. & Acres. \\
\cline { 6 - 6 } 1880 & 16,102 & 13,867 & 3,680 & 20,232 & $?$ \\
1881 & 22,260 & 39,832 & 7,022 & 20,487 & 6,158 \\
1882 & 42,735 & 42,802 & 7,582 & 31,357 & 20,475 \\
1883 & 70,030 & 58,065 & 7,742 & 44,480 & 27,295 \\
1884 & 130,192 & 83,615 & 13,215 & 58,261 & 60,162 \\
1885 & 188,230 & 101,462 & 13,067 & 60,847 & 58,038 \\
1886 & 276,967 & 118,037 & 11,147 & 61,250 & 88,737 \\
1887 & 413,792 & 165,512 & 22,050 & 66,662 & 136,825 \\
1888 & 535,817 & 166,762 & 20,222 & 83,637 & 122,025 \\
1889 & 749,502 & 143,707 & 22,102 & 75,840 & 213,685 \\
1890 & $1,090,045$ & 155,595 & 23,442 & 80,955 & 340,543 \\
1891 & $1,130,705$ & $?$ & $?$ & $?$ & 40,660 \\
1892 & $1,323,650$ & $?$ & $?$ & $?$ & 192,945 \\
1893 & $1,521,532$ & $?$ & $?$ & $?$ & 197.882 \\
1894 & $1,658,035$ & 126,130 & 21,860 & 88,312 & 136,502 \\
& & & & & \\
\hline
\end{tabular}

TABle No. 2.

DECREASE OF CARBON BI-SULPHIDE, COMPARED WITH THE INCREASE IN AREA OF AMERICAN VINES IN THE DEPARTEMENTS WHERE CARBON BI-SULPHIDE HAS BEEN MOST USED.

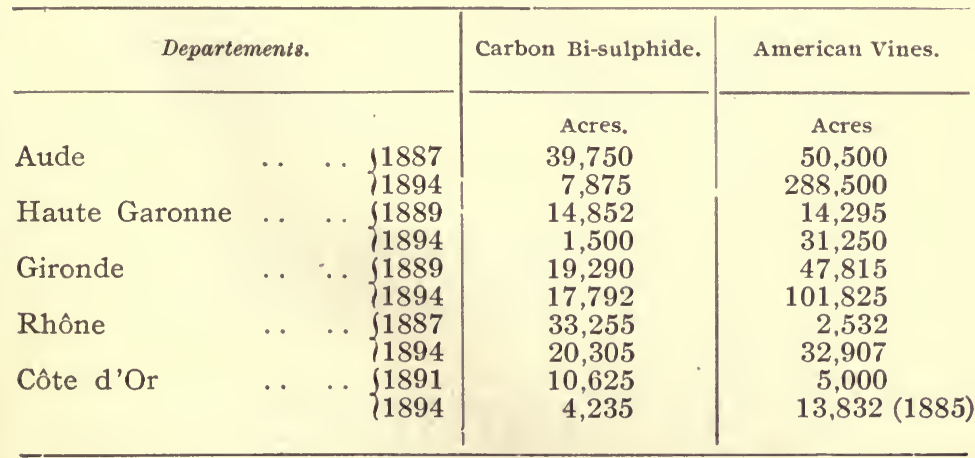




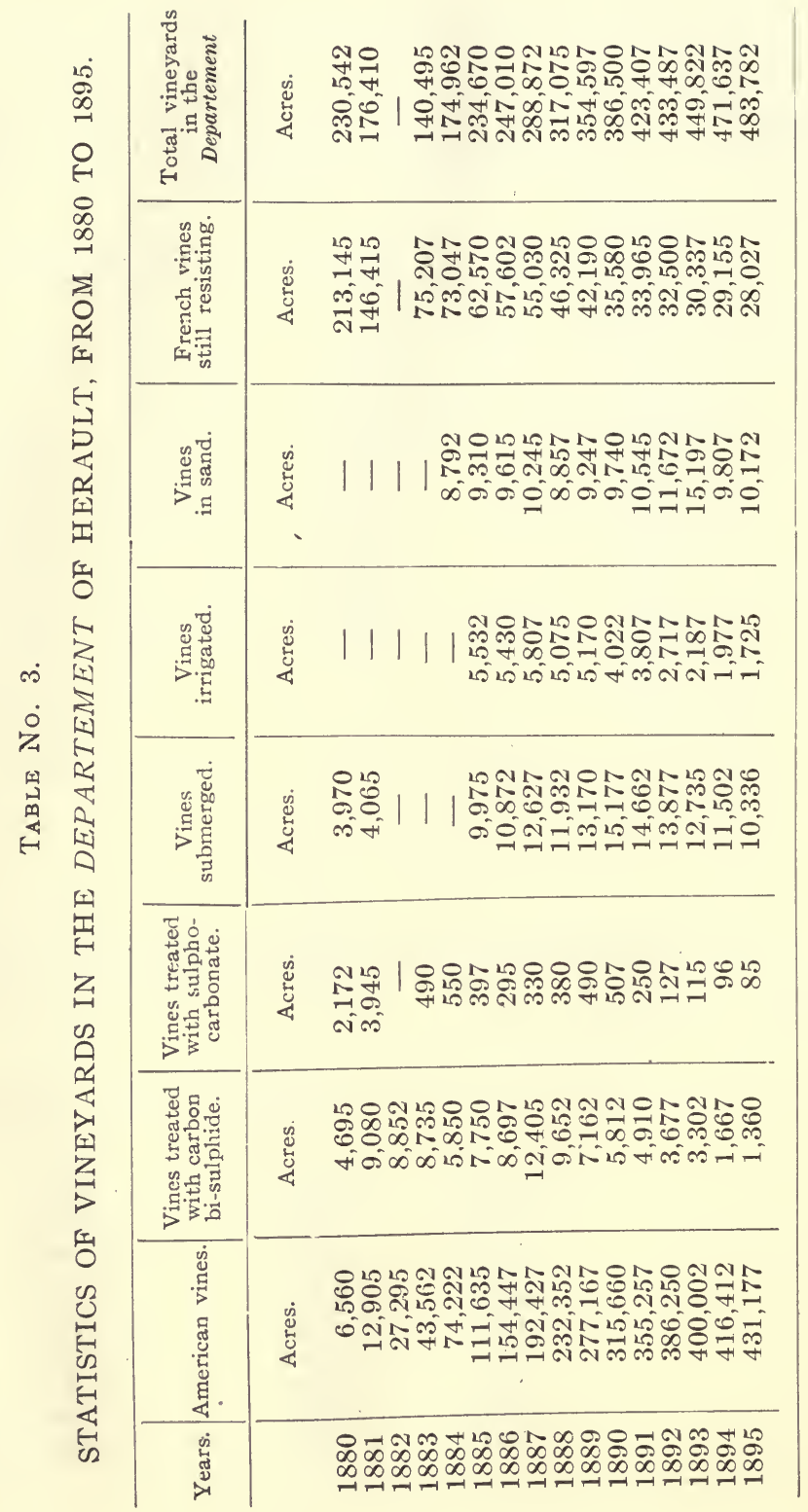


TABLE No. 4.

COMPARATIVE IMPORTANCE OF AMERICAN VINES AND OF INSECTICIDES IN HERAULT, IN RATIO TO THE AREA, EXPRESSED AS 100, OF THE TOTAL VINEYARDS OF THE DEPARTEMENT.

\begin{tabular}{|c|c|c|c|c|c|c|c|}
\hline \multirow{3}{*}{$\begin{array}{c}\text { Years. } \\
1880 \\
1881\end{array}$} & \multicolumn{4}{|c|}{ American rines. } & \multicolumn{3}{|c|}{ Insecticides. } \\
\hline & \multicolumn{4}{|c|}{2.8 per cent. } & \multicolumn{3}{|c|}{2.8 per cent. } \\
\hline & & $7.3^{\bullet}$ & " & " & 7.3 & & $"$ \\
\hline 1883 & & 31.0 & $"$ & $"$ & $6.5 "$ & " & $"$ \\
\hline 1884 & & 42.0 & " & $"$ & $2.2 "$ & " & $"$ \\
\hline 1885 & & 48.0 & $"$ & $"$ & $3.4 "$ & $"$ & $"$ \\
\hline 1886 & & 62.0 & $"$ & $"$ & $3.0 "$ & $"$ & $" \prime$ \\
\hline 1887 & & 60.0 & $"$ & $"$ & $4.0 "$ & " & $"$ \\
\hline 1888 & & 76.0 & $"$ & $"$ & $30 "$ & $"$ & $"$ \\
\hline 1889 & & 78.0 & $"$ & $"$ & $2.0 "$ & " & $"$ \\
\hline 1890 & & S0.0 & $"$ & $"$ & $1.0 "$ & $"$ & $"$ \\
\hline 1891 & & 83.0 & $"$ & $"$ & $1.28 "$ & " & " \\
\hline 1892 & & 86.0 & $"$ & $" \prime$ & 0.0 & " & $"$ \\
\hline 1893 & & 87.0 & " & $"$ & 0.7 & " & $"$ \\
\hline 1894 & & $8 S .0$ & $"$ & $"$ & $0.32 "$ & $"$ & $"$ \\
\hline 1895 & 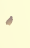 & 94.0 & $"$ & $"$ & 03 & $"$ & $"$ \\
\hline
\end{tabular}




\section{BIBLIOGRAPHY.}

A.

AuDoynaud.-Adaptation au sol des cépages américains (Journal de l'Agriculture, I88r, Vol. II, p. 302.)

B.

BALTET (Ch.)-L'Art de greffer ( $5^{\mathrm{e}}$ édition, 1893 , Paris, Masson).

BETHMONT (D.) - Essai des vignes en terrains calcaires (Revue de Viticulture r894 et r895).

BUSH AND SUN AND MEISSNER.-Illustrated descriptive Catalogue of American grape-vines (I895, Saint-Louis; traduit en français par J.-E. Planchon et L. Bazille. C. Coulet, Montpellier).

C.

Cahuzac.-La Greffe en écùsson, 1885.

CAZEAUX-CAZALET (G.)-Notice sur le greffage des vignes américaines (Bordeaux, Féret, I884).

“Instruction pratique de la greffe d'été (Bordeaux, Féret, 1888).

“ Divers in;Bulletin du Comice de Cadillac (I886-r895).

Champin (A.)-Traité théorique et pratique du greffage.

CHAUZIT B.)-Recherches chimiques sur quelques terrains où l'on a planté la vigne américaine (Messager agricole, 25 septembre I880).

"Etat actuel de la question du phylloxéra en France (Nîmes, r885).

“ Etude sur 1'adaptation au sol des vignes américaines (1889.- - In Une Mission viticole, par P. Viala, p. 303-375).

“ Rôle de l'argile dans l'adaptation au sol des plants américains (Revue de viticulture, r894).

CoRnu (Max). - Le Phylloxéra vastatrix (avec planches, Paris, 1878).

CouDERC (G.)-Etude sur 1'hybridation artificielle de la vigne (Montpellier, r887).

“ Conférence de Beaune (octobre I89r).

"Catalogue pour I889-189o des hybrids obtenus par M. G. Couderc (Aubenas, Ardéche).

" Divers in Progrès agricole (1890-1895).

“ Conférence sur les hybrids (Congrès de Mâcon, I887, Congrès de Chambéry, I890, Congrès de Beaune, I89r.

D.

DANIEL (L.)-Sur la greffe (Comptes rendus Académie des Sciences, I89i à I895.)

DAUREI (J.) - Traité pratique de Viticulture (Bordeaux, I895).

DAvin (G.) - Hybridation des vignes (la Provence horticole, mars I888).

DEJARDIN.- - Recherches et observations sur la résistance de la vigne au phylloxéra (Paris, Masson).

DEGRULLY (L.) - Plants américains en sols calcaires (C. Coulet, Montpellier, I895). 
DEGRULIY (L.) et VIALA (P.)-Les vignes américaines à l'Eccole nationale d'agriculture de Montpellier (Montpellier, Coulet, I884).

DESPERRIERE (G.)-Ecussonnage de la vigne en vert (Revue de viticulture, I894).

DESPETIS $\left(D^{r}\right)$. - Note sur les Riparias et sur leur classification au point de vue agricole (Bull. Soc. cent. agr. Hérault, Montpellier, I879, p. 4I7).

“Traité pratique de la culture des vignes américaines (Montpellier, C. Coulet, I889).

DrouhaulT (B.)-Greffage normal de la vigne en écusson (Revue de viticulture, I895).

DURAND (E.)-Qualité des vins des vignes greffées sur Rupestris et Franco-Rupestris (Revue de viticulture, I895).

F.

FoEx (G.)-Notes relatives aux effets produits par le phylloxéra sur les racines de divers cépages américains et indigènes (Comptes rendus Acad. scienc., I8 décembre 1876 et 15 Janvier I877).

" Note relative aux circonstauces météorologiques qui ont influé sur la marche de la chlorose des vignes américaines à l'Ecole nationale d'agriculture de Montpellier, pendant les années I884, I885, I886, I887, I888, 1889, et I890. (Ann. Ecol. nat. agric. Montpellier, Vol. V, r89o.)

"Manuel pratique de viticulture (Montpellier, C. Coulet, 6 édition, I899).

"Sur les causes de la chlorose chez l'Herbemont (Ann. de l'Ecole nat. d'agr. de Montpellier, I882 à r89r).

"Cours complet de viticulture ( $4^{\mathrm{e}}$ edition, Montpellier, Coulet, I895).

Foex (G.) et Vrara (P.)-Ampélographie américaine ( 1 vol. in folio, avec 80 planches phototy piques, $188_{3}$ ).

"Recherches relatives au diamè're réciproque des sujets et des greffons (Vigne américaine, I885.)

G.

GABARRET (J.)-De la greffe en écusson de la vigne. Greffe Salgues. GANZIN.-De l'hybridation artificielle et des services qu'on peut en attendre pour l'avenir de la viticulture (Revue scientifique, I88I, Vol. XXVIII, p. I43).

“ Les Hybrides à production directe (Revue de viticulture, 1894 et I895).

GIRERD (Ferdinand). - Le Guide pratique pour greffer (Lyon, r890).

GoDor.-Traitement de la chlorose, action des badigeonnages (Revue de viticulture, Vol. IV, I895).

GCETHE (Hermann). - Ueber das Veredeln der Reben (Ampelo. graphische Berichte, mai I880).

"Stazione sperimentale per lo studio biologico della vite (traduzione del tedesco di.Giuseppe Velicogna, Gorizia, r89r).

GRIS (Arthur).--Recherches microscopiques sur la chlorophylle (Annales des sciences naturelles $4^{\circ}$ série, Vol. VII, 1857, p. I79).

Gurlion (J.-M.)-Expériences sur le traitement de la chlorose et divers in Revue de viticulture, 1894, I895, 1896.) 
H.

Houdairl, et Semichon.-Le Calcaire et la Chlorose (Revue de viticulture, I894).

Houdarlif et MAZADE.-L'Humidité du sol et la Chlorose (Revue de viticulture, r894).

" Le Rupestris du Lot en terrain calcaire (Revue de viticulture, I895.)

J.

JEANJEAN (A.)-La Géologie agricole appliquée à la culture de la vigne dans le departement du Gard (Montpellier C. Coulet, I887).

JoUliE (H.) - Sur la chlorose de la vigne (Journal d'agriculture pratique, r889).

L.

LAVERGNE (G.)-Un Vignobles dans 1'Agenais (et divers, in Revue de viticulture, I894, - I895).

LENE (E.) - La Reconstitution dans les terrains calcaires, emploi de l'argile (Revue de viticulture, I895, Vol. IV).

M.

Marguerite-Deiachardonnay (P.) - Le Fer dans le végétation (Journal d'agriculture pratique, I890).

MARRE (E.)-Greffage en écusson de la vigne (I89I).

MAYET (V.)-Les rongeurs de boutures et de greffes (Revue de viticulture, Vol. II, I894).

MAZADE (M.)-De l'écussonnage en placage à bois sec (Revue de viticulture, Vol. I, I894).

“ Etude sur les Rupestris (Revue de viticulture, Vol. I, 1894).

"Etude sur les Berlandieri (Revue de viticulture, Vol. V, I896).

" Du Berlandieri et de la greffe-bouture (Revue de viticulture, Vol. I, I894).

MillaARDET.-Pourridié et Phylloxéra (Bordeaux, Féret, I879).

"Bouturage et greffage des vignes américaines (Journal d'agri. culture pratique, Vol. I, I88r, p. 729).

"Notes sur les vignes américaines, résistance au phylloxéra; de l'adaptation au sol et au climat (Journal d'agriculture pratique, Vol. I, pp. 8r, I57, 400, 53I).

"De l'hybridation entre diverses especes de vignes américaines à l'état sauvage (Journal d'agriculture pratique, I882, Vol. II, p. 470$)$.

“ Historie des principales variétés, et espèces de vignes d'origine américaine qui résistent au phylloxéra ( $\mathrm{I}$ vol. in-folio, I885, avec 24 planches; Paris, Masson; Bordeaux, Féret).

"Note sur les vignes américaines (séries I, II, et III, I885 à I888; Bordeaux, Féret; Paris, Masson).

“ Note sur les résultats de l'hybridation de la vigne (Congrès international d'agriculture de Paris I889, p. 714).

“ Essai sur l'hybridation de la vigne (Revue des Pyrénées, Vol. III, I89r, pp. 47 I-499).

“Sur les résultats généraux de l'hybridation de la vigne (Revue de viticulture, Vol. I, I894). 
MILIARDET et DE GRASSET.-Cataloyue des hybrids de vignes obtenus. depuis l'année I 880 à 189.2 inclusivement (Revue de viticulture, Vol. I, 1894).

MILLARDET et DE GRASSET. - Un porte-greffe pour les terrains crayeux, Chasselas X Berlandieri $n^{\circ} 4 \mathrm{I} B$ (Revue de viticulture, Vol. II, 1894).

Munson ( $\mathrm{r} .-\mathrm{V}$.) - Les vignes américaines en Amérique (Revue de viticulture, 1894, I895, I896).

"Explorations viticoles dans le Texas (Revue de viticulture, Vol. II, I894).

"Les portes-greffes des terrains crayeux secs (Revue de viticulture, Vol. III, 1895).

\section{N.}

NARbonne (Paul).-La Chlorose de la vigne, préservation et traitement (Narbonne, I888).

P.

PERRAUD (J.)-La résistance du Vialla en Beaujolais (Revue de viticulture, I894 et I895).

PETit (Emile) - La chlo'ose, recherche de ses causes et de ses remèdes (B)rdeaux, i888).

Patrot.-Les vignes américaines dans la côte chalonaise (Congı̀̀s de Beaune, I89I).

Pranchon (J.E.) - Les vignes américaines leur culture, etc. Montpellier, Coulet, I875).

"Le Coltis ou pousse en ortille, malıdie des sarments de la vigne (Vıgne américaine, I882, p. 232).

Ponsot $\left(\mathrm{M}^{\mathrm{me}} \mathrm{V}^{\mathrm{e}}\right)$. - Les vigues américaines (Bordeaux, Féret, 1890 ).

PUl, IAT (V.)-Manuel du greffeur de vignes (Montpellier, Coulet, I885).

R.

RAssiguier ( $D^{r}$ ).-Traitement de la chlorose (divers, in Revue de viticulture, I895).

Rathay (Emerich).-Die Geschlechtsverhaeltniss der Reben (Wien, I 888).

Ravaz (L.)-Excursion dans les vignobles de l'Hérault (1888).

"Monographie du Portugais bleu et du Saint-Sauveur (Progrès agricole et viticole, I886).

" Recherches sur le bouturage de la vigne (Comptes rendus de l'Académie des sciences, I5 septembre, I890).

"Articles divers, in Journal du Syndicat de la CharenteIn'érieure.

"Rapports à M. le Présideut du Comité de viticulture de l'a:rondissement de Cognac (Cognac, I889 à I896).

"Les Vignes américaines; résistance au phylloxéra et résistance à la chlorose (Cognac, I895).

“ Défoncement et plantation dans les terrains calcaires (Revue de viticulture, I895).

“ Le Riparia du Colorado (Revue de viticulture, 1894).

“ Divers, in Revue de viticulture (I894, I895, I895).

“ Les Riparias, les Rupestris, les Berlandieri (Revue de viticulture, Vol. III, I895).

"Choix des porte-greffes (Revue de viticulture, Vol. IV, I895). 
RAvaz et Gouirand.-Recherches sur l'affinité des vignes greffèes (Revue de viticulture, Vol. I et Vol. 1I, r894).

Rougier (L.) - Instructions pratiques sur la reconstitution des vignobles pir les cépages américains $\left(2^{\mathrm{e}}\right.$ édition, 1890 ; Montpellier, Coulet).

S.

SACHS (J.)-Sur le traitement des plantes chlorotiques (Arbeiten des bot. Institute zur Würzburg, III, 433; Wolluys Forschungen, XII, I30).

SaHuT (Félix). - L;s vignes américaines, leur greffage et leur taille (Montpellier, C. Coulet, I887).

"De l'adaptation des vignes américaines au sol et au climat suivie d'une étude sur le bouturage à un œil (Montpellier et Toulouse, I888).

"La Jaunisse ou chlorose des vignes (Montpellier, C. Coulet, I890).

SaINT-Por, (Vicomte de).-Enquête sur les vignes américaines (Bulletin de la Société des agriculteurs de France, I890-I89I).

SAIAS y AMAT. - Histoire d'une vigue en terrains très calcaires (Revue de viticulture, I895).

STol, (R.)-Ueber die Bildung des Kallus bei Stecklingen (Bot. Zeitung, 1874).

T.

TALI,AVIGNES.-Greffes aériennes de la vigne (Revue de viticulture, Vol. I, I895).

TORD (Max).-Recherches sur le traitement des vignes chlorotiques.

V.

VERNEUIL, (A.) - Le champ d'essai de Conteneil (Revue de viticulture, I895 et 1896$)$.

VrALA (P.) - Des soins à donner aux greffes (1884).

"Les Hybrides-Bouschet (Montpellier, Coulet, I886).

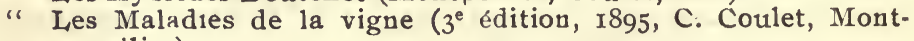
pellier).

“Une Mission viticole en Amérique (I889, I vol. avec 8 planches en chromo; C. Coulet, éditeur, Montpellier; Paris, G. Masson).

" Mission viticole pour la reconstitution des vignobles du département de Maine-et-Loire (Angers, Hudon, 1890)

"La reconstitution des vignobles de la Côte-d'Or (Beaune, 189I).

"La reconstitution des vignobles de la Loire-Inférieure (Nantes, I vol. in-I2, I89I).

"Une Maladie des greffes-boutures (Revue de hotanique, I891).

“ Monographie du Pourridié des vignes et des arbres fruitiers (C. Coulet, Montpellier, avec 7 planches, 1891 ).

"Mission viticole pour la reconstitution des vignobles de l'Allier (I893).

“Mission viticole pour la reconstitution des vignobles de l'Yonne (I894). 
Viala Mission viticole pour la reconstitution des vignobles du Puy-de Dôme (I895)

“De l'action de certaines substances toxiques sur la vigne (Revue de viticulture, Vol. I, 1894).

“Le bouturage du Berlandieri (Revue de viticulture, Vol. I, I894).

" Divers in Revue de viticulture (1894, I895, I896).

"Le champs d'expériences du "Mas de las Sorres" (Revue de viticulture, Vol. V, ז896).

“ Les Rupestris Mission (Revue de viticulture, I895).

“Variétés de V. Monticol» (Revue de viticulture, Vol. V, 1896).

“ Le Rupestris du Lot (Revue de viticulture, Vol. IV, I895).

VIALA et MAZADE.-La multiplication du Berlandieri (Revue de viticulture, I895).

Viala (P.) et NANOT (J.) - Tableau du greffage de la vigne (Montpellier, C. Coulet, 1892).

“Tableaux des cours de viticulture et d'arboriculture de l'Institu e nationale agronomique (1890).

Vral,a (P.) et Ravaz (L.) - La mélanose (Montpellier, C. Coulet, I887).

“ Le Black Rot et le Coniothyriuu diplodiella (2 édition, Montpellier, C. Coulet, I888).

“ Le bouturage en pousse (Revue de viticulture, 1894).

VIALI,A (Louis). - Observations sur la plantation des cépages américains (Montpellier, Grollier, 1877).

“ Des vignes américaines et des terrains qui leur conviennent (in Messager agricole, ro octobre 1878 , et Messager du Midi des 2 et 3 septembre, 1878 ).

VIVIER (A.) - Traitement au sulfate de fer contre la chlorose (Revue de viticulture, Vol. IV, I895).

W.

WichurA.-Die B istard.Befruchtung im Pfanzenreich erlaitert an den $B$ istarden der Weiden (I865).

Wochirisg (H.)-De la traniplintation sur le crops de la plante (Botanische Zeitung, 189 ).

Z.

ZACHAREWICZ et TACUSSEL.-Champ d'expériences en terraiu calcaire (Revue de viticulture, r896). 


\section{GLOSSARY. OF PRINCIPAL SCIENTIFIC TERMS USED IN PRESEN'T VOLUME*}

ABNORMaL - Contrary to the general rule.

ABORTIVE-An organ or flower is said to be abortive when its development has been arrested at a very early stage.

Acuminate, leaf (Bot.) - Ending in sharp point.

ADAPTABILITY - The quality of being capable of adaptation.

ADAPTATION-When speaking of a plant, that act or process of adapting itself to certain conditions of the surroundings.

Alluvial (Geol.)-Composed of alluvium; relating to the deposits made by flowing waters, washed away from one place and deposited in another as alluvial soil.

Alpine Diluvium (Geol.) - A deposit of superficial loam, sand, gravel, stone, etc., caused by former action of flowing waters, or the melting of glacial ice in the Alp ranges, south of France.

Ampelopsis (Bot.) - A family of plants closely related to Vitis, commonly called Virginian creepers.

Analogous-See Analogy.

ANALOGY-That resemblance of structure which depends upon similarity of relations. Such structures are said to be analogous or analogues to each other.

Anastomosis-Intercommunication between two or more vessels.

Anthers (Bot.) - The summits of the stamens of flowers in which the pollen or fertilizing dust is produced.

Apex (Bot.) - The tip, top, point, or summit of a leaf or stem.

Araneous (Bot.)-Cobweblike; extremely thin and delicate down on vine leaves.

Atavism - See Reversion.

Atropine-A white crystallizable poison, extracted from different plants, remarkable for its power of dilating the pupil of the eye.

AUTOFECUNDATION-Self-impregnation.

BATHONIAN-Applied to rocks belonging to a certain division of the Jurassic age. The term refers to the age of the rocks alone, and not to their character or composition.

BIFURCATION-A forking or division into two branches

BINARY HYBRID-Hybrid resulting from the crossing of two cépages only.

BLoom-When speaking of fruit, the delicate, powdery external coating, as on grapes.

Calcareous-Partaking of the nature of limestone.

CALYX-The outer covering of a flower.

CAMBIUM (Bot.) - A series of formative cells lying outside the wood proper and inside of the inner bark; the growth of the new wood takes place in the Cambium. which is very soft.

*This Glossarı has been given because several viticulturists have complained that some of the terms used in previous publications were unintelligible to them - (Trans.) 
Cambrian Formation (Geol.)-A series of very ancient palæozoic rocks, between the Laurentian and Silurian, until recently regarded as the oldest fossiliferous rocks. It is named from its occurrence in Cambria, or Wales.

Carbonate of Lime-Limestones.

CARBONIC ACID GAS-This term is generally applied to a compound of carbon and oxygen, more correctly called carbon dioxide.

CARBONIFEROUS Formation (Geol) - A series of rocks, including sandstone, shales, limestone, and conglomerates with beds of coal, which make up the strata of the carboniferous age.

Cartilaginous or Cartilagineous-Firm and tough, like cartilage.

CELL (Biol.) - One of the minute elementary structures of which the greater part of the various tissues and organs of plants is composed.

CePAge (French)-Has no equivalent in English. Any vine when under cultivation.

Chalaze or Chalaza (Bot.) - The place on a seed where the outer coats cohere with each other and the nucleus.

Chalazic Depression (Bot.) - Natural depression in a seed formed by the chalaze.

Chlorosis (Bot.) - A disease in plants causing the leaves to lose their normal green colour and turn yellow.

ConCAVE-Said of the interior of a curved surface.

ConCRETION (Geol.) - Rounded mass or nodule produced by the aggregation of the material round a centre, as the calcareous concretions common in beds of clay.

Conglomerate (Geol.) - A bed of fragments of rock, or pebbles, cemented together by other material.

ConICALLY - Having the general shape of a geometrical cone, round and tapering to a point, or gradually decreasing in circumference.

ConvEX-Said of the outside of a curved surface in opposition to concave.

Corallian (Geol.) - A deposit of coralliferous limestone forming a portion of the middle division of the oolite.

CORDIFORM or CORDATE-Having the general shape of a heart, as a cordiform leaf.

COROLLA-The second envelope of a flower, usually composed of coloured leaf-like organs (petals) and may be united by their edges in the top part, as in vine flowers.

Corona of THE Stigma-Crown-like appendage at the top of the stigma.

Cretaceous Formation (Geol.) - The series of strata of various kinds containing beds of chalk, green sand; also called chalk formation.

Cryptogam (Bot.) - Plants belonging to the series or division of flowerless plants propagated by spores, and generally living as parasites on other plants. A fungus is a cryptogam.

CRYPTOGAMIC DiSEASE-An alteration in the state or the function of a plant, caused by a cryptogam such as mildew, black rot, etc.

DEFOLIATION-The falling or shedding of the leaves.

DESICCATION-The state of being dried up or deprived of moisture.

Devonian Formation (Geol.) - A series of Palæozoic rocks, including the old red sandstone.

DIAPHRAGM (Bot.)-Partition of wood separating the pith of two internodes in a vine cane.

Diluvium-See Alpine Diluvium.

DiscoID-Having a circular structure like the berries of certain vines 
Elongated or Elongate-Drawn out in length, as an elongated leaf. Emarginate (Bot.)-When speaking of a leaf, means that, in entire leaves, the limb becomes narrow suddenly below the two teeth forming the two lateral lobes.

ENTIRE (Bot.) - When speaking of a leaf, means one consisting of a single piece, having a continuous edge without any lobes.

EOcene (Geol.) - The earliest of the three divisions of the Tertiary epoch of geologists. Rocks of this age contain shells.

Excision-The act of cutting out or cutting off.

EXCORIATED-When speaking of bark means that detaching in strips.

EXFOLIATING-When speaking of bark, that separating from the trunk and coming off in long pieces.

FECUND-Fruitful; prolific.

FERTILITY - The state of being fruitful or producing offspring

Fibro-VASCULAR BundLes-Vegetable tissue composed partly of sap tubes.

Filament (Bot.) -The thread-like part of the stamen supporting the anther.

Filiform-Having the shape of a thread or filament.

Florescence (Bot.) - The bursting into flower or blossoming.

Fluted TRUNK.- Trunk with natural grooves situated lengthwise.

Fossiliferous (Geol) - Containing fossils.

FruCtifERous (Bot:) - Bearing or producing fruit.

FRUCTIVITY (Bot.) - The quality of bearing fruit.

FUNGI, sing. Fungus (Bot.) - A class of cellular and flowerless plants belonging to the cryptogams.

Fusion of CHARACTERS - When speaking of a hybrid, means that the characters of both parents are united in the offspring.

$\mathrm{G}_{\mathrm{ALL}}$, of phylloxera-An excrescence produced on the leaves of American vines by one of the wingless forms of phylloxera.

GARIGUES SoILS-Red, siliceous, dry loam, covering the rock formation of certain hills in the south of France.

GLABROUS-Smooth, having a surface without hairs.

GLAND-An organ which secretes some peculiar product from the sap of plants.

GLA UCOUS-Of a sea-green colour; of a dull green passing into greyish blue.

GLOBULAR-Having the form of a ball or sphere.

GOFFERED or GAUFFERED - Crimped like the leaves of some vines.

GRANITE-A rock consisting essentially of crystals of felspar and mica in mass of quartz.

Groies (French) - Applies to certain calcareous soils of the Charente district.

HERBACEOUS-Having the nature, texture, or characteristics of a herb; a shoot in a green state.

HeRMAPHRODITE-Possessing the organs of both sexes.

HONEYCOMB StRUCTURE-When speaking of vine leaves, a symetrically uneven, wrinkly, or goffered surface. See Goffered.

Humid-Containing sensible moisture; damp; moist.

Humidity-Moisture; dampness; a moderate degree of wetness perceptible to the eye or touch.

HUMIFEROUS-Containing humus.

Humus-That portion of the soil formed by the decomposition of animal or vegetable matter. It is a valuable constituent of soil.

HYвRID-The offspring of the union of two different species 
HYBRIDIZATION-The act of hybridizing.

HYBRIDIZE - To produce a crossing between two species.

INDENTATION-A notch or recess in the margin of a leaf.

INDENTED-Notched along the margin; cut on the edge into points, like teeth.

INFLORESCENCE-The mode of arrangement of the flowers of plants.

INTERNODE-The space between two nodes or points of the stem from which the leaves properly arise.

INTERSTICES-Spaces between closely set soils or rocks.

INTRINSIC-Real, inherent, not merely apparent or accidental.

INULIN-A substance found dissolved in the sap of the roots of many composite and other plants. It is intermediate in nature between starch and sugar.

Jurassic (Geol.) - Of the age of the middle Mesozoic, named from certain rocks in the Jura mountains.

Juxtaposition-Being placed side by side with opposite parts corresponding.

KNIT-United: joined, so as to grow together. Used as a noun, means the grafts joined together: the union.

LACUSTRINe DEPOSITS (Geol.) - The deposits which have been accumulated in fresh water areas.

Laminated Strata (Geol.) - Divided into thin layers.

LANCEOLATE LEAF-Rather narrow, tapering to a point at the apex.

LANCINATED-Torn: lacerated.

LENTICLES (Bot.)-Small, oval, or rounded spots upon the stem or branches of a plant. Small lens-shaped glands on the under face of some leaves.

LESION-Change in the texture of a vegetable organ resulting from an injury

LIBER - The inner bark of plants, lying next to the wood.

LigNEOUS (Bot.) - Of the nature of, or resembling wood.

Lignification (Bot.) - Change in the character of an herbaceous shoot by which it becomes harder or woody.

LIGNIFIED (Bot.) - Converted into wood or into ligneous substance.

Lim B, of a leaf (Bot.) The flat part of the leaf of any plant

LITTORAL-Bordering the seashore.

LOAM-A soil formed of a mixture of clay and sand with organic matter, to which its fertility is chiefly due.

LOBATED OR Lobate (Bot.) - Having lobes.

LOBE-A rounded projection or division of a leaf.

MARGIN, of a leaf-The outer edge or border.

MARL-A mixed soil consisting of carbonate of lime, clay, and sand in very variable proportions, and accordingly designated as calcareous, clayey, or sandy.

MEDUllary Rays (Bot.) - The rays of cellular tissues seen in a transverse section of exogenous wood which run from the pith to the bark.

MErIs-The offspring of the union of two varieties of the same species.

Metization-The act of producing a crossing between two varieties of the same species.

Mrocene (Geol.) - Middle division of the Tertiary.

MORPHOLOGY - The law of form or structure, independent of function.

MUCRO (Bot.) - A minute, abrupt point of a leaf.

MrCelium (Bot.) - The white threads or filamentous growth from which a mushroom or fungus is developed; the so-called mushroom spawn. 
Nitrogen-A colourless gas composing four-fifths of the atmosphere by volume. It is incapable of supporting life, but forms many important compounds, as ammonia, nitric acid, etc., and is constituent of all organized living tissues, animal or vegetable.

Node (Bot.) - The joint of a stem, or the part where the leaf is inserted. Nodosities-Small swellings produced on vine roots by phylloxera.

NODULE-A round mass of irregular shape.

Normal-According to an established rule. (Geom.) Perpendicular to a surface or forming a right angle with it.

NuClEus (Bot.) - A whole seed, as contained within the seed coats.

NUTRITION-A process or series of processes by which the living organism is maintained in its normal conditions of life and growth.

NUtRItive MatTERS-Matters having the quality of nourishing.

OBTUSE-Not pointed or acute; blunt.

Ocherous Solls-Containing an impure earthy ore of iron, or a ferruginous clay. Such soils are usuallv red or yellow.

Oolitic-A great series of secondary rocks, so-called from the texture of some of its members, which appear to be made up of small egglike calcareous bodies.

OPERCULUM-Any lid-shaped structure in a leaf or flower.

ORBICULAR-Having a spherical form.

Ovate (Bot.) - Having the shape of an egg, that is to say an.oval border at the base.

Ovord (Bot)-Resembling an egg in shape.

OVuLE, of plants-The seed in the earliest condition.

Oxfornian (Geol.) - Applied to rocks of a certain age in the Jurassic series.

PARABOLA-A kind of geometrical curve; one of the conic sections formed by the intersection of the surface of a cone with a plane parallel to one of its sides.

PARASITE (Bot.)-A plant living upon or in another plant.

PARENCHYMA (Bot.)-The soft cellular substance of the tissues of plants, like the pulp of leaves.

Pedicle or PEDicel (Bot) - A stalk which supports one flower or fruit. One of the many divisions of a peduncle.

Peduncle (Bot) - The stem or stalk which supports a cluster of flowers or fruits.

Pentagonal Leaf-Having five sides.

Petals (Bot.) - The leaves of the corolla, a second circle of organs in a flower.

Petiolar Sinus-Depression between two adjoining lobes into which the petiole is inserted.

Petiole-A leaf stalk; the stalk connecting the stem with the blade or limb.

Physiological-Relating to the "science of the functions of living organisms.

Physiology-Study dealing with vegetable or animal life.

Pinching (Hort.) - Operation consisting in cutting about one inch off the extremity of young shoots a little before or directly after florescence

PIstil (Bot.) - The female organs of a flower, which occupy a position in the centre of other floral organs. The pistil is generally divisible into the ovary, the style, and the stigma.

PITH (Bot.) - The soft, spongy substance in the centre of the stem of many plants. 
Plane or Plain-A flat, level, smooth, even surface.

PLASTICITY - Retaining any impressed form or shape.

Pollen (Bot.) - The male element in flowering plants, usually a fine dust produced by the anthers, which by contact with the stigma effects the fecundation of the seeds. This impregnation is brought about by tubes (pollen tubes) which issue from the pollen grains adhering to the stigma and penetrate through the tissues until they reach the ovary.

Polygamus Plants-Plants in which some flowers are unisexual and others hermaphrodite.

PourRIDIE (French) - Disease on the roots of vines caused by different fungi.

PROCREATION-Generation or production of young.

PRODUCTIVITY - The quality or state of being productive.

PROTUBERANCE-A swelling or prominence, such as the protuberance of a node.

PUBESCENT-Covered with fine short hairs, as the leaves of some vines.

QUATERnARY TUFA (Geol ) - A soft, porous stone formed by deposition from water, usually calcareous, belonging to the quaternary age.

RADICEL (Bot.) - A small branch of a root; a rootlet.

RAPHE or RHAPHE (Bot.) - The continuation of the seed stalk along the side of an anatropous seed, forming a ridge or stem.

REVERSION-To return towards some ancestral type or character; atavism.

RIB (Bot.) - The chief nerve or one of the chief nerves of a leaf; also any longitudinal ridge on a stem, as in V. Berlandieri.

ROUNDED LEAF-Having a curved outline without lobes.

RudimentARY - Very imperfectly developed; in an early stage of development.

Rugose, leaf-Having the veinlets sunken and the spaces between them elevated.

ScHIST-Any crystalline rock having a foliated structure.

Schistose Soils-Are usually metamorphic clays.

ScION-A piece of branch cut for grafting into another.

SEM I-Prefix signifying half, as in semi-erect, semi-climbing habit, etc.

SEPALS-The leaves or segments of the calyx, or outermost envelope of an ordinary flower. They are usually green.

SHOULDERED GRAPES-Those in which the two ramifications of the base are well developed.

Sieve TUBFS (Bot.)-Also called cribriform tubes. Those having here and there places perforated with many holes.

Sil ICA-Quartz, silicon dioxide.

Silicfous Nodules-See Nodule.

Silice OUS OR Silicious SoILS-Those containing silica or quartz.

SILURIAN (Geol.) - A term applied to the earliest of the Palæozoic strata.

Sinus (P1. sini or sinuses) - A depression between adjoining lobes in a leaf.

SPECIES-An ideal group of individuals which are believed to have descended from common ancestors, which agree in essential characters and are capable of indefinitely continued fertile reproduction through the sexes. A species as thus defined differs from a variety or sub-species only in the greater stability of its characters and in the absence of individuals intermediate between the related groups. 
STAMENS-The male organs of flowering plants, standing in a circle within the petals. They usually consist of a filament and an anther, being the essential part in which the pollen or fecundating dust is formed.

STERILE-Incapable of reproduction; not able to germinate or bear fruit, as a sterile flower, which bears only stamens.

STIGMA - The apical portion of the pistil in flowering plants.

STOCK, grafting-Part which bears the scion in plants.

Strata, sing. stratum (Geol.) - Beds of earth or rock of one kind formed by natural causes, and consisting usually of a series of layers.

STRIATED-Marked with striæ, or fine grooves or lines; showing narrow structural bands of lines.

Style (Bot.) - The middle portion of the perfect pistil, which rises like a column from the ovary and supports the stigma at its summit.

Suberous Tissue (suberous or suberose)-Having a corky texture.

Sub-Medium-Under the average.

SUB-ORBICULAR-Having an elliptic outline.

Suв-Ribs-Secondary ramifications of the ribs of a leaf.

Sub-Veins-Same meaning as sub-ribs.

Sulphate of COPPER-Compound of sulphuric acid and copper, commonly called bluestone.

SulPHATE OF IRON-Compound of sulphuric acid and iron, commonly called green vitriol.

TENDRIL (Bot.) - A slender leafless portion of a plant, by which it becomes attached to a supporting body, after which the tendril usually contracts by coiling spirally. The tendrils of a vine are metamorphosed grapes.

Ternary Hybrid-Hybrid resulting from the crossing of three cépages.

TERTIARY - The latest geological epoch, immediately preceding the establishment of the present order of things.

Tomentose (Bot) - Covered with matty woolly hairs.

Tomentum (Bot.) - The closely matted hair or downy nap covering the leaves or stems of some plants.

Tоотн-Angular or rounded prominence on the margin or edge of a leaf.

TRILOBATE-Having three lobes.

TUBEROSITIES-Knob-like prominences developing on vine roots attacked by phylloxera.

TuFA-See quaternary tufa.

UNDULATING LEAF-Rising and falling like waves.

VARIATION-A varied form of a variety.

VARIETY-Differs from a species in that when propagated by seed it will revert to another form. See species. 


\section{TABLE OF ILLUSTRATIONS.}

Fig. 1. Young shoot of $\mathrm{V}$. Rotundifolia............................ Page

Fig. 2 .

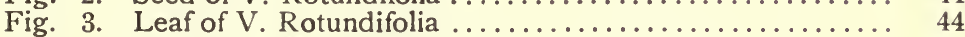

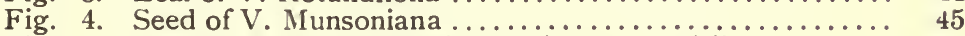

Fig. 5. Shoot of V. Labrusca with continuous tendrils.......... 46

Fig. 6. Shoot with discontinuous tendrils ................ 46

Fig. 7. Leaf of V. Labrusca ....................... 47

Fig. 8. Seed of V. Labrusca ...................... 47

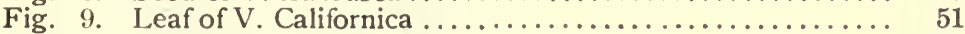

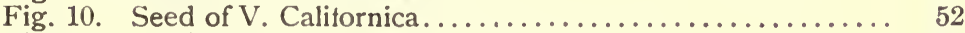

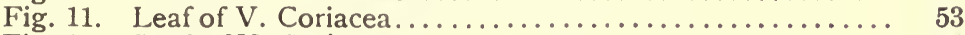

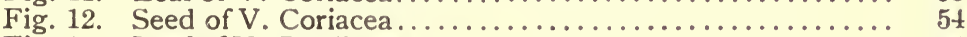

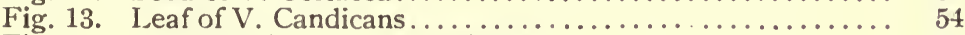

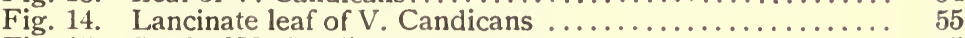

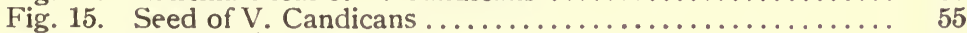

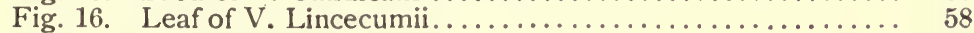

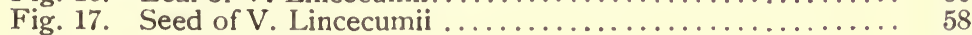

Fig. 18. Seed of V. Bicolor ........................ 59

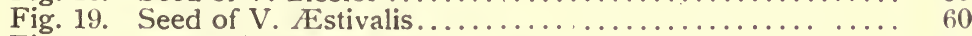

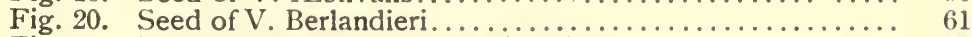

Fig. 21. Leaf of Berlandieri Résseguier No. 1............. 64

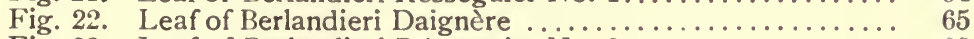

Fig. 23. Leaf of Berlandieri Résseguier No. 2............. 66

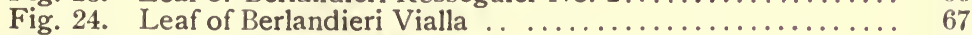

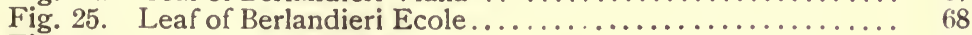

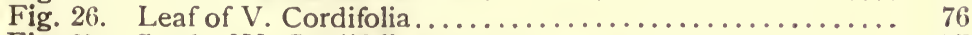

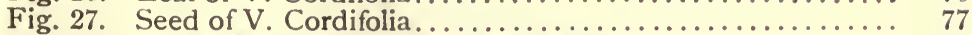

Fig. 28. Leaf of $V$. Cordifolia Sempervirens .............. 78

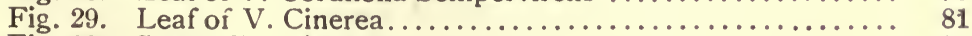

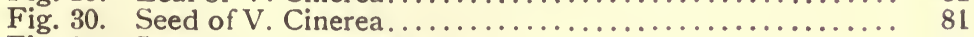

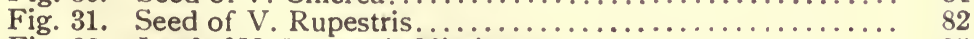

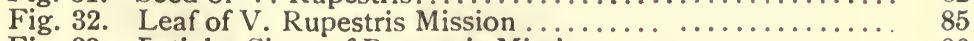

Fig. 33. Fetiolar Sinus of Rupestris Mission ............... 86

Fig. 34. Leaf of Rupestris du Lot ................... 86

Fig. 35. Petiolar Sinus of Rupestris du Lot $\ldots \ldots \ldots \ldots \ldots \ldots \ldots \ldots \ldots . \ldots \ldots$

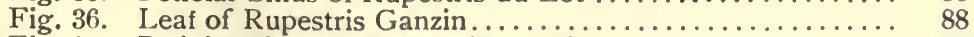

Fig. 37. Petiolar Sinus of Rupestris Ganzin................ 88

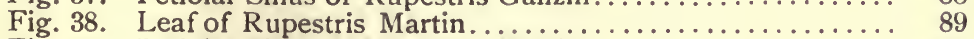

Fig. 39. Petiolar Sinus of Rupestris Martin ................. 89

Fig. 40. Leaf of Rupestris Metallica ...................... 90

Fig. 41. Petiolar Sinus of Rupestris Metallica ................ 90

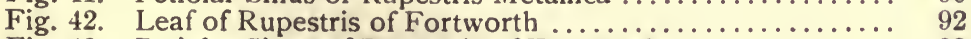

Fig. 43. Petiolar Sinus of Rupestris of Fortworth .............. 92

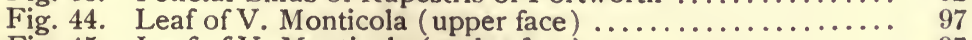

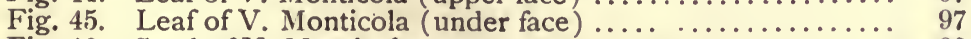

Fig. 46. Seed of $V$. Monticola ................................ 98

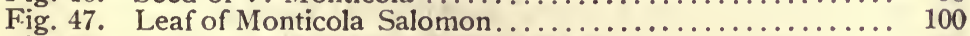

Fig. 48. Leaf of $\mathrm{V}$. Monticola Munson No. $1 \ldots \ldots \ldots \ldots \ldots \ldots \ldots \ldots . \ldots \ldots$ 
Fig. 49. Leaf of $\mathrm{V}$. Monticola Munson No 3 . Page

Fig. 50. Leaf of $\mathrm{V}$. Arizonica ............................ 103

Fig. 51. Seed of V. Arizonica......................... 103

Fig. 52. Leaf of Riparia Gloire ...................... 104

Fig. 53. Leaf of Riparia Grand Glabre................... 105

Fig. 5t. Seed of V. Riparia......................... 105

Fig. 55. Seed of V. Rubra .......................... 113

Fig. 56. Seed of V. Vinifera......................... 115

Fig. 57. Normal vine flower ........................ 120

Fig. 58. Different stages in the opening of a Chasselas flower (after Millardet) ............................. 120

Fig. 59. Male flowers ............................ 121

Fig. 60. Flowers with long stamens................... 122

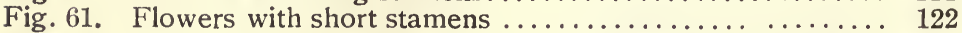

Fig. 62. Upper face of vine leaf, showing the opening of phylloxera galls............................... 127

Fig. 63. Side view showing phylloxera galls ............. 127

Fig. 64. Nodosities and tuberosities $(a)$ on vine roots......... 128

Fig. 65. Penetrating tuberosities .... .................... 129

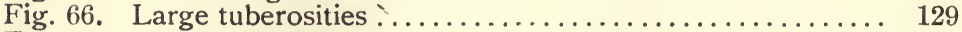

Fig. 67. Non penetrating tuberosities ...................... 129

Fig. 68. Non penetrating tuberosities on roots of American vines 129

Fig. 69. Leaf of York Madeira.......................... 133

Fig. 70. Leaf of Noah............................. 137

Fig. 71. Leaf of Clinton .......................... 138

Fig. 72. Leaf of Vialla ........................... 140

Fig. 73. Leaf of Taylor Narbonne.. ................. 142

Fig. 74. Leaf of Barnes............................... 144

Fig. 75 . Leaf of Champin................................. 146

Fig. 76. Leaf of Belton ................................. 148

Fig. 77. Leaf of Riparia $X$ Candicans ......................... 150

Fig. 78. Leaf of Solonis ......................... 153

Fig. 79. Leaf of Novo-Mexicana (Mobeetie ) ................ 155

Fig. 80. Leaf of Duaniana ....................... 156

Fig. 81. Leaf of Berlandieri $X$ Riparia No. 33 Ecole ............ 164

Fig. 82. Leaf of Berlandieri $X$ Riparia No. 34 Ecole ........... 165

Fig. 83. Leaf of Colorado ............................ 168

Fig. 84. Leaf of Riparia $X$ Rupestris No. 101-14 (Millardet and

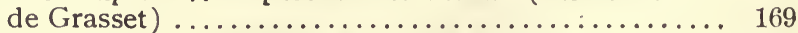

Fig. 85. Leaf of Riparia X Rupestris No. 3306 (Couderc) ........ 170

Fig. 86. Leaf of Riparia $X$ Rupestris No. 3309 (Couderc) ......... 171

Fig. 87. Leaf of Jacquez........................... 179

Fig. 88. Leaf of Herbemont ......................... 181

Fig. 89. Leaf of Cabernet $X$ Berlandieri No. 333 Ecole.......... 185

Fig. 90. Leaf of Chasselas $X$ Berlandieri No. 41 (Millardet and de

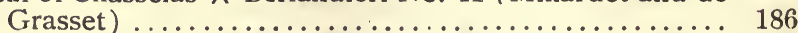

Fig. 91. Leaf of Aramon $X$ Rupestris Ganzin No. $1 \ldots \ldots \ldots \ldots \ldots . . . . . . .188$

Fig. 92. Leaf of Othello ............................ 194

Fig. 93. Callus or knitting tissue developed on a scion............ 210

Fig. 94. Grafting knife ................................ 225

Fig. 95. Grafting bill..................................... 225

Fig. 96. Grafting bill with curved blade .................. 225

Fig. 97. Stock and scion prepared for the whip-tongue graft .... 226

Fig. 98. Preparation of stock for the whip-tongue graft $\ldots \ldots \ldots \ldots, 226$ 
Page

Fig. 99. Section of stock and scion ................... 227

Fig. 100. Joint of whip-tongue graft .................. 227

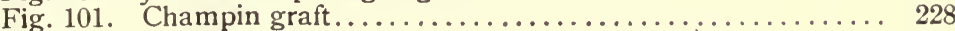

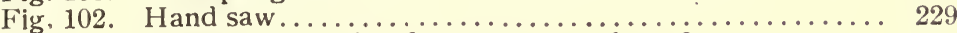

Fig. 103. Wedge-shape scion for ordinary cleft-graft ......... 229

Fig. 104. Ordinary cleft-graft on old stock .............. 229

Fig. 105. Wedge-shaped scion for English cleft-graft .......... 230

Fig. 106. Double cleft-graft on old stock................. 230

Fig. 107. English cleft-graft. Stock and scion joined............ 231

Fig. 108. Showing the disposition of generative layers on stock and scion.............................. 231

Fig. 109 and 110. Shouldered cleft-graft prepared with a grafting

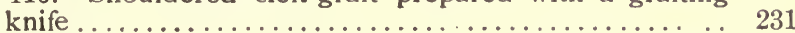

Fig. 111 and 112. Shouldered cleft-graft prepared with a grafting

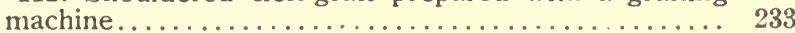

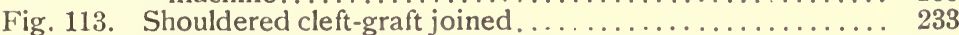

Fig. 114. Aglet graft, stock, scion and graft united......... . 233

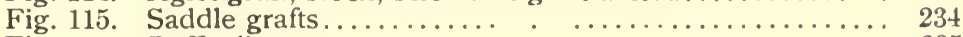

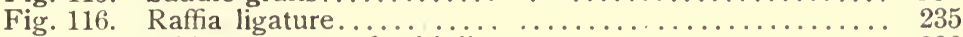

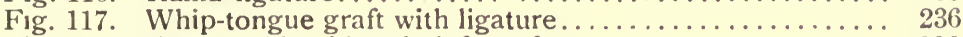

Fig. 118 and 119. Shouldered cleft-graft ............... 236

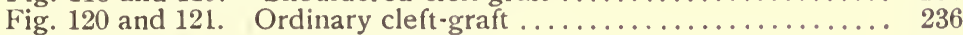

Fig. 122. Ligature of an Aglet graft ................. 237

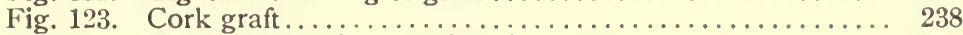

Fig. 12t. Mattock used for severing the roots.............. 242

Fig. 125. Liberated graft $(a)$ strong scion roots $(b)$ weak roots of

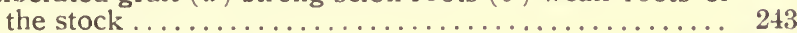

Fig. 126 and 127. Cidillac graft $(a)$ stock $(b)$ scion......... 245

Fig. 128 and 129. Cadillac graft $(a)$ stock $(b)$ scion............ 245

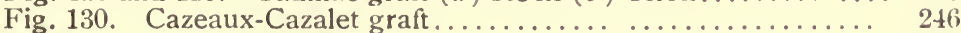

Fig. 131. Defective cleft......................... 247

Fig. 132. Cadillac side cleft-graft................... 247

Fig. 133. Gaillard graft......................... 248

Fig. 134. Showing the way of removing the eyes of the stock .... 250

Fig. 135. Grafted cuttings planted with a dibble............. 253

Fig. 136. Nursery beds......................... 253

Fig. 137. Grafted cuttings placed in nursery rows ............ 254

Fig. 138. Arrangement of the soil.................... 254

Fig. 139. Showing the arrangement of the sand around the top eye 254

Fig. 140. Grafted cutting (a) slender roots of the stock (b) strong

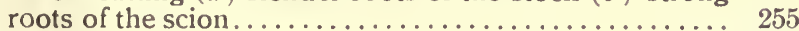

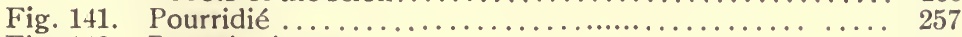

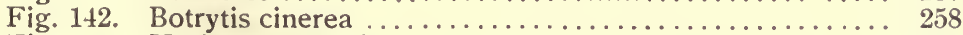

Fig. 143. Herbaceous graft knitted (after H. Goethe) ............ 259

Fig. 144. Stock prepared for the herbaceous graft (after H. Goethe) 259

Fig. 145. Side graft (after Goethe $\ldots \ldots \ldots \ldots \ldots \ldots \ldots \ldots \ldots \ldots . \ldots \ldots$

Fig. 146. Side graft joined (a) scion, (b) ligature, (c) stock (after

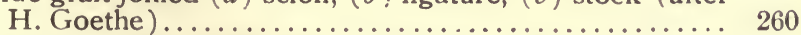

Fig. 147. Section of the union of a herbaceous graft (after $H$. Goethe )

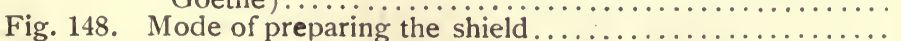

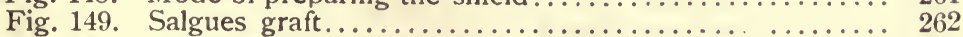

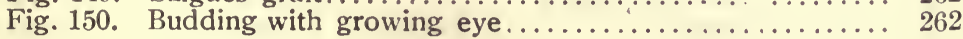




\section{ALPHABETICAL INDEX.}

A.

Page

Advance ........................................... 193

Æstivalis with large berries......................... 57

Æstivalis with large berries No. 13 (Jæger) .................. 57

Estivalis X Bicolor................................... 158

Astivalis X Cinerea ................................. 159

Estivalis $X$ Cordifolia .................................. 158

Estivalis X Coriacea ................................ 167

Estivalis X Riparia.................................. 160

Estivalis X Rupestris ............................... 159

Affinity ......................................... 214

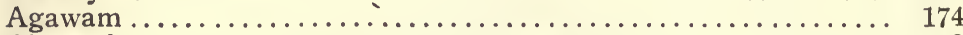

Alexander.................................... 48

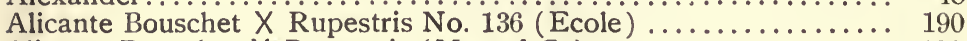

Alicante Bouschet X Rupestris (M. and G. )................ 190

Alicante Ganzin ................................... 191

Alicante X Rupestris Terras No.20...................... 190

Alma........................................... 193

Alvey.......................................... 177

Amber-Queen $\ldots \ldots \ldots \ldots \ldots \ldots \ldots \ldots \ldots \ldots \ldots \ldots \ldots \ldots \ldots \ldots, 136$

Aramon X Riparia (M. and G. $\ldots \ldots \ldots \ldots \ldots \ldots \ldots \ldots \ldots \ldots \ldots \ldots \ldots \ldots \ldots \ldots \ldots \ldots \ldots, 192$

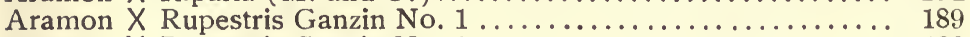

Aramon X Rupestris Ganzin No. 2 ...................... 189

Ariadne ......................................... 136

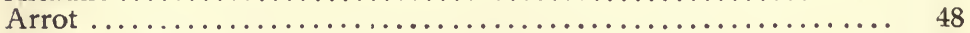

Asiatic vines ..................................... 114

August Giant $. . \ldots \ldots \ldots \ldots \ldots \ldots \ldots \ldots \ldots \ldots \ldots \ldots \ldots \ldots \ldots \ldots, 193$

Autuchon .......................................... 193

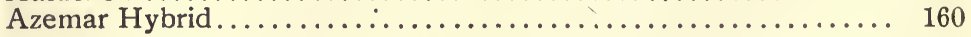

B.

Bacchus....................................... 136

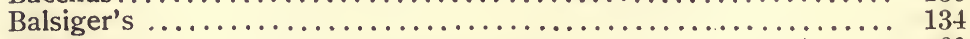

Baxter ........................................... ${ }^{6}$

Barnes.............................................. 145

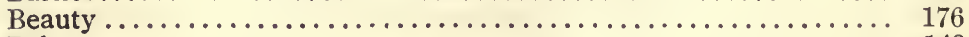

Belton........................................... 148

Belvidere........................................ 48

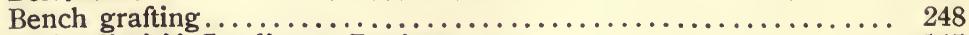

Berlandieri $X$ Candicans, Bouisset $\ldots \ldots \ldots \ldots \ldots \ldots \ldots \ldots \ldots \ldots \ldots \ldots \ldots \ldots \ldots \ldots \ldots, 145$

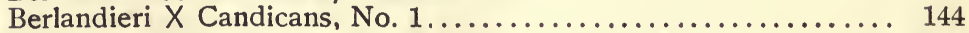

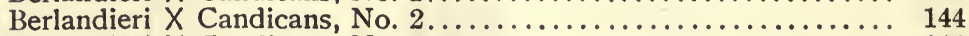

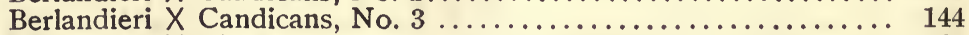

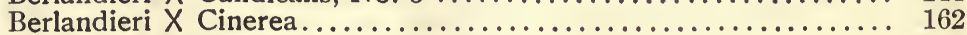

Berlandieri $X$ Cordifolia .............................. 162 


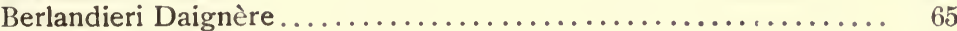

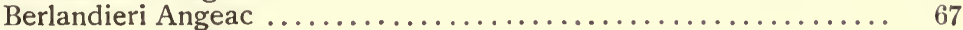

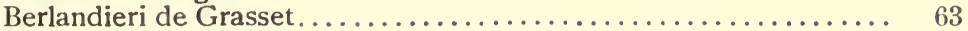

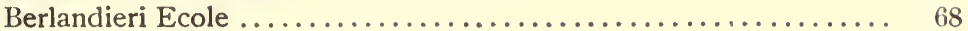

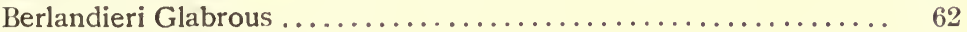

Berlandieri Lafont, No. $9 \ldots \ldots \ldots \ldots \ldots \ldots \ldots \ldots \ldots \ldots \ldots \ldots \ldots$

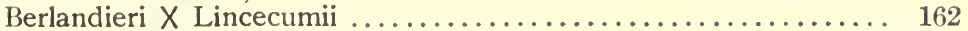

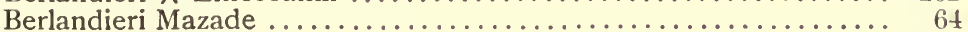

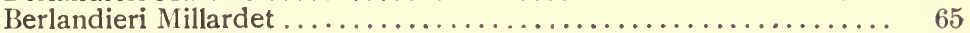

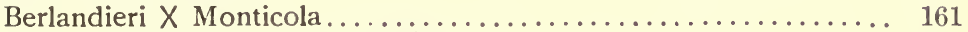

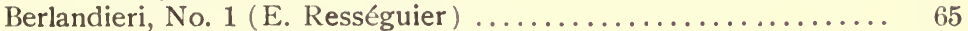

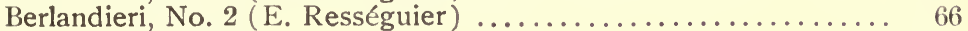

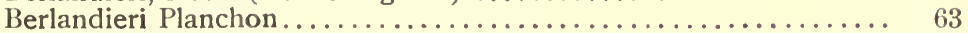

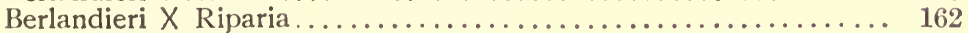

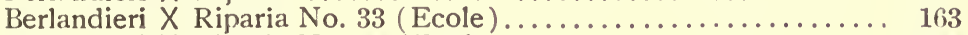

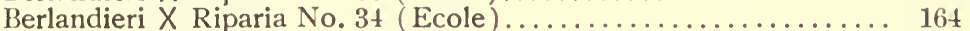

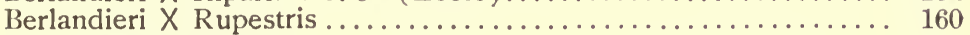

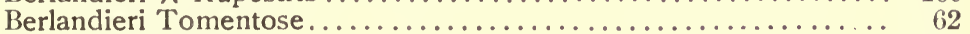

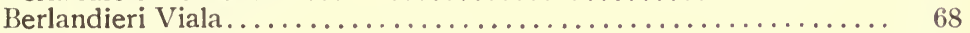

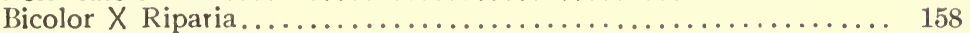

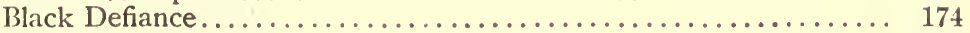

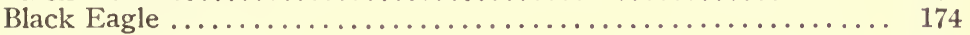

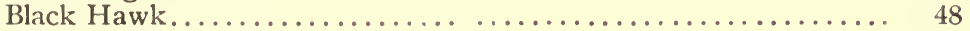

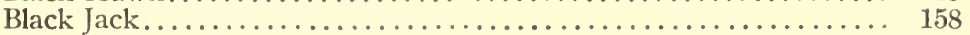

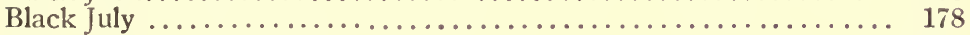

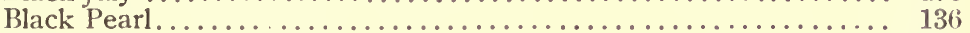

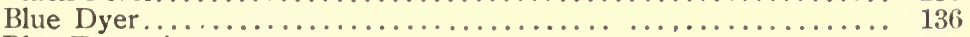

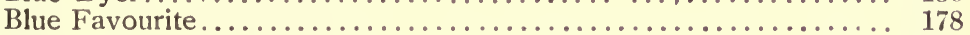

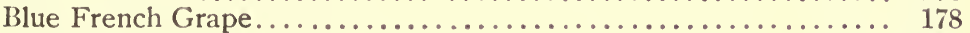

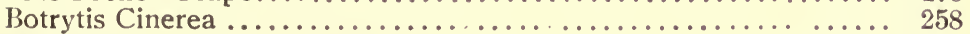

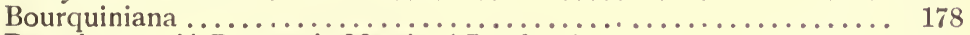

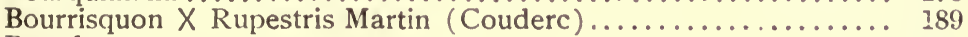

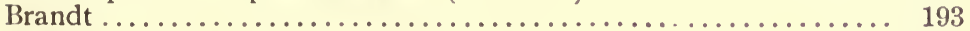

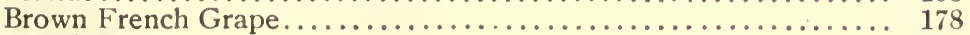

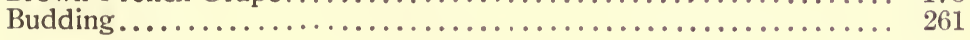

C.

Cabernet $X$ Berlandieri No. 333 (Ecole) ................. 186

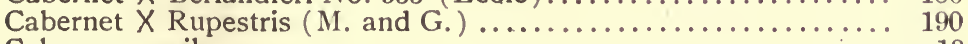

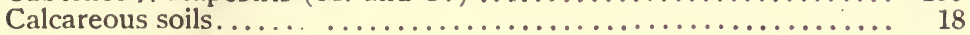

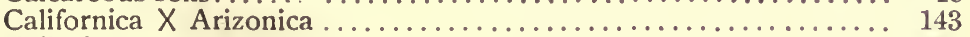

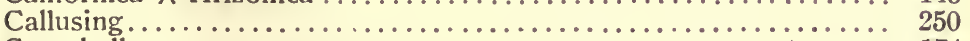

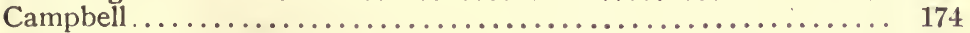

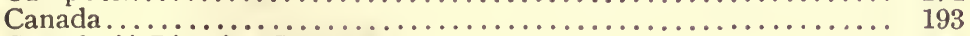

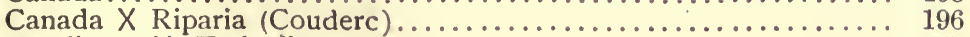

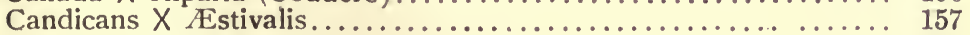

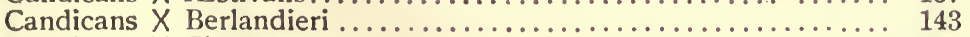

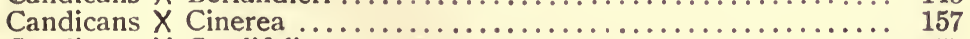

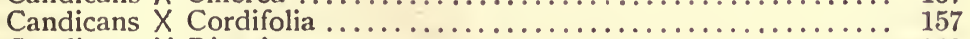

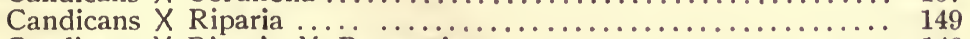

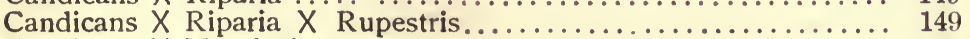

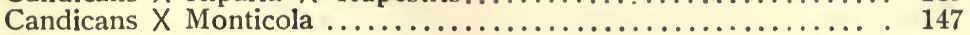


Candicans $X$ Monticola No. 32 (Ecole)

Candicans $X$ Rupestris..................................... 145

Carbonate of Lime and Chlorosis ........................... 31

Carbonate of Magnesia............................... 33

Carpar ............................................. 178

Catawba.......................................... 136

Centennial........................................ 175

Cépages........................................... ${ }_{41}$

Champin ....................................... 145

Champin (glabrous) $\ldots \ldots \ldots \ldots \ldots \ldots \ldots \ldots \ldots \ldots \ldots \ldots \ldots \ldots \ldots \ldots \ldots, 146$

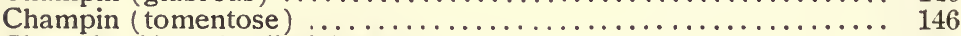

Chasselas X Berlandieri (M. and G.) ...................... 187

Chasselas X Rupestris Martin (Couderc) .................. 189

Chlorosis ........................................ 18

Chlorosis, characteristic symptoms of ................... 18

Chlorosis, cause of ................................ ${ }_{22}$

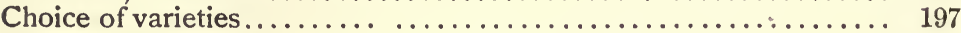

Cinerea $X$ Coriacea ................................... 167

Cinerea (glabrous) $\ldots \ldots \ldots \ldots \ldots \ldots \ldots \ldots \ldots \ldots \ldots \ldots \ldots \ldots,{ }_{8}$

Cinerea X Novo Mexicana ............................... 157

Cinerea X Riparia ................................... 167

Cinerea $X$ Rupestris ................................. 169

Cinerea (tomentose) $\ldots \ldots \ldots \ldots \ldots \ldots \ldots \ldots \ldots \ldots \ldots \ldots \ldots, \quad 80$

Clairette (golden) Ganzin ............................... 191

Clay (Role of ) ................................. 15

Climate and Chlorosis .................................. 29

Clinton .......................................... 138

Cognac (Couderc) ........................................ 176

Colombeau..................................... 116

Colombeau X Riparia (Couderc) .............................. 192

Colombeau X Rupestris Martin (Couderc)................ 189

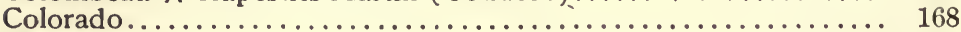

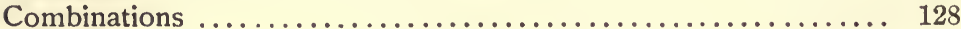

Compactness ....................................... 15

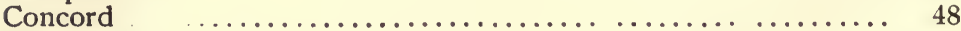

Concord $X$ Cynthiana ................................ 134

Coniothyrium diplodiella $\ldots \ldots \ldots, \ldots, \ldots, \ldots, \ldots, \ldots, \ldots, \ldots, \ldots, \ldots, 258$

Conqueror ........................................... 136

Cordifolia $X$ Cinerea....................................... 165

Cordifolia $X$ Coriacea ......................................... 167

Cordifolia $X$ Riparia $\ldots \ldots \ldots \ldots \ldots \ldots \ldots \ldots \ldots \ldots \ldots \ldots \ldots, 166$

Cordifolia X Rupestris .................................... 166

Cordifolia X Rupestris de Grasset No. $1 \ldots \ldots \ldots \ldots \ldots \ldots \ldots \ldots, 166$

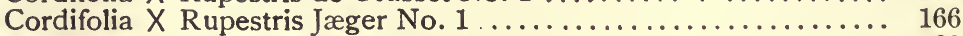

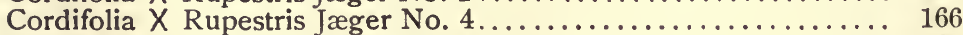

Cordifolia X Rupestris Jæger No. 5..................... 166

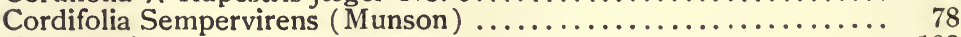

Cornucopia......................................... 193

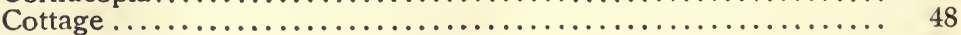

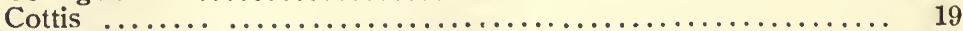

Crossings ........................................... 128

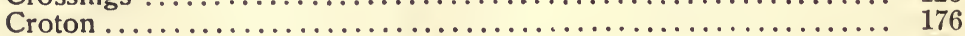

Culture............................................... 197

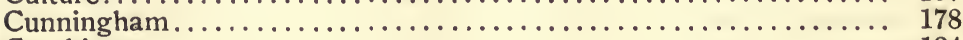

Cynthiana $\ldots \ldots \ldots \ldots \ldots \ldots \ldots \ldots \ldots \ldots \ldots \ldots \ldots \ldots \ldots \ldots \ldots \ldots \ldots \ldots \ldots \ldots \ldots, 134$ 
D.

Deep ploughing.

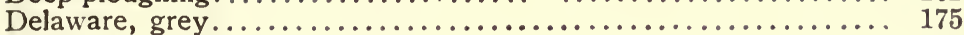

Delaware, white ..................................... 175

Diana ............................................... 136

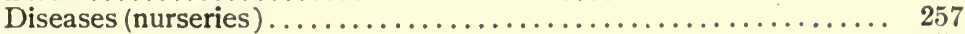

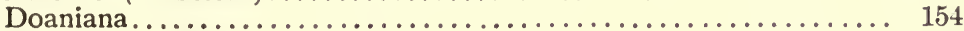

Doaniana, early................................... ${ }_{15}$

Doaniana, late..................................... 157

Dolomite......................................... 33

Duchess........................................... 176

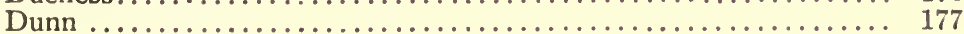

E.

Early Victor................................... 48

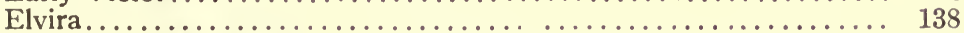

Elvira No. 100 (Jæger) .............................. 138

Empire State .. ................................ 136

Etraire de l'Adhui ...................................... 116

Etta ......................................... 136

Eumélan ......................................... 175

Eureka.......................................... 48

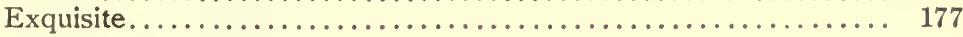

F.

Faith.......................................... 136

Far West............................................ 58

Fecundation................................................ 120

Ferrand's Michigan ............................................. 136 and 141

Fertility ............................................... 17

Fibrillaria $\ldots . \ldots \ldots \ldots \ldots \ldots \ldots \ldots \ldots \ldots \ldots \ldots \ldots \ldots, 258$

Flowers ........................................... 43

Franklin ....................................... 141

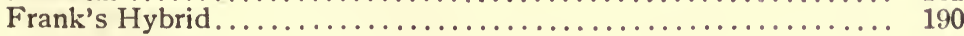

G.

Gamay Couderc ..................................... 189

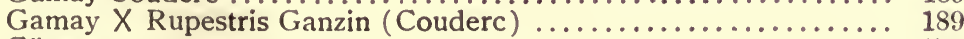

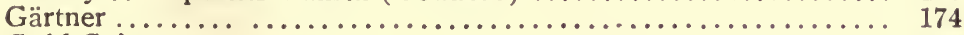

Gold Coin ............................................. 134

Golden Clairette Ganzin................................. 191

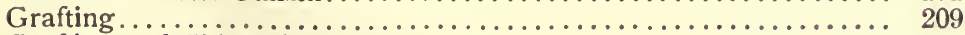

Grafting and Chlorosis ..................................... 38

Grafting, most favorable time for $\ldots \ldots \ldots \ldots \ldots \ldots \ldots \ldots \ldots \ldots \ldots \ldots, 239$

Grafting, Bench.................................... 248

Grafting, Rootlings ....................................... 257

Grafting, Herbaceous ...................................... 259

Grafting on growing stocks $\ldots \ldots \ldots \ldots \ldots \ldots \ldots \ldots \ldots \ldots \ldots \ldots \ldots \ldots \ldots \ldots, 239$

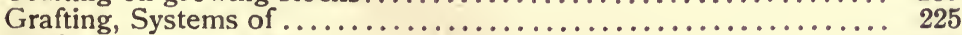

Graft, Anatomy of the ................................... 209

Graft, Physiology of the .............................. 209 
Graft, aglet...................................... 233

Graft, whip-tongue................................ 226

Graft, cork ..................................... 238

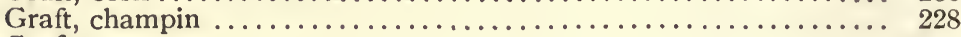

Grafts, autumn ................................ 244

Graft, Cadillac................................... 245

Graft, double cleft ................................ 230

Graft, ordinary cleft................................ 228

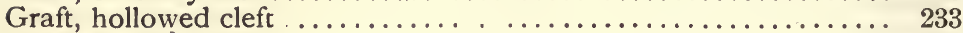

Graft, English cleft................................ 230

Graft, dovetail................................... 234

Graft, Gaillard.................................... 248

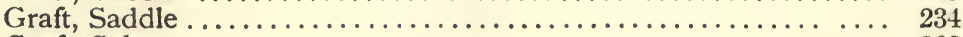

Graft, Salgues ..................................... 262

Grein's Golden ......................................... 136

Grey Delaware .................................. 175

Gros Colman X Rupestris (M. and G.) ......................... 190

Gwyn grape .................................... 148

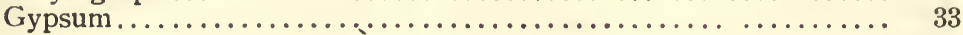

H.

Hartford Prolific.................................. 48

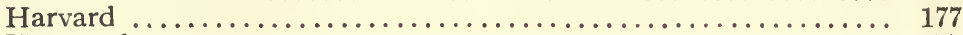

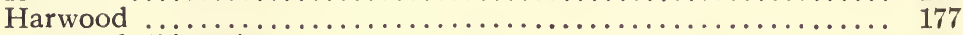

Heat and Chlorosis ........................................ ${ }_{28}$

Herbemont............................................. 177

Herbemont of Aurelle....................................... 178

Herbemont Touzan................................ 178

Herbemont, White................................ 178

Herbert ............................................. 174

Hermann ......................................... 134

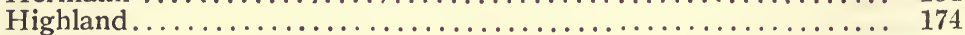

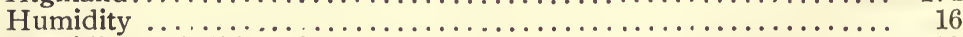

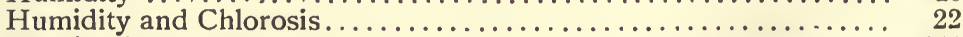

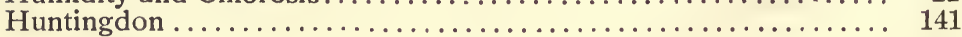

Hutchison..... ............................................. 154

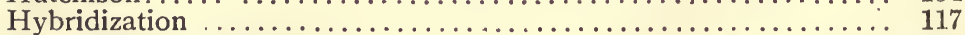

Hybridization (Historical) $\ldots \ldots \ldots \ldots \ldots \ldots \ldots \ldots \ldots \ldots \ldots, 117$

Hybridization (Technique) ............................ 122

Hybrids...................................... 117

Hybrids (Americo-American) . . . . . . . . . . . . . . . . . . . 132

Hybrid, Franc's .................................... 190

Hybrids (Franco-American) $\ldots \ldots \ldots \ldots \ldots \ldots \ldots \ldots \ldots \ldots \ldots \ldots \ldots \ldots \ldots \ldots \ldots \ldots, 172$

Hybrids, Seibel's ........................................ 191

Hybrids of American vines............................. 132

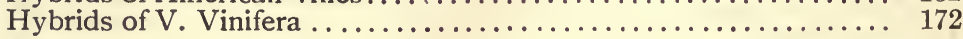

I.

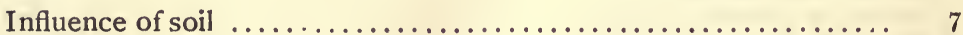

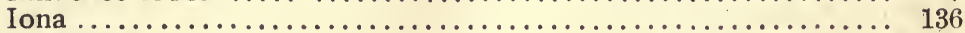

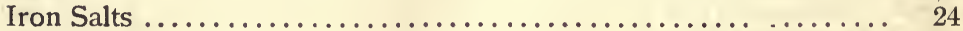

Ironclad.................................................. 136 
Iron and Chlorosis

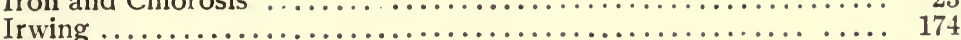

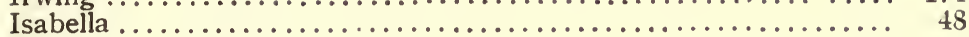

Israella.............................................. 48

Ives seedlings $\ldots \ldots \ldots \ldots \ldots \ldots \ldots \ldots \ldots \ldots \ldots \ldots \ldots \ldots, 48$

$\mathrm{J}$.

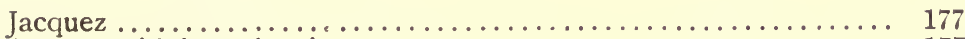

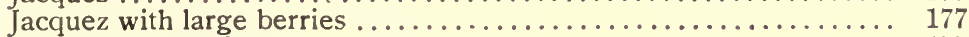

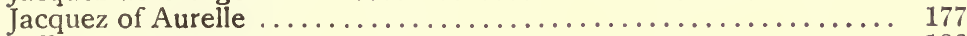

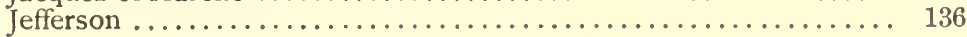

K.

Knitting tissue............................... 210

L.

Labrusca $\times$ Æstivalis ............................. 132

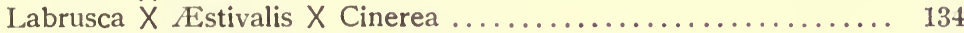

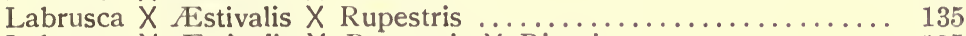

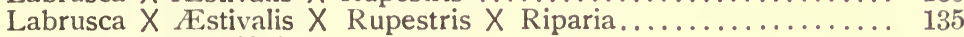

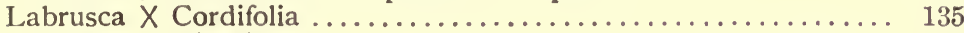

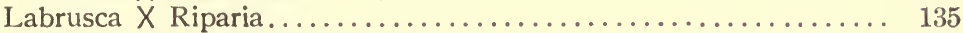

Labrusca X Riparia X Rupestris ...................... 141

Lady ......................................... 48

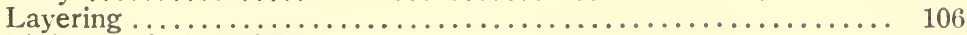

Lifting grafted cuttings............................ 256

Ligatures................................... 237

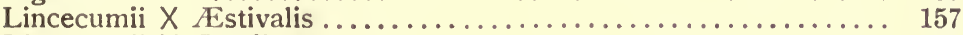

Lincecumii $X$ Candicans .................................. 157

Lincecumii $X$ Cinerea............................... 157

Lincecumii $X$ Cordifolia............................. 157

Lincecumii No. 13 (Jæger) ........................... 58

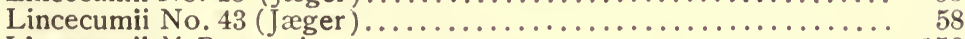

Lincecumii X Rupestris............................. 158

Lindley ................................................ 174

Love-lady ....................................... 145

Light and Chlorosis........................................... ${ }_{28}$

Luty ........................................ 136

M.

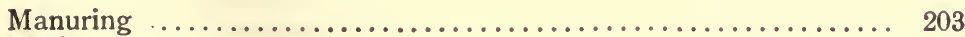

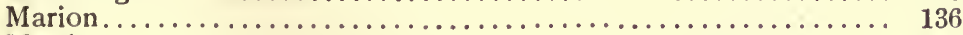

Martha........................................... ${ }_{48}$

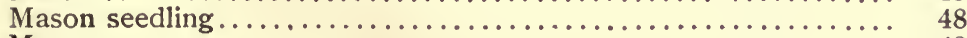

Maxatawney...................................... 48

McKee.......................................... 178

Mildew ............................................. ${ }_{38}$

Mildew and Chlorosis.............................. 38

Mish ........................................... 43

Missouri Riesling ..................................... 136 


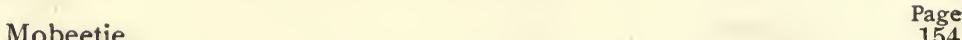

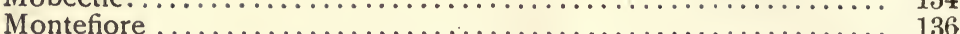

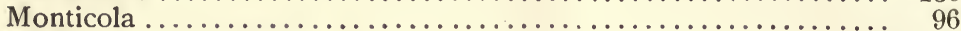

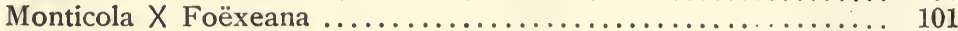

Monticola Munson, No. 1 .......................... 100

Monticola Munson, No. 2 and No. $3 \ldots \ldots \ldots \ldots \ldots \ldots \ldots \ldots \ldots$

Monticola X Riparia............................ 167

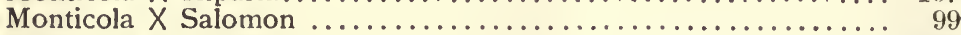

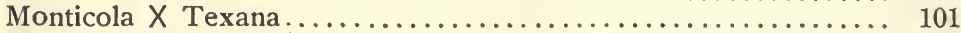

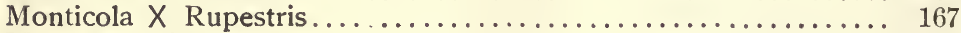

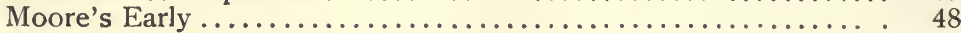

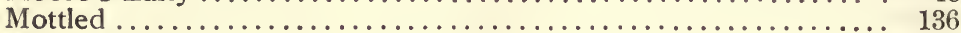

Mourvèdre X Rupestris, (Couderc)...................... 189

Mourvèdre X Rupestris Ganzin (Couderc) ................. 189

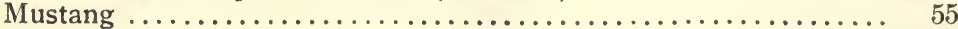

N.

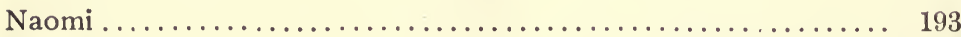

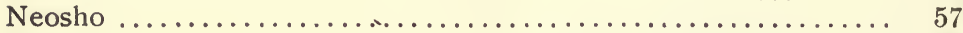

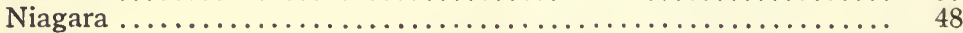

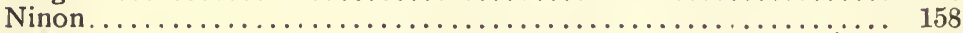

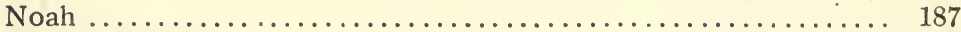

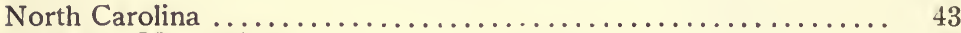

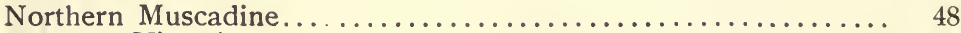

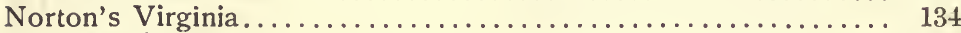

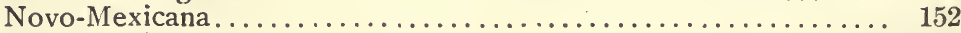

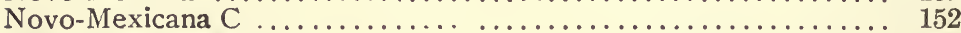

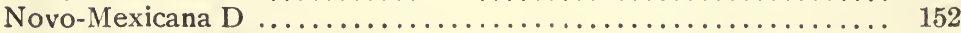

Novo-Mexicana Microsperma........................ 152

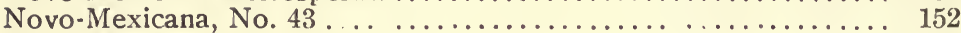

Novo-Mexicana, No. $56 \ldots \ldots \ldots \ldots \ldots \ldots \ldots \ldots \ldots \ldots \ldots \ldots \ldots \ldots \ldots$

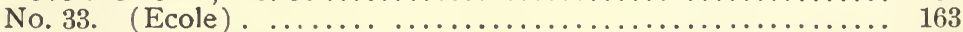

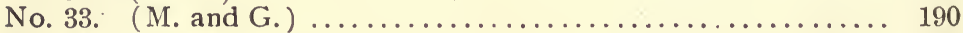

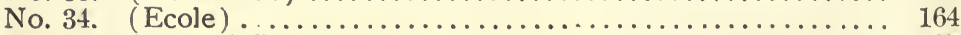

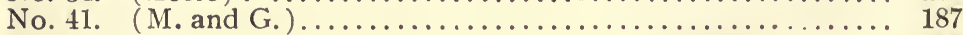

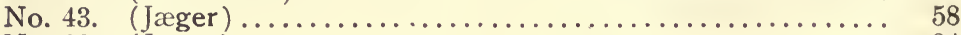

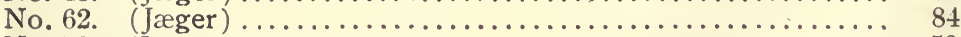

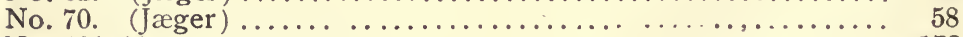

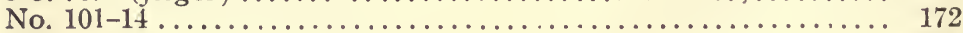

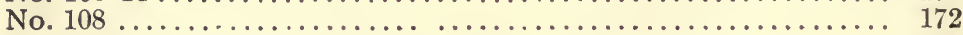

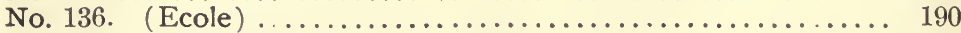

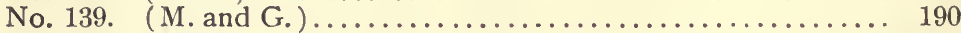

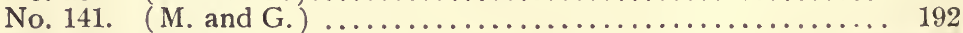

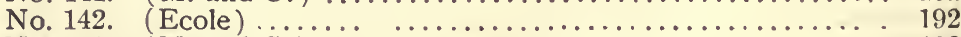

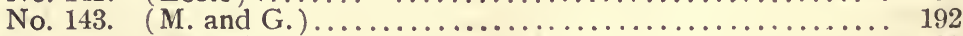

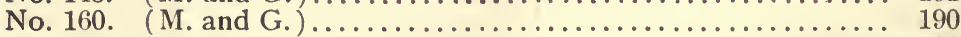

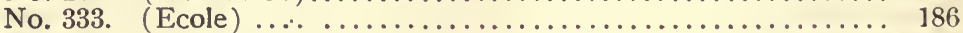

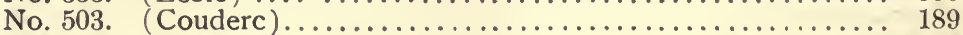

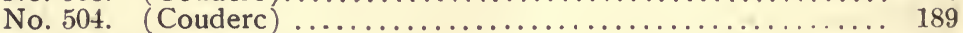

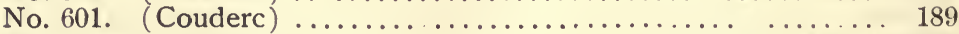

No. 603 . (Couderc) .............................. 189

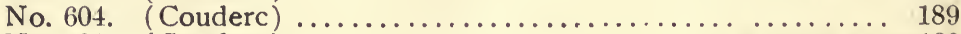

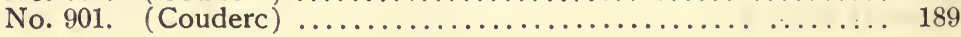


Page

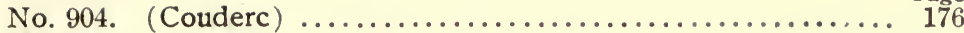

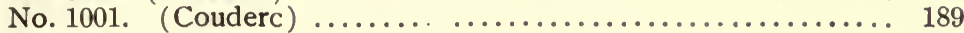

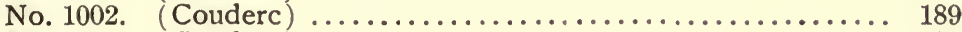

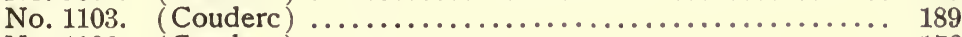

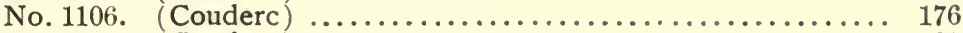

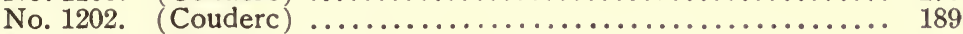

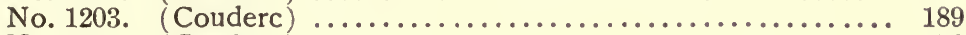

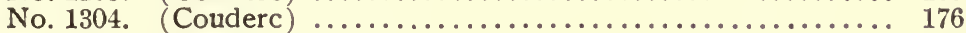

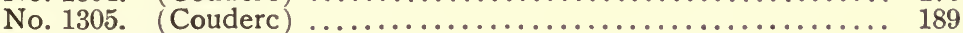

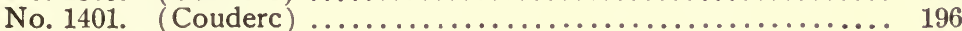

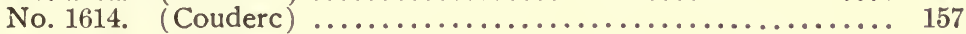

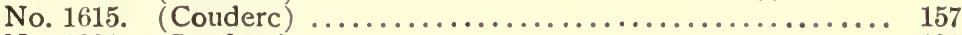

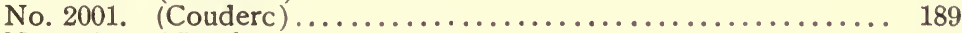

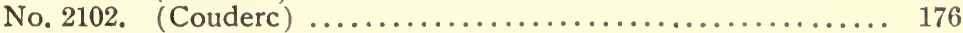

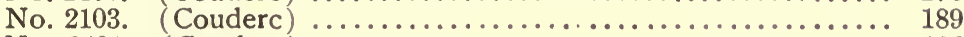

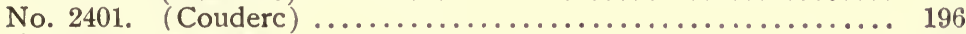

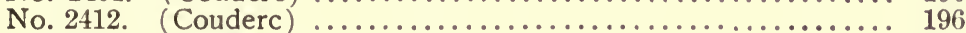

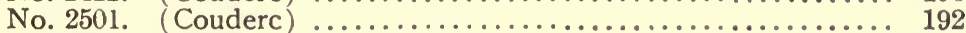

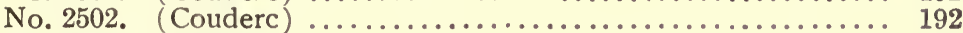

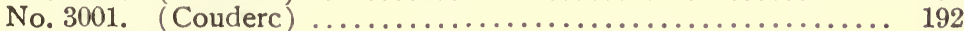

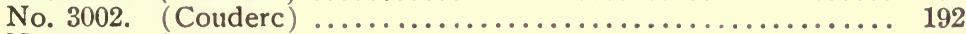

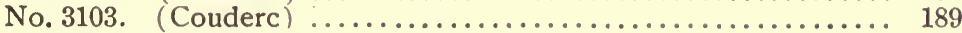

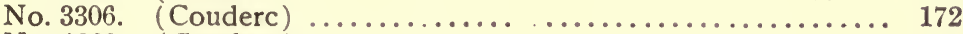

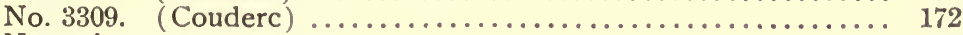

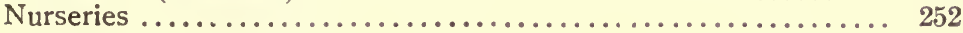

O.

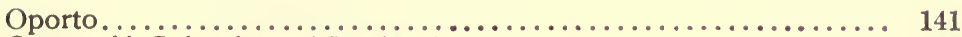

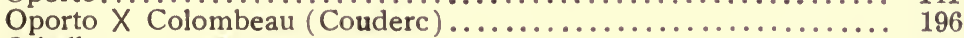

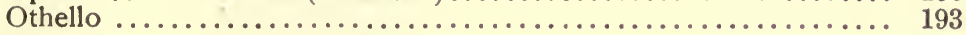

P.

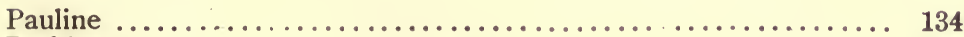

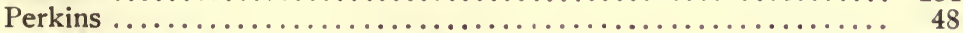

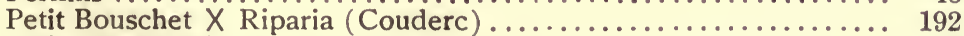

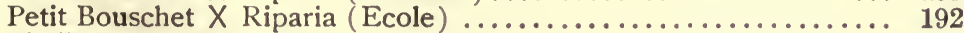

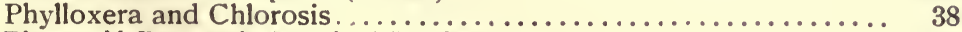

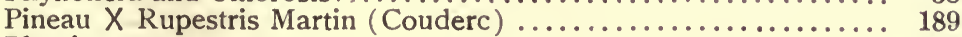

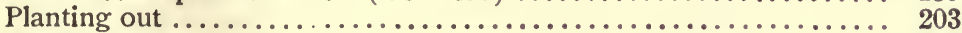

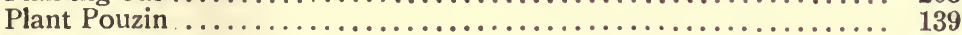

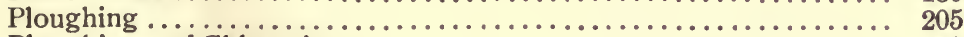

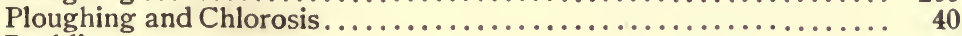

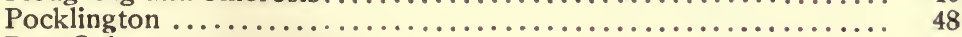

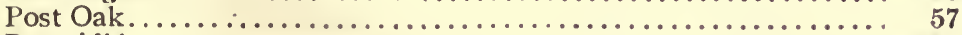

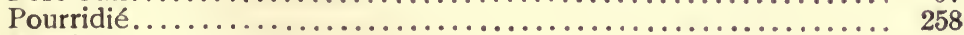

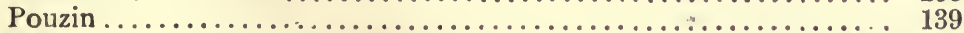

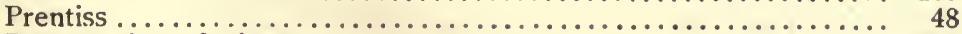

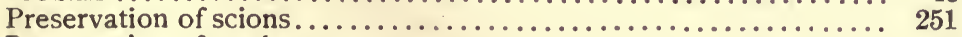

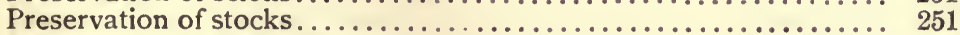

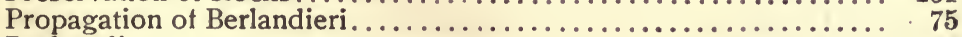

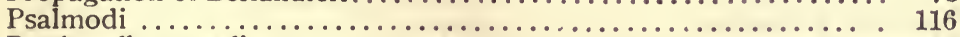

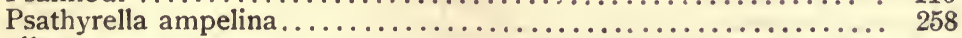

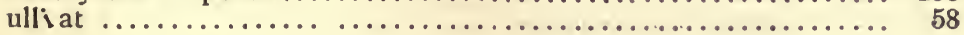


R.

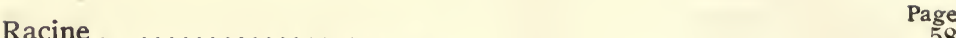

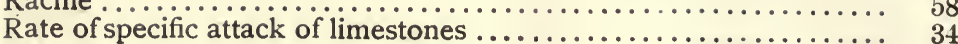

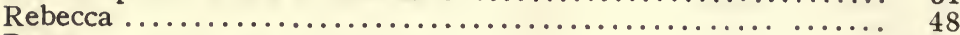

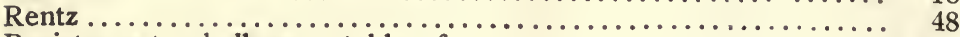

Resistance to phylloxera, table of.................... 197

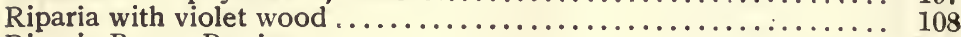

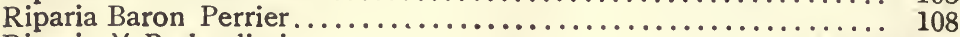

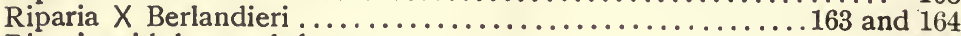

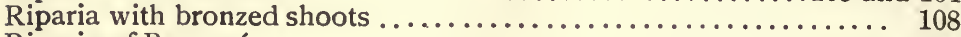

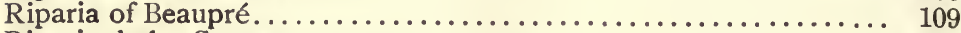

Riparia de las Sorres................................ 109

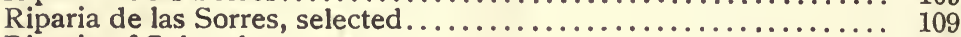

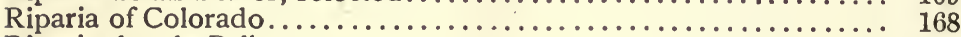

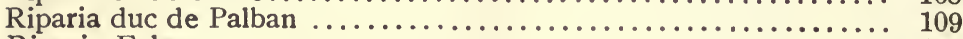

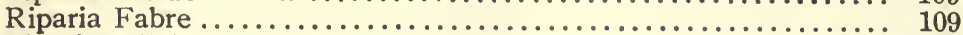

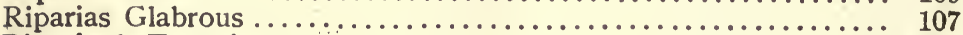

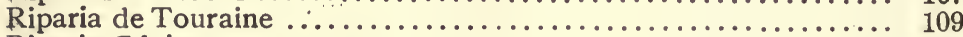

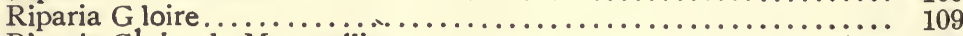

Riparia Gloire de Montpellier........................ 109

Riparia Gloire de Touraine.......................... 109

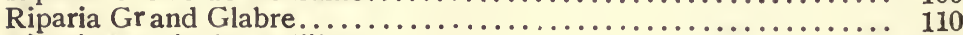

Riparia Martin des Pallières . . . . . . . . . . . . . . . . . . . . 109

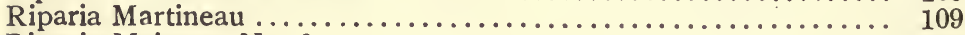

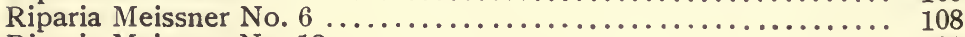

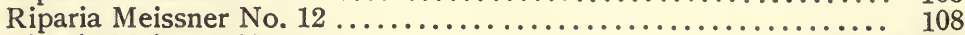

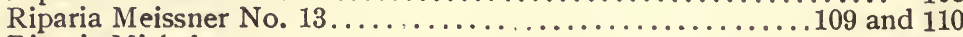

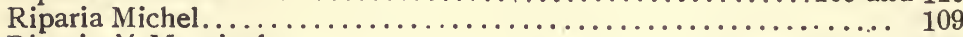

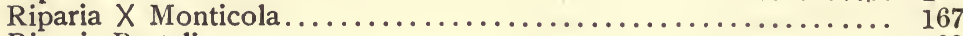

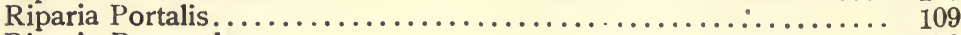

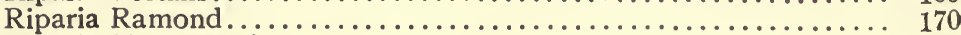

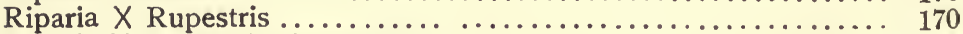

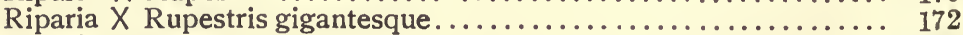

Riparia Saporta ............................. 109

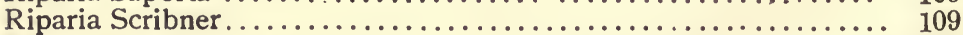

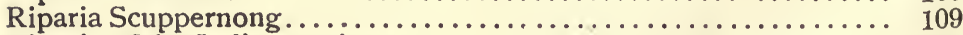

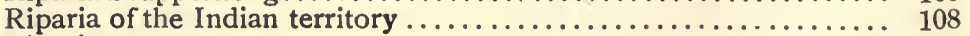

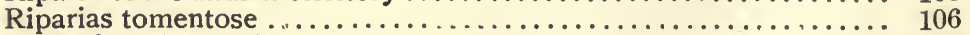

Role of sand and clay ............................... 15

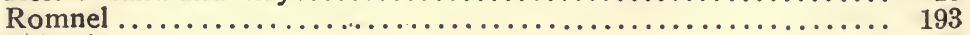

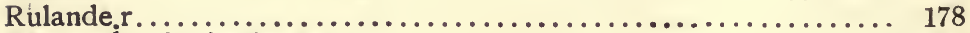

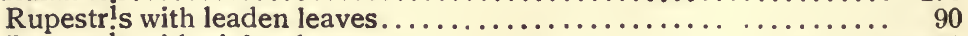

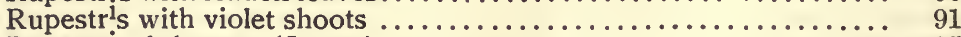

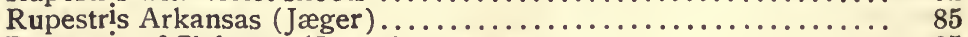

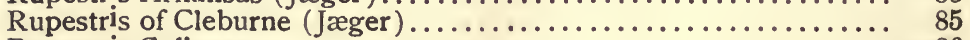

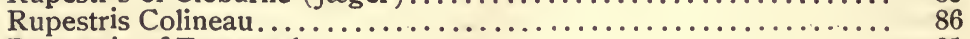

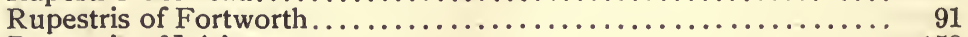

Rupestris of Lézignan . . . . . . . . . . . . . . . . . . . . . . 159

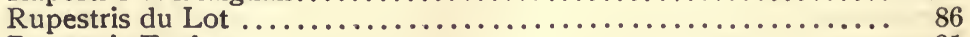

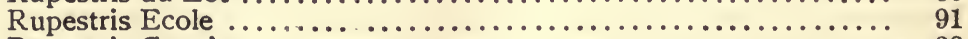

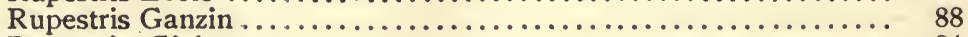

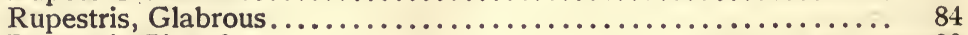

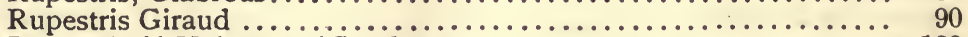

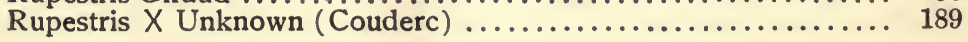


Page

Rupestris Lacastelle ........................... 86

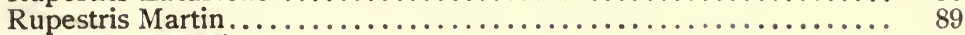

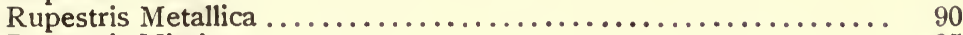

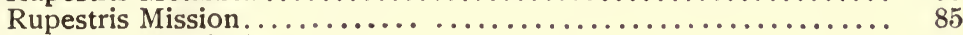

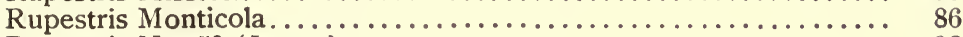

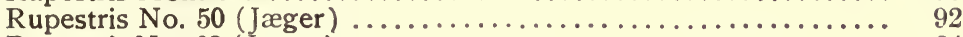

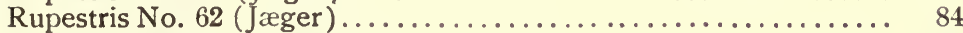

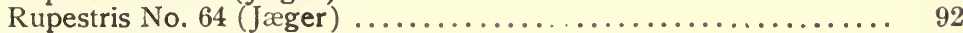

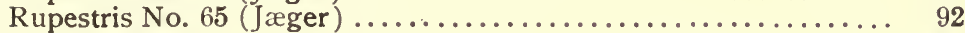

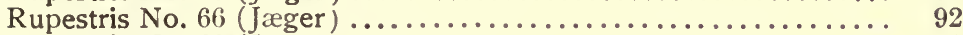

Rupestris No. 68 (Jæger) . ......................... 92

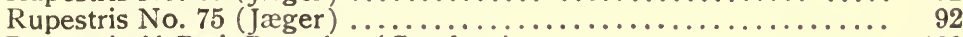

Rupestris X Petit Bouschet (Couderc) .................... 189

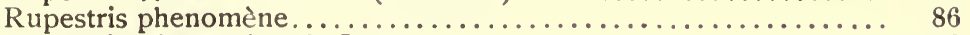

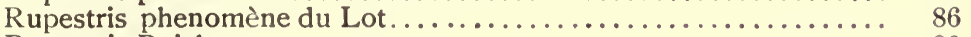

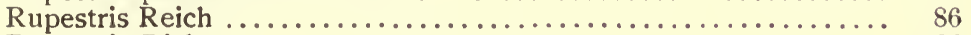

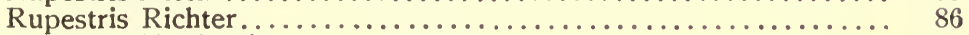

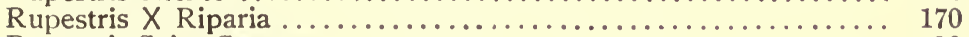

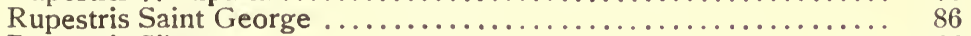

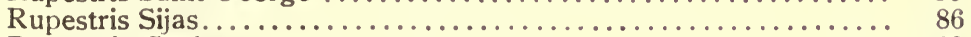

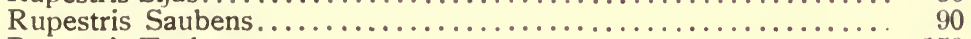

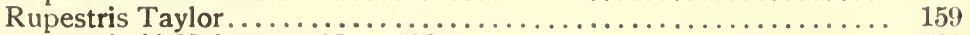

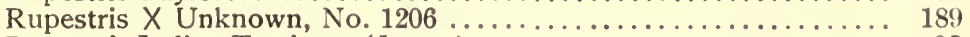

Rupestris Indian Territory (Jæger) . . . . . . . . . . . . . . . ${ }^{9}$

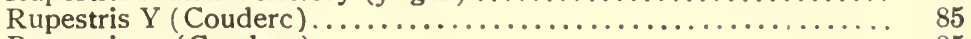

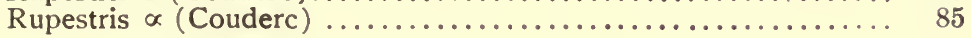

S.

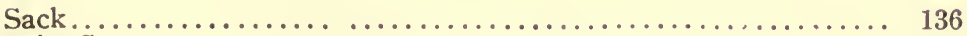

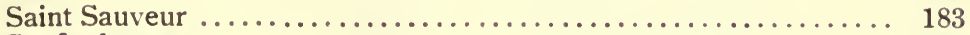

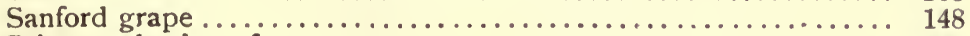

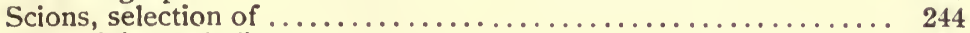

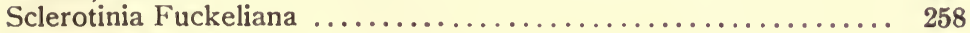

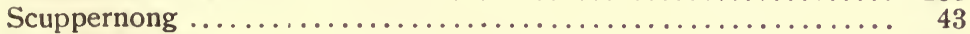

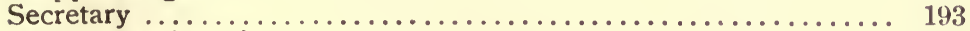

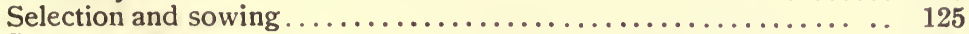

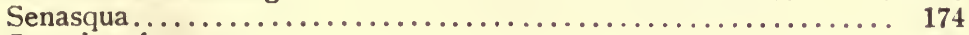

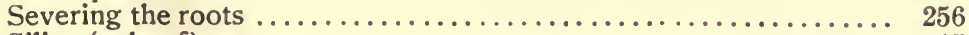

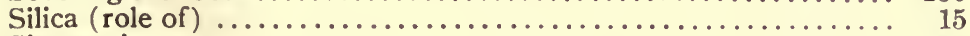

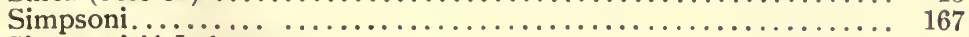

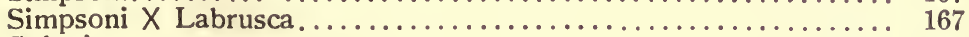

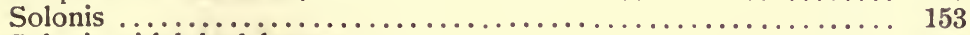

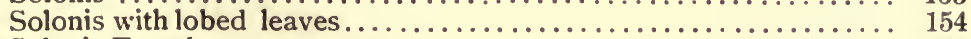

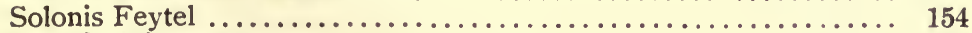

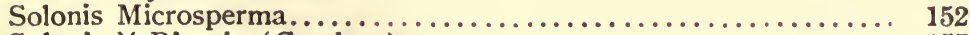

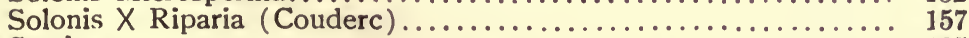

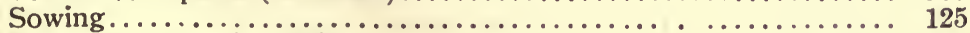

Species of American Vines................................ ${ }_{42}$

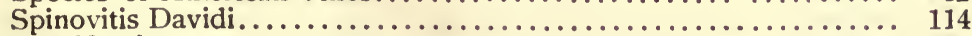

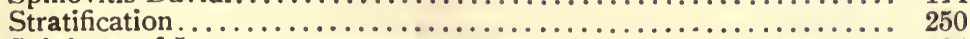

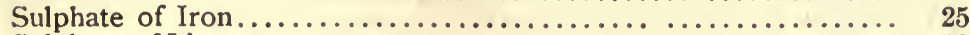

Sulphate of Lime................................... 33 
T.

Taylor $\mathrm{X}$.

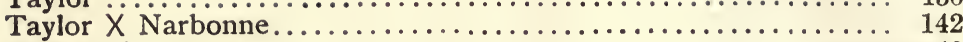

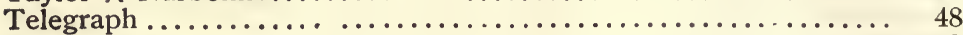

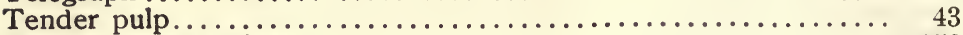

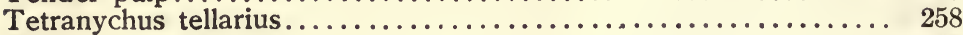

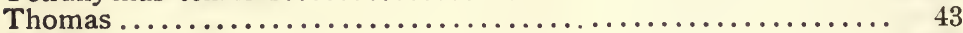

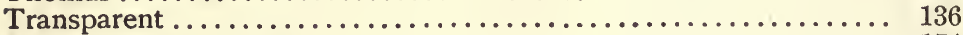

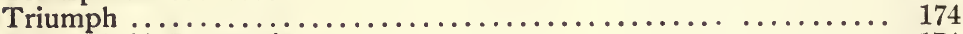

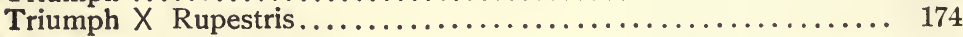

U.

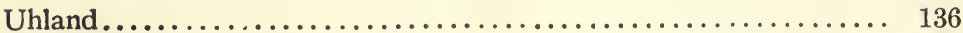

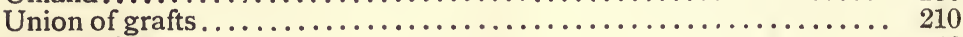

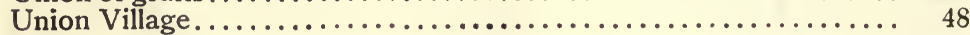

V.

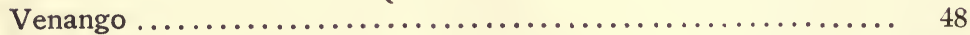

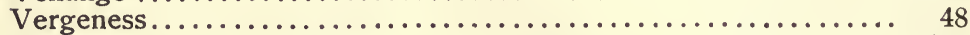

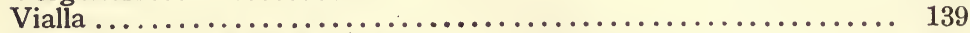

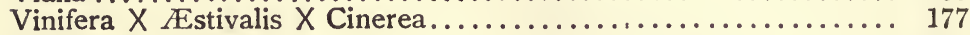

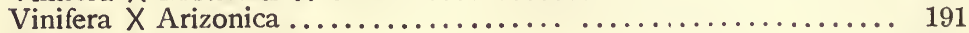

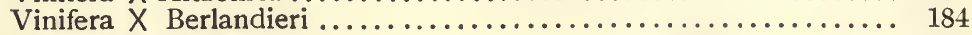

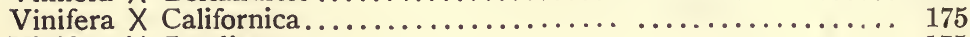

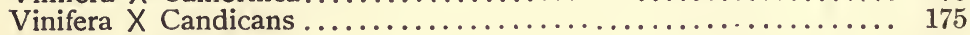

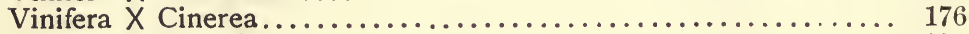

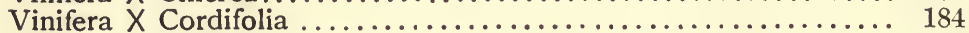

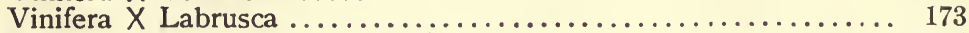

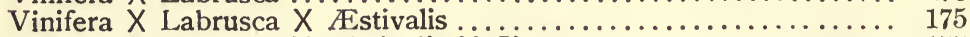

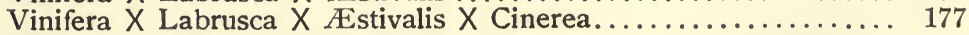

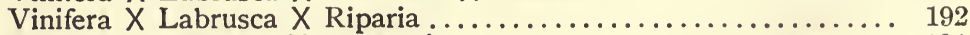

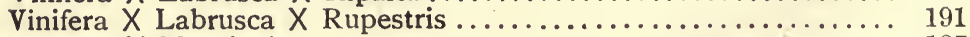

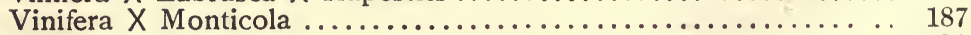

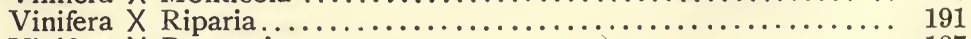

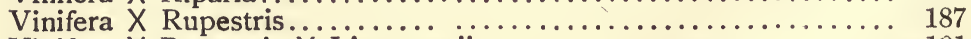

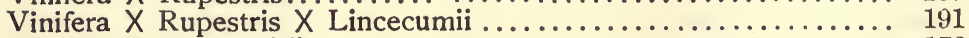

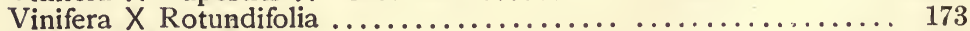

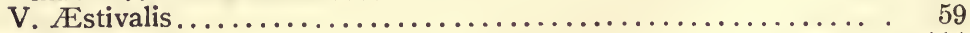

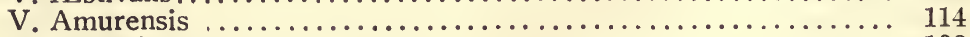

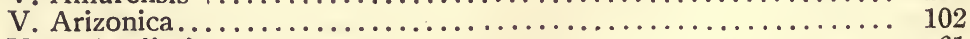

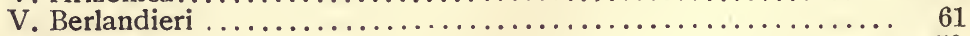

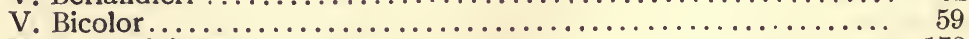

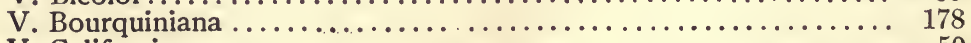

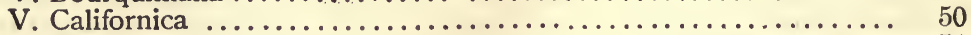

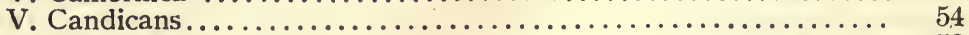

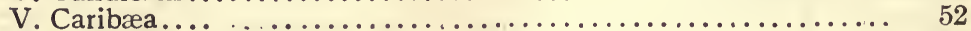

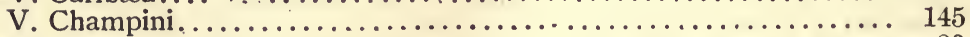

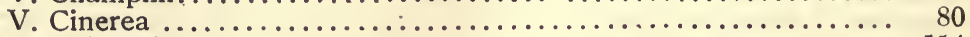

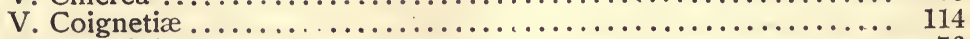

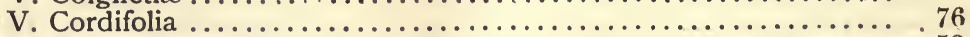

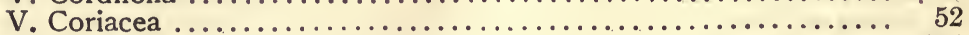

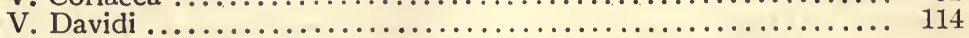


V. Doaniana

Page

V. Foëxeana

154

V. Girdiana

V. Labrusca

50

V. Lanata . .

45

V. Linsecomii ..................................... 57

V. Monticola ................................... 96

V. Munsoniana .................................... 45

V. Pagnucii....................................... 114

V. Palmata ........................................... 107

V. Pedicellata .................................... 114

V. Riparia ......................................... 104

V. Romaneti ........................................ 114

V. Rotundifolia ..................................... 43

V. Rubra........................................ 113

V. Rupestris................................... 82

V. Simpsoni ..................................... 167

V. Texana ...................................... 98

V. Thumbergi....................................... 114

V. Vinifera......................................... 115

W.

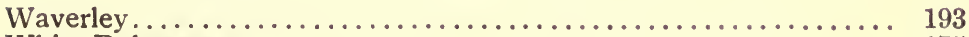

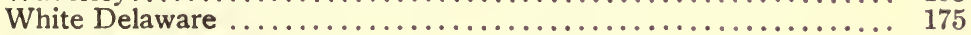

White Herbemont ...................................... 178

Wichita .........................................

Woford's winter grape $\ldots \ldots \ldots \ldots \ldots \ldots \ldots \ldots \ldots \ldots \ldots \ldots, 167$

Y.

Yoakum ......................................... 177

York-Madeira ................................... 132 


\section{GENERAL INDEX.}

Preface to the American Edition..................... Page

TRANSLATOR'S INTRODUCTION .......................... 7

\section{PART I.-ADAPTATION.}

INTRODUCTION $\ldots \ldots \ldots \ldots \ldots \ldots \ldots \ldots \ldots \ldots \ldots \ldots, 11$

II. INFLUENCE OF SoIL ........................... 15

A. Soils slightly or non calcareous.................... 15

(a) Role of sand and clay........................... 15

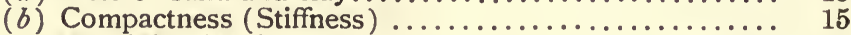

(c) Humidity (Moisture) .......................... 16

(d) Fertility ................................. 17

B. Calcareous soils-Chlorosis...................... 18

(a) Characteristic symptoms of chlorosis.............. 18

(b) Cause of chlorosis ........................ 22

Chlorosis and humidity ........................ 22

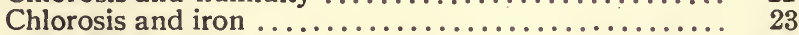

Chlorosis and iron salts ....................... 24

Chlorosis, light and heat....................... 28

Chlorosis and climate............................ 29

Chlorosis and carbonate of lime.................... 31

Chlorosis and mildew ........................... 38

Chlorosis and phylloxera........................... 38

Chlorosis and grafting.......................... $\quad 38$

Chlorosis and ploughing ....................... 40

\section{PART II.-CEPAGES.}

I. Species of American Vines ..................... 42

V. Rotundifolia .................................. 43

(a) Description ...................................... 43

(b) Varieties ................................. 43

(c) Adaptation and culture....................... 43

V. Munsoniana .................................. 45

V. Labrusca ................................... 45

(a) Description ............................... 45

(b) Varieties ...................................... 47

(c) Adaptation and culture...................... 48

V. Californica ..................................... 50

(a) Description ........................................... 50

(b) Varieties .................................. 50

(c) Adaptation and culture .......................... 51

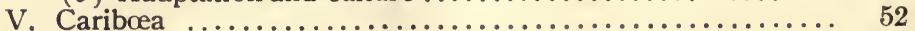

$\mathrm{V}$. Coriacea........................................... 52 
V. Candicans .................... Page

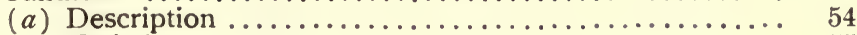

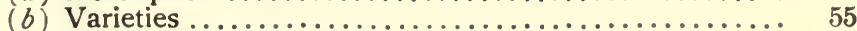

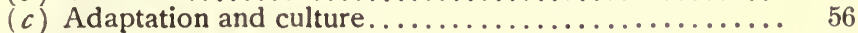

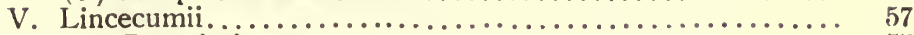

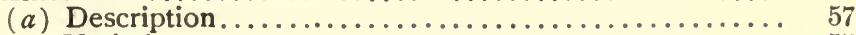

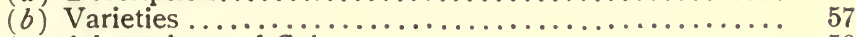

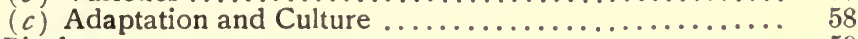

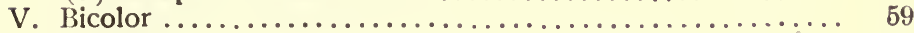

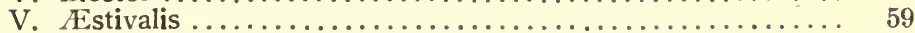

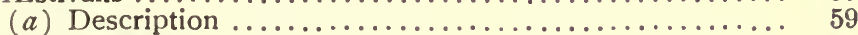

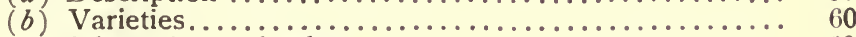

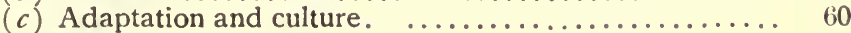

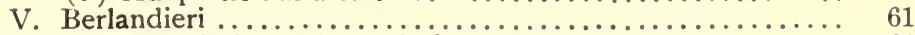

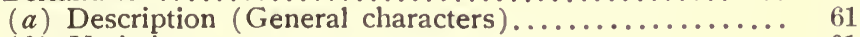

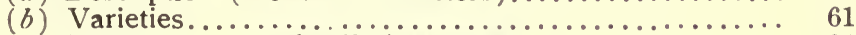

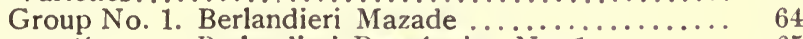

Berlandieri Rességuier, No. 1 .......... 65

Berlandieri Daignère $\ldots \ldots \ldots \ldots \ldots \ldots \ldots 66.65$

Berlandieri Millardet .............. 65

Group No. 2. Berlandieri Rességuier, No. 2 ........ 66

Group No. 3. Berlandieri de Lafont, No. 9 ......... 66

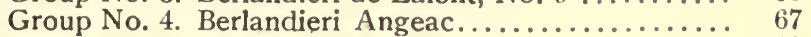

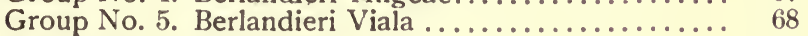

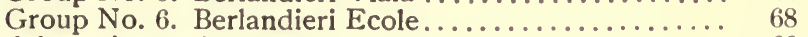

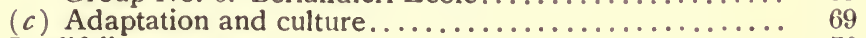

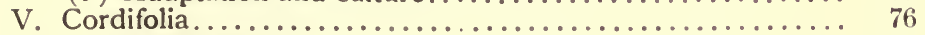

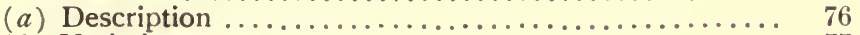

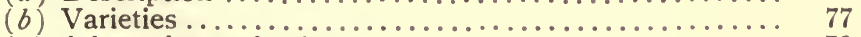

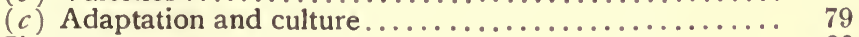

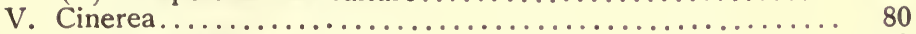

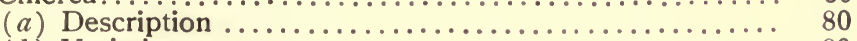

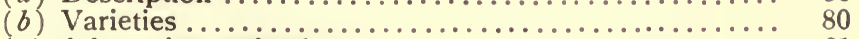

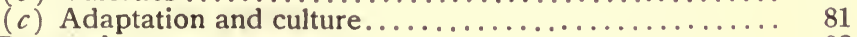

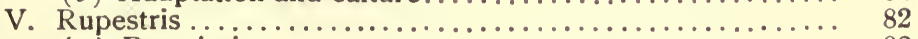

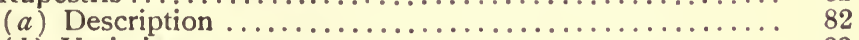

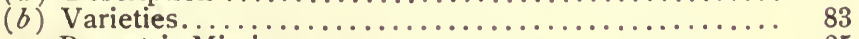

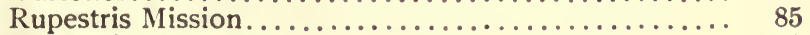

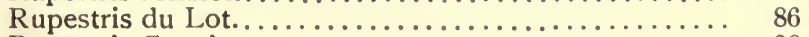

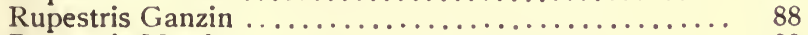

Rupestris Martin....................... 89

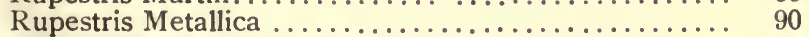

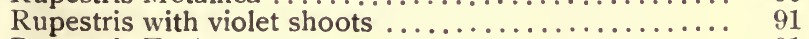

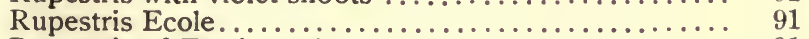

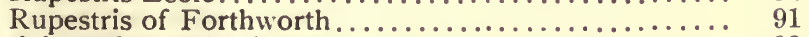

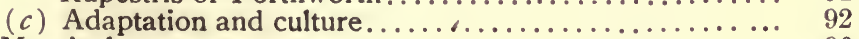

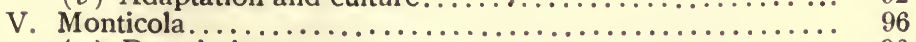

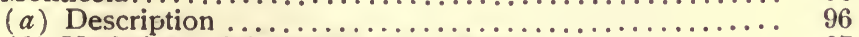

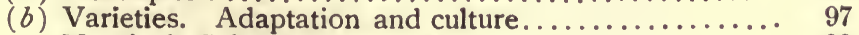

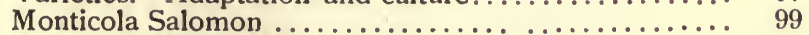

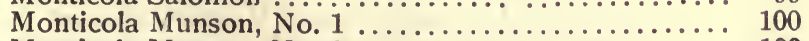

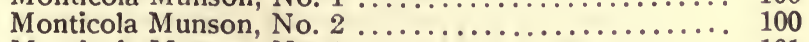

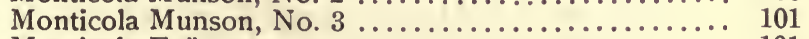

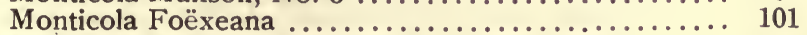

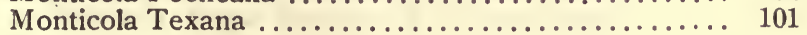




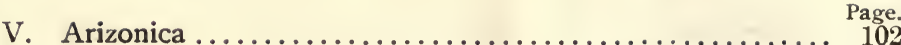

V. Riparia.................................... 104

(a) Description ............................. 104

(b) Varieties .............................. 105

Riparia Gloire de Montpellier................. 109

Riparia Grand Glabre ........................... 110

(c) Adaptation and culture...................... 110

V. Rubra .................................. 113

II. Asiatic Species ............................. 114

III. Vitis VinifERA $\ldots \ldots \ldots \ldots \ldots \ldots \ldots \ldots \ldots \ldots \ldots \ldots, 115$

IV. Hybrids.................................. 117

A. Hybridization $. \ldots \ldots \ldots \ldots \ldots \ldots \ldots \ldots \ldots \ldots \ldots \ldots, 117$

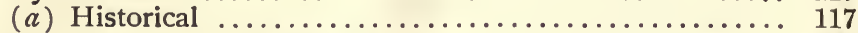

(b) Fecundation of the vine .................... 120

(c) Technique of hybridization................... 122

(d) Sowing and selection $\ldots \ldots \ldots \ldots \ldots \ldots \ldots \ldots \ldots \ldots \ldots \ldots \ldots \ldots, 125$

(e) Crossings and combinations................... 128

B. Hybrids of American vines (Americo-American) ......... 132

Hybrids of V. Labrusca and V. Estivalis............ 132 York Madeira .......................... 132

Hybrids of V. Labrusca, $V$. Estivalis and $V$. Cinerea... 134

Hybrids of V. Labrusca, V. Estivalis and V. Rupestris.. 135

Hybrids of V. Labrusca, V. Estivalis, V. Rupestris, and V. Riparia ......................... 135

Hybrids of V. Labrusca and V. Cordifolia .............. 135

Hybrids of V. Labrusca and V. Riparia.............. 135

Taylor................................. 136

Noah................................. 137

Elvira...................................... 138

Clinton ................................ 138

Vialla ................................. 139

Franklin. ........................... 141

Hybrids of V. Labrusca, V. Riparia and V. Rupestris ... 141

Huntingdon ........................... 141

Taylor-Narbonne............................ 142

Hybrids of V. Californica and V. Arizonica ............. 143

Hybrids of V. Candicans and V. Berlandieri.......... 143

Barnes ................................ 145

Berlandieri X Candicans Bouisset ............... 145

Love-lady ........................... 145

Hybrids of V. Candicans and V. Rupestris........... 145

Hybrids of V. Candicans and V. Monticola ........... 147

Belton. ............................ 148

Hybrids of V. Candicans and V. Riparia............. 149

Hybrids of V. Candicans and V. Riparia and V. Rupestris 149 Solonis .................................. 153

Hutchison ......................................... 154

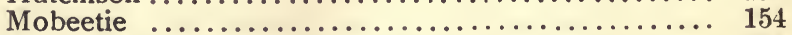

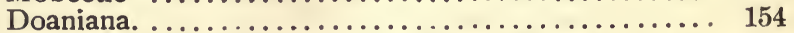

Hybrids of V. Candicans and V. Astivalis- of V. Candicans and V. Cordifolia - of V. Candicans and V. Cinerea

Hybrids of V. Lincecumii and V. Estivalis-of V. Lincecumii and V. Candicans-of V. Lincecumii and V. Cinerea - of V. Lincecumii and V. Cordifolia......... 
Hybrids of V. Lincecumii and V. Rupestris ......... 158

Hybrids of V. Bicolor and V. Riparia ............. 158

Hybrids of $\mathrm{V}$. . Estivalis and V. Cordifolia............ 158

Hybrids of V. Æstivalis and V. Cinerea ............. 159

Hybrids of V. . Estivalis and V. Rupestris............ 159

Rupestris Taylor ....................... 159

Rupestris de Lézignan...................... 159

Hybrids of V. Estivalis and V. Riparia............ 160

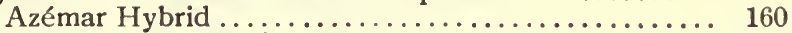

Hybrids of V. Berlandieri and V. Rupestris .......... 160

Hybrids of V. Berlandieri and V. Monticola .......... 161

Hybrids of V. Berlandieri and V. Cordifolia- of V. Berlandieri and V. Cinerea-of V. Berlandieri and V.

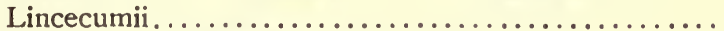

Hybrids of V. Berlandieri and V. Riparia............ Berlandieri X Riparia No. 33 Ecole...............

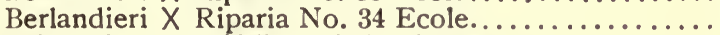

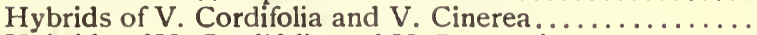

Hybrids of V. Cordifolia and V. Rupestris............

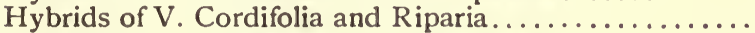

Hybrids of V. Cinerea and V. Coriacea. . ............

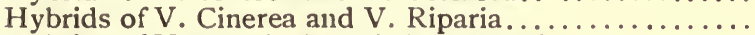

Hybrids of V. Monticola and V. Rupestris............

Hybrids of V. Monticola and V. Riparia............. Colorado

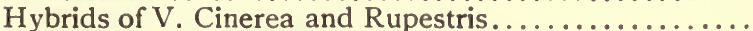

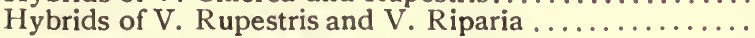

C. Hybrids of V. Vinifera (Franco-American).......... 172

Hybrids of $\mathrm{V}$. Vinifera and V. Rotundifolia.......... 173

Hybrids of V. Vinifera and V. Labrusca ........... 173

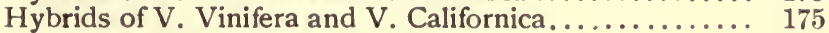

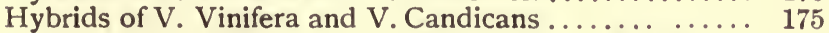

Hybrids of V. Vinifera, V. Labrusca, and V. Æstivalis.. 175

Hybrids of V. Vinifera and V. Cinerea ............ 176

Hybrids of V. Vinifera, V. Labrusca, V. Æstivalis, and

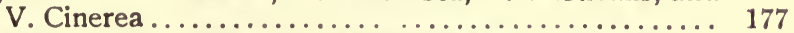

Hybrids of V. Vinifera, V. Estivalis, and V. Cinerea ... 177

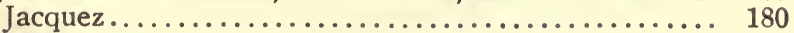

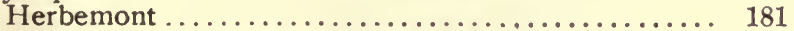

Hybrids of V. Vinifera and $V$. Cordifolia.................. 184

Hybrids of V. Vinifera and V. Berlandieri ................ 184

Hybrids of V. Vinifera and V. Monticola ............. 187

Hybrids of V. Vinifera and V. Rupestris.............. 187

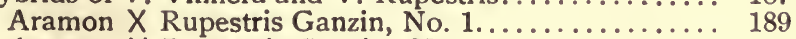

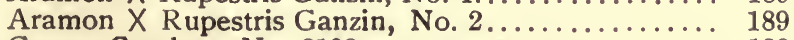

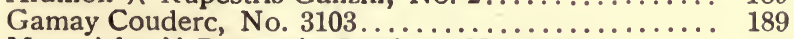

Mourvèdre X Rupestris Couderc, No. 1202........ 189

Gros Colman X Rupestris, No. 160 (M. and G.)..... 190

Cabernet X Rupestris, No. 33 (M. and G.)......... 190

Alicante Bouschet X Rupestris, No. 139 (M. and G. ). 190

Alicante Bouschet X Rupestris, No. 136 (Ecole)..... 190

Franc's Hybrid, etc... ..................... 190

Hybrid of V. Vinifera, $V$. Labrusca and $V$. Rupestris.... 191 
Page Seibel's Hybrids ......................... 191

Hybrids of V. Vinifera and V. Arizonica.............. 191

Hybrids of V. Vinifera and V. Riparia.................. 191

Hybrids of V. Vinifera, V. Labrusca and V. Riparia..... 192 Othello ................................ 193 Canada, Brandt, Secretary, Cornucopia, Autuchon.... 195

PART III.-CULTURE.

Culture

(a) Conclusions (Choice of varieties) ................ 197

I. Humidity............................ 200

II. Compactness ............................ 200

III. Aridity ............................... 200

IV. Predominance of silica ................... 200

V. Amount of limestone in the soil................ 200

VI. The vigor of the graft..................... 201

VII. The affinity............................. 201

VIII. Fertility of graft ..................... 202

IX. Earliness of ripening fruit.................. 202

(b) Deep cultivation............................. 202

(c) Manuring and planting ............................... 203

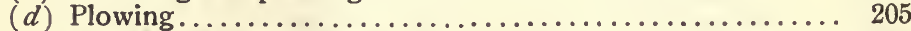

(e) Distance between vines......................... 205

(f) Layering .................................. 206

$(g)$ Quality of wines from grafted vines ............... 207

PART IV.-GRAFTING AND NURSERIES.

I.-Anatomy and Physiology of the Graft .......... 209

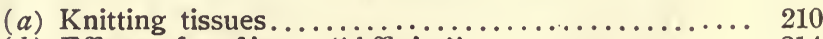

(b) Effects of grafting. - "Affinity"................. 214

II.-Systems of Grafting ... .................... 225

(a) Whip-tongue graft .................... 226

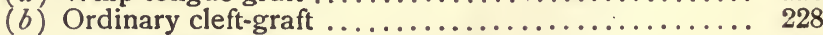

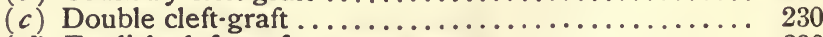

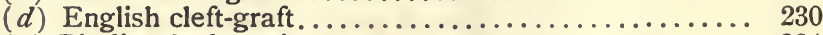

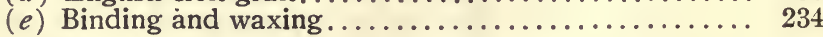

III.-Grafting on Growing Stocks and Bench Grafting. 239

A. Grafting on growing stocks................ 239

(a) Time of grafting.................... 239

(b) Operation of grafting .................... 240

(c) Severing the roots ................... 241

(d) Care to be given to grafts ................ 243

(e) Care to be given to scions................ 244

$(f)$ Autumn grafts........................... 244

Cadillac graft................................ 245

Gaillard graft........................ 248 
B. Bench grafting........................... 248

(a) Grafting on cuttings.................... 248

(b) Stratification and callusing ............... 250

(c) Preservation of stocks and scions............. 251

IV.-NURSERIES......................... 252

(a) Selection and preparation of soil............... 252

(b) Plantation ............................. 252

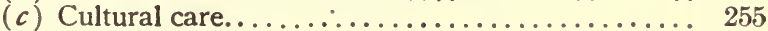

(d) Removal of roots from the scion............ 256

(e) Lifting grafted cuttings................. 256

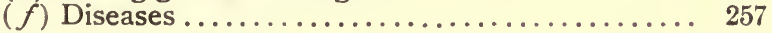

White grubs....................... 257

Tetranychus tellarius................. 258

Coniothyrium diplodiella .............. 258

Pourridié........................... 258

Mildew.......................... 258

Fibrillaria ..................... 258

Sclerotinia Fuckeliana................ 258

V.-Herbaceous Grafting ....................... 259

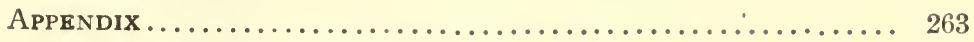

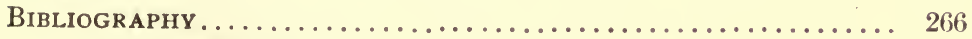

Glossary of the Principal Scientific Terms used in the PRESENT VOLUME .............................. 272

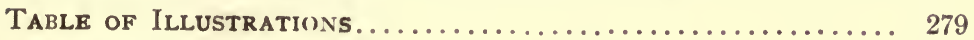

Alphabetical Index .................................. 282

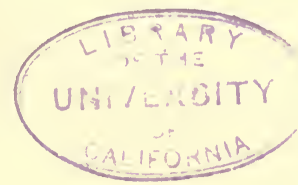











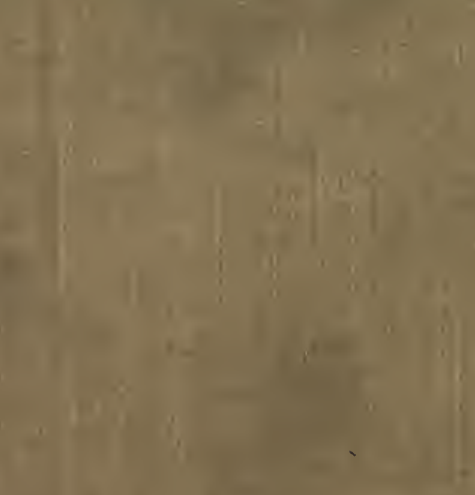

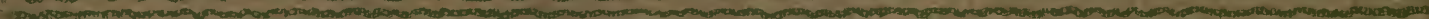

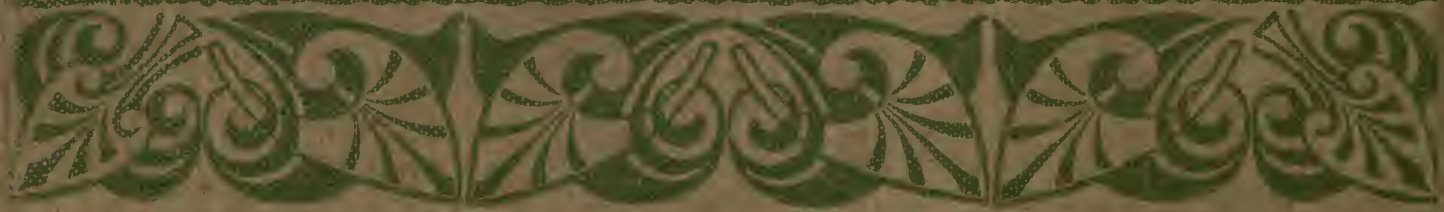

